\title{
Governance and Development of the East African Community: The Ethical Sustainability Framework
}

\author{
Dickson Kanakulya
}

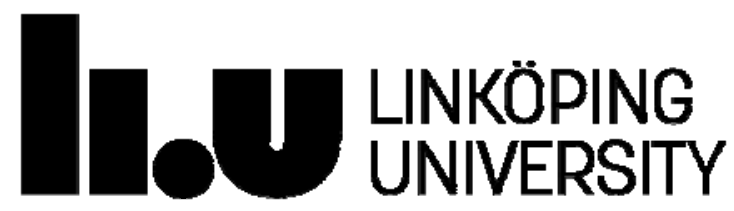

Faculty of Arts and Sciences

Studies in Applied Ethics 16

Linköping University, Department of Culture and Communication Linköping 2015 
Studies in Applied Ethics 16

Distributed by:

Department of Culture and Communication

Linköping University

58183 Linköping

Sweden

Dickson Kanakulya

Governance and Development of the East African Community: The Ethical Sustainability Framework

Licentiate thesis

Edition 1:1

ISSN 1402-4152:16

ISBN 978-91-7685-894-3

(c) The author

Department of Culture and Communication 2015 


\section{Declaration:}

I declare that this study is my original work and a product of my personal critical research and thought.

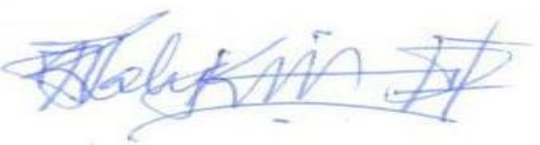

Kanakulya Dickson,

Kampala, Uganda

November, 2015 


\section{Approval:}

This research report has been submitted with the approval of my supervisor:

Prof. Goran Collste

Co-Supervisor's name:

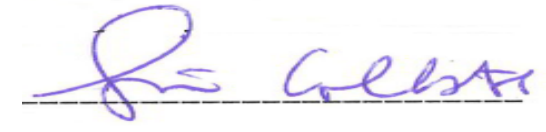

Signature:
--2015--11--09-----

Date 
(C) 2015 Kanakulya Dickson

All rights reserved 


\section{Dedication:}

This work is dedicated to the Lord of all Spirits and Letters; accept it as a feeble effort to serve your eternal purposes.To Caroline Kanakulya, a beautiful and kindred spirit. To the healing of the spirit of East Africans. To the watchers who stood steadfast in the days of the multiplication. Great mysteries await across! 


\section{Acknowledgements:}

I acknowledge the Swedish Agency for International Development (Sida) and Makerere University for funding this research; and the staff of Makerere Directorate of Graduate Research and Training for support during the study.

My deepest gratitude goes to my wife Caroline Kanakulya, my travel companion in life's journey; thanks for standing my flaws and supporting me. You are such a beautiful spirit; may the guardians take you safe across. Thanks to my family.Great inspiration for academic pursuits did I receive from Prof. Zacharias Tanee Fomum, a Makerere trained biochemist anda Doctor of Science (University of Durham) holder with a deep sense of spiritually-inspired academic dedication. His life exemplifies the best I have known in the service of the Lord Jesus Christ through the pursuit of both spiritual and academic excellence. You left an eternal impression on my spirit towards an academic career to the glory of Our Lord Jesus Christ and hope this little effort makes you proud in Beaulah Land! I also express eternal gratitude to Dr. Michael Nyisomeh and his wife Dr. Macrine Nyisomeh of Christian Missionary Fellowship International (CMFI) for their tremendous input in shaping my life and for praying and encouraging my academic pursuit; what a memorable work we have wrought for our generation. AM grateful to my beautiful mother, Norah Nakiwala, and sister, Suzan Nakayenga for your input. To all the members of CMFI who stood beside meby wayof the 'greatest force' in the universe:I am grateful. Maranatha!

Acknowledgements go to Prof. Katri Pohjolainen-Yap for her encouragement to pursue this research at a time of low energy.Thanks to the academic communities that have challenged my ideas and encouraged me a lot: academic communities at Department of Philosophy, Makerere University; Centre for Applied Ethics-CTE (Linköping University); and at Uganda Christian University.You added great value to my research. Thank you Prof. Göran Collste for advising me along the way; Prof. Wamala Edward for pushing me and giving me insightful comments; Prof. Anders Nordgren for providing a conducive study environment at the CTE. Heartfelt thanks go to the experts on the East African Community that I interacted with during my study visits across the region; Amb. Butagira Francis (former Ugandan envoy to the EAC), Prof. Chacha Nyaigotti (Catholic University of Eastern Africa), Mr. Nganatha Karugu (Kenya School of Government), Ms. Henjewele Florida (Political Integration Programme-EAC Secretariat), Dr. Wanyama Masinde (Institute for Regional Integration and Development- 
Kenya), Mr. Barrack R. Ndegwa and Mr. Gwaro Ogaro (Min. of EAC Affairs-Kenya), Mr. Sebina Edward (Min. of EAC Affairs-Uganda), Prof. Mahmoud Masaeli (Sch. of International and Global Studies-Univ. of Ottawa), Ms. Sarah Tangen (Friedrich Ebert Stiftung-Uganda), Dr. Rico Sneller (Humanities-Leiden University), and Prof. Wolfgang Schmidt (Linköping University). The list can't be exhausted but am grateful to the silent majority.

I can't forget to thank Aisha Nakiwala: together we took the academic journey as novicesat the School of Liberal and Performing Arts (Makerere University) and helped eachother find our bearing in the academic world. Congratulations to you too Aisha! Special thanks to: Dr. Maren Behrensen, Dr. Elin Palm, Yusuf Yekusedag, Cristina Marano, Richard Golooba, Michael Kizito,Antonina Matundura, Ibale Hope, John Ahumuza, Samson Olum, Mark Omong (the list is endless); thanks for sharing great ideas that contributed to this piece in the 'Osagyefo' movement (this is an Akan word which means 'redeemer' given to one who returned victorious in battle; it was ascribed to the famous Ghanaian Kwame Nkrumah for his courage and foresight in advocating for African independence and unity). A heartfelt thank you to Sylvia Nakiirya for proofreading the final text in a dedicated way. 


\section{Table of Contents:}

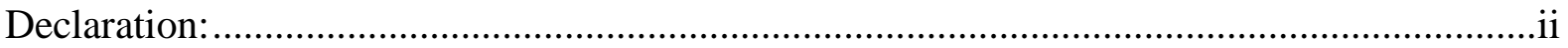

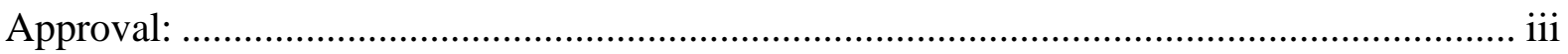

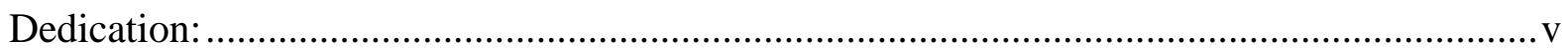

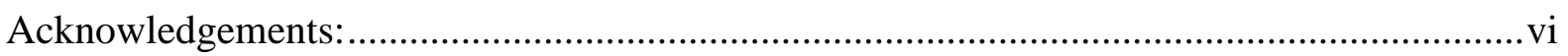

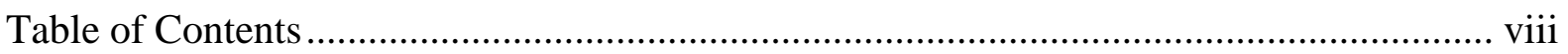

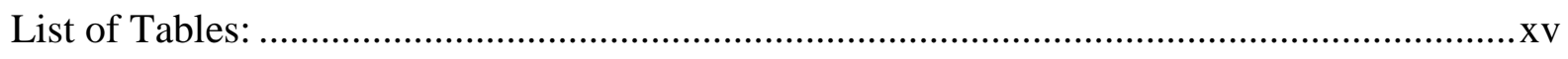

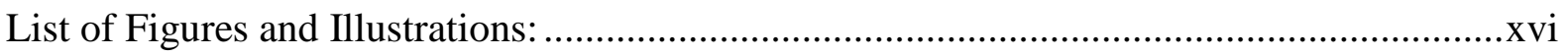

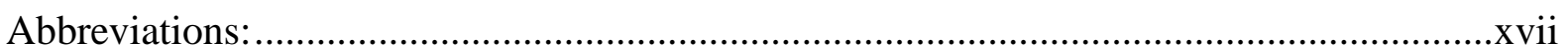

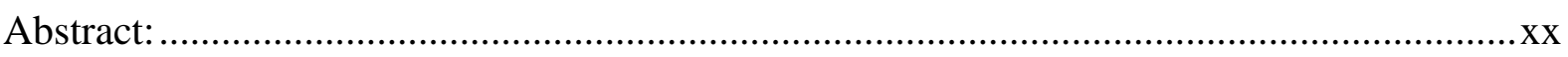

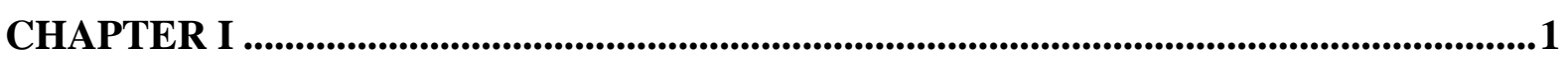

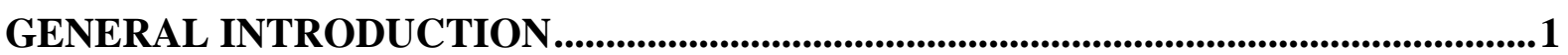

1.1 Introduction:

1.1.1 Unsustainability Fissures in the East African Community: ..................................... 1

1.2 Applied Ethics and the Quest for Sustainable Development: ...........................................

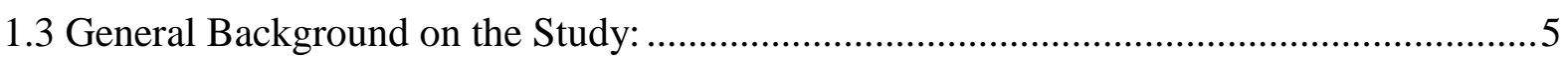

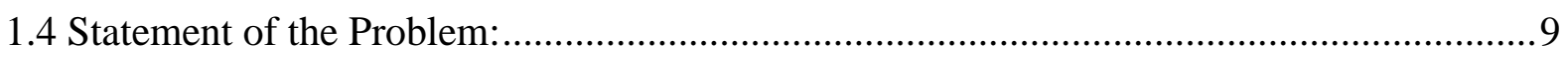

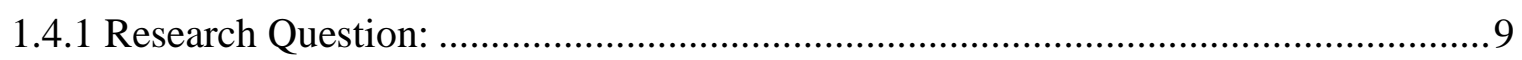

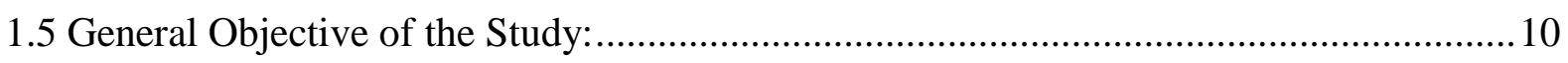

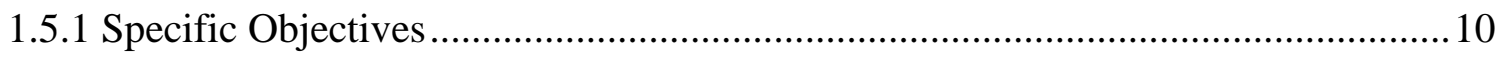

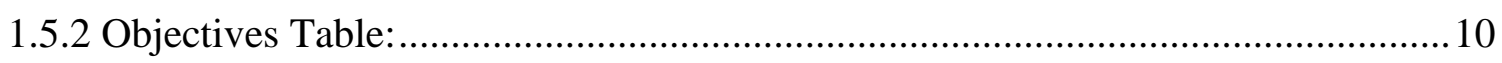

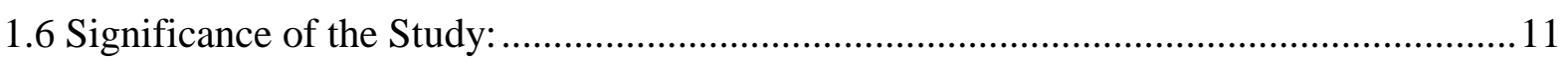

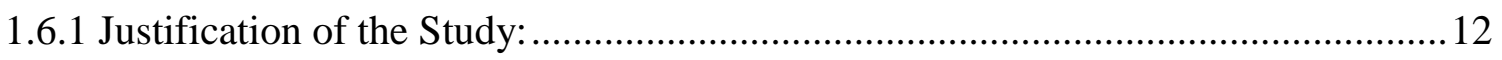

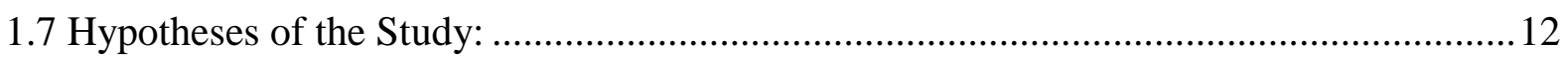

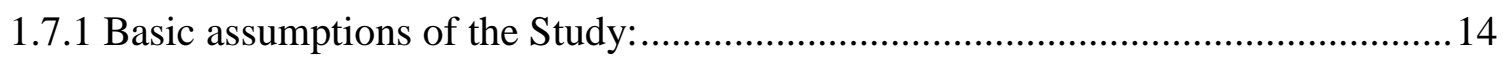

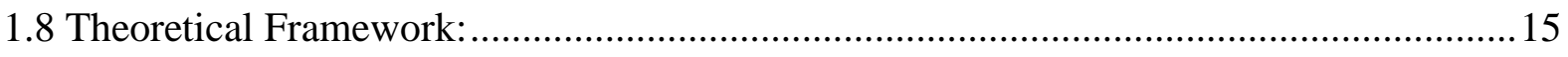

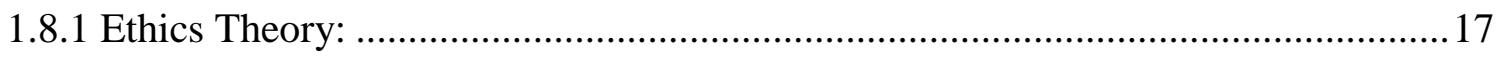

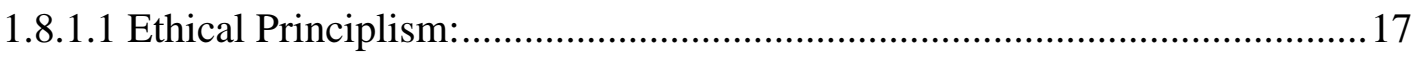

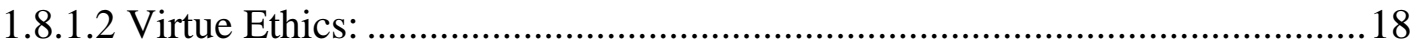

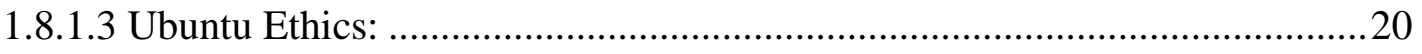

1.8.1.4 Kohlberg's Stages of Moral Development: .............................................. 22

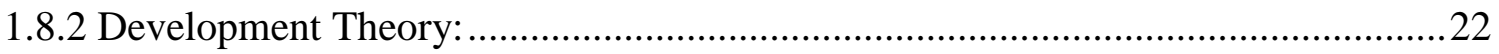

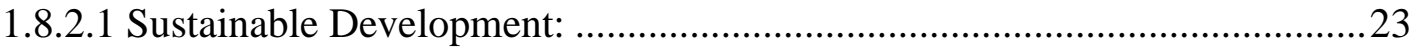

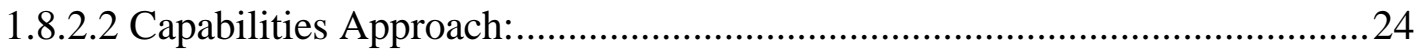




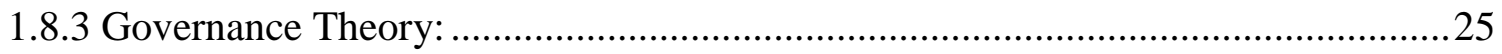

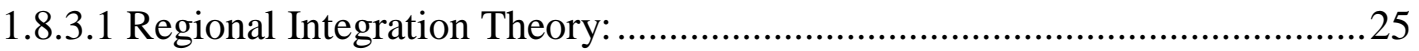

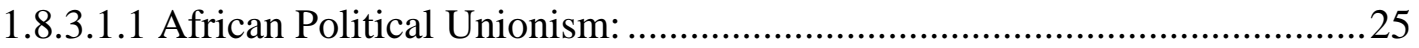

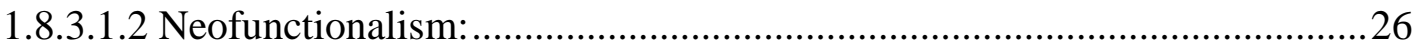

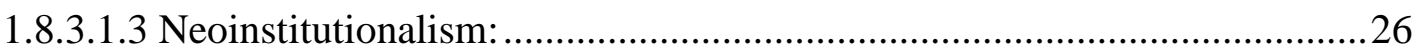

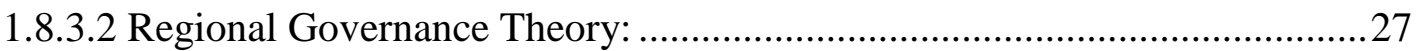

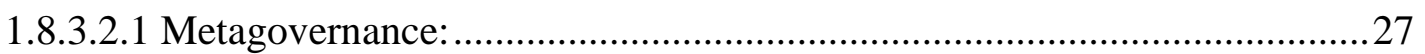

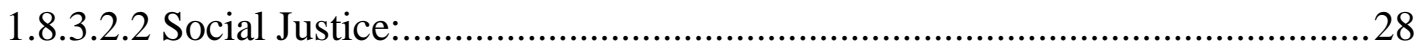

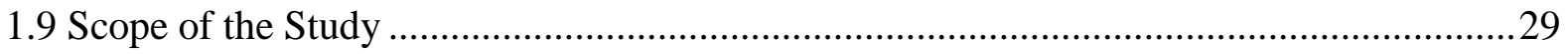

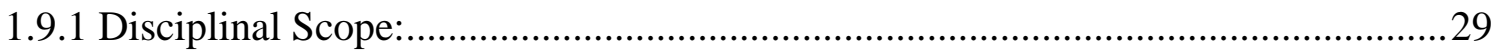

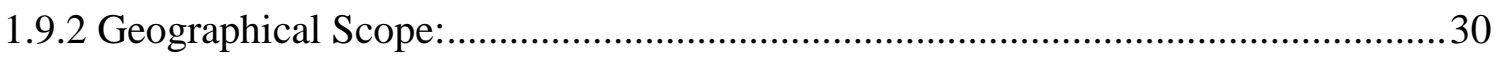

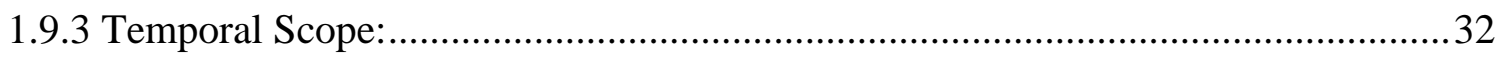

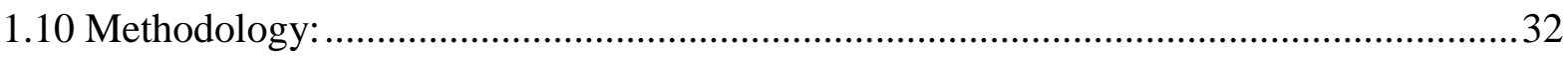

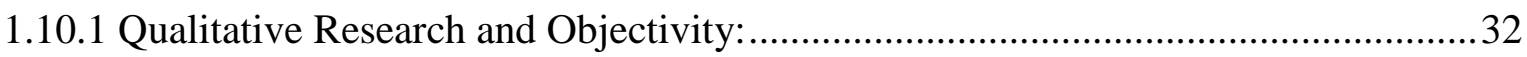

1.10.2 Reflective Equilibrium Method in Applied Ethics:............................................... 34

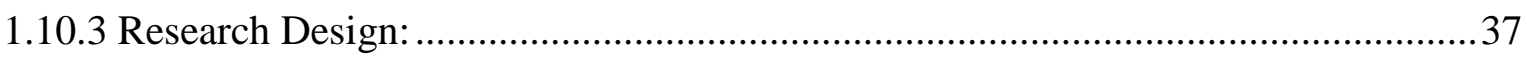

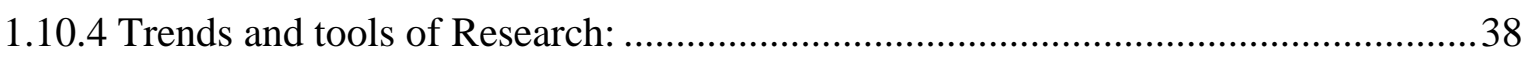

1.10.4.1 Combination of Trends in Applied Ethics Research: ................................ 38

1.10.4.1.1 Trend 1: Practical Theorization on Moral Issues: ................................... 38

1.10.4.1.2 Trend 2: Practicalization of Ethical Theory:.............................................. 39

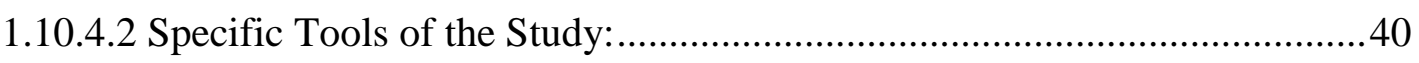

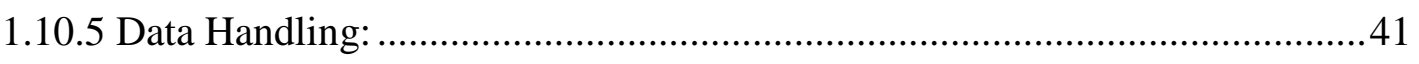

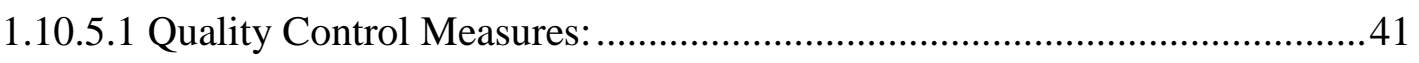

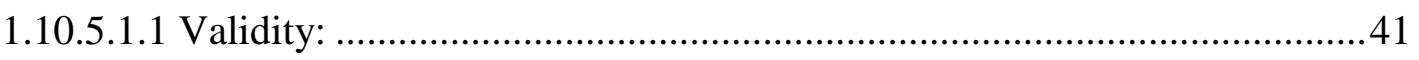

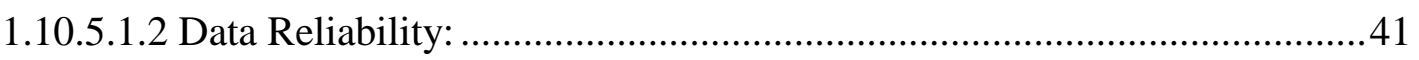

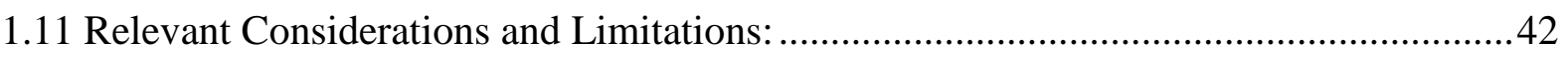

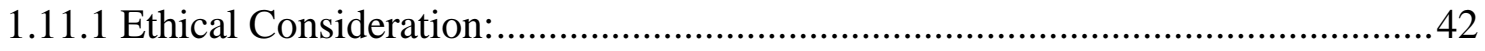

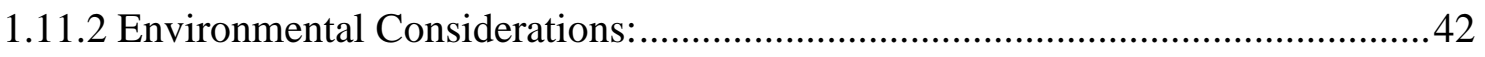

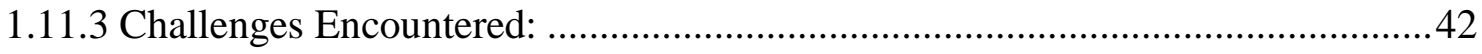

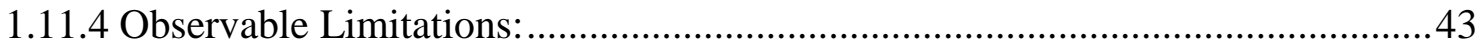

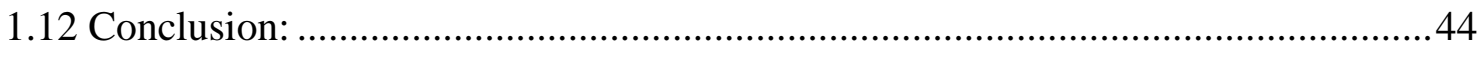

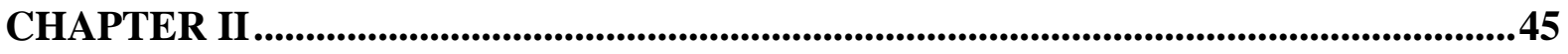

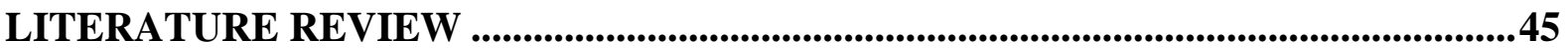

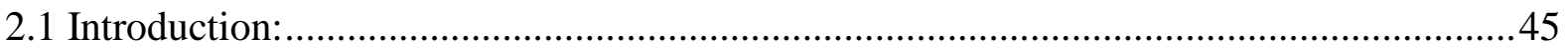

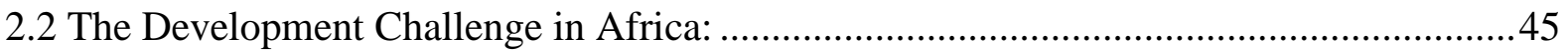


2.2.1 Solving by Re-dignifying Africa: 47

2.2.2 Solving by Unifying Africa: .48

2.2.3 Solving by Re-constructing Africa: . .49

2.2.3.1 Re-constructing with Appeal to Traditional Concepts and Norms: .49

2.2.3.2 Re-constructing with Modern Conceptual Narratives: 49

2.3 Identifying the Actual Development Problem in Sub-Saharan Africa: .............................52

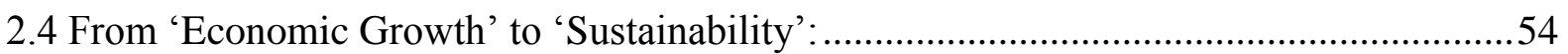

2.4.1 On the Unsustainability of Modern Economic Thinking: ........................................56

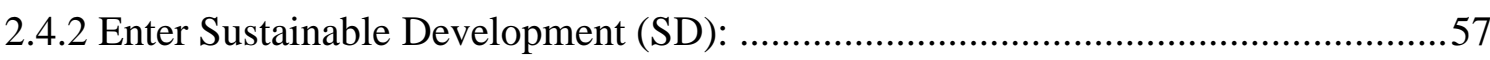

2.4.2.1 Adapting the conventional understanding of 'Sustainable development':..58

2.4.2.2 Observations from the 'SEE' - 'TBL' Correlation: ....................................61

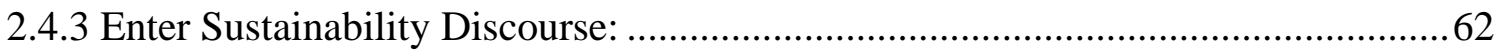

2.4.3.1 'Capitalistic' and 'Traditional African' Sustainability Logic: ...................63

2.4.4 Review of Kaitlyn Orr's version of ‘Ethical Sustainability' :.................................66

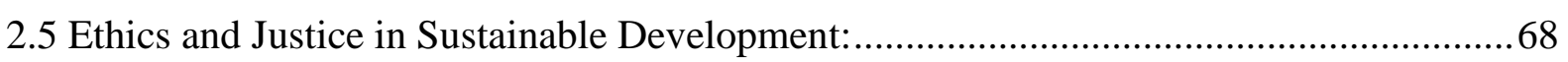

2.5.1 On Meaning of Ethics and its Place in Sustainable Development: .........................69

2.5.2 Correlation Between Public Ethics and Sustainable Development:........................ 72

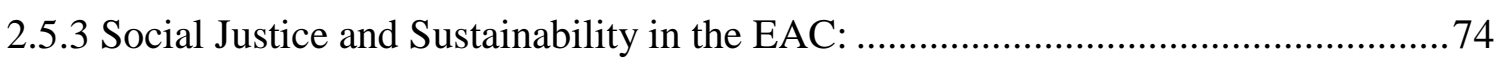

2.6 Regionalization and Justice in Cosmopolitan Governance:.............................................79

2.6.1 Brock Gillian and Justification for a Global Account of Justice:............................ 81

2.6.1.1 Rawls' Reformulation of the 'Original Position': ...................................... 81

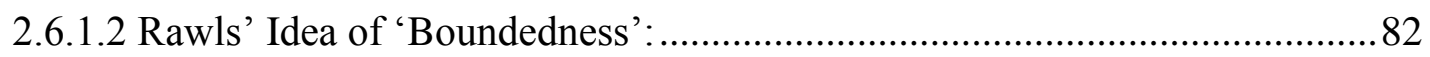

2.6.1.3 Equating 'Liberalism' with Continuous 'Wealth Creation': ........................84

2.6.1.1.4 Relating Rawls-Brock debate to the East African Community: .................84

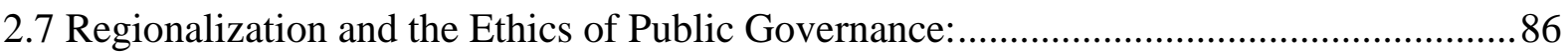

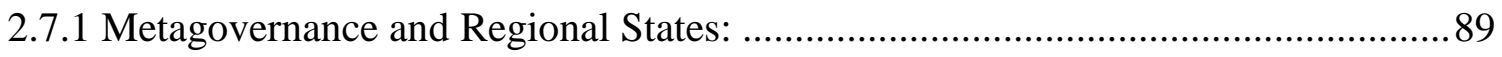

2.7.2 The EAC Treaty and its Principles of Regional Governance:................................ 91

2.7.2.1 EAC principle 1: People Centeredness: .......................................................92

2.7.2.2 EAC principle 2: Balanced Sustainability: .............................................. 92

2.7.2.3 EAC principle 3: Mutual Benefit:................................................................93

2.7.2.4 EAC principle 4: Variable Geometry: ....................................................... 93

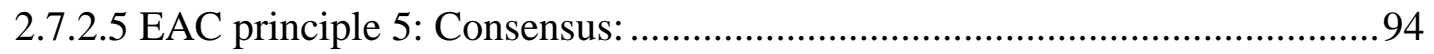

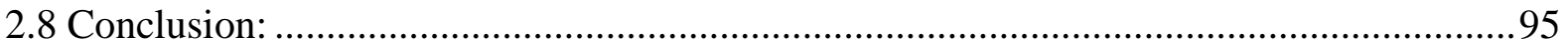

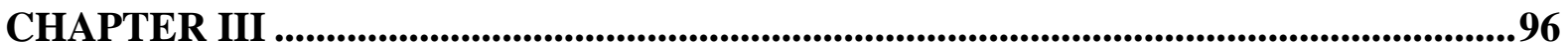

EAC INTEGRATION AND THE CHALLENGE OF SUSTAINABILITY ....................96 
3.1 Introduction .96

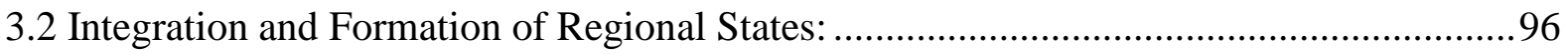

3.3 The EAC Project: From Colonial Protectorate-ism to Indigenous Regionalism? ............ 97

3.4 Justification of the East African Community Regional Integration Project: ....................99

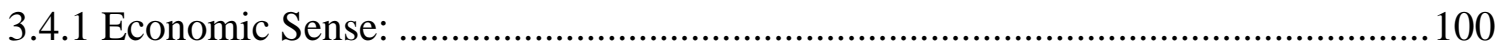

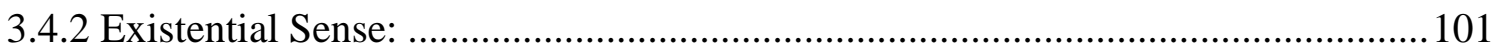

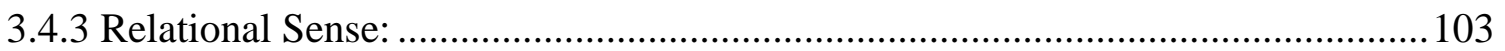

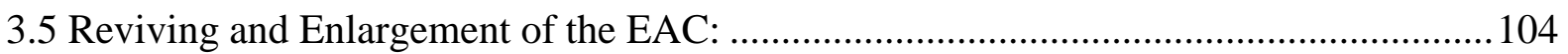

3.5.1The 'Economic Magnetic Pulls' thesis on EAC integration: .................................. 105

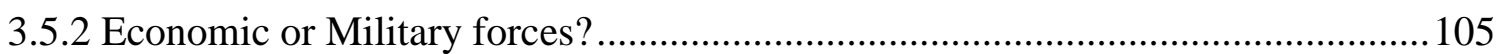

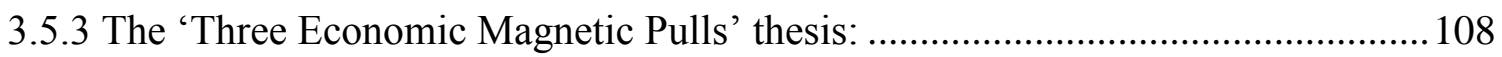

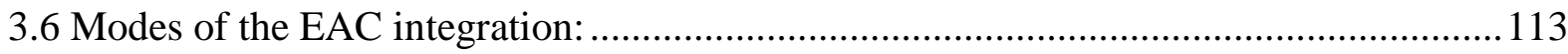

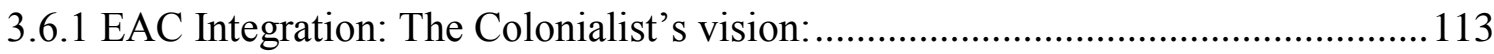

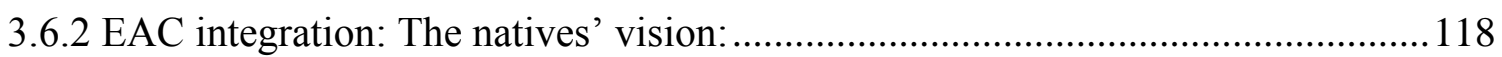

3.7 From a functionalist to a neo-functionalist approach to the EAC: ................................122

3.8 Divergence in leadership and institutions: the need for metagovernance: ....................... 123

3.9 Unsustainability resulting from governance and justice issues: .................................. 127

3.9.1 Unsustainability resulting from social injustice and in-capabilities:..................... 130

3.9.2 Unsustainability resulting from colonial governance ........................................ 132

3.10 Native leaders' capacity for governing big (groups of) states: ................................... 135

3.10.1 Tanzania: the travails of an African political marriage: .................................... 137

3.10.2 Uganda: governing an amalgam of traditional states: ...................................... 138

3.10.3Kenya: the challenge of 'uhuru' and sustainability:............................................. 141

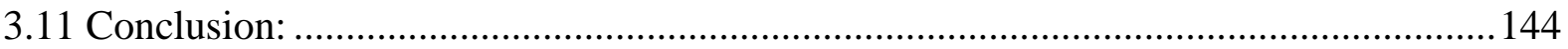

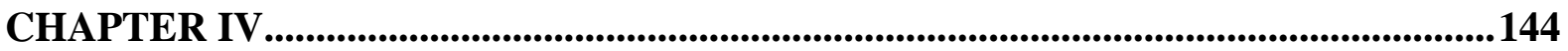

COMPREHENSIVE ETHICAL SUSTAINABILITY ...............................................144

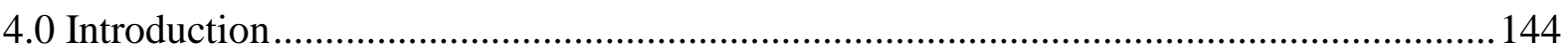

4.1 Definition of Comprehensive Ethical Sustainability (CES): ....................................... 145

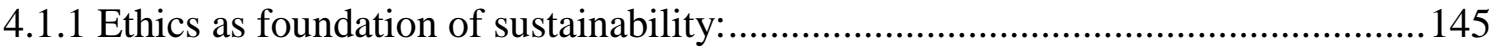

4.1.2Understanding theComprehensive Ethical Sustainability (CES): .......................... 147

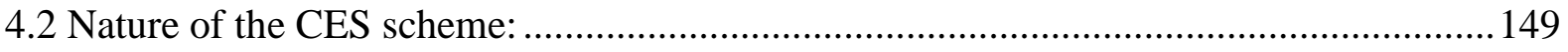

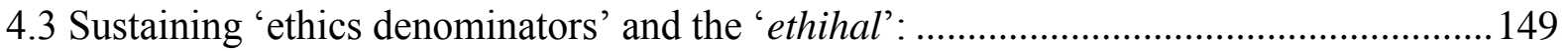

4.3.1 Two complimentary modes of comprehensive ethical sustainability: ..................150

4.3.1.1 Mode 1: Ensuring sustainability that is ethical: .................................... 150

4.3.1.2 Mode 2: Sustaining the ethical fabric of society itself: ...........................157 
4.4 On using the 'principle-approach'in attaining sustainability:

4.5 Reconciling the 'virtue' and 'principle' approaches in applied ethics:

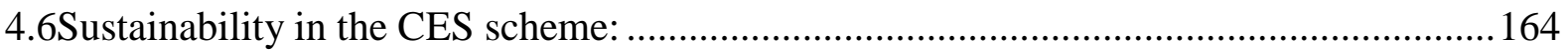

4.6.1 Nature of the principles of Comprehensive Ethical Sustainability(CES):

4.6.1.1 The Justice principle:

4.6.1.2 The Integrity principle:

4.6.1.3 The Ubuntu principle:

5.0 Introduction:

5.1 On meaning of justice:

5.2 Justice as a principle of Comprehensive ethical sustainability:

5.3 Variations in conception of justice:

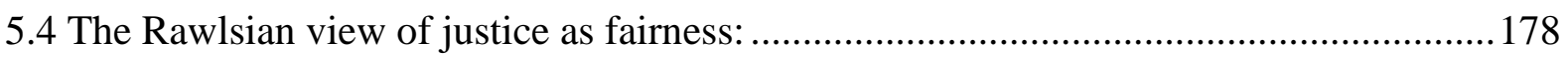

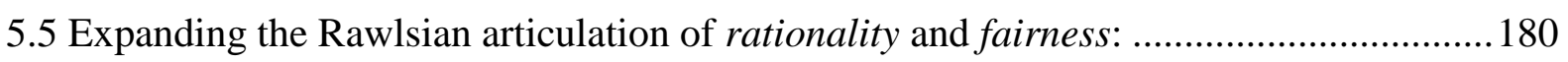

5.5.1 Social justice and the Rawlsian assumption about rationality: ............................ 181

5.5.1.1 Social justice and conscientious rationality: ......................................... 183

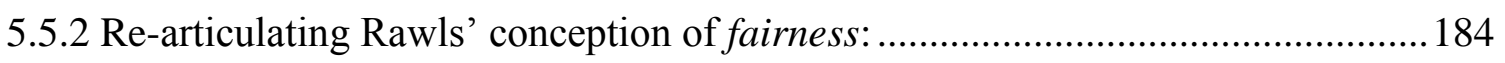

5.5.2.1 Reconciling contractarian and libertarian visions of justice: ................... 186

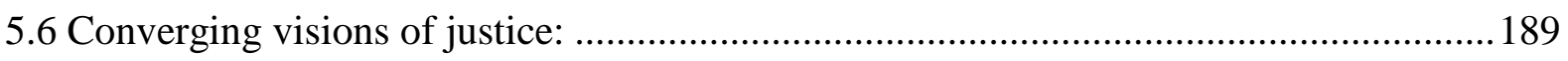

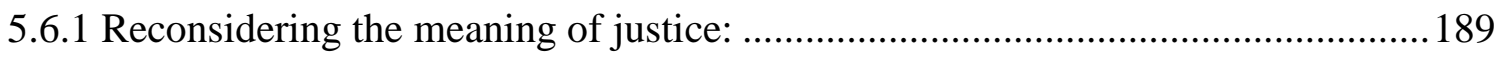

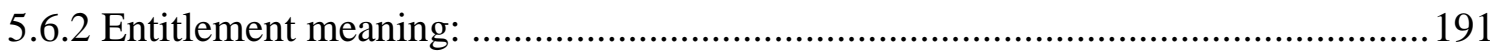

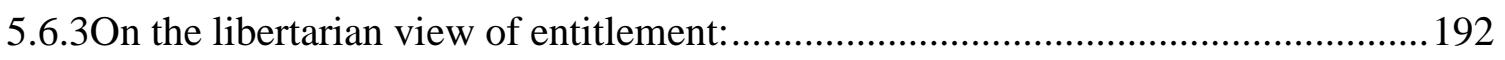

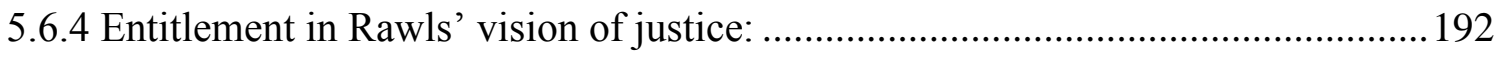

5.6.5Achieving fairness amidst arbitrary talents and abilities: ................................... 193

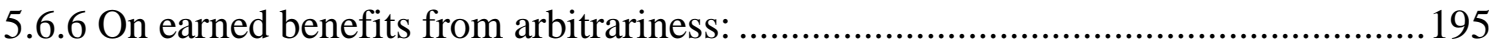

5.6.7 On entitlement from arbitrariness of natural talents and abilities: ....................... 196

5.7 Justice and undoing victim disaffection and villain encumbrance: ................................ 197

5.7.1 Victim disaffection and the unsustainability of unjust systems: ........................... 197

5.7.2 Villain encumbrance and the unsustainability of unjust systems:........................ 199

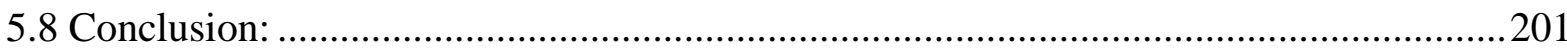




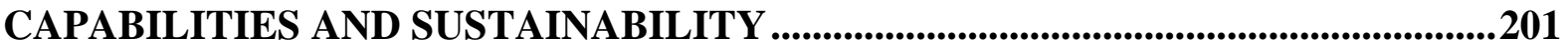

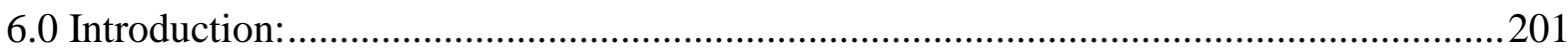

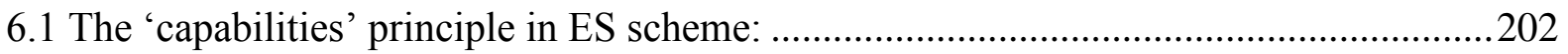

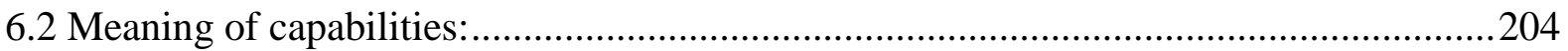

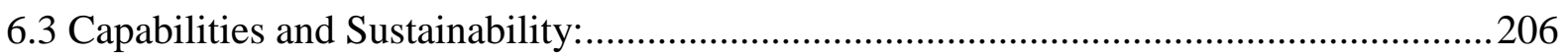

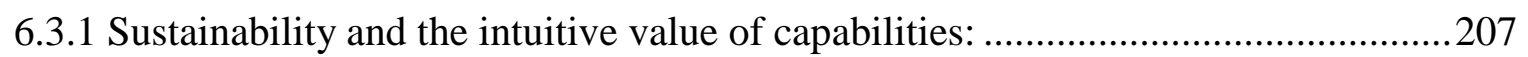

6.3.2 Capabilities and the spheres of sustainable development: .....................................208

6.4 'Arrangement-focus' and 'realization-focus' in Sen's The Idea of Justice: .....................210

6.4.1 Reconciling 'Arrangement' and 'realization' focused approaches:........................211

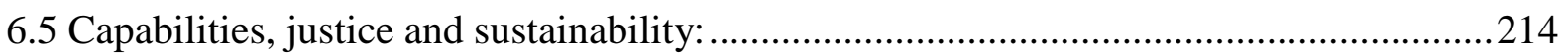

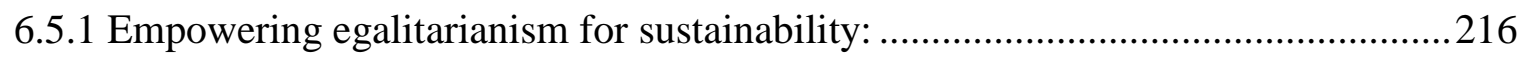

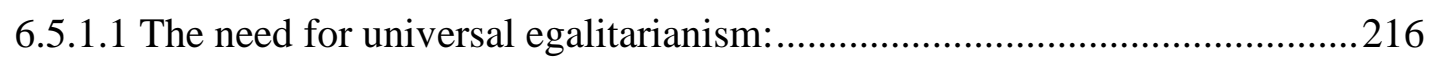

6.5.1.2 Natural and constructed foundations of a global basic structure: ...............219

6.5.2 Necessity of empowerment in partaking of justice:............................................221

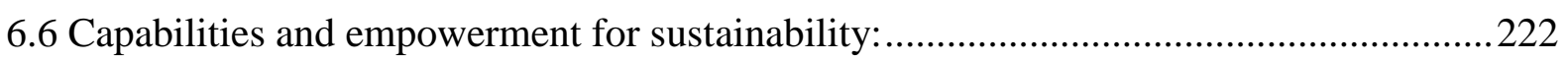

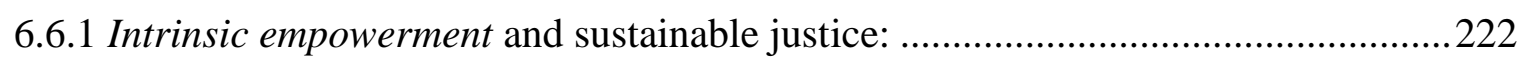

6.6.2 Extrinsic empowerment and sustainable justice:.................................................22

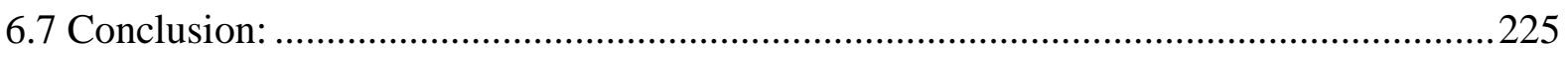

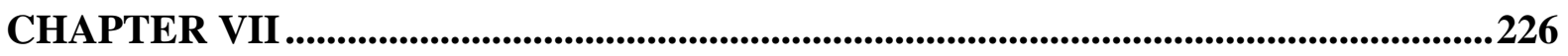

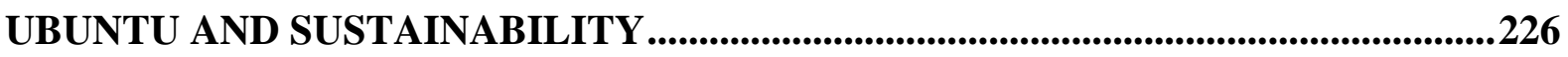

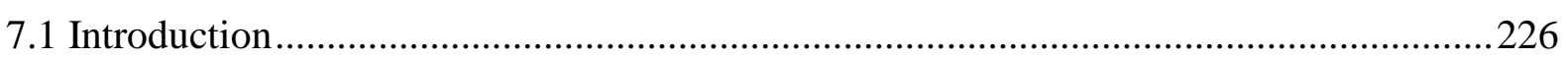

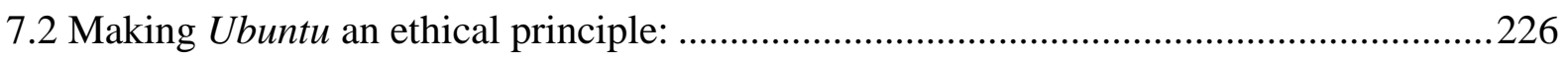

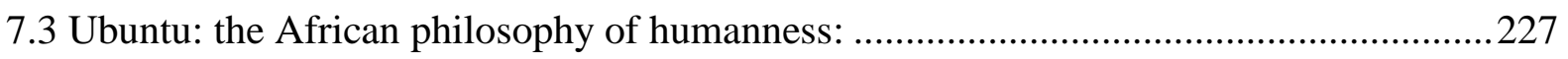

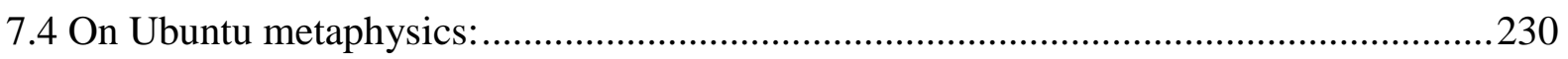

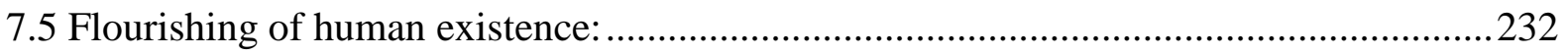

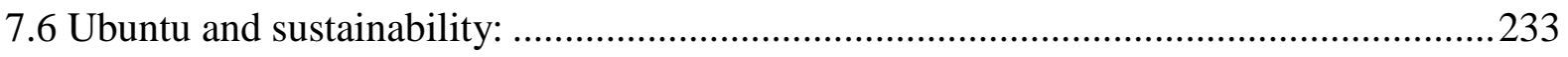

7.6.1 Converging the divergences in sustainability logic: .........................................234

7.6.1.1 Reconciling 'capitalist' and 'socialist' views of governance: ....................234

7.6.1.2 Resolving the development antagonism exhibited in Darwin's Nightmare:....236

7.6.1.3 Reconciling traditional and modern governance philosophies: ..................237

7.7 Using ubuntu to solve contemporary African governance problems: ............................239

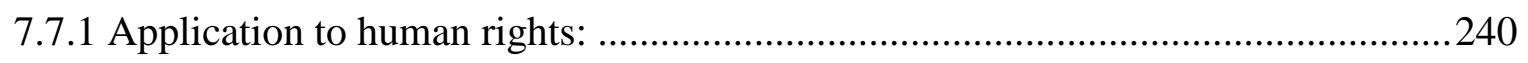

7.8 Ubuntu and governance: Observations on Buganda political philosophy:.....................242

7.8.1 On origin and nature of Buganda'sgovernance philosophy:......................................243 


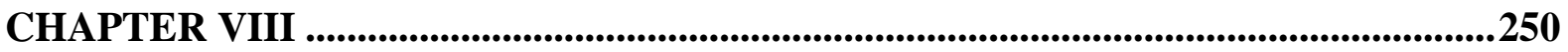

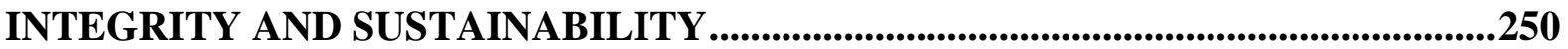

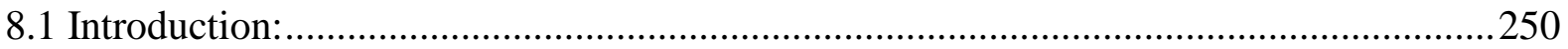

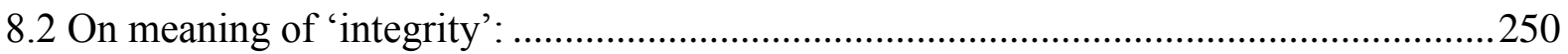

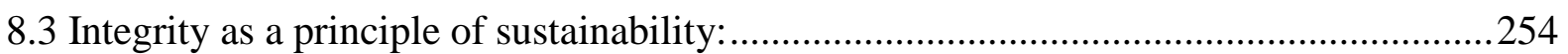

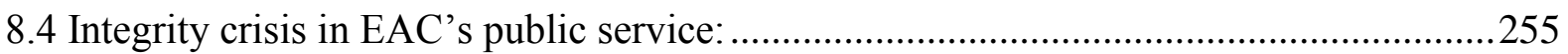

8.4.1 Integrity crisis and compromise of professionalism and rule of law: ...................257

8.4.2 Integrity crisis; subverting law enforcement and fueling conflict:.......................258

8.4.3 Integrity crisis and undermining the principles of the integration: .......................259

8.5 Understanding the nature of the 'Integrity Crisis' in the EAC's public service:.............262

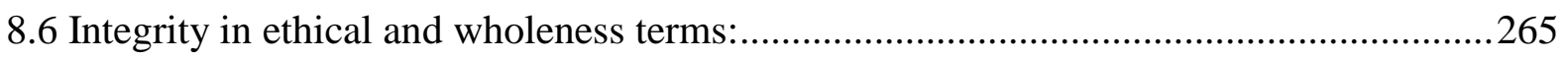

8.6.1 Ethical: Personal and professional integrity:...................................................265

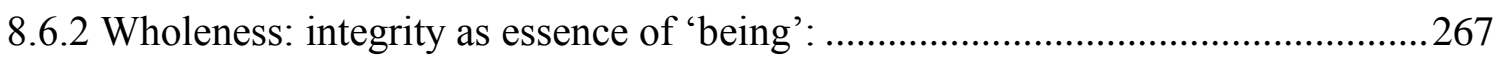

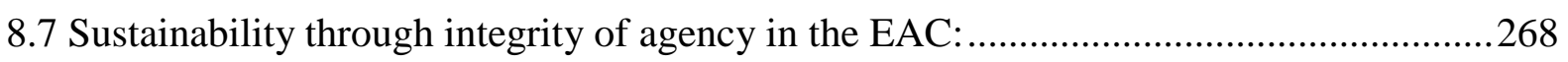

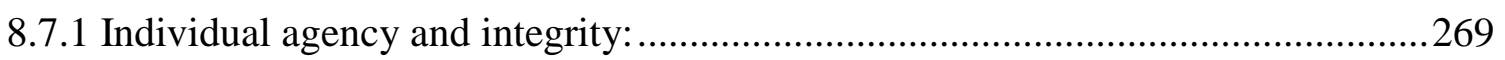

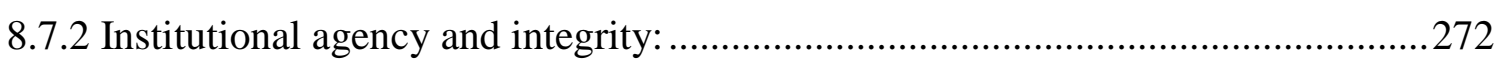

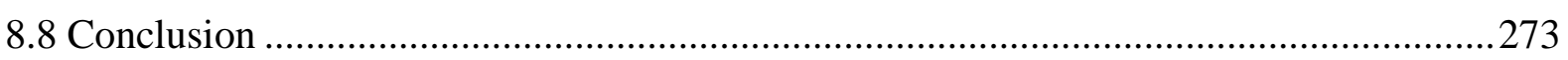

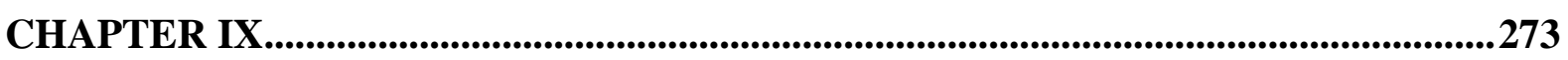

CONCLUSIONS AND RECOMMENDATIONS..............................................................273

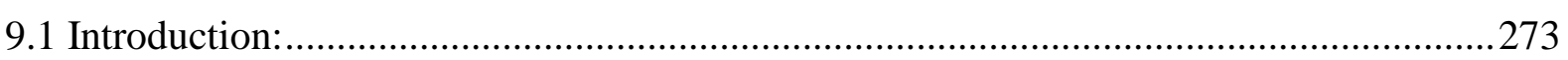

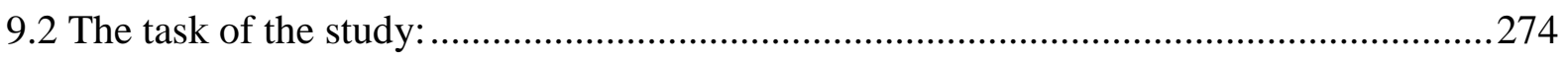

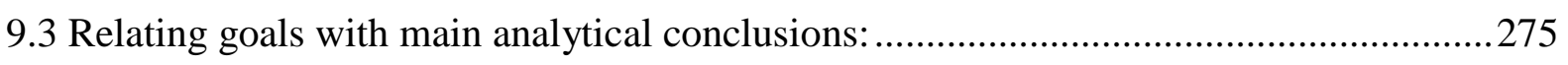

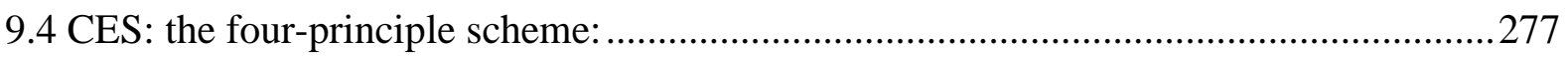

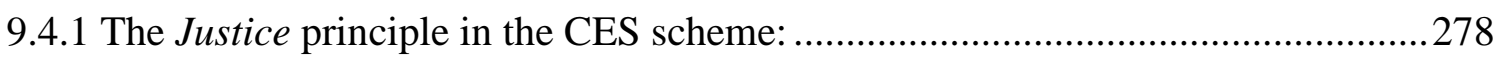

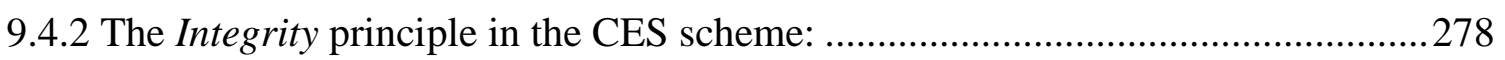

9.4.3 The Capabilities principle in the CES scheme:.................................................279

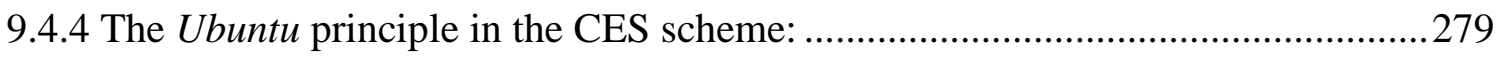

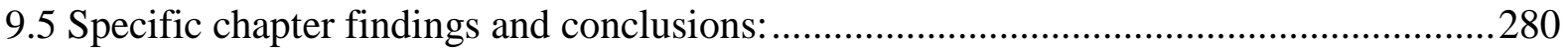

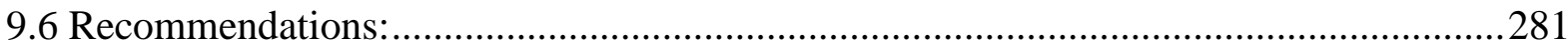

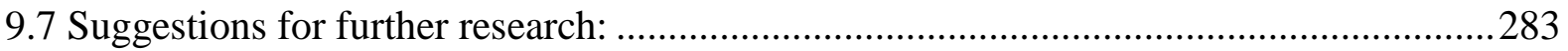

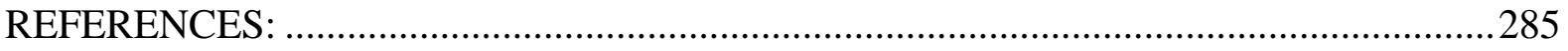




\section{List of Tables:}

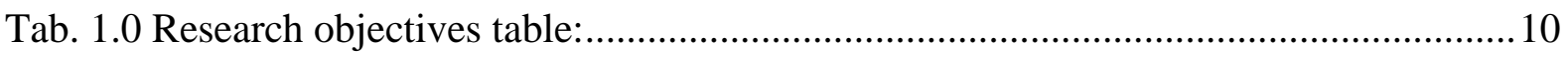

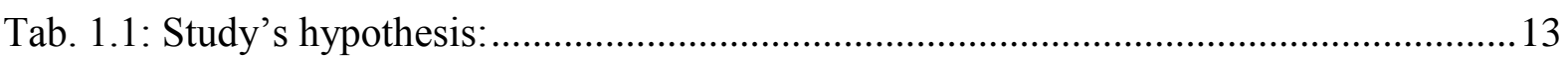

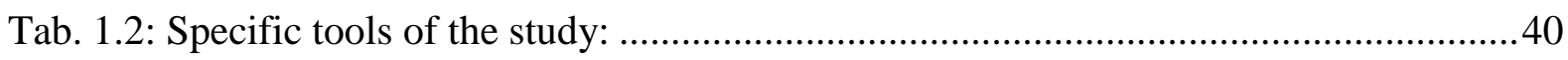

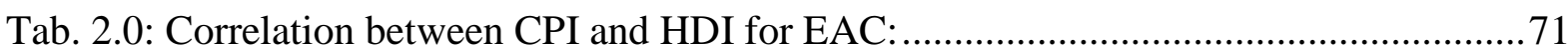

Tab.2.1: Global Corruption Barometer-2013 for the EAC region: ........................................ 72

Tab. 3.1: Phases of the EAC project and ideological orientations: .......................................98

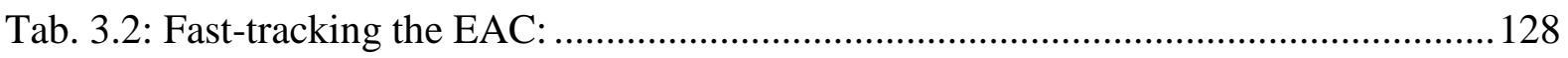

Tab 4.1: Kohlberg's Classification of Ethical Progress.................................................... 154

Table 4.2: Ethical reasoning in Kohlberg's classification of ethical progress....................... 155

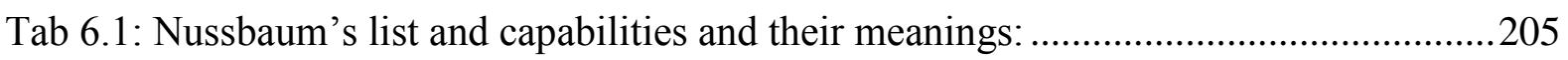

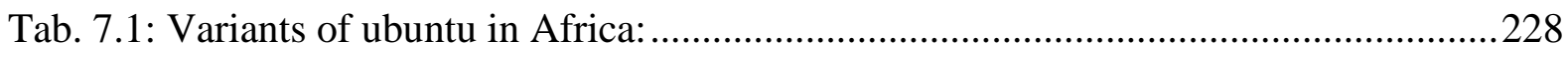

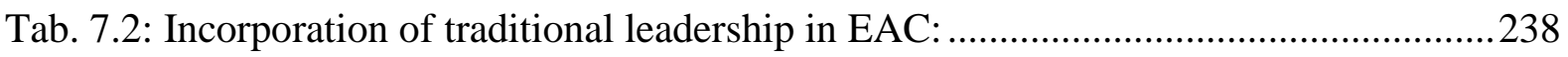




\section{List of figures and illustrations:}

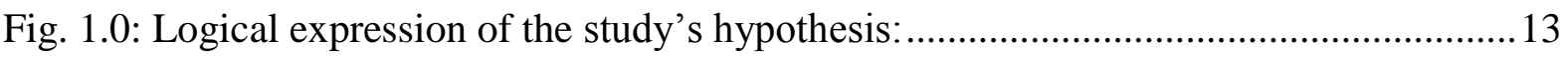

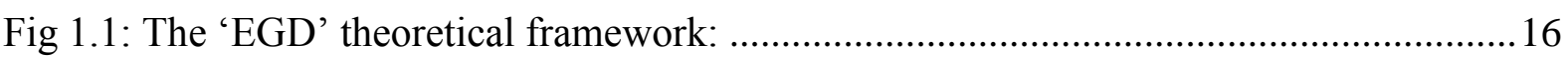

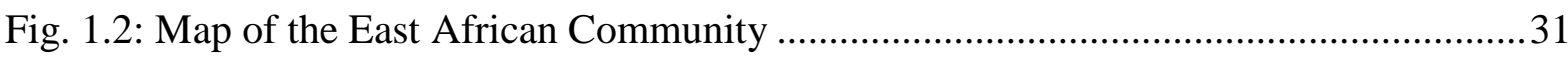

Fig.2.0: Relating the 'SEE' and 'TBL' models of sustainable development: ........................59

Fig.2.1: Divergence between 'market' and 'traditional African' sustainability logic: ............66

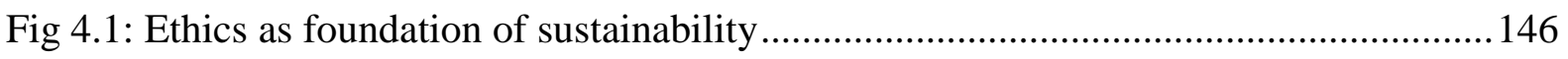

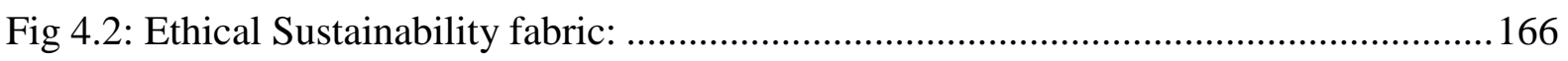

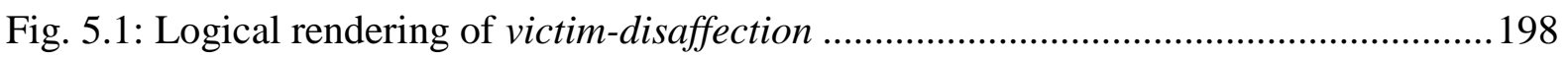

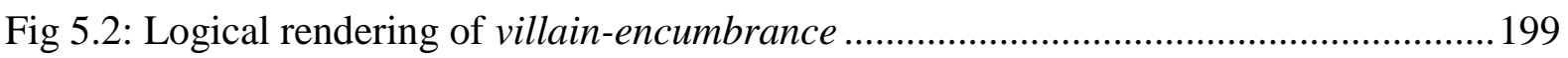




\section{Abbreviations:}

ADB

BUKITAREPA

CA

CASSOA

$\mathrm{CCM}$

CES

CGS

CII

CoW

CPI

CSR

DRC

EAC

EAC-1

EAC-2

EACLA

EADB

EALA

EASF

EGD

EPPC

ES

EU

FDI

FDLR

GCB

GEF

HDI

ICC

IDPs

IISD

IMF
African Development Bank

Bunyoro Kitara Reparations Association

Capabilities Approach

Civil Aviation Safety and Security Oversight Agency

Chama Cha Mapinduzi

Comprehensive Ethical Sustainability

Colonial Governance Style

Corruption Indicators Index

'Coalition of the Willing'

Corruption Perceptions Index

Corporate Social Responsibility

Democratic Republic of Congo

East African Community

East African Community project 1

East African Community project 2

East African Central Legislation Assembly

East African Development Bank

East African Legislative Assembly

East Africa Standby Force

Ethics, Governance,and Development Framework

Economic Performance of Post-Colonial

Ethical Sustainability

European Union

Foreign Direct Investment

Democratic Forces for the Liberation of Rwanda

Global Corruption Barometer

Global Environmental Facility

Human Development Index

International Criminal Court

Internally Displaced Persons

International Institute of Sustainable Development

International Monetary Fund 
IPCC

IUCEA

JAP

KANU

KDF

KRA

LP

LTTC

LVBC

LVEMP

LVFO

MIS

NFA

NGO

NRM

NRM-O

RE

RBS

SAPs

SD

SEE

Sida

SJ

SPIS

SPLA

SSA

TAA

TANU

TAS

TBL

TCCN

TI

TJ

UNDP
Inter-Governmental Panel on Climate Change

Inter-University Council for East Africa

Jubilee Alliance Party

Kenya African National Union

Kenya Defense Forces

Kenya Revenue Authority

Law of Peoples

Luo Thrift and Trading Corporation

Lake Victoria Basin Commission

Lake Victoria Environmental Management Policy

Lake Victoria Fisheries Organisation

Market inspired sustainability

National Forestry Authority

Non Governmental Organisation

National Resistance Movement

National Resistance Movement Organisation

Reflective Equilibrium

Regional Basic Structure

Structural Adjustment Programs

Sustainable Development

Social, Environmental, and Economic

Swedish Development Agency

Social Justice

Post-Independence States

Sudanese Peoples Liberation Army

Sub-Saharan Africa

Tanganyika African Association

Tanganyika African National Union

Traditional African Sustainability

Triple Bottom Lines

Transfer of Capabilities from Colonizers to Natives

Transparency International

Theory of Justice

United Nations Development Program

xviii 


$\begin{array}{lll}\text { UNECA } & - & \text { United Nations Economic Commission for Africa } \\ \text { UNEP } & - & \text { United Nations Environmental Programme } \\ \text { UPC } & - & \text { Uganda Peoples' Congress } \\ \text { ViD } & - & \text { Victim Disaffection } \\ \text { ViE } & - & \text { Villain Encumbrance } \\ \text { VOI } & - & \text { Veil of Ignorance } \\ \text { WA } & - & \text { WelfareApproach } \\ \text { WCED } & - & \text { World Commission on Environment and Development } \\ \text { WTO } & - & \text { World Trade Organisation } \\ \text { ZPPP } & - & \text { Zanzibar and Pemba's Peoples Party }\end{array}$




\section{Abstract:}

The pursuit of sustainability of governance and development has become a major challenge in contemporary times because of increasing realization that: various ecological and social systems are interconnected; and the complexity of our natural and constructed environs requires holistic approaches to avoid catastrophic fissures in the systems on which humans depend. As regional governments such as the East African Community (EAC) become important in Africa (and other regions), they present opportunities to generate cross-national approaches to achieving sustainability albeit success in that direction is limited and sporadic. In order to mitigate the underlying causes of that situation, we need to reconceptualize and reconstruct sustainability thinking and policy. From an applied ethics perspective, the study set out to explicate the value of and constructively generate a more viable conceptualization of sustainability in relation to the EAC. The study used qualitative methodology; designed as an atypical regionalization case-study and an analytical-constructive research; compatible research tools were employed in interrogating and analyzing secondary sources relating to member states of the EAC and the research was executed between 2011 and 2014.

The research found a divergence between the two main conceptual approaches to sustainability in Africa, namely, the 'Market inspired sustainability' (MIS) logic and the 'Traditional African sustainability' (TAS) logic. The study also uncovered colonial Social Darwinism as a major underlying governance philosophy that motivated the EAC's former colonial rulers; which became a key ingredient in the application of a colonial-functionalist approach to the region's earlier integration project (EAC-1). This was traced as a major premise on which the unsustainabilities within the contemporary regionalization project (EAC-2) were crafted. The research also found some acceptable levels of competence in regional governance within the individual EAC member countries in terms of: i) hierarchical, ii) network, and iii) market styles of metagovernance. However, closer analysis revealed: i) an inverse relationship between transfer of capabilities from colonizers to natives (TCCN) and the sustainability of postindependence states (SPIS); and ii)a directly proportional relationship between colonial governance style (CGS) and the economic performance of post-colonial (EPPC) East African countries. It also revealed an ambitious but inadequately grounded drive to expand the EAC project without due attention being given to existing fault lines of possible disintegration such as: perpetuation of colonially-initiated injustices, citizens' incapacity to partake of the benefits of the integration, and low levels of integrity, among others. 
The EAC faces a risk of turning into colonial victimization and villainization writ large; which is unsustainable due to the social laws of victim-disaffection (ViD) and villain-encumbrance (ViE). Further analysis showed that these fault lines of disintegration could be exasperated internally by the governance styles and stances taken by the ruling regimes of the core member states: Kenya's Jubilee Alliance Party (JAP) has to balance between the forces of ethnically inspired devolution and multicultural capitalism; Tanzania's Chama Cha Mapinduzi (CCM) still has to overcome a socialist single-party hangover and manage the political marriage between the mainland and the island; and Uganda's National Resistance Movement (NRM) has chosen a governance philosophy of hybrid Marxism. From a justice point of view, the study advocates for establishing a Regional Basic Structure (RBS) that uses a 'one-step original position' as a mitigation measure. The RBS should be founded on universal egalitarianism so as to minimize misrepresentation and diminish the political elitist culture of betrayal of the electorate at all levels of representative leadership.

In a reconstructive fashion, the research amplified the classical philosophical position that ethical values within society (the ethical fabric) provide the foundation on which other dimensions of sustainability are built. On the basis of that premise, the study generated and proposes the Comprehensive Ethical Sustainability (CES) framework as a scheme of axiomized ethical principles designed to be used towards the realization of the sustainability of systems and processes. The CES scheme is a principlistic recasting of selected intuitively valuable dominant approaches to development; designed to be convertible into a comprehensive program of action (or sets of regional policies) towards the attainment of governance and development sustainability in an integrated EAC. The CES framework is fashioned as a reorganized, multi-dimensional formation of four compound, compatible and complimentary principles i.e.: i) Justice, ii) Capabilities, iii) Ubuntu and iv) Integrity, whose application would make the regional bloc sustainable. These principles are considered and proposed as pillars in the: i) theorization of sustainability; and ii) policy formulation, structural arrangements and individual action aimed at sustainability. 


\section{CHAPTER I}

\section{GENERAL INTRODUCTION}

\subsection{Introduction:}

This chapter is a general overview of the premises upon which the study was conceived and its direction. This section furnishes the reader with general introductory observations on the East African Community and background to the problem that the research was concerned with. It also presents the research problem which the investigation pursued plus the scope of the study in terms of geography, time and discipline. This introduction also gives the objective(s) that the study set out to achieve and the methodology that was used. And apart from also laying out the theoretical framework that guided the research, it presents the justification and significance of the study in this section.

\subsubsection{Unsustainability fissures in the East African Community:}

Between December and February 2007 Kenya experienced unprecedented election-triggered ethnic and tribal-inspired clashes that still threaten its social and political coherence (after claiming over 1200 lives and displacing more than 600,000 persons). Most analysts blamed that violence on a convergence of various systematic injustices ingrained in Kenyan development (Njogu, 2009; Materu, 2014). After the death of Mwalimu Nyerere, the Tanganyika-Zanzibar union (Tanzania) has come under tremendous pressure in the recent years threatening the sustainability of one of the most successful African political union experiment (Mwakikagale, 2014a; Thembi, 2012). Despite current political stability, recent phenomena exposed the fissures in Uganda's political and social set up; from the 2009 Buganda riots (with 20 people reported dead, many injured and arrested), to the 2011 'Walk-to-Work' protests (Musaazi, 2011; Kobusingye, 2010:17-18), indications are that Uganda has to seriously consider how to ensure long term sustainability. The cases of the possible unsustainability of the other two East African Community member countries, Burundi and Rwanda are well known and documented world over. Additionally, there is a greater threat to the region's social, political and economic sustainability, in form of high percentage of unemployed youth vis-àvis the population; Uganda leads in this category with $78 \%$ of its population below 35 years of 
age, Kenya follows with $70 \%$ while Tanzania is at $60 \%$. This youthful population is not necessarily negative but they pose a challenge for the leaders in the region of channeling this human resource into productivity and sustainable economic growth. Despite registering an average of $6 \%$ economic growth rate and the euphoria over the discovery of hydrocarbons in recent years, observers argue that, if this enormous youthful resource and energy is not harnessed well, it could turn into a major problem for the region (Analo, 2014).

Disillusioned and unfulfilled youth are most likely to join any external threat to the sustainability of the East African Community (EAC) because such threats abuse the abundant youthful energy by recruiting and directing them towards negative agendas. For example, African and non-African terrorist groups such as the Al Qaida inspired Al Shabaab radicalizes and recruits youth into their ranks, thus proving a formidable security threat (Botha \& Abdile, 2014). In order to provide fulfilling jobs for these youths, a bigger regional market is a necessity (Museveni, 2013); but despite the 40\% growth in intra-EAC trade between 2005 and 2009 (Kiiza \& Perdeson, 2013:1) there is great competitive disadvantage in the face of stiff economic competence from Asian products. This undermines the economic sustainability of the EAC by undercutting industrialization and consequent job and wealth creation strategies in the region.

Relatedly, researchers, Okungu and Opango (2012) found that being the most industrialized in East Africa makes Kenya the biggest threat to the sustainability of Lake Nalubaale (Victoria). After studying only 3 rivers, they found that the total pollutants (in tons) flowing into the Lake per year are: Suspended Solids $(4,390,644)$, Silicon $(140,849)$, Nitrogen $(12,193)$, and Phosphate (2,113). In 2007 the Ugandan President consented to a proposal by a private sugar corporation to convert $25 \%$ of 30,000 ha of Mabira forest reserve into sugar plantation. This provoked intense riots that forced the government to abandon the plan by September 2007 but only after 5 people dying and several getting injured. In 2011 the President resurrected the idea and certain reports indicate that the conversion has been going in the deeper sections of the forest away from the public scrutiny. Relatedly, in November 2014 there were media reports that Museveni was angered that Ugandan sugar was being denied entry into Kenya (East Africa's biggest market) due to non-tariff barriers. Conversely, in 2003 a consortium of 30 environmental NGOs successfully lobbied against a \$580 million, 200 megawatt hydroelectric dam project Bujagali on river Nile forcing the American energy giant, AES to withdraw. Meanwhile Uganda loses about $4 \%$ of forest cover annually (60\% to the informal charcoal industry and $10 \%$ to large scale agro-business) and experts at the National Forestry Authority 
(NFA) warns that, at that rate, the country could have no forests by 2050 . The controversial documentary, Darwin's Nightmare (2005) was an example of how problematic the exploitation of resources in and around Lake Nalubaale (Victoria) can get if sustainability is ignored by the countries of east Africa.

\subsection{Applied ethics and the quest for sustainable development:}

In recent ethics discourse, there has emerged a strong move to distinguish between 'philosophical ethics' and 'applied ethics' (De Marco \& Fox, 1986; Almond, 2009). Applied ethics is one of the major disciplines that are increasingly becoming relevant in addressing society's challenges today because: i) it allows room for a multi-disciplinary discourse on human problems, and ii) it provides conducive epistemological grounds for the generation of more suitable conceptual frameworks that can assist in understanding and addressing contemporary ethical and other challenges. The latter reason was particularly considered a more viable premise on which to base an applied ethics study as this that deals with Africa. The continent is considered an emerging region (see: The Economist, 2011) with enormous potential that is slowly being realized; in such an environment there is room for researchers to creatively contribute to the building of the continent. Nevertheless, as the continent is billed to rise from the dust, it also faces the challenge of realizing systems and institutional setting that can sustain its young and growing population. It's in response to this enormous challenge that this study was undertaken.

The pursuit of sustainable development has become a staple challenge for both high and low income countries in contemporary times (Peter R., et al, 2012; Okechukwu \& Osita, 2005; UNECA, 2012); and also for both urban and rural communities (Manzi, et al 2010). This growing emphasis on the pursuance of 'sustainable development' presupposes an understanding of what 'sustainable' means and the parameters of what sustainability is. That is why it is pertinent in such an era to investigate and enrich our understanding of sustainability. The idea of sustainability and its thinking has been around for quite a long time (Ulrich, 2007); and its conceptualization has had effect not only on domains like development but also other areas such as: business, governance (Jan-Peter, et al, 2006; Klaus, et al 2008), urban transport (Marsden, et al, 2012), among others. Some thinkers trace the growth in concern over 'sustainability' from as far back as the 1798 Malthusian essay on the 'principle of population' (Kelly, 2011); some trace it from the concerns over 'sustainable' harvest of forests in 17th century Europe (Ulrich, ibid) up to the most recent Rio+20 international conference that sought 
to push for more 'greening' sustainable use of natural resources (IISD, 2012:12). Though the concern over it has increased today, our observations indicate that sustainability thinking has been around for a long time.

The progressive realization of the importance of sustainability by the international community in contemporary times indicates that: i) sustainability is what buttressed various ecological, and social systems all along but it is human thinking that had taken long to realize it (Ulrich, op cit); ii) as humans realize the complexity and interconnectedness of their natural and constructed environs, they have to think in new dimensions to create relevant theories to avoid catastrophic results from the pressure exerted on the systems on which our lives depend (Espinosa \& Walker, 2011). This study concerns these two major realizations: in the former case, it is a project in making explicit what has always been implicit as far as the value of sustainability is; and in the latter case it is a constructivist contribution to the generation of befitting conceptual and theoretical tools to realize sustainability within systems that are becoming more compound and complex, albeit from an ethical perspective.

There are various aspects of our environs that are increasingly becoming compound and complex; but this study focuses on the sustainability of development in relation to governance of bigger amalgamate states or regional blocs, particularly in Africa. There are a number of regionalization projects that have been registered or currently taking place in Africa (Bach, 1999), and in some cases the phenomenon aims at bringing about bigger countries ('megastates') and these projects present unique challenges of development and sustainability. With the increased or accelerated regionalization in Africa, and their attendant regional governments, ethical challenges inevitably emerge as far as governing them is concerned; and these challenges affect their overall sustainability. Governance determines a lot as far as achieving development goals is concerned (World Bank, 1992), yet we cannot discuss development without encountering ethical questions (Gasper, 2004). Issues of ethics and morality are increasingly being acknowledged to be relevant to development discourse because the discourse is focusing more on the development of the human person rather than mere 'things' as it were (Sen, 1999).

As globalization takes place, it impacts on governance and one of its expressions in Africa is in form of regionalization projects (Bach, op cit); this does not take away the concerns that ethicists have traditionally raised over governance but it simply takes them to a regional level. 
From the traditional layers of governance, namely, local and national levels, as ethicists we find ourselves having to contribute to ethical governance at the regional level. Where layers of government are concerned, given the pace of globalization, it is imperative, from an ethicist's point of view to study the implications of higher levels of governance on the ethics of development and the sustainability of those regions. This study holds that to minimize the challenge of unsustainability of the development of regional-states we need: i) to investigate the theoretical grounds on which policies and institutions of regionalized states are based; and ii) to generate more suitable frameworks on which social, economic and political development discourse could be premised and operationalized.

Such a study is more necessary in face of the weaknesses (both perceived and real) in most of sub-Saharan Africa's regionalization projects. Even though Bach et al (1999) focused on West Africa in particular, their observation that in most of Africa, "the effects of regionalization and globalization combine with a crisis of the post-colonial states to reshape state-society relations" (p. xvii), points to the challenge that African governments face of balancing neo-colonial forces with ensuring the realization of the aspirations of the natives of those countries as regionalization takes root on the continent. The social and political landscape in between those forces is lurked with both pitfalls and great possibilities of framing a better and sustainable future for the countries involved. This study approaches the opportunity of contributing to framing a sustainable future from an ethicist's point of view. But as Nitin observed, “...it is beneficial to gain a better understanding of the complex ethical concerns and social impacts while pursuing development activities" (Nitin, 2000:1). With that in mind, in order that I constructively contribute to framing a sustainable future for the natives of eastern African countries, in this study I investigate the ethical complexities involved in the establishing of the East African Community and propose a more suitable approach to its sustainability.

\subsection{General background on the study:}

Historically the territories that are now referred to as East Africa, namely Burundi, Kenya, Uganda, Tanzania, Rwanda (and Somalia, South-Sudan plus parts of Ethiopia) are recorded to have had ethnic, cultural, economic and political ties that dated back into antiquity (see: Derideaux, 2002) long before the East African federation was conceived and its intermittent collapse (Muriuki, 1978:2). Historical studies also attest to the fact that this region has had past episodes of running big and complex governments; from the ancient Aksum Kingdom in Ethiopia (which flourished both in before and after the time of Christ) to the contemporary 
Buganda Kingdom in Uganda (which flourished both before and after colonialism). With that perspective in mind, then the regionalization of the East African community ought to be considered as an African experiment in the of re-organization of government to cover a wider geographical space among people who share a rich history before the colonial masters. By the time of modern contact with foreigners, much of the east African region was characterized by multiple small kingdoms and chieftainships that dotted the landscape from coast to the interior, which were in constant contest over territorial influence, which implies that it was a challenge to sustainably govern the larger kingdoms of the past. Nevertheless, these kingdoms and chiefdoms continued to share and cooperate in many aspects such as trade, culture, among others.

It is these multiple kingdoms that the colonial masters later conquered or manipulated or coerced into forming the modern states in the region (Audrey, 2014); by implication thereof, even the modern states in east Africa are groupings of various traditional kingdoms, cultures and tribes. The colonialists majorly undertook the venture for economic purposes (Gann \& Duignan, 1975; Byrd, 1971) with more interest in the economic output and benefit from those colonies than the benefit of the natives; and that legacy has continued to haunt the region's governments (Mutiibwa, 1992; Koigi, 2002; Knud, 2007). So by the time the idea for the formation of the East African federation was mooted, it was more or less motivated by colonial economic expediency and its sustainability would come under enormous pressure once the colonialists were forced to grant the natives independent rule. This led to the collapse of the first East African Community enterprise (EAC-1), which has been revived in recent years thus begging the question of whether the second attempt will be sustainable. It suffices to not however, that the current attempt to form the East African Community (EAC-2) embodies both continuations and discontinuations of the colonial legacy in the region; thus the need to investigate them and find more suitable ways of ensuring the project's sustainability.

In modern terms, the cooperation among the east African states started during the colonial era with the first East African customs union that was between Kenya and Uganda in 1917; Tanganyika joined in 1927. In 1948 the colonial powers that controlled the Kenyan territory (a colony by then), Uganda (a protectorate by then) and Tanzania (by then called Tanganyika) signed and made those territories to enter into an Inter-territorial Co-operation agreement which established the East African High Commission. This trend began a history of cooperation and integration of the East African community. 
The East African Community regionalization was originally officially founded in 1967; then it collapsed in 1977, and was officially revived on 7 July 2000. The Treaty re-establishing the East African Community was signed by the governments of Kenya, Tanzania and Uganda in Arusha, Tanzania in November of 1999, and came into force in July, 2000; later, Burundi and Rwanda joined in 2007 and currently South-Sudan has submitted an application to join the bloc. The EAC is therefore a regional intergovernmental organization comprising five countries (Burundi, Kenya, Tanzania, Uganda and Rwanda) and its administrative Secretariat is in the city of Arusha, Tanzania. The region of the EAC covers an area of 1.8 million $\mathrm{km}^{2}$, with an estimated population of 132 million and a combined GDP of 38 billion USD. The organ is headed by a Summit of Heads of State followed by the Council of Ministers (individually selected by the partner states) and its Secretariat is run by the Secretary General (EAC Treaty, Art 9 Chap 4, 5, \& 6). There are increasing reports (plus concerns) that the bloc is being fasttracked to become a political federation (Kasaija, 2006; Naturinda, 2011); and in 2004 the Summit set up a special committee tasked with generating a 'fast tracking mechanism' after raising concerns over the slow pace of the integration (EAC, 2007). Most Heads of State such as Mkapa who were members of the Summit by 2004 considered the regional integration as "necessary strategy for sustainable development" (Kasaija, p.2).

The bloc is considered by scholars to have higher bets of succeeding because apart from the shared history, the countries have similar cultural ties, trade interests and natural endowments; its anticipated success is also expected by economists to act as a motivator for other weaker regional communities in Africa (World Bank, 2007:v). It also is considered by far the fastest progressing regionalization project in comparison with others in Africa (ibid.). It is reported that by 1977 ,

Regional integration in East Africa had reached the highest level experienced in the world. The EAC was both a fully-fledged Customs Union and a Common Market. It shared railways and harbours, airlines, civil aviation, inland waterways, road transport systems, post and telecommunications, power and lighting, customs and tax management, health and medical research, aviation training, pesticides research etc. Importantly, and until 1970, the EAC also ran the University of East Africa. At the same time, under the EAC umbrella were the East African Court of Justice, an East African 
Legislative Assembly, and a regional Secretariat. Not even the current European Union has an institutional framework as elaborate and powerful in decision making as that of the EAC at the time of its collapse in 1977. (Mwapachu, 2010:10)

But at same time there are concerns over its sustainability which are mainly expressed in terms of economic growth (World Bank, 2007:37). In the international development industry there is a growing concern over attaining sustainable development in Africa (UNDP, 1997; Rarieya, 2009). Concurrently, regional governments (such as East African Community) are growing in importance and impact, which is apparently shifting responsibility over and analysis of development from national to regional levels. The challenge is therefore how to govern such a regional bloc and yet achieve sustainability. For that reason the 1997 UNDP report, Governance for Sustainable Development, explored the relationship between governance and the achievement of sustainable development. And in response various thinkers have investigated and elevated the relationship between the two at a regional level exploring how regional management can be harnessed for sustainable development (see: Lyons \& Deutz, 2010). As regional governments become progressively important to sustainable development, there is need for competence in the management of those entities. This implies the ability to manage groups of governments that have come together from a number of states; in other words it could be referred to as the 'governance of governance'.

Scholars have come to refer to this as 'metagovernance'; i.e., the governance of governance is a theory of governance that shifts from the traditional 'command and control' fashion of bureaucracy to "indirect steering of actions and interactions of relatively autonomous stakeholders" (Bevir, 2009:132). The gist of metagovernance is the 'engineering' of the environment or conditions of governance (Jessop, 2008:7) and steering them towards a desired social goal. With the historical experience of the dissolution crisis that took place in the EAC there is historical evidence that the management of a regional state or 'grouping of states' as it were, is necessary in current times. There is therefore a good rationale to investigate whether the regional bloc has capacity to effectively govern itself and if so, how the EAC regionalisation project is applying metagovernance to engineer sustainability. This research used metagovernance as part of a theoretical framework to explore policy engineering and innovation for sustainable development in the region and apply its principles in generating a more suitable approach to sustainability. It is the application of the ethics of governance 
towards the realization of sustainable development, albeit at a regional level, which requires that development is analyzed from an ethical perspective.

Governance is therefore related to the ethics of development and the latter is increasingly becoming an indispensable element of development discourse (Gasper, 2004); therefore in order to realize sustainable development at a regional level of governance, ethical concerns cannot be ignored. Classical thinkers such as Socrates, Plato, Aristotle, are understood to have taken matters of ethics and justice to be an integral part of governance and political theory (Brown, 2011; Crisp, 2005). Likewise in contemporary times, ethics is indisputably an integral aspect of sustainable human development. This understanding of the indispensability of ethics in human endeavors greatly contributed to motivating this investigation and analysis of sustainability of the EAC which is necessary in a globalized world if east Africans are to achieve sustainable development and overall improvement of the human condition in that part of the world.

\subsection{Statement of the Problem:}

The challenge that confronts governance and development thinkers and practitioners in Africa today is how to achieve sustainable development. One of the greatest presuppositions of development thinking and goal-setting is that good and competent governance exists in the given geographical areas of jurisdiction; however, in many places in Africa that is not the case. It is noteworthy that most of the anthropocentric challenges documented in governance that hinder sustainable development (such as corruption, abuse of office, incompetence, etc.) are basically ethical in nature yet many governance and development experts pay less than necessary attention to ethics. Nonetheless, ethicists have a task of contributing to the resolution of this challenge and the problem is how to apply ethics thinking in bridging the disjoint between development and governance in order to achieve sustainable development. Constructively applying ethics to the art and science of governing regional governments (metagovernance) in Africa could yield better ways of approaching and resolving the problem of sustainability on the continent.

\subsubsection{Research Question:}

The research question is: how would we constructively apply ethics to the governance and development of a regional government in east Africa such that we can achieve sustainability? 


\subsection{General objective of the study:}

The general objective of this study was to ethically enrich sustainable governance and development discourse in the East African Community by: i) interrogating and enriching the conceptualization of sustainability; and ii) generating a more suitable framework through sustainable governance and development could be achieved in the East African Community (EAC) as a case of regional government.

\subsubsection{Specific Objectives}

i) To establish the cause(s) of the unsustainability of the earlier East African Community from a philosophical and ethical perspective

ii) To elucidate the significance of incorporating ethics in the conceptualization and pursuance of sustainability in the East African Community and beyond

iii) To generate a more suitable theoretical framework for the realization of sustainability of the East African Community region

\subsubsection{Objectives table:}

The following is a tabulated expression of the specified objectives of the study. The table relates each specific objective with the applied method and the execution strategy that was used during the research followed by the highlights of the outcomes. The use of a tabular format in laying out the objectives was purposed for: i) making it easier to track the attainment of the objectives of the study; ii) monitoring and ease in relating the application of research method to the strategy of execution.

The table below lays out the concrete steps on how the concepts and theoretical direction of the research was executed and the results obtained. The conception of this table is meant to display in a simple format the objectives of the study and their corresponding methods; it also indicates the execution strategy that the study thought to be well suited for a given method and the outcome. The table demonstrates that the research was carried with a backdrop of enough thought given to the relationship between objective, method and outcome.

Tab. 1.0 Research objectives table:

\begin{tabular}{|l|l|l|l}
\hline Objective & Tool & Execution & Outcome \\
\hline
\end{tabular}




\begin{tabular}{|c|c|c|c|}
\hline $\begin{array}{l}\text { 1) Establish } \\
\text { fundamental } \\
\text { cause(s) of } \\
\text { unsustainability } \\
\text { of the EAC }\end{array}$ & $\begin{array}{l}\text { Analytical } \\
\text { observation, } \\
\text { philosophical } \\
\text { critique }\end{array}$ & $\begin{array}{l}\text { Analyzed documents } \\
\text { relating to EAC } \\
\text { governance } \\
\text { (Treaties, policies, } \\
\text { reports, etc.) }\end{array}$ & $\begin{array}{l}\text { Observed: } \\
\text { i) Social-Darwinism } \\
\text { ii) Colonial- } \\
\text { Functionalist } \\
\text { approach }\end{array}$ \\
\hline $\begin{array}{l}\text { 2) Explain } \\
\text { necessity of } \\
\text { incorporating } \\
\text { ethics in } \\
\text { sustainability } \\
\text { conceptualization }\end{array}$ & $\begin{array}{l}\text { Analytical } \\
\text { observation, } \\
\text { conceptual } \\
\text { clarification, } \\
\text { diagnostic } \\
\text { analysis }\end{array}$ & $\begin{array}{l}\text { Centralized ethics in } \\
\text { sustainable } \\
\text { development theory } \\
\text { Located ethics in } \\
\text { framing of EAC } \\
\text { (used secondary } \\
\text { data). }\end{array}$ & $\begin{array}{l}\text { i) Explained } \\
\text { implicit ethical } \\
\text { values in EAC } \\
\text { Treaty \& policies } \\
\text { ii) Demonstrated } \\
\text { ethics as foundation } \\
\text { of sustainability }\end{array}$ \\
\hline $\begin{array}{l}\text { 3) Generate a } \\
\text { more suitable } \\
\text { sustainability } \\
\text { theoretical } \\
\text { framework }\end{array}$ & $\begin{array}{l}\text { Prescriptive } \\
\text { analysis, } \\
\text { constructive } \\
\text { argumentation, } \\
\text { axiomatic } \\
\text { reasoning }\end{array}$ & $\begin{array}{l}\text { Analyzed and } \\
\text { developed concepts } \\
\text { (justice, capabilities, } \\
\text { ubuntu \& integrity) } \\
\text { into schematic } \\
\text { principles }\end{array}$ & $\begin{array}{l}\text { Generated the } \\
\text { Comprehensive } \\
\text { Ethical } \\
\text { Sustainability (CES) } \\
\text { scheme }\end{array}$ \\
\hline
\end{tabular}

\subsection{Significance of the study:}

The major significance of the study lies in the generation of a framework termed as, Comprehensive Ethical Sustainability (CES), which will enrich the conceptualization of sustainability (sustainable development) as a whole by emphasizing the ethical as a foundation on which other aspects lean. In both the academic field of regionalization studies less than necessary attention is given to understanding how ethics contributes to theory and practice; but this is significant in reversing that tradition. Numerous scholars researching on how to incorporate ethics in development and governance have a tendency to mainly focus on individuals and national psychological and neuro-scientific analysis but this study is significant in taking the analysis to a regional level.

Additionally, this study is significant in that it encourages ethical and good governance in the East African Community an area that has high incidence of bad governance and failed states in the globe. Likewise the study also promotes competence in the governance of regional blocs in the EAC, which will contribute to better lives for the citizens of the region. This study will also be quite helpful for the evaluation of policies and leadership at the regional level in the EAC. It will also serve as an important reference for future researchers on issues of ethics of governance and development in the region. 


\subsubsection{Justification of the study:}

The justification of the study stems from the realization that attaining sustainable development is no longer a concern of a selected few, neither is it just an ivory-tower pipe dream. Since the publication of the pivotal works: i) The Limits of Growth (1972) by the Club of Rome and ii) Our Common Future (1987) by the United Nations, the concern about the sustainability of human existence has increasingly gripped the human mind. In 1992 the Earth Summit conference which resulted into Agenda 21 on biodiversity conservation and the Johannesburg Declaration on Sustainable Development (2002) and both events cemented the need for sustainable development as one of the foremost concerns of human society. The theory of sustainable development (SD) has progressively come to be defined in terms of the balancing of the economic, social and environment domains of human society. But this conceptualization of SD has been variously criticized on many counts ranging from lack of clarity to noncompatibility with the dominant economic doctrine of perpetual growth and poverty reduction. This study is justifiable in the sense that it answers that challenge by arguing for the founding of the three domains of sustainable development on an ethics base. The study re-conceptualizes 'sustainability' as such and permeates it with ethics, without which the ideals of SD would be difficult to realize.

The second aspect of the study's justification stems from the need to extrapolate the SD discourse from the lofty world organizations' offices to the realities in which Africans live. Quite a number of African scholars are working at generating contingent conceptions of SD that may get applicability mileage in the peculiar African experiences. For example Okechukwu and Osita (2005) argue that, "sustainable development is generally homegrown and not something that is readily or easily exported from one place to another" (p.1); implying that African thinkers have to generate their own homegrown visions of SD that put into consideration the African experiences and their histories. This study is justifiable in that it sought to generate a vision and conceptualization of sustainability that is situated in the historical realities and lived experiences of the east African peoples.

\subsection{Hypotheses of the study:}

The study used a research hypothesis in addressing the research question. A hypothesis is in simple terms defined as a testable proposition (Silverman, 2001:3). As a tentative generalization subject to testability (Lokesh, 2009), the proposition had to be put under a 
validity test (Goode \& Hatt, 1952) and this was done within the sustainable development conceptual environment and regional integration in the East African Community. The case of the East African Community was chosen because it possesses characteristics of an atypical case (I explain this more under the methodology section of the text). Given the complex and huge amount of data available on both the research problem and the geographical area under research, the choice of using a hypothesis was deemed necessary in order to: i) prevent a blindfold and indiscriminate gathering of data, ii) get a definite direction for the research, and iii) delimit the main and peripheral fields of study. For that matter, the hypothesis that guided the investigation is stated thus:

Tab. 1.1: Study's hypothesis:

The elusiveness of achieving sustainable governance and development in the East African Community is traceable from an ethics gap in traditional governance and development theorization and in order to overcome it, we need to incorporate ethical reasoning in development and governance theorization and institutions.

Below was the logical expression of the research hypothesis followed by an explanation of the logic in the hypothetical direction of the research:

Fig. 1.0: Logical expression of the study's hypothesis:

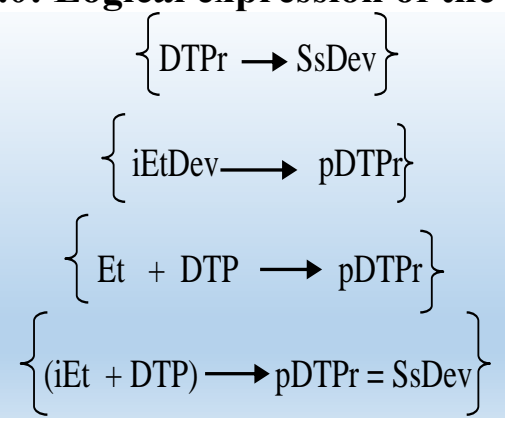

In an age of complex cross-national problems like climate change, immigration, etc. the purpose of governance and development theory (DTPr) in regionalization projects should be to achieve sustainability (SsDev) of institutions and processes. But it is the incorporation of ethical thinking in development (iEtDev) that would lead to the sustainability of development 
theory and practice (pDTPr) in those regional blocs. Ethical thinking (Et) ought to be combined with development theory and practice (DTP) such that proper and appropriate development theory and practice (pDTPr) is arrived at. This is what would help achieve sustainable development (SsDev).

Mostly following classical modern economic theorization, many contemporary development and government thinkers and practitioners hold that ethics thinking is exclusive from development theorization and praxis. But perennial development challenges have pushed thinkers to argue that in the pursuance of the ultimate goal of development i.e., sustainable development, ethics cannot be ignored (Gasper, 2004). This study was therefore designed to contribute to the attainment of sustainable development through the ethical reconceptualization of sustainability.

To that end the hypothesis was generated and its validity tested by evaluating the ethical analytical and practical value of the data that was interrogated (Pittenger, 2001:152). This hypothesis was tested and validated both logically and analytically during the research. As Pittenger points, whether it is primary or secondary data, a researcher ultimately makes "value judgments regarding the importance of the conclusions made from the data" (ibid). The study used Pittenger's position about the nature of data by which he holds that any activity known as data analysis is, as a matter of necessity, value-laden; the same position was taken by the researcher in testing the validity of the hypothesis by examining the 'value-implicitness' in the conceptualization of sustainability and regional integration in the EAC. This was done using purposively selected ethical (or moral) variables that included: i) 'justice', ii) 'capabilities', iii) 'ubuntu' and iv) 'integrity' (the reasons behind the purposive selection of these variables are contained in the chapter on 'comprehensive ethical sustainability').

\subsubsection{Basic assumptions of the study:}

This study was buttressed by two major and self-evident assumptions; these assumptions were considered to be realistic and adequate bases upon which to choose research instruments, generate re-conceptualizations and therefore influence the governance and development agenda in the East African Community. The assumptions include:

1) That the need for sustainability is a universal goal for the future of human existence.

2) That ethics is at the core of and therefore relevant to all human activities. 


\subsection{Theoretical framework:}

A theoretical framework in research can be defined as a theory or set of theories used to approach a given research problem or research question (see: Silverman, 2001:2-4; Anafara \& Mertz, 2006). The choice of a theoretical framework ought to be made on the basis of variables such as relatedness, explicability, and compatibility, among others. With that in mind, the study chose to apply a tripodal theoretical framework which included: ethics, governance, and development theory. I use the acronym 'EGD' to refer to the generic and abbreviated expression of the framework; wherein each letter stands for one of the three prongs of the framework, i.e. 'E' for ethics prong, ' $\mathrm{G}$ ' for governance prong, and ' $\mathrm{D}$ ' for development prong.

The justification for the choice of this framework is explicable using three reasons: i) applied nature of the study; and ii) tripodal reasoning; and iii) the multi-disciplinarity of the study. As regards the first, the study being majorly in the scope of applied ethics, the researcher thought it logical to use traditional ethics theory as a springboard to launch into fields of study that are considered to be more practical, namely governance and development studies. The second reason stems from an observation that normally, (and generally speaking), human thinking tends to oscillate within a three dimensional perception of reality. For example, from the metaphysical and theological conception of the creator as a Trinity to the tripartite understanding of the nature of man, apparently many things are easily understood in a tripodal manner. Well as the third reason simply reinforces the increasing movement towards multidisciplinary research that avoids the pitfalls of mono-disciplinary research and provides a richer appreciation of reality.

The three are relatable in the sense that ethics being a fundamentally philosophical discipline, it examines and provides a philosophical basis for the deeper 'primary' value-system, as it were, that motivates and on which governance and development perceptions and institutions are founded (see: Rawls, 1999:113-8). This is because underneath each and every governance and public administration culture there are values that may be explicit or implicit (Lewis, 1991). At the same time the values that a given government cherishes determine the type of or direction that development will take in a given region. And as particular development paradigms are executed they lead to the entrenchment of certain practices, which also give ethicists conditions in which to test whether the ethical theories are relevant and applicable or not. In other words, the three are profoundly interconnected and having them in a theoretical 
framework is a logical decision. Below is a figurative expression of the theoretical framework for the research:

Fig 1.1: The 'EGD' theoretical framework:

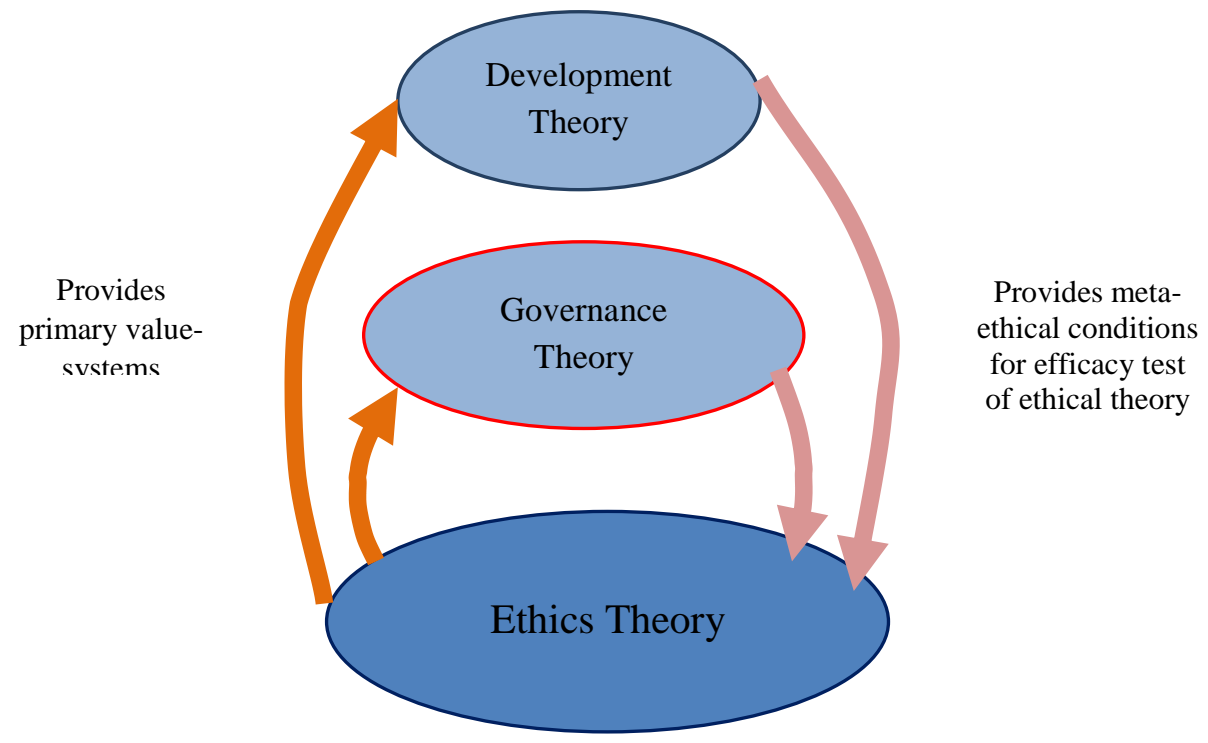

EGD Theoretical Framework

Theoretical frameworks are formulated by scholars for various reasons such as 'explaining', 'understanding' or 'predicting' certain phenomena; but there are also those that are formulated for extending existing knowledge within the limits of the critical bounding assumptions (Swanson, 2013). The choice of the framework for this research was made with the purpose of extending the knowledge boundaries in the domain of sustainability. It therefore required a critical interrogation of the conventional meaning of sustainable development in order to extend it in terms of incorporating and bringing ethics to have a wider bearing on its conception. And since the research is applied in nature it also required testing the hypothesis on a particular spatial parameter which was the East African Community. I therefore surmise that in generating a theory in an applied ethics it is pertinent to choose suitable contingent meta-ethical conditions that would theoretically prove the efficacy of the perspective; in this case the governing and development of the East African Community was deemed conducive. 


\subsubsection{Ethics theory:}

The ethics strand of the study's theoretical framework was comprised of: i) Ethical principlism, ii) Virtue ethics, and iii) Ubuntu ethics. This was complimented with a selective use of the moral-educational theory of Lawrence Kohlberg known as stages of moral development. These three aspects provided the main thrust of the ethics strand of the framework and they were applied to the study so as to: i) explicate the implicit ethical values in the governance and development phenomena in the East African Community; and ii) an ethically richer conceptualization of sustainability in the social and political development of the bloc.

\subsubsection{Ethical Principlism:}

Ethical principlism supplied the first aspect of the ethics strand of the theoretical framework during the study. It is traceable from the methodologies of classical Greek thinkers, particularly Plato in examining issues of public morality. This approach has been expounded and popularized by Beauchamp and Childress (2001), in the famous book, Principles of Biomedical Ethics, that is now in its fifth edition, and in which they proposed four main principles that should guide bioethical decision making, especially in clinical practice. The term 'principlism' is derived from the four-principle approach to bioethical challenges advanced by the two whose perspectives are now referred to as the Georgetown school. The four principles include: nonmaleficence, autonomy, beneficence and justice. 'Nonmaleficence' asserts an obligation for practitioners (either clinicians or otherwise) not to consciously inflict harm on others; while 'autonomy' implores us to respect the individual's freedom i.e. being free from controlling interferences by others and from personal limitations that prevent meaningful choices. 'Beneficence' calls for actions performed that contribute to the welfare of others; while 'justice' refers to the fair, equitable, and appropriate treatment in light of what is due or owed to any person in society (Beauchamp \& Childress, 2001).

Some scholars define principles as, "general statements from which particular decisions are to be drawn by a process of deduction", (Van Hooft, 1999:21), a definition that is derived from the Platonic dialogical method of ethical inquiry. In bioethics principlism is an approach to solving bioethical dilemmas through a deductive reasoning that applies basic guidelines to various situations or fields. As an approach to solving ethical dilemmas, it has gained prominence in bioethical circles because it is thought to be: neutral, pluralistic and allembracing (Miyasaka, 2002). Although the application of principles to various fields of human life can be traced from a long way back in philosophy, bioethical principlism is relatively a 
recent development. It was after a US Commission on biomedical research on human subjects (appointed by the US President Ford in 1974) had issued the Belmont Report of 1978 that 'principlism' came into mainstream bioethics. This Commission had been created after public outcry over revelations of the infamous 40 years longitudinal Tuskegee syphilis study, when doctors consciously withheld available medical treatment from African-American subjects during the study. The Commission had identified and defined three ethical principles that would guide medical research that included human subjects: 'respect for persons', 'justice' and 'beneficence' (Irving, 2001). It is this background that inspired the Georgetown duo to expand those principles to become four and the four principles became popular because of, “...the orderliness and relative clarity of Principlism...had a special appeal for practical-minded clinicians who adopted it widely" (Pellegrino, 1993:82). Nonetheless there has been a number of criticisms brought against this approach and I discuss them in a later section of this study.

In this study I drew inspiration from the work of Beauchamp and Childress and related thinkers to make the argument that principlism is methodologically relevant and useful in arriving at guidelines of public governance in regional governments and it can be useful in generating applicable perspectives on sustainability. Beauchamp and Childress revealed that the set of principles that they had proposed could be traced from both the Kantian moral tradition and the outcome-based ethics of Jeremy Bentham and J. S. Mill (Beauchamp \& Childress, 1994:125-6). This thinking enables us to apply their reasoning both in a 'consequentialist' and 'intuitive' way thus allowing us room to bring forth the innate ethical values embedded in governance a development thinking while at the same time allowing us theoretical room to generate practicable ethical principles. The success of this approach is attributable to their later positioning of the principles within a conceptualization of a "common morality" (2001:23) a concept that they expound better in the fifth edition of their publication. This provided the researcher a theoretically fertile ground on which exploration of commonality of morality in the East African Community was done, and from which generalizable principles were generated to aid the Community's sustainability.

\subsubsection{Virtue Ethics:}

Virtue ethics supplied the second aspect of the ethics strand of the theoretical framework applied in this study. This type of approach to public ethics is also traceable from the ancient Greek philosophers Plato and Aristotle but more from the latter (Merihew, 2006; Hursthouse, 2013). Philosophical concern over virtuous living among humans was one of the themes that Plato dealt 
with in his The Republic. The ancient Greek philosopher's investigation yielded what has come to be known as the four cardinal virtues, namely, wisdom, justice, fortitude and temperance. For example, in Socrates dialogue with Cephalus and Polemarchus as recorded by Plato in The Republic, 'justice' emerges as a key virtue to be honored and pursued by the citizens of the polis (Bk I). But in many cases most inspiration for virtue ethics emanates from the Aristotle and his investigations into public and private conduct. The main contribution of virtue ethics to the discipline of ethics is the focus on molding 'human character' (Trianosky, 1997) with a consideration of lived experiences in contrast to other rule-based approaches to ethics (Hursthouse, ibid.). This emphasis on the ethical molding of the agency of a human being to contingently act and emotionally connect ethically has spilled over into other approaches to ethics, i.e. the deontology and utilitarianism, so much so that there are experiments of developing a "virtue theory" (Hursthouse, ibid.) within the other approaches (Nyquist, 2002; Oakley, 1996).

Many virtue ethicists have explored the application of this approach to various ethical challenges in society, such as to public reason (Audi, 2009); to racial and labor relations (Nyquist, 2002); to the debate on differentiation between 'right' and 'wrong' (Scalon, 1998); to Africa's moral crisis (Ntibagirirwa, 2001); to moral complexity (Larmore, 1987), and many others. This study chose to use that variety of virtue ethics that would be utilizable in understanding how to reason on right and wrong in milieus of complexities, given the reality of the globalized existence that we share as humans. This is justifiable in the sense that applying virtue ethics to a bigger political entity like the East African Community necessitates views that appreciate the complexity and complicatedness encountered in theorizing on governing such a big bloc. To that end I chose to use Thomas Scanlon's What We Owe to Each Other (1998) and Charles Larmore's Patterns of Moral Complexity (1987); albeit the study uses other related views to enrich the discussion. Both these scholars majorly apply the virtue ethics approach to examine ethical issues in society.

In this study I drew on Scanlon's theory of virtuous 'contractualism' to make my argument for reasonably justifiable 'basic' grounds (Scanlon, 1998:5) for East-Africans to cooperate in the EAC project in 'non-betrayal' (ibid.) manner and thus sustain the Community. Scanlon's theoretical turn of prepositioning his contractual ethical reasoning on "informed, unenforced general agreement" (p.153), is especially useful as an entry point for reconciling virtue ethics

\footnotetext{
${ }^{1}$ Hursthouse delimits 'virtue theory' as a "term which is reserved for an account of virtue within one of the other approaches [to ethics, especially deontology and utilitarianism]". She explains that it has "generated virtue ethical readings of [other] philosophers ... and thereby different forms of virtue ethics have developed" (Hursthouse, 2013)
} 
with a utilitarian kind of consequentialist reasoning that could be necessary to ingrain social justice in public reason in the EAC to apply a combination of ethical principles and virtuous character in society. A 'contractualist' take on public and private motivation for virtuous living is surely relevant in the framing of a complex social contract such as the EAC. Since he emphasizes to distinguish between his and other versions of contractualism (such as the Kantian and the Rawlsian) by appealing to 'reasons' rather than 'rationality' (p.191), he inadvertently avoids the pitfall of a condescending attitude towards the rationality of 'others' (such as Africans) that much of Western conception of rationality has been variously criticized for (see: Eze, 1993, 2008). This study uses Scanlon's view to elucidate that a big and compound grouping of countries like EAC may not espouse a public 'rationality' that informs the governance and development of the Community but for sure east Africans have plenty of 'reasons' to cooperate and treat each other in a right way.

Given that there is room for the possibility of 'virtue ethics' being reconcilable with the other approaches through the incorporation of 'virtue theory' in the reading of other traditionally non virtue ethics philosopher, the study hoped to successfully apply principlism with virtue ethics. Despite a seeming dichotomization between the 'virtue-approach' and 'principles-approach' to ethical analysis in Larmore's work, Patterns of Moral Complexity (1987), by conceding that he follows Aristotle in, "regarding virtuous action as dependent upon...motives. It is action that is done because it is right and willingly so..." (Larmore, 1987:12), he provides room to use the Aristotelian tradition to argue that the two are inseparable. That postulation gave the study room to develop a richer and more suitable theorization of ethics that provides for good behavior among the member states and the citizens thereof through ethical principles that can be codified and institutionalized and virtuous character among the agents in society.

\subsubsection{Ubuntu ethics:}

Being a study on Africa, it was all the more logical to expound and apply one of the most important philosophies to emanate from the continent, namely Ubuntu philosophy. Though Ubuntu philosophy is quite wide in scope, this study focused on the ethics that emanates from it, i.e. Ubuntu ethics, and its applicability to governance and development. Quite a number of scholars have and are working on the nature and application of Ubuntu philosophy (Broodryk, 2005; Mogobe, 1999; McDonald, 2010; Zandberg, 2014), and it has been applied to fields such as economics, politics, sociology, business, management and many other areas of research. This applicability is largely owed to its rich metaphysics of human reality and the cosmos that is deemed relevant in many ways (Bhengu, 2010). 
This study relied on the richness of the metaphysical base within Ubuntu philosophy to recast a singularly expressible Ubuntu principle, as such, within the Comprehensive Ethical Sustainability (CES) scheme; it involved using the wider scope and meaning of the Ubuntu worldview to advocating for a humane and community sensitive style of governance and development in the EAC. I also use the same continuum to affirm the viability of a type of ethics termed as Ubuntu ethics that is increasingly gaining traction in ethics discourse; to that end I argue for a peculiar African contribution to the global ethics discourse. By devising the principle of Ubuntu within the scheme of comprehensive ethical sustainability this study contributes to making traditional African moral perceptions to be part of applied ethics studies.

The application of this African philosophy is part of a movement of thinkers who are developing the meaning of the term 'Ubuntu ethics'. For example Leonard Chuwa (2014) has tried to delimit the meaning of this field in his work, African Indigenous Ethics in Global Bioethics, (2014). In this work he postulates that 'Ubuntu ethics', as it were, has "three constituent components" (Chuwa, 2014:33); and these include: i) relation between individual and universal rights, ii) the cosmic and global context of life, and iii) the unification of individuals and communities within a cosmic context (ibid). On the other hand Douglas F.P Taylor (2011) defines it in terms of distinguishing right and wrong; he states that Ubuntu is a normative theory of action which holds that, an action is right insofar as it promotes cohesion and reciprocal value amongst people. An action is wrong insofar as it damages relationships and devalues and individual or group (Douglas, 2011).

The continuous work towards refining the meaning of Ubuntu ethics and applying it to various fields of study (Chuwa, 2014:33-88; Louw, 2010; Douglas, 2014; Karenga, 2010) lends credence to the view that there is such a thing as 'Ubuntu ethics'. That observation therefore afforded the study to: i) draw attention to the profound ethical wealth within the philosophy, and ii) apply it to the generation of a more suitable conceptualization of sustainable governance and development in the East African Community.

The study relied on Ubuntu metaphysical and ethical views on human life and society to generate the 'ubuntu principle', as such, within the overall 'scheme of principles' in Comprehensive Ethical Sustainability. It was within the framework of Ubuntu worldview that 
the study undertook to apportion meaning and attach value to the 'ubuntu principle' and also to propose applicability parameters to the sustainability of the regional bloc.

\subsubsection{Kohlberg's Stages of moral development:}

The study also purposively used the moral education model advanced by Lawrence Kohlberg called Stages of moral development (Kohlberg, 1971) as a way of exploring avenues of possible practical application of the generated principles within the framework for Comprehensive Ethical Sustainability (CES). Apart from the practical relevance of the Kohlberg's model, the main motivation of using Kohlberg in the study is the acknowledgement and appreciation of contemporary movement towards multi-disciplinary academic research. According to some thinkers, multi-disciplinary research is being encouraged by many scholars because research shows that it leads to more innovativeness (see: Trewhella, 2009). This approach is in line with Kohlberg since he was able to cross epistemological boundaries from moral psychology into philosophy and also into education; he was able to innovatively produce a theory that has proved relevant in various fields of inquiry (see: Rest, 1979; Hedl, et al, 2005).

The study also used Kohlberg's model to innovatively explicate and also demonstrate the practical applicability of the Comprehensive Ethical Sustainability scheme. The use of Kohlberg affords us to make the argument that it is possible to borrow ideas from across disciplines and generate richer and more relevant perspectives on the issues or challenges under investigation. To that end I use his conceptualization of moral growth to incorporate a nonstatic view of the personal and cumulative moral virtue of the East African Community. In a progressive regional project such as the EAC, which has one of the youngest populations in the world, it is logical to imbue the society's vision with the possibility of continual ethical improvement.

\subsubsection{Development theory:}

The development strand of the study's theoretical framework was hewed from two paradigms in development discourse: i) Sustainable Development, and ii) Capabilities Approach. These aspects provided the concepts and the continuum within which to interrogate the sustainability of the regionalization enterprise. The use of the Sustainable Development paradigm afforded the study the basis from which to critique the conceptualization of sustainability in general and also in the EAC in particular. One the other hand the Capabilities approach to development acted as the rail on which to: i) investigate the existence of 'capability' or 'competence' among 
the natives for the sustainable governance of the regions, and ii) generate the principle of 'capabilities', as such, as part of the 'scheme of principles' under the Comprehensive Ethical Sustainability approach to governance and development. It also contributed to the generation of the principle of 'integrity' in the schematic proposal.

\subsubsection{Sustainable Development:}

As indicated earlier in the introduction, this study drew its justification majorly from the pursuit after sustainable development that has come to be an important one for contemporary society. The notion of Sustainable Development (SD) is no longer just that but it has turned into a whole paradigm that we as humans have to embrace if we are to find better solutions to the threats of extinction that our environment and ultimately our lives face. There are various definitions of SD; (it is reported that there are over three hundred definitions: see Bonevac, 2010) but the commonest definition of SD is the one which was provided by the World Commission on Environment and Development (1987), which defined it as, "development that meets the needs of the present without compromising the ability of the future generations to meet their own needs" (WCED, 1987:43). This definition has come under a lot of criticism and many of its limitations have been discussed; but it is credited for setting the ball rolling for a gradual global paradigm shift from simply focusing on an economic perpetuity in exploiting resources (or a consumeristic living for now) towards thinking about the sustainability of future generations and other beings in our environment.

The WCED explanation of SD was dominated by ecological and economic views and much of its analysis was on economic growth in relation to the natural environment. But over time thinkers have realized that the issue is no longer simply about 'sustainable development', as such but it encompasses our overall thinking about 'sustainability' as a whole. This study used Bonevac's analysis in the article, "Is Sustainability sustainable?" (2010) as a springboard to interrogate the whole understanding and conceptualization of what sustainability is. The study postulates that the conceptualization of 'sustainability' as such is very important in the whole SD discourse and, as Bonevac argues, if we do not establish viable foundations of the concept of 'sustainability', our efforts towards achieving SD may actually prove to be unsustainable.

The study used that realization to argue for a re-conceptualization of sustainability such that its applicability towards the achievement of SD wholly be based on more solid and reasonable grounds. To that end the research constructively generated a framework termed as 
Comprehensive Ethical Sustainability that was conceived as 'scheme of principles' and applied in generating a certain criterion of principles that could guide sustainability efforts. These principles are grounded in a re-conceptualized idea of sustainability which is considered to be more viable and defensible in light of the identified challenges within the conceptions of SD that were considered by the research. The study argues that any conception of sustainability which is not sustainable would be short-lived and may not exist for a long time. To that end it interrogates the dominant 'tripodal' rendering SD (that includes the economic, ecological and social aspects) in order to establish more viable foundation on which all these aspects are based and which takes precedence in the conceptualization of sustainability.

\subsubsection{Capabilities Approach:}

The other aspect of the development strand of the study's theoretical framework is the Capabilities Approach (CA) to development. Originally coined by Amartya Sen in his book, Development as Freedom (1999), it is now almost 25 years that the CA has established itself as a major theory in political and economic philosophy. The study therefore considered it a relevant continuum within which to investigate the ethics of development, as it were, in this part of the developing world, particularly East Africa. In the study's view, the appeal of Sen's capabilities approach in different parts of the world stems from the fact that it captures and conveys some time-transcending and space-transcending truths and aspirations of the human person, particularly those of freedom and self-reliance. It is for that reason that I render the capabilities approach as a principle in the scheme of comprehensive ethical sustainability; and that is coupled with its applicability to various arguments for justice and fairness in development and political discourse.

The study was aware of and considered the possibility of Sen and his followers objecting to the reductionist rendering of his paradigm in form of a 'principle'. This awareness stemmed from the researcher's reading of Sen's later work, namely, The Idea of Justice (2009) in which he appears to identify and distinguish between two approaches to justice, namely, i) the "arrangement-focused" approach(i.e. transcendental institutionalism), and ii) the "realizationfocused comparison" approach(Sen, 2009:7). The study endeavored to calm these fears by using Sen's views to continue the debate on and probably strike a reconciliatory tone between the 'principles-approach' and the 'virtue-approach' to establishing a just society. 


\subsubsection{Governance theory:}

The governance strand of the study's theoretical framework was comprised of two major aspects: a) Regional integration, and b) Regional governance. The former included the theories of: ai) African political unionism, aii) Neofunctionalism, and aiii) Neoinstitutionalism; while the latter included the theories of bi) metagovernance and bii) social justice. These aspects provided the main locus upon which the study's governance theoretical framework rotated, albeit other related concepts were summoned where necessity arose to guide the analysis. Their application enabled the study to: i) trace the roots of the collapse of the first East African federation attempt (EAC-1) in both the governance style and the integration approach that the colonial masters employed in the region; and ii) to explicate the importance of social justice in EAC's regionalization project. It should be kept in mind, however, that there is a lot of interplay and inter-relatedness between regional integration and regional governance.

\subsubsection{Regional integration theory:}

The aspect of regional integration theory included, i) African political unionism, ii) neofunctionalism, and iii) neoinstitutionalism.

\subsection{African political unionism:}

African political unionism refers to the Africanization of the political integration processes and the creation of institutional frameworks that reflect indigenous values and aspirations. In delimiting this understanding, the notion of 'political unionism' should not be confused with 'trade unionism'; the latter being mainly used as a reference to economic and industrial labor relations, albeit also motivated by the politics of the day. This theoretical approach captures the spirit behind the various African thinkers such as Nkrumah Kwame, Nyerere Julius, Mbeki Thabo, Museveni Kaguta, Muammar Gaddafi, among others who have espoused varying ideas and visions of the political unification of the African continent.

The study drew from this theoretical framework to: i) expound on the similarities and dissimilarities in the envisioning of the political unity of the African people; and ii) investigate the influence of some ideas of selected thinkers on the East African community. The study being on Africa it was obviously logical to examine the conceptions of integration that the native thinkers have generated and the sustainability benefit of applying them to the East African Community in particular. 


\subsubsection{Neofunctionalism:}

Neofunctionalism, as such, was first systematically explained as a theory of political cooperation among nations in the seminal work by Ernst Haas on regional integration: The Uniting for Europe, Social and Economic Forces, 1950-1957. In this work, Haas, whose desire was to reposition post-war Europe as a global political and economic power, grappled with the challenge of how to transcend differences and unite a Europe that was deeply divided by ethnic and nationalist ideologies (such as those that had been espoused in Nazism). His theory, which was greatly inspired by pragmatism, was a criticism of traditional functionalism that had dominated the 1940s in international relations discourse. Perhaps the most definitive expression of how this theory approaches regional integration was captured in the often cited statement that he made in reference to Europe: according to him regional political integration, "is the process whereby political actors in several distinct national settings are persuaded to shift their loyalties, expectations and political activities to new center, whose institutions possess or demand jurisdiction over pre-existing national states. The end result is a new political community, superimposed over pre-existing ones" (Haas, 1958:16). The type of 'functionalism' as it were, that he suggested in this 'neo' approach was in the use (i.e. functionalization) of the jurisdiction of the extra-national institutional setup to transform the locus of political activity from national level to the new regional level.

In this study I draw from the work of Haas and others who have expounded neofunctionalism because in my view, it is ultimately a more constructive approach to regional integration in African settings. This theoretical continuum has epistemological space within which a researcher can bring into being political and social institutions that may not have naturally occurred or emerged; and it also allows for the precipitation of those concepts that would organically have taken longer to occur in society. The study therefore found the theory particularly useful in the analysis of the colonial masters' approach to the regional federation of the East African states towards the end of direct colonialism in the region. It was also useful in investigating the discontinuities and continuities of the colonial legacy on the current regionalization drive by the native leaders of the region.

\subsection{Neoinstitutionalism:}

Neoinstitutionalism gained traction mainly in the 1980s when widespread concern grew over the increasingly intrusive character of institutions into human life, yet society had little knowledge about the actual informal functionings of contemporary institutions. The approach 
was mainly a reaction to the limitations of using traditional behavioralism in analyzing contemporary institutions; traditional behavioral approach to institutions was criticized for focusing more on rational choice tools and concepts that placed emphasis on aggregate patterns other than the social and historical contexts within which institutional decisions take place. Neoinstitutionalism therefore rejects theories of rational technical efficiency in informing institutional building, monitoring and strategies, and prefers a social contextual and history sensitive view of institutions.

In the field of regional integration, neoinstitutionalism, was systematically expounded and applied to the European Union by Nugent Neill in his book: The Government and Politics of the European Union (1999). He referred to it as a 'theoretical approach' that not only considers formal but also informal procedures, practices, relationships and norms in a given institutional setup (Nugent, 1999:527-3). A consideration of an institution in that sense enables one to appreciate its actual functioning and understand not only the rational choice narratives within but more so the sociological and historical dynamics that influence it. The study took this approach to institutional building and analysis to be quite relevant in an African context like that EAC given the historical dynamics that have influenced its discourse.

The study therefore used this understanding of institutions as part of its framework in explicate the observation that colonial history had a lot of influence on the regionalization process in the east African region. It was also employed to point out the sociological realities in the region (such as tribalism, demographic trends, etc.) that have great impact on the political sustainability of the Community. To that end the study hopes that the region's policy framers and future analysts and researchers will find value in incorporating these realities in their work.

\subsubsection{Regional governance theory:}

The aspect on regional governance theory was comprised of two paradigms, namely, i) metagovernance, and ii) social justice.

\subsection{Metagovernance:}

As hinted earlier in the text, the study used 'metagovernance' in the basic definitional form that of 'the governance of governance' (Bevir, 2009:132-5). This essentially means the art and science of managing amalgamated groups of states, which, though having national interests, share a common vision. Metagovernance is therefore a theory that transform the conception of 
governance, i) from the traditional 'command and control' fashion of bureaucracy to "indirect steering of actions and interactions of relatively autonomous stakeholders" (ibid p.132); and ii) from a nationalistic (or individualized) to a regionalized (or grouping) view of power relations and political allegiance.

Scholars have observed that there are three ideal styles or combinations of metagovernance, and these include the i) hierarchical, ii) network, and market styles (Jessop, 2011:106-23). Within any of these styles, the practical meaning of governance is not defined by the institutions or agents at the regional or group level but by the constituent members of the group. The gist of metagovernance, according to Jessop, in another of his works, is the 'engineering' of the environment or conditions of governance (Jessop, 2008:7). In political terms this implies that regional leaders (or leaders of groups of states) are tasked with ensuring a conducive environment for constituent member countries to define their meaning of governance as long as these definitions adhere to the commonly shared vision of cooperation. Given the complexity of modern societies, this requires expertise not only in deciding on the appropriate style of metagovernance to adopt but also a necessarily competent knowledge of the local, national and regional conditions in which to apply it.

This research considered that conceptualization of regional governance to be relevant to the East African Community case and it used the framework to: i) interrogate the competence of the leadership in governing the region towards the stated goals of the Community, and ii) to explore possible policy engineering and innovation avenues for sustainable development in the region. Using this framework the study unraveled some inadequacies in the metagovernance capabilities of the framers of the regional bloc and used it also to suggest ways in which the identified inadequacies could be addressed.

\subsection{Social Justice:}

Under the social justice portion of the framework, the study employed John Rawls' theory of justice, namely, justice as fairness. Rawls seminal work, A Theory of Justice (1971) has had tremendous impact on the contemporary discussion of justice in the global system. Since regionalization in Africa is an expression of globalization, as it were, the study considered it relevant to apply the Rawlsian view of justice in examining the existing injustices in the institutional and social 'regional order' of the East African Community and proposing a possible way of minimizing them thus ensuring the sustainability of the project. 
Apart from using his theory to analyze the justice dynamics in the EAC, another aspect of utilizing Rawls view of justice is the inspiration from his incorporation of 'principles-approach' to the challenge of building just institutions in society. The study generally considered Rawls to have succeeded in generating objective and applicable principles to institution building, from which success the research was motivated to also generate 'principles' that could be applicable in the sustainable governance and development of the EAC. To that end the study carries out critical appraisals of some aspects of the Rawlsian view of justice and considers the possibility of reconciling his contractualist perspective with the libertarian perspective on justice. This was deemed necessary in order to broaden the appeal of the proposed 'scheme of principles' to the libertarians whose ideas pervade much of the economic domain of the region.

The study also relied heavily on Rawls view of justice to generate the 'justice principle', as such, within the overall 'scheme of principles' in Comprehensive Ethical Sustainability and to explicate its implicit value and application to the sustainability of the regional bloc. It is on the basis of this that the study provides valuable insight into the dangers lurking underneath the twin conditions of 'victim disaffection' and 'villain encumbrance' that could threaten the existence of any society where injustices are entrenched.

\subsection{Scope of the study}

The following is a delimitation of the geographical, temporal and academic scope of the study:

\subsubsection{Disciplinal Scope:}

In disciplinal terms, this study's foundational base was provided for under the discipline of philosophy and in the branch of applied ethics and the sub-branch of development ethics. This is because the researcher's maiden discipline was philosophy and it is still his area of research. Nevertheless, the study was a multidisciplinary exercise which borrowed relevant theoretical frameworks, concepts, paradigms and literature from other disciplines that were relevant and necessary for the successful completion of the research. To that end there are aspects of development studies, political science, moral education and international relations within the same research. It thought that this multidisciplinary did not diminish the epistemological efficacy of the research; on the contrary it made it richer and more realistic and applicable to the contemporary East African situation. More educationists are calling for this kind of research (see: Trewhella, 2009) the innovation incidence within multidisciplinary and its value to human society is immerse. 


\subsubsection{Geographical Scope:}

Geographically, this study was situated in the East African Community albeit its findings are applicable to a number of regions facing the same challenge as encapsulated in the research problem. The study was majorly premised on those naturally occurring (i.e. geographical, cartographical) and humanly constructed (i.e. political, economic and social) phenomena within the spatial extension referred to geographically as East Africa.

That geographical space is currently transforming into a political regional Community known as the East African Community. The current political conglomerate of nations referred to as the East African Community (EAC) is made up of five countries, namely, Burundi, Kenya, Rwanda, Tanzania and Uganda and the region is located between: $5^{0} 30^{\prime \prime} \mathrm{N}, 12^{0} \mathrm{~S}$ and $28^{0} 4^{\prime \prime} \mathrm{E}$, $41^{0} 50$ "E. However, the study focused on the 'core' countries that provided the membership of the original EAC and they are, Kenya, Tanzania and Uganda. 
Fig. 1.2: Map of the East African Community

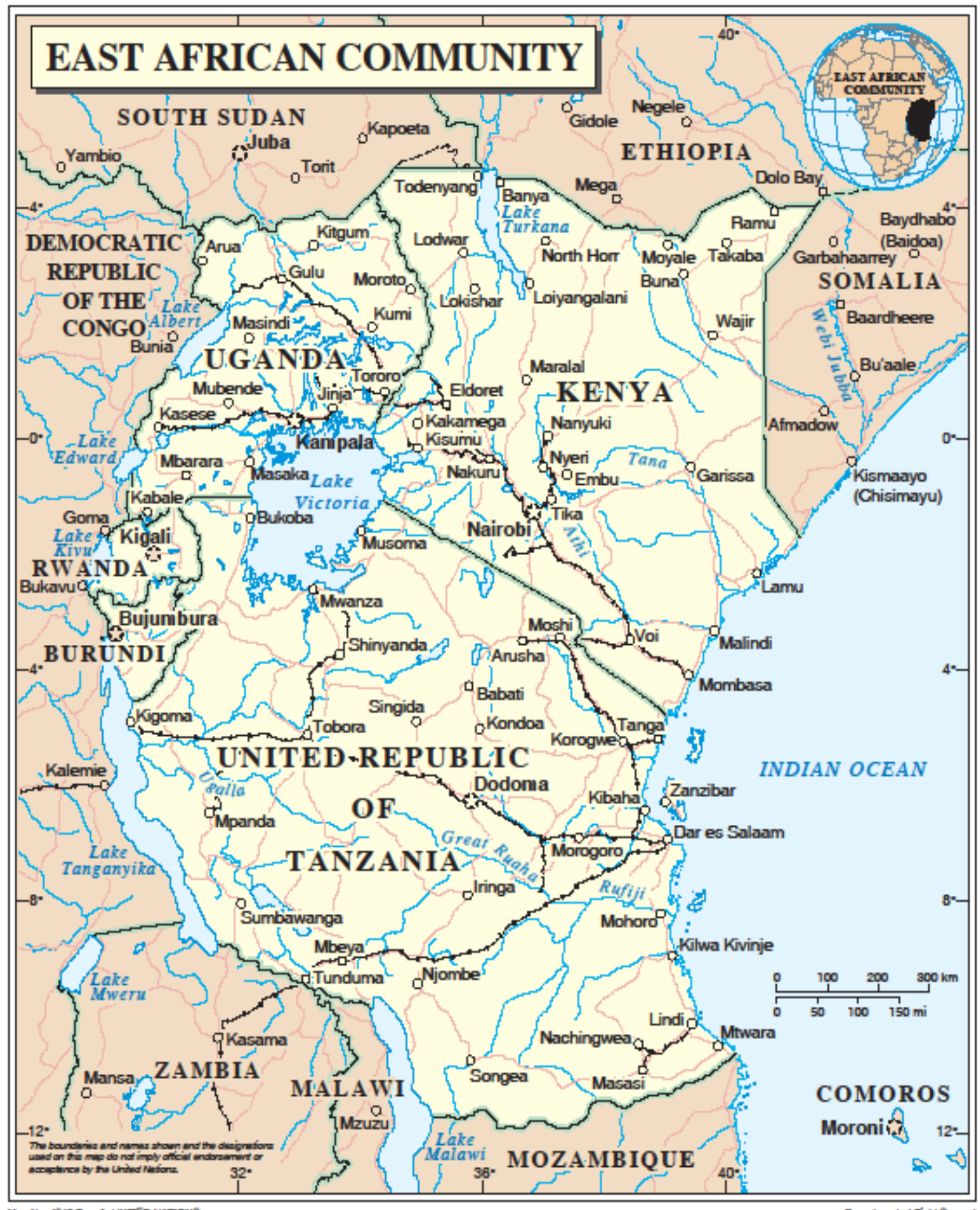

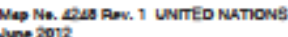

Centegraphic Baction 


\subsubsection{Temporal Scope:}

In terms of actual research period, the research took place between 2011 and 2014; the period catered for under the Sida-Makerere Phase II research collaboration that funded the study. However, in terms of the literature and referential timeframe the study utilized literature on both the earlier attempt at creating the EAC and the current one which dates back into the colonial days and since the 1997 revival by the "core" member states (i.e. Kenya, Tanzania, and Uganda). But for purposes of historical acknowledgment and where it was necessary, the inquiry reached archival information of the pre-colonial time of regional integration.

\subsection{Methodology:}

The following is a description of the research methodology that was applied in the study and the justifications behind it and the tools used.

\subsubsection{Qualitative research and objectivity:}

The research methodology that the study used in carrying out the investigation falls under the broad category of qualitative research. The study used qualitative method because: i) it was a research in basic conceptualization and their perceptible influences, and ii) it sought to delve into the social processes and their implicit meanings and impact on East Africa. It is arguable that human conceptualizations and their bearing on institutional and social behavior could have been quantitatively studied (yes that approach may have its advantages), but the analysis of the 'deeper' ethical meanings of those concepts on social processes and projections is, in my view, best studied using qualitative methodology (Silverman, 2001:32).

To understand the values and perceptions that influence governance and development behavior in such a region as the EAC required the use of appropriate research methods that can competently unravel the relationship between conceptualization and practice. It was necessary for the study to understand the meanings behind the, aspirations, political ideological systems, perspectives and experiences of the people of east Africa in order to generate more suitable theoretical frameworks for sustainability in the region. The social and political experiences of east Africans and information or data thereof was studied not as a simplifiable binary code of nature, but as unstructured social constructions with influences from both within and without the region. In order to make viable analysis of such data and to make good generalizable conclusions from it the study decided to use qualitative research. 
The researcher is aware of the usual doubts raised by those in favor of quantitative methodology who hold that qualitative methods may have a problem with objectivity; they usually consider qualitative research as, "unscientific, or only exploratory, or entirely personal and full of bias" (Denzin \& Lincoln, 1994:4). The label 'unscientific' is commonly given to qualitative research to imply that such methodology is not 'objective', but as Lorraine Daston and Peter Galison (1992) have detailedly discussed, 'objectivity' is a discourse wherein epistemic power is negotiated for the sake of advantage in epistemic-economics and academic-politics. In most cases what is considered as 'scientific' is automatically presumed to be 'objective'. But we should note that 'objectivity' itself emerged out of a discourse; as Daston and Galison observed that, "philosophers of science routinely use objectivity as a panhistorical honorific, awarding it to this or that discipline... but paying little attention to when objectivity itself developed or to what served as its source" (Daston and Galison, 1992:84).

Since the term 'objectivity' is commonly taken to be synonymous with 'scientific', it is necessary to understand what 'scientific' means. Daston and Galison (1992) have argued that the term 'objectivity' has a history and a discourse behind that is full of constructions and framings and creation of epistemic value-systems. That is why contemporary philosophers of science such as Lorraine Daston, Peter Wagner, Bruno Latour, among others agree that scientific objects have a history (Daston, 2000:1-6). Daston and Galison (1992) have pointed out that there was a long discourse that went into the creation of the modern understanding of 'science' and the objectivisation of the knowledge and objects created within it. Therefore the methods of 'science', as it were, are not devoid of underlying histories and value preferences that were shaped by humans who pioneered these disciplines (Daston and Galison, 2007).

From a post neo-Kantian perspective of philosophy of science (that seeks to transcend the traditional noumena/phenomenon distinction of reality), Daston observes that in science different things, “...come into being and pass away as objects of scientific inquiry." (2000:1); and determine which one comes into being or passes away is dependent on the value preferences of given researchers. She thus echoes the view that the creations of science are as subject to the social and historical influences that the scientists experience as in any other domain of research. This implies that there is no particular approach to research that may viably claim to be superior to the other since every researcher is subject to the historical and social realities within which the researcher operate. 
The existence of scientific and technological objects is not entirely a result of unbiased objectivity but they belong to the, “...dynamic world of what emerges and disappears from the horizon of working scientists." (ibid). In discussing this dynamism, Daston and Galison point out that in contemporary times the use of mechanical (or technological) tools to produce scientific knowledge or objects has undeniable impact on the conception of objectivity (1992:98). This implies that no method of research has a monopoly of objectivity; so whether quantitative or qualitative objectivity is constructed. This means 'objectivity' (or 'scientific' in this case) has a history behind it and that history reveals continuations (and discontinuations) of the moral valuation that took place underneath it as it emerged as a prized goal of research. For that matter, no methodological approach can claim superiority over the other; rather both qualitative and quantitative approaches represent aspects of the story of human knowledge.

Unfortunately, over the recent past, the politics of objectivity, a la Daston, has been skewed in favor of the quantitative methodology in contemporary times because "Governments favour quantitative research because it mimics the research of its own agencies. They want quick answers based on 'reliable' variables" (Silverman, 2001:26). In my opinion these 'reliable variables' are taken to be so because they are politically expedient and are useful in pushing a chosen narrative about the government and the foundations that fund research (ibid). In retrospection, therefore the use of qualitative methodology in this study does not in any way diminish its objectivity, neither does it reduce the validity of its findings.

\subsubsection{Reflective Equilibrium method in applied ethics:}

The qualitative-quantitative distinction and contention in research, as briefly discussed above, reflects the classical epistemological debate between deductive or inductive reasoning. Sometimes engaging in that discussion may turn out to be an intractable debate going back and forth with no clear conclusion; and if we are not careful as applied ethicists, we may find our energies consumed by that debate. It could therefore be useful to find ways to extricate ourselves from such a situation. Some thinkers have developed what could be considered a method of reasoning that would provide a better alternative to, and would have a converging effect on the two traditional types of reasoning: this approach is known as the reflective equilibrium method.

The term 'Reflective Equilibrium' was coined by John Rawls in his famous work, A Theory of Justice (1971:18) in which he presents a system or course that could be taken in order for the 
rational participants in a social contract to come up with principles that would enable the realization of 'justice as fairness' and mirror a 'reflective equilibrium'. It is widely held that the method of 'reflective equilibrium' played a central role in 'both the construction and justification' of Rawls' theory of justice (Norman, 2013). To Rawls the resultant principles that he came up with using this method are 'pruned' and 'adjusted' according to 'considered judgments'. "This state of affairs I refer to as reflective equilibrium. It is an equilibrium because at last our principles and judgments coincide; and it is reflective since we know to what principles our judgments conform and the premises of their derivation. At the moment everything is in order. But this equilibrium is not necessarily stable. It is liable to be upset by further examination of the conditions which should be imposed on the contractual situation and by particular cases which may lead us to revise our judgments. Yet for the time being we have done what we can to render coherent and to justify our convictions..." (Rawls, 1971:18). It is this common-sense presentation of the RE that makes thinkers like Norma Daniels (1996) to conclude that as an approach, RE provides, i) a good coherentist justification of a given theory, and ii) a good method of solving practical problems (Norman, 1996). By the same rendering, however, Rawls set the stage for a fruitful discussion of RE as either a method or a product of another method of reasoning (see: Folke, 1993). In this study reflective equilibrium is considered as majorly a method (reflective equilibrium process) and secondary as a result.

Perhaps we can cite Wilbren and Willigenburg's (1998) explanation of what Reflective Equilibrium (RE) is: "The basic idea behind reflective equilibrium is that, in developing and justifying moral theories and in seeking answers to practical moral problems, we bring it to bear - in some ordered way - all kinds of moral and non-moral beliefs and theories. A reflective equilibrium process pays attention to our moral and non-moral beliefs at various reflective levels (particular intuitions, moral principles, abstract theories), and 'tests' various parts of our belief system by revising and refining beliefs at all levels. In a process of mutual adjustment, we seek coherence among the widest possible set of beliefs that are arguably relevant in establishing a moral theory, in selecting moral principles or in deciding a specific moral problem" (Wilbren \& Willigenburg, 1998:1). The above explanation captures the basics of the RE method and the key phrase is that of 'reflective equilibrium process'. This is important to note because there are some thinkers who render it merely a 'product' rather than a 'method'. But as Bo Petersson (2000) points out, it would be difficult to take RE as just a product without taking note of the process by which that product came to be (p.23-44). He points out that despite the existence of some differences in defining RE, it has "a lot of valuable features... [such 
as]...the idea that our considered moral judgments must be a point of departure when constructing a moral theory... the emphasis on coherence, and avoidance of a problematic foundationalism and the recognition of common needs to adjust and revise our beliefs" (p.43). Therefore this study used Reflective Equilibrium first and foremost, as a method of reasoning; and for that matter we shall take it that the resultant principles and theories that the study generated display a reflective equilibrium as a final outcome.

When it comes to employing the RE method in applied ethics, Wibren can der Burg (2000) has observed that the dynamic nature of reflective equilibrium (RE) makes it "intuitively attractive and roughly corresponds with the way in which we tend to think when we are dealing with practical moral problems...a natural way of arguing and reflecting" (p.70). In this particular applied ethics study, this 'natural' way of arguing and reflecting entailed: i) basing our thinking on reasonable grounds, ii) using morally relevant facts; and iii) incorporating all possible voices of stakeholders. All this is done while re-examining and revising the established or foundational theoretical frameworks and deriving practical solution suggestions or principles that are convergent and natural to us. Just as the title to the field connotes, research and studies in applied ethics have to strive to be as applicable as can be possible in order to overcome given practical problems in society. To this end, the RE method provides a practical reasoning continuum with which to generate ethics applications.

The research was aware of some of the limitations and criticisms that this method may encounter. Wilbren and Willigenburg (1998) identify the two major ones, namely, i) the challenge of broadness of evidence, and ii) questioning the claim of critical revision of beliefs or traditional theories (Wilbren \& Willigenburg, 1998:2-9). According to them, critics of the RE method point out that these two aspects of the method are problematic because they render it 'unworkable' (p.4) in the first instance and its equilibrium 'provisional' (p.3) in the second instance; thus being susceptible to 'epistemological doubts and questions' (p.5) and making it none any better than other methods of reasoning. In my view, these criticism may not necessarily lead to the conclusion that the RE method is altogether useless. To the contrary, these challenge ought to be taken as areas that need working on in order to improve the RE method. Nonetheless it suffice to mention that what may be considered as weaknesses in the RE method may actually be its strengths. For instance, the fact of being 'reflective' requires that it revises the traditional or established beliefs and theories; and then, as Wilbren and Willigenburg have pointed out, "this openness to revision is an important advantage of 
reflective equilibrium in dealing with criticisms and alternatives" (p.3). Additionally, its 'broadness' in scope is based on the necessity of applied studies to allow for collaboration with scholars other fields and the use of relevant facts from those fields. Instead of taking this as a weakness, it ought to be considered as acknowledgement of the multi-dimensionality of reality. For that reason, the RE method can guide us towards generating more suitable and workable solutions to society's problems.

\subsubsection{Research Design:}

The general research design accorded to this study was an analytical-constructive qualitative research. The purpose for that choice was to theoretically analyze and test the hypothetical proposition and to propose solutions to the research problem. In order to execute this, the study used selected methods and tools to ensure effectiveness of the research and also to come up with valid results. The specific design was an atypical case study within a multidisciplinary research. An atypical case study was chosen because it yields a wealth of information and valuable insight ${ }^{2}$ (Gerring, 2007). A case study design was chosen for this study because scholars argue that it can act as both a methodological paradigm and a data technique (see: Eisenhardt, 1989, Flyvbjerg, 2006). The study was an in-depth examination of the instance of the EAC regionalization approach and the implication of its framing and policy engineering on the sustainability of governance and development. This provided a sharpened understanding of how the integration discourse impacts on governance and development practice in regionalized states.

The EAC was chosen as an information-laden case study because it has a peculiar history; whereby after the collapse of the first East African Union, the community has been revived recently, a phenomenon that is peculiar to this region. This could hold interesting research findings that would inform other regional projects in Africa and beyond. Secondly, as indicated earlier in the text, the bloc is considered by scholars to have higher bets of succeeding and anticipated to act as a yardstick for other regionalization projects on the continent (World Bank, 2007). The East African regionalization project is also considered by far the fastest progressing regionalization project in comparison with others on the continent of Africa. The other aspect

\footnotetext{
${ }^{2}$ Atypical case studies are better than typical cases in certain research cases because typical cases do not yield such in-depth information as atypical ones. Similarly random sampling which emphasizes representation may lack the 'sharpness' that needed in this case.
} 
that is worth mentioning is that this project, like most on the continent, is public sector driven and a study of that condition would be informative for others.

\subsubsection{Trends and tools of research:}

Since the study was foundationally in the domain of applied ethics, it employed the research methods of applied ethics; and being a multidisciplinary domain the study used conceptual tools from other disciplines related to the topic of research, such as governance studies, political science and development studies. Under this section I mention two aspects of the research method, namely i) trends in applied ethics research, and ii) specific tools of research.

\subsubsection{Combination of trends in applied ethics research:}

The study combined the two main threads of methods within applied ethics discourse, namely i) practical theorization on ethical challenges, and ii) practicalization of ethical theory. The reason why the study combined these two is because literature review indicated that there are slight variations in the understanding and practice of applied ethics and it was necessary to respect these variations in methods but also to benefit from their use. There are therefore cross overs and interactions between the two trends but they are nonetheless worth taking note of. It should also be noted the research has a background in philosophy and since ethics emanates from there, the study employed the traditionally recognized philosophical tools ${ }^{3}$ where applicable.

\subsection{Trend 1: Practical theorization on moral issues:}

One of the variants of methods on applied ethics that the study employed is the practical theorization on moral issues in society. This, in my view, is the rendering of the applied ethics theorization to be experience based. Jef van Gerwen (2002), in a chapter titled, "Three methods in applied ethics: A critical review", identifies the three main methods of applied ethics, namely, i) case studies, ii) legal codification, and iii) corporate or institutional analysis. $\mathrm{He}$ observes that these are the methods employed in teaching applied ethics and in business ethics. He argues that the preferred methods should be the third type because it 'bridges' the gap between amoral business practitioners and ideal ethicists (Jef, 2002:60-61). The emphasis here

\footnotetext{
${ }^{3}$ The qualitative nature of this study was tilted towards the philosophical background of the researcher where it was deemed necessary in order to analysethe deeper meanings of concepts, processes and events. In order to preserve its philosophical integrity of such analysis, traditional "tools” of 'rationality', 'critique' and 'systematicity' were employed in i) establishing conceptual clarity, ii) analyzing underlying discourses, and iii) unearthing the hermeneutical meanings of social and governance realities and documents.
} 
is that ethicists ought to generate their theories from the experiences of corporate and institutional managers.

The study employed the method in examining the ethical realities on the institutional managers and framers in the East African region in order to generate an applicable theoretical framework that can contribute to sustainability. The interrogation of natives experiences during the formation of the regionalization project from the colonial days to the present was able to enrich the understanding of what the real nature of the ethical challenges that the leaders of the bloc today face. For example an understanding of the colonial injustices that were experienced by the natives and their psychological impact on the region's economic imbalances and political practices gave the study valuable insight in developing the principle of justice and its preferred characterization within the overall scheme of Comprehensive Ethical Sustainability.

\subsection{Trend 2: Practicalization of ethical theory:}

Another variant in the methods of applied ethics from which the method, 'practicalization of ethical theory', was taken can also be found in Göran Collste's article, "Applied and professional ethics" (2012). He identifies three trends in applied ethics: i) the application of ethical theories to analyzing moral challenges in practical oriented disciplines such as medicine, technology, etc.; ii) professional specific ethical study of moral problems, and iii) joint study between professionals and theorists. In questioning the adequacy of the definition of ethics provided by Childress, and confirming the perspective of other applied ethicists, Collste Göran states that, "for the sake of relevance, applied ethics presupposes an interplay between theory and practice, experience and reflection and intuitions and principles" (Collste, 2012:18).

In my view, by insisting that the relevance of applied ethics presupposes an 'interplay' between theory and practice, experience and reflection; and intuitions and principles, Collste shows a preference for the 'practicalization' of ethics as the essence of the discipline. By 'practicalization' I intend to mean not only the attempt to bring ethical theory to bear on the practical reality but also to capture the experience aspect of applied ethics such that it is not taken as simply an art of giving advice to society but also living ethically in real life. Collste uses the positions of two prominent ethicists, namely Peter Singer and Ronald Dworkins to argue that applied ethics ought to combine the above aspects such that it remains relevant to human society (p.26-27). 
The study employed this method variant of applied ethics in the, i) clarification of certain concepts and theoretical leanings, ii) application of established ethical theory to given moral challenges in the East African Community, and iii) rendering the generated 'principles' within the Comprehensive Ethical Sustainability scheme practically relevant to institutions and common life in the region. As mentioned earlier in the text, this method enabled the study to analysis the data accessed and validate the hypothesis of the research. It was also useful in recasting the selected theories in applied ethics as principles of comprehensive ethical sustainability.

\subsubsection{Specific tools of the study:}

The following is a table indicating the specific research tools that were employed in the study.

Each method is listed randomly and its corresponding usefulness is indicated besides.

Tab. 1.2: Specific tools of the study:

\begin{tabular}{|l|l|l|}
\hline \multicolumn{1}{|l|}{ Tool } & Uefinition & Usefulness \\
\hline $\begin{array}{l}\text { Conceptual } \\
\text { clarification }\end{array}$ & $\begin{array}{l}\text { Making meaning if } \\
\text { concepts clearer }\end{array}$ & $\begin{array}{l}\text { Clarified conceptual meaning of: } \\
\text { sustainable development, justice, } \\
\text { integrity, Ubuntu, etc. }\end{array}$ \\
\hline $\begin{array}{l}\text { Philosophical } \\
\text { critique }\end{array}$ & $\begin{array}{l}\text { From the Greek word } \\
\text { krino' meaning of } \\
\text { philosophical } \\
\text { assessment }\end{array}$ & $\begin{array}{l}\text { Making inferences and critically } \\
\text { unraveling logical inconsistencies in } \\
\text { certain positions }\end{array}$ \\
\hline $\begin{array}{l}\text { Diagnostic } \\
\text { analysis }\end{array}$ & $\begin{array}{l}\text { Establishing } \\
\text { underlying causes }\end{array}$ & $\begin{array}{l}\text { Analyzing the underlying causes of } \\
\text { unsustainability in the EAC }\end{array}$ \\
\hline $\begin{array}{l}\text { Prescriptive } \\
\text { analysis }\end{array}$ & $\begin{array}{l}\text { Exploration and } \\
\text { proposition of } \\
\text { solutions }\end{array}$ & $\begin{array}{l}\text { Suggesting solutions to the challenge } \\
\text { under research }\end{array}$ \\
\hline $\begin{array}{l}\text { Constructive } \\
\text { argumentation }\end{array}$ & $\begin{array}{l}\text { Making proactive } \\
\text { arguments for } \\
\text { proposed solutions }\end{array}$ & $\begin{array}{l}\text { Used to construct the Comprehensive } \\
\text { Ethical Sustainability framework }\end{array}$ \\
\hline
\end{tabular}




\subsubsection{Data handling:}

The study used secondary data sources and harvested secondary data from various platforms. Secondary data refers to data that has already been processed at the primary level and has been reported using certain means (see: Vartanina, 2011:3). The justification for the use of secondary data included three main reasons: i) such data is greater breadth since most of the reports are bigger comparative studies; ii) secondary data is higher quality since most of it has already undergone processing from the primary level; and iii) using such data is an economically smart decision especially in terms of time and funds.

The platforms from which the secondary data was harvested included: government databases, libraries, academic websites, study centers, seminars, conferences, documentaries, talk shows, among others. In order to access these platforms researcher personally carried out study visits to these places wherever it was possible. The research tools and techniques that were employed in processing the data included: literature surveys, online data mining, illustrating, tabulating, among others.

\subsubsection{Quality control measures:}

Under the aspect of quality control, the study had a section of validity and data reliability. As far as validity was concerned the study considered the degree of truthfulness of the analysis and reflections made in the discussions and the logical consistency of the conclusions made. While in the case of data reliability the study considered the genuineness of the data sources that were interrogated in the course of the research.

\subsection{Validity:}

In order to ensure that the quality of the investigation was high enough, the study employed philosophical logical reasoning and systematic analysis of the argumentations and positions that were under consideration. This was aimed at ensuring the detection of fallacious arguments or inconsistent positions within the data, in order to be able to make inferences and conclusions that could be as truthful as possible.

\subsection{Data reliability:}

For purposes of quality control, the study applied the following techniques: i) proper citation procedures, ii) analytical triangulation, iii) open critique (e.g. at seminars, conferences, etc.), iv) consistency checks, and v) file format validation. These techniques were chosen for the 
following purposes: i) to ensure the integrity of the originality of the researcher; ii) to provide appropriate records of the work in order to ease the validation process by other researchers; and iii) to make the work easily accessible and re-usable.

\subsection{Relevant considerations and limitations:}

The study necessarily considered a number of auxiliary but important variables that were relevant to the execution of the research and they include ethical guidelines, environmental effect, plus the challenges and limitations of the investigation.

\subsubsection{Ethical consideration:}

Researching governance and development issues can be very sensitive and raise ethical concerns. Therefore as far as research ethics, the researcher labored to observe and respect the following principles of research ethics:

1. Intellectual integrity

2. Social sensitivity

3. Personal Integrity

4. Community Benefit

\subsubsection{Environmental considerations:}

The study was carried in an environmentally sensitive manner as far as it was possible. For example printing of written texts on paper (which contributes massively to deforestation) was minimized and most of texts were saved on computers and the much of the reading took place there.

\subsubsection{Challenges encountered:}

The researcher encountered a number of challenges during the course of the study from conception, execution and final submission; and these include the following:

- Due to massive use and reading on computers the researcher developed optical complications and had to consult opticians who recommended the use of eye glasses

- Application of recent technological research tools such as the Internet search engines, and others on data mining about African countries proved frustrating at times

- Teaching and supervisory obligations to the university 
- Family commitments that made it difficult at times to concentrate and carry out faster and deeper analysis

- Adjusting to European weather during winter study visits to the Center for Applied Ethics, Linköping university

\subsubsection{Observable limitations:}

The researcher acknowledges a number of limitations that the study may have suffered from and the observable ones include the following:

- Capturing the complex facets of the socially dynamic issues within applied ethics is quite challenging and relating them to governance and development is all the more challenging. In this respect therefore the study may have suffered a limitation in being able to consider all the variables in such complexity, and that may be frustrating to some readers. But the researcher endeavored to do as much justice could possibly be accorded to the many variables that had to be considered.

- Being conceived as a multidisciplinary research the study faced the usual disadvantages of such research. One of them is the tendency to digress in discipline-specific debates that harbor a danger of going off-rail. It is notable that in some respects the research had to deal with some discipline-specific issues and that may pass as a limitation. However, this was done out of necessity rather than digressing.

- One of the challenges of applied ethics is the delicate balance between getting lost in the discipline-specific intricacies and having enough knowledge of the subject matter in order to competently provide useful ethical analysis. This study have faced that challenge also; that is why in some cases it appears to get engrossed in the subject matter in order to make reliable analysis and conclusions.

- There are certain interesting themes that emerged during the study's literature reviews and interrogation of the texts used in the research. But the study could not explore them further due to factors such as scope and time. So in that aspect the study was limited in terms of exploring some themes that would be contributive to the wider governance and development discourse in the region. 


\subsection{Conclusion:}

In this chapter I have presented a general overview of the premises on which this study was grounded. I have given the background of the study and a demarcation of the scope of the research. In addition I have discussed the theoretical and conceptual frameworks of the study on top of the methodology that guided it plus the justification and significance of the study. 


\section{CHAPTER II}

\section{LITERATURE REVIEW}

\subsection{Introduction:}

This review is a survey of selected and indicative literature aimed at identifying the problem that the study focused on. The first section reviews the literature on the development challenge in Africa and East Africa region; it also reviews literature on sustainable development; and the other section of the review deals with governance issues. The review also examines ideas by prominent thinkers on global governance and justice, issues that are critical to regionalization. The last section of the review briefly discusses selected literature dealing with the governance of the regional bloc and the new Treaty that re-established the bloc.

\subsection{The development challenge in Africa:}

The African continent and particularly the sub-Saharan region has one of the poorest development indicators both in human and economic terms. In terms of Human Development, most indicators show that the region has consistently been the one with the least Human Development Index values since this kind of reporting started in 2010. The 2014 Human Development Index (HDI) report attested to this fact when it observed that the region has the lowest HDI values at 0.502 , the lowest in a ranking system where the highest was 0.890 (UNDP, 2014:33). The ranking uses a number of variables to calculate the HDI values and in terms of one of them, namely, healthcare, the region was found to have the highest healthcare inequalities in the world (p.21).

Such statistical reports about the region are paradoxical if not inimical considering the enormous natural resource endowment that sub-Saharan Africa (SSA) has; a situation that has prompted some thinkers to refer to it as the biggest 'resource curse' (Basedau \& Mehler, 2005; Igwe, 2012). Some attribute the failure by SSA to transform its natural resource endowment into higher development to external factors while other blame internal factors. The classical representation of what is now being referred to as the 'externalists' approach to the causes of development failure in Africa is the seminal thesis in Walter Rodney's classic, How Europe Underdeveloped Africa (1973); in this work he lays a socialist Marxian explanation of Europe's responsibility in curtailing Africa's developmental progress. On the other hand, one of the most 
recent expressions of the 'internalist' view is in Stanley Igwe's, How Africa Underdeveloped Africa (2012) in which he mostly blames internal institutional failure for Africa's development woes. I have made further comments on the 'externalist-internalist' distinction under the chapter on political developments in the EAC, where I consider George Ayittey's (2005) analysis of the root causes of underdevelopment in Africa in the article, "The "colonialismimperialism' paradigm is kaput" (Ayittey, 2005).

Nonetheless, it suffice to mention (and as thinkers from both the above schools of thought hint) that the nature of the 'development challenge' in Africa is so complex and multifaceted that using terms such as 'externalist' and 'internalist' to refer to it may lead to the obfuscation of certain important aspects of the problem. To avoid that pitfall, there is need to appreciate the multifaceted nature of the development challenge in Africa so as to make better and more relevant analysis of the issues at hand. Some notable scholars on African issues have warned about this danger one of them the African philosopher Paulin Hountondji who has admonished thinkers to desist from "accept[ing] any formulations that could lead to oversimplification of Africa..." (Hountondji, 1996:xxvi), which he condemns as "a reductionist view of the societies under study" (p-xvii, 148-9). In A History of Sub-Saharan Africa (2013), Robert Collins and James Burns also comment on this tendency observing that it fosters 'stereotypical' thinking (Collins \& Burns, 2013:40-42). For this reason a better analysis of the development challenge in Africa needs application of terms that capture the various dimensions of the problem.

In order to avoid oversimplification and arrive at a clearer understanding of the nature of the 'development problem' in Africa, we could commence from analyzing the solutions that have been suggested over the years. This is deemed viable ${ }^{4}$ based on the observation by Jean Pertz et al (2003) that problems are not defined 'outside their environment' and problem solving is 'not as sequential' as it is usually portrayed (Pertz, et al, 2003:1-6). For that matter when we survey the modern history of the continent to look at the solutions proposed by various thinkers and leaders, we notice certain trends that emerge and these trends can be categorized into three main categories, i.e., i) attempts at re-dignifying Africa, ii) attempts at unifying Africa, and iii) attempts at re-constructing Africa.

\footnotetext{
${ }^{4}$ The viability of this approach could be questioned by a strict logician on basis of accusing it of being fallacious according to the law of 'reductio ad absurdum' which holds that it is untenable to define something using its negation. However, in this case we are not 'defining by negation' but we are 'defining by solving' because we are using the proposed solutions to the problem in order to understand its nature.
} 


\subsubsection{Solving by re-dignifying Africa:}

As far as re-dignifying Africa is concerned we can trace it from the enormous anti-slavery and anti-colonialism movements that shaped the political discourse on the continent towards and shortly after the attainment of independence. The word dignity means 'honor' and 'worthiness' and therefore, re-dignify means to restore the 'worthiness that the person had before'. So in terms of solving the development problem, this category is used refers to those proposed solutions that suggest or seek to solve Africa's problems by appealing to and using concepts that require the restoration of the dignity of the African. Most thinkers who fall under this category blame the colonial legacy and its dehumanizing effect on the African psyche. They tend to argue that if African dignity is restored and they begin to believe in themselves then many ailments on the continent would be resolved. Streams of this approach flow through the veins of African development thought from the works of famous anti-slavery activists like W.E.B Du Bois, Marcus Garvey, through native thinkers like Cheikh Anta Diop into African theological studies and in formidable politicians like Nelson Mandela. One of the intellectual highlights of this school in the contribution of Cheikh Anta Diop to the idea of Africa being the 'cradle' of mankind (Sertima \& Obadele, 1986). This 'cradlelization' of Africa is the stem on which various branches of African dignification have sprouted (Babacar, 2012:253). Chu Stan (2006) who represents a more contemporary variant of this approach echoes its essential message when he points a finger at the persistent "crisis of identity" that emanates from colonialism (Chu, 2006:26-80) and he suggests the restoration of a 'deeper meaning' of African life (p.299-300). Restoring a dignified identity of the African is the key in this approach.

In practical terms, within this approach there are those who prefer to restore African dignity by use of 'militant' means and those who are 'non-militant'. One of the thinkers who represent the former is Frantz Fanon; his philosophical rationalization of the use of 'violence' as a justifiable means of attaining human freedom (Fanon, 1965), had great impact on the young minds of some of the present leaders of the EAC, notably President Yoweri Museveni (1971) who inadvertently influenced President Paul Kagame of Rwanda. I make more comments on this issue in the chapter on the EAC and sustainability. On the other hand, there are African thinkers who prefer to use 'non-militant' means to restore African dignity; examples include Desmond Tutu (1997) who calls for forgiveness and recognition of the humanity in everyone. 


\subsubsection{Solving by unifying Africa:}

The second approach to trying to solve the African development challenge is by appealing to the unification narrative. To unite means to make separate things into one whole. This approach means the attempt to solve Africa's development challenge by pushing for unity. The 'unification narrative', as it were, refers to all varieties of calls for the unity of Africans in order to overcome disunity-related bottlenecks to the continent's development. Influence on this approach comes from, i) globalization, and ii) local reaction to colonial boundaries. But most influential of those two roots is the colonial experience that African people underwent. They dislike the arbitrary and short-sighted manner in which the colonial powers divided up Africans and placed them under inorganic boundaries referred to as 'countries' according to modern international law.

There are both international globalization interests and local forces that are pushing for this approach to the African development challenge. As far as the former is concerned, there is recognition that globalization is influencing the call for unification or regionalization of Africa, albeit mainly driven by economic interests rather than humane ones (Ummy, 2004). Ummy Mwalimu has discussed the implication of globalization on the EAC concluding that economic global interests are the major driving force behind regionalization in the region. These interests are represented by the policies recommendations and pressures of international agencies such as the International Monetary Fund (IMF), World Bank, African Development Bank (ADB), among others. In all these international calls for unification of Africa are mostly driven by the economic gains that the multi-national corporations envisage from a bigger unified market (see: Dobronogov \& Farole, 2012).

The other forces pushing for the unification are local or from the natives of the continent. Among these are those locals who push for unification on economic grounds and there are those who are pushing for it to realize a sense of African capability in the global order. There are elites within the African regionalization discourse who are popularizing a federation based on economic fundamentals (see: Matsiko Kahunga, 2011); and these are mainly driven by local elite economic interests. But there are also those who are calling for federation based on political ideals. For example Muammar Gaddafi was well known for pushing this version of African unification (Mofeli, 2014:309-10). Nevertheless, some thought that his vision was too rushed and could result in problems of prematurity; for there were disagreement between him and other African leaders like Museveni and Mbeki, a disagreement that brought out two main 
camps in the African unification movement, namely the 'gradualists' and the 'fast-trackers' (Welz, 2012:147-50). The 'gradualists' call for a slower and organic piece-meal process while the 'fast-trackers' want a faster process.

\subsubsection{Solving by re-constructing Africa:}

By using the term, re-constructing, I did not intend to refer to the practical building industry (even though that would be the practical expression of the ideas in this category); instead I use the term to mean. The reconstructive approach to solving the development challenge in subSaharan Africa means the application of theoretical and practical tools to generate categories that re-build African institutions and processes to be resilient and robust enough for development purposes. Since re-construction is about re-established what was once in existence, this approach includes those who are: i) motivated by varying levels of nostalgia about pre-colonial institutions that are glorified in rural and urban African folklore; ii) using modern discourses, concepts and lexicon to re-build African institutional frameworks and systems; and iii) those who employ a combination of the two above.

\subsubsection{Re-constructing with appeal to traditional concepts and norms:}

One of the representative voices for the first category under the re-construction school in contemporary times is Ambe Njoh. In his work, Tradition, Culture and Development in Africa (2006) Ambe argues for the thesis that since native Africans had accomplished institutions and social systems even before the colonialist encounter, modern Africans can use those precolonial institutional frameworks to realize development (Ambe, 2006). Having been preceded by a revival of African culture, this kind of re-construction of Africa using traditional precolonial narratives has permeated many aspects of society such as film (Diawara, 1988), medicine (Iwu \& Wooton, 2002), public administration and governance (ECA, 2007; Bungu, 2014), among others.

\subsubsection{Re-constructing with modern conceptual narratives:}

The second category under the re-construction approach to solving the African 'development challenge' is the one that uses modern narratives, discourses and epistemic tools to contribute to re-build institutions and processes that can be useful in development. In some cases, the use narratives that mirror a continuation of pre-colonial pride in traditional thinking and in other cases the mirror a total break with the African traditional narratives and seek to use non-African concepts to re-build. Kwame Gyekye is one of those who work in trying to re-build modernized 
narratives of African concepts in order to make them remain relevant. In his book: Tradition and Modernity (1997), he carries out a modern interrogation and re-working of traditional African cultural concepts in order to make them understandable and appropriate for modern culture. He argues for "cultural revivalism" (p.233) within African cultural studies in order to reclaim indigenous cultural categories that were suppressed by the colonialism experience.

The department where this researcher is based seems generally to be in the re-constructive approach to solving the development challenge in Africa. For example in one of the researchers' publications titled, The Foundations of Life: Uganda Philosophical Studies I (1992), the issues discussed range from re-conceptualizing tradition African epistemology to using tradition parameters in analyzing contemporary Ugandan urban life (Dalfovo, et al 1992). Edward Wamala (1992) in his paper, "The socio-political philosophy of traditional Buganda society", he uses Buganda's traditional conception of power to address the modern challenge of transfer of power that Uganda faces. The approach of re-interpreting and modernizing traditional concepts in light of modern challenges is also depicted in advancing African logical systems as Wilfred Lajul (2014) does when he argues that the Acholi people of Uganda use a "base system of logic" (Lajul, 2014:75-76).

This version of African re-constructive philosophy was not bad, to the extent that it informed the building of resilience and adaptability in African institutions and social processes in the face of myriads of challenges. However, concerns over its inadequacy emanated from the possibility of the approach being more 'reflexive' than African thinking should be. This means that this approach to the re-construction of Africa, is a form of 'reactionary reasoning', which means that it was less 'proactive'. In a rapidly changing global order and with youthful and dynamic demographics as Africa has in these days, there is need for more 'proactivity' than 'reactivity'. In fact this concern was raised by Ciaffa Jay (2008) in the article, "Tradition and modernity in postcolonial African philosophy", in which he analyzed the ideas of Kwame Gyekye. Ciaffa amplifies the fear that this type of argumentation could lead to a binary view of reality (in Ciaffa's paper he uses 'religion' and 'science'), which may lead to failure to notice avenues of cross-pollination of ideas.

This concern is to a greater extent eliminated in Edward Wamala's subsequent article titled, "Cultural elements in social reconstruction in Africa" (1995). In this article he crosses analysis among concepts from Max Weber, Francis Fukuyama and African social realities. The better version of the re-constructive approach to African development problems was exhibited in the 
book, Social Justice: Perspectives from Uganda (2013). In this work, the re-constructive approach to resolving Africa's development challenges was employed by the authors from the perspective of applied ethics and used to interrogate issues ranging from healthcare systems in Uganda to poverty reduction policies. The editor reveals the pressing problem of 'weak' institutions and social systems resulting from both the legacy of the colonial masters and actions of the natives (Collste, 2013:6-7) as the key challenges that the authors addressed.

Further insights could be gleaned from Wamala's continued application of this approach to Africa's development problems. In his paper, "Status to contract society: Africa's integrity crisis" (2008) he problematizes the 'transitional' character on the modern African as the cause of the poor levels of integrity within society. Using Ali Mazrui's concept of 'trans-class-man', Wamala observes that the typical contemporary African finds himself having to be a loyal 'tribesman' (i.e. being an 'honorable' member of his tribe's tradition) and all the while having to fulfill the demands of a modern state (such as legal and institutional obligations). He refers to this type of African as the "tribesman in transition" (Wamala, 2008:195) whose existence is evidence of the failure of sub-Saharan African societies to complete the "moral evolution from a tribal, ethnic set-up to a modern contractual set-up" (p.203). The result of this condition are multiple development challenges such as "corruption and graft...nepotism, greed and all manner of office abuse' (p.195). It is my observation that explicating the contemporary African experience, Wamala demonstrates that the re-constructive approach has analytical power to critique and also make us understand the true nature of the 'development problem' in Africa. In another article, "Building an ethical Public Service for improved service", (2010), which I discuss in the chapter on 'integrity and sustainability', Wamala demonstrates that this approach can also be useful in generating and suggesting possible solutions to the development challenges in sub-Saharan Africa.

As part of the overall research theme under which this project was, there was a postdoctoral project on: "Ethics and integrity in governance for sustainable livelihoods" ${ }^{5}$ with a team comprising of Lajul Wilfred, Wamala Edward and Kasozi Ferdinand. The direction of the postdoctoral study can be categorized as re-constructive based on the discussions that ensued during a workshop held on 21/06/2013. Their study observed that, since the sustaining of

\footnotetext{
${ }^{5}$ This particular project was part of a bigger research with the theme: Ethics and Integrity in Governance, under which the study was undertaken. This team had both a post-doctoral and doctoral component. One of the cosupervisors for this study was part of the post-doctoral team
} 
livelihoods in Uganda (and much of Africa) is shifting from traditional households to modern corporations and institutions, there is a shift in moral allegiances from the former to the latter. Consequently, the foundation of ethics and integrity in African societies is shifting from traditional household virtues to institutionalized codes. Resulting from this shift is "a rise in anonymity and individualism among today's generation... [and] the collapse of ethical social capital, a fertile breeding ground for individual narcissism" (Wamala, Lajul \& Kasozi, 2013). Their discussion indicates a concern for the institutional shift that is taking place in Africa and by so doing, they showcase a desire to re-construct the institutional framework which would drive development programs in the region.

From this review it is reasonable to adduce that the re-constructive approach to understanding and solving sub-Saharan Africa's development challenge is preferable. The first premise of making that conclusion is the observation that at the analytical level, it makes the actual nature of the problem easier to grasp. The second premise is that it helps the researchers or analysts to avoid the tendency of entirely relying on 'reflexive reasoning' to make proper arguments and decision. And the third one is that it yields richer analysis because it uses concepts from both African and non-African narratives of the problem at hand.

\subsection{Identifying the actual development problem in Sub-Saharan Africa:}

As projected at commencement of this review, the analysis of the dominant approaches used in conceptualizing and guiding efforts towards the realization of development that is sustainable in sub-Saharan Africa inadvertently reveals the actual nature of the problem. It is observable that the main issue that all these thinkers are revealing is that the institutions and social systems and processes in place in sub-Saharan Africa are not commensurate with the demands of modern development. The reason why these institutions and systems are like that is due to inadequate conceptualization of the various dimensions of the development needs of the region (see: Ikejiaku, 2009).

We now realize that one of the main explanations of the paradox of having great natural resource endowment yet having the least development, is the 'disconnect' between the conceptualization and the actualization. When the nature of SD is not well conceptualized one of the results is the inadequate institutional and policy framework put in place for its realization. This state of affairs manifests itself in various expressions of frustration by the citizens of this region if forms such as civil unrest, social disorder, crime, wars, immigration, among others. 
And if such expressions persist society becomes unsustainable. Therefore the systems that are put in place ought to be up to the task of handling the theoretical and practical pressures of the development discourse in a given geographical setting.

This is the problem that the thinkers Amartya Sen in his book, Development as Freedom (1999) and Martha Nussbaum in, Women and Human Development: The Capabilities Approach (2000) are actually dealing with. The proper conceptualization of development enables people's capabilities of flourish and that is the gist of development. What has come to be known as the Capabilities Approach means that we use the concepts of 'functionings' and 'capabilities' in measuring development. To Sen, freedom is "intrinsically important as the preeminent objective of development" (Sen, 1999:37). Sen uses the notion of 'functionings' to denote the 'being' and 'doing' of humans, i.e. the 'freedoms' in terms of which development should be measured (Nussbaum, 2000:70-96). The 'capabilities' are the doings and opportunities that the functionings affords the people, i.e. substantial freedoms (Sen, 1999:1415). The conceptualization that Sen and Nussbaum provided had great impact on the generation of the Human Development Index (Sakiko, 2003:303) which is being used by the UNDP to measure actual development in the whole world. This approach to conceptualizing development is relevant to the development of the East African Community in two major ways: i) the right conceptualization of development would enhance the capacity of the government to work towards the realization of SD; ii) it would also enhance the capabilities of the citizens of the region to enjoy their freedoms and thus supporting and maintaining the structure.

The same concern is raised by William Easterly in his book: Tyranny of Experts: Economists, Dictators and Forgotten Rights of the Poor (2015). In his book he faults the 'expert' approach to resolving the problem of poverty in less developed countries because it decreases the 'freedom' of the poor and thus perpetuates the cycle of poverty. He argues that these poverty experts end up propping up benevolent dictators: "The dictator who the expert expect will accomplish the technical fixes to technical problems is not the solution; he is the problem" (Easterly, 2015:43). Likewise alternative new industries that are trying to approach development differently may be falling in similar theoretical and practical problems. For example the emergence of the Aid Industry was considered a new breath of fresh air in the fight against poverty and under development. But in the book: Lords of Poverty: The Power, Prestige and Corruption of the International Aid Business (1992), Graham Hancock exposes an inherent weakness in the reliance on the 'aid-model' due to its failure to transcend the 
traditional economic focus on material growth. This means that the insistence on mere economic growth without due attention being paid to relevant issues such as 'human rights' renders the classical 'expert' economic model of development weak and void.

\subsection{From 'economic growth' to 'sustainability':}

This 'disconnect' that is observable between the conceptualization of and the actual efforts to realize development is not only peculiar to sub-Saharan Africa; many other regions in the world are grappling with both the defining and realization of sustainable development. In my view, if we focus on that gap we can correctly interrogate the meaning of 'sustainable development' and come up with reasonable conclusions. Alan Cajes (2011) in his book, Philosophy of Sustainable Development: A Critique, has hinted on this when he mentioned that after working in professional environmental protection practice for a numbers of years he realized that the conceptual range that he had was not adequate enough to 'sustain' his professional work and fulfillment. He states that he had to "wrestle with the meaning of sustainable development" (Cajes, 2011:12) from long. The question then becomes: what is the meaning of 'sustainable development'?

As pointed out earlier in the study, The Limits of Growth (1972) was a major step in re-focusing human attention to the question sustainability of human life on this planet. The authors used 'long-range' modeling methods to explore how far human life would be sustained if our understanding of "growth" continued as it was; they identified key challenges which include "accelerated industrialization, rapid population growth, depletion of nonrenewable resources and deteriorating environment" (Meadows, et al, 1972:21). Even though many thinkers critiqued that publication as a doomsday fantasy (Jahoda, et al, 1973), the questions it raised remained pertinent. For the first time there was a systematic questioning of the logic of limitless economic growth and it started a movement of trying to rectify the inherent legacy of 18th century industrialization. Later this background would provide the backbone of sustainable development concept emerging.

Many development thinkers realized that pursuing development in the traditional sense of basic materialist consumerism was resulting into many unintended consequences. In the publication by the Brundtland Commission, Our Common Future (1987) many problems facing humanity were presented and this encouraged various thinkers to research on these problems. The 
Brundtland Commission managed to place the achieving of sustainable development, which has multiple dimensions, on the priority list of human society. There arose interest in the incorporation of sustainability in development in order to rectify the pitfalls of the traditional approaches (Pearce, Barbier \& Markandy, 1990; Roosa, 2010). Many thinkers understood that in order to realize it we need to re-conceptualize development to change from what we have known it to be all along. The concern over the 'sustainability' of human life has spread across nations and academic disciplines; from history to medicine, from Europe to Africa.

One thinker who exemplified this cross-cutting nature of 'sustainability' was the Swedish cancer researcher, Karl-Henrik Robèrt (1991) who studied human pollution of both natural and social environments. His thesis was that pollutant consumerism was unsustainable to human life because it affected the human cell; he discovered a direct correlation between unsustainable lifestyles and increase in cancer cases because the systems that support the cells were becoming unsustainable. He observed that there were many unnatural processes introduced by man into the natural cycles and they were producing "molecular garbage" (Karl-Henrik, 1991:10), which could not be re-cycled by nature; this was unsustainable in the long run. His arguments convinced many scientists who joined hands to form a movement famously known as the Natural Step. This is a network of thinkers from various fields who are united by their desire to see that human life respects natural laws on which sustainability depends.

The work of Karl-Henrik and his followers has helped to raise key issues that are central to the sustainability discourse and are important to our present discussion: i) the multi-dimensionality concession, ii) the centrality of anthropocentric responsibility, and iii) need to include the ethical dimension in sustainability discourse. The first point is demonstrable in the fact that Karl-Henrik circulated is views to various scholars and invited them to deliberate on the issues he raised. In so doing he acknowledged the multi-dimensionality of the sustainability debate; he had discovered during his research that the ability of the human cell to sustain human life was greatly dependent on the natural and social environment that surrounds it. This implies that the sustainability discourse should not be a mono-dimension but an inter-disciplinary subject; to that end he pushed for the creation of the Natural Step as a multi-disciplinary "network of experts from various fields who are attempting to find...strategies needed to reverse [the] deterioration [of the environment]" (Karl-Henrik, 1991:11). As concerns the second point, he observed that man is to blame for "disrupting the cyclical processes of nature at an accelerating pace" (ibid). By humans thinking and pursuing a linear concept of 
development, they are inadvertently putting out high amounts of molecular garbage that are affecting the cell which is the building block and the sustaining block of all processes in the environment. In my view this implies that humans have a higher level of responsibility over what is happening to the environment that sustains life. This brings me to the third point that we can get from Karl-Henrik's arguments: since humans are at the center of interfering with the natural processes, they carry a heavy responsibility to reverse that impact. In my interpretation, it implies that human conduct is key in ensuring sustainability; this means that sustainability discourse ought to pay more attention to the nature of human conduct and how it affects the cyclical processes of the environment. Since human conduct is evaluable in terms of 'good' or 'bad' actions, this attitude necessarily implies a 'value system' (i.e. those actions that promote 'sustainability' are considered 'good' in contrast to the others); and acknowledging that means accepting that $\operatorname{ethics}^{6}$ (which is the science of moral values) is a central part of sustainability discourse. I discuss more on this in later sections of the study.

\subsubsection{On the unsustainability of modern economic thinking:}

At the turn of the last century many economic theorists were thinking in terms of "natural laws of economics', which they sought to 'discover' just like a chemist would discover unchanging molecular laws (see: Gasper, 2004:32-5). The prevalent logic behind was based on the thinking that: i) the natural end of merchandise is simply making material wealth; ii) the natural tendency of merchants is to serve self-interests; and iii) the natural tendency of serving selfinterest to make wealth by increasing productivity. From these premise they argued that human moralization would 'un-naturally interfere' with this 'natural flow' of the economy; therefore letting 'natural economic laws' such as the "Invisible Hand", would make the markets 'selfregulating'.

This thinking buttressed the famous Chicago School of economics that has popularized it worldwide. This logic still underlies the globalized economy of today; for example, according to the Truman Doctrine of a program of development, 'greater production' was the key to prosperity and peace (Escobar 1995:3). Commenting on the Truman Doctrine, Escobar

\footnotetext{
${ }^{6}$ More comments are made by the researcher on the meaning of 'ethics' in various sections of the study but more so under the section on 'contribution of applied ethics'.

${ }^{7}$ With the doctrine of the 'Invisible Hand' Adam Smith actually brought the ideas of the Physiocrats to maturation by which he argued that humans are self-interested but this nature can be good for propelling economic growth. Each human setting out for his self-interest he instead promoted the common good, albeit unknowingly. By so arguing Adam Smith turned what was traditionally considered vice into an economic virtue.
} 
observes that it's goal was to engender (or replicate) conditions necessary for reproducing the same mode of development that existed in 'advanced societies' in other parts of the globe (ibid, p.4). Using discourse analytical terms, he argues that powers with empire intentions "invented" that type of development logic giving less than necessary attention to sustainability. The whole discourse and 'invention of development' was founded on the linear and unidirectional view that nature is 'forever' there for utility and exploitation. Within this logic of development are two fundamental tenets: i) the exploitation of natural resources for human utility; and ii) mass production to eradicate material need.

Even though that logic of development led to better material life in the Europe, United States of America, and some parts of Asia, this has not been the case in other parts of the world, particularly sub-Saharan Africa. There was a high global price to be paid by the 'poorer' regions in order to maintain the materialistic consumerist development in the 'richer' regions. Part of that price involved morally indefensible problems such as: slavery, commodification of poor peoples, environmental damage, irreversible natural resource depletion, industrial catastrophes, and miserable labor conditions, among others. This mode and logic of development failed to eradicate extreme poverty in many parts of the world despite all the promises of material wealth.

\subsubsection{Enter Sustainable Development (SD):}

As noted earlier, the 1992 Earth Summit defined sustainable development (SD) as, development that meets the needs of the present generation without compromising the ability of future generations to meet their own needs. This definition set the ball rolling for subsequent analysis and attempts to rectify the pitfalls of the earlier development logic. In 2002 the Johannesburg Declaration on Sustainable Development identified three, “...pillars of sustainable development i.e. economic development, social development and environmental protection [to take place] at the local, national, regional and global levels" (United Nations, 2002:1).

Socially the Declaration highlighted the increasing disparities between the rich and poor countries of the world which poses a threat to stability and security. Environmentally it noted the degradation that nature is being subjected to as a threat to the sustainability of future generations; and politically it highlighted the challenges that globalization has brought to development causing some regions to remain below unacceptable poverty lines. This tripartite 
categorization has influenced most of the conceptions of 'sustainable development' that have emerged in the past decade. But a close look at these challenges to sustainable development shows that the Declaration either relegated or did not pay necessary attention to the ethical aspect of sustainable development; and my contention is that a closer investigation yields that the identified social disparities, environmental woes and the economic evils are a result of neglect of ethical concerns in development discourse.

\subsubsection{Adapting the conventional understanding of 'sustainable development':}

The three aspects, i.e. 'social', 'environmental', and 'economic' (SEE), which were given official UN endorsement by the Johannesburg Declaration, have shaped the common understanding of 'sustainable development' and many thinkers are exploring ways in which to apply them both in public policies and private business. Some success has been registered in this respect, especially in the private sector, as evidenced by the increase practice of 'corporate social responsibility' (CSR) in private business. Those efforts are applaudable but they can still be made more fundamental by finding ways of giving ethics a more prominent position than the one that it is enjoying right now within the SD doctrine. However, as we notice later in this section there are some challenges emanating from focusing on private corporations.

We can discuss how the SD doctrine has been utilized using John Elkington's book, Cannibals with Forks (1997). Elkington is considered one of the prominent consultants on how private businesses can practicalize the sustainable development doctrine in their business models. In that book, which is conceived within the capitalist logic, Elkington first criticizes the tendency of big multinational corporations to give little attention to 'sustainable development'. He presents the thesis that it is possible for capitalist private businesses to adopt SD principles and yet remain 'profitable'. He argues that his propositions, "are not simply philosophical: they are fundamental to the future of capitalism" (Elkington, 1997:147). He believes that the capitalist business forces such as 'liberal trade', 'competition' and "corporate cannibalism” can still be used within the environment of sustainable development for profitable business. In a nutshell he advances a business model termed the Triple Bottom Lines (TBL) in which he prescribes: i) three themes to guide change in business, ii) seven revolutions and dimensions, and iii) thirty nine steps to execute the change. 
After carrying out a survey of business experts on corporate social responsibility and sustainable development (Elkington, 2013:1) he proposed "a triple bottom line against which corporations should measure the value they create and destroy" (p.86). In the "Triple Bottom Line' (TBL) model Elkington and his followers admonished profit-motivated corporations to use the three basic issues and restructure their business in order to confirm to the SD doctrine and achieve sustainability in business. According to him, this triple bottom line is made up of three elements (i.e. three 'Ps') each of which has equal weight, namely, profits, people and planet (p.100-110). These elements were inspired by and fashioned in the same vein as the three (social, environment, and economic - SEE) that were advanced by the Johannesburg Declaration.

In Elkington terms the first is about corporate profit i.e. profit and loss measurement. The second is the relationship between the corporation and the people i.e. measuring how socially responsible the organization is in its operations. The third is the corporation's connection to the planet i.e. measuring the extent of environmental responsibility. The Triple Bottom Line (TBL) approach to business has been adopted into sustainability discourse and this conception of sustainability has gained traction among thinkers and practitioners. This has been illustrated as follows:

Fig.2.0: Relating the 'SEE' and 'TBL' models of sustainable development:

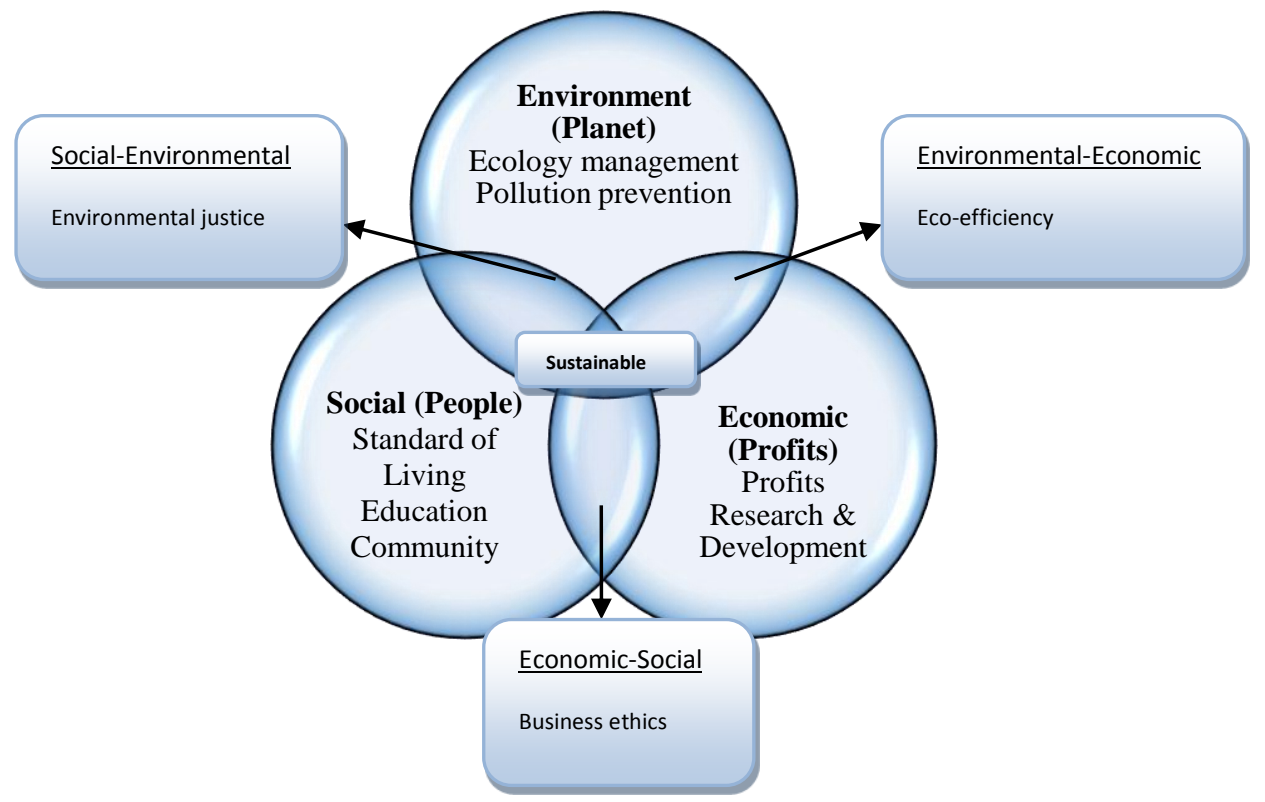

Adapted from: Rodriguez S., et al, (2002) 
The above illustration indicates that the 'social-economic-environment' (SEE) scheme of sustainability is in many respects similar to the 'profit-people-planet' (TBL) scheme (i.e. the triple bottom line (TBL) agenda). The goal of the TBL model is to re-focus business corporations on the three variables of SD i.e. economic, environmental and social. According to this view sustainability is achieved when the three are balanced out; in the illustration above, the various points of intersection indicate how sustainability is realized. The environmental sphere of the SEE includes: environmental management and pollution prevention; the social sphere includes: standard of living, education and community; while the economic includes profits, research and development.

According to some thinkers, the common definition of what sustainable development hides certain other complexities that should not be ignored. Commenting on that observation, Rodriguez et al (2002) have stated that there is, "complexity [in] defining sustainability for a wide variety of actors, from individuals to communities to organizations (Rodriguez, et al, 2002:2). In their paper they observe and list four main inputs that have to be considered in SD i.e. ecological, material, human, and social. Under the ecological they identified natural renewable resources and "healthy ecosystems"; the material refers to non-renewable resources; the human referred to knowledge and means such as income and freedom or opportunity to express it; while the social referred to elements such as, “...trust, reciprocity norms, equity, and other conditions that permit coordination and cooperation for mutual benefit." (ibid).

According to them development involves two critical elements: i) availability of the ecological, material, human, and social resources to meet basic needs and ii) equitable access to resources both inter-generationally, i.e. among all members of the current generation; and intragenerationally, i.e. between the current and future generations (p.3). But a focus on sustainability, according to them, would provide two opportunities; i) to avoid the costs of deteriorating social, environmental, and economic systems; and ii) to improve the rate and extent of human development. Using a neo-Malthusian approach, they present the case that sustainability is a necessity; citing concerns such as global population growth, global warming, species extinction, and rapid loss of bio-diversity and ozone depletion among others. These realities are pushing governments, communities and corporations towards serious consideration and implementation of sustainable development. 


\subsubsection{Observations from the 'SEE' - 'TBL' correlation:}

The above discussion on the correlation between the 'SEE' and 'TBL' variations of understanding sustainable development yields a number of observations:

a) The TBL school of thought also takes ethical values to be important in business. Elkington argues that "values and ethics" are one of the "components of the winning formula" for business in the $21^{\text {st }}$ Century (p.167). This emphasis is necessary especially coming from the private business sector because many ethicists complain that much of the global business community cares less about ethical issues.

b) The TBL scheme has been developed and applied specifically for the private sector and to a greater extent it has been welcomed by the business community and also registered a good level of success. This implies that 'Sustainable Development' is achievable as long as it is adapted to given conditions.

c) From an essentialist of semiotical perspective, the translation of the 'SEE' into the 'TBL' harbors a great risk of losing the original meaning and essence behind the doctrine of sustainable development. A critical observation reveals that in the TBL scheme, 'Sustainable Development' is actually replaced with 'Sustainable Business'. Apparently the inventors of the TBL are more intent on making business sustainable rather than the making all of human existence and its stratospheres sustainable. In the TBL scheme, the fundamental 'profits-increase' ideal is kept alive and given the dominant business structure of 'shareholders' demanding more returns on their investment, there is a danger that the business policies and actions may be cosmetic.

d) The successful testing of sustainable development ideology in the private sector (as the TBL indicates) means that it can also be successful in other avenues, such as regional governance in the East African Community. This study's quest to enrich the governance and development discourse in the region with ethics is therefore achievable.

e) Based on observation (c) above, the recasting of 'sustainable development' as 'sustainable business' implies that the discussion has shifted from 'sustainable development' as such to 'sustainability', as it were. As Bonevac (2010) has discussed, the future debate in SD discourse is about whether 'sustainability' itself is 'sustainable'. 
In the paper, "Is sustainability sustainable?", Bonevac investigates whether the 'concepts' used in arguing for 'sustainability' are themselves 'sustainable' in terms of promoting the doctrine of sustainable development (Bonevac, 2010:84).

\subsubsection{Enter Sustainability discourse:}

The concern is now increasingly about the understanding of 'sustainability' as such; it is even obvious that the doctrine of 'sustainable development' presumes that we know what 'sustainability' means. So what does 'sustainability' mean and why is its conception very important in sustainable development discourse? At the dawn of the modern times, the first European use of the term sustainability that is nearest to the current meaning, is said to have first started with the German forest scientist, Hans Carl von Carlowitz in 1713 in his work: Silvicultura oeconomica (1713). He used the German word, nachhaltigkeit, to refer to sustainability of the wood industry, which meant 'something that is long-lasting'; his purpose was to ensure that not more wood was cut than that which was growing in order to have sustainable forests (Ulrich, 1999). At that point the use of the term was mainly confined to the field of forestry and ecological studies. However, by the 1970s sustainability thinking started crossing over into other fields of study.

And for Bonevac, the "chief conceptions of sustainability in the environmental literature are not themselves sustainable" (ibid). In his view, this is because most of the common sustainable development "interpretations...lack ethical foundations [and therefore] they face obvious counterexamples when applied to individual lives and communities" (Bonevac, 2010:84). I agree with his argument because it is logically obvious that a genuine understanding of sustainable development require a proper and viable meaning of sustainability. Establishing the nature of 'sustainability' is of as great importance as working towards the realization of sustainable development. As believers in the doctrine of 'sustainable development' we would only appear unpersuasive if they claim to propose ways in which humanity can achieve SD without giving adequate attention to what it means for something 'to be sustainable'. To answer the question: 'what is sustainable development?' without asking ourselves: 'what does it mean to be sustainable?' is like placing the cart before the horse. To extrapolate discussions on 'sustainable development' from the philosophical inquiry about the meaning of 'sustainable' would sound unpersuasive if not fallacious because the former takes place within the latter. 
Bonevac uses the understanding of sustainable development as 'development that lasts'; and to him, a sustainable policy, for example, is one that we can continue to follow in the long run. Basing on the notion that something 'sustainable' connotes the idea of "continuance ... indefinitely into the future" (p.85), he postulates that such an understanding of sustainability expresses 'ethical insight'. He questions the genuineness of sustainability thinkers who invoke words like 'limits', 'finite resources', etc. yet they shy away from acknowledging the same in their future projections; their projections and simulations go far into a time that humans cannot reasonably grasp and that places a question mark on those who define sustainability as something that exits forever. He states that:

For the concept of sustainability to have any real use, 'the long run' must be restricted to a time period about which we can reasonably claim to have justified beliefs: a century or two, at most. Anything more than that, and dialogue about sustainability leaves the realm of reasoned policy discussion, not to mention science, and becomes nothing more than rhetoric. (Bonevac, 2010:87)

Two issues emanate from the above statement, namely, that any conception of sustainability i) is dependent on time and belief; and ii) must be of relevance to reasonable policy discussion. The first aspect means that our framing of the concept of 'sustainability' should not be so far away in time such that such that it become unreasonable to justify a belief in such a concept. This means that we should conceive 'sustainability' in terms that of a timeframe that the human mind can reasonably accommodate. The second aspect means that our conceptualization of sustainability ought to within the 'reasonable reach' of policy discussion. If a certain conception of sustainability places it outside the parameters of policy relevance, then it is redundant and worthless. In my view this is making 'sustainability' relevant and contingent to human existence.

\subsubsection{1 'Capitalistic' and 'traditional African' sustainability logic:}

Since we are discussing the manner in which to properly frame the concept of 'sustainability' we need to relate it to the area of study within which this research is situated. Situating the discussion of 'sustainability' in the African region would assist us to learn some insights that can contribute towards the realization of sustainable development. Sustainability thinking, as such, is not entirely a new way of thinking in Africa; it existed among natives of the continent 
long before modern development discourse. For example traditional Africans have sustainably preserved forests for millennia using indigenous knowledge (Gombya-Ssembajjwe, et al, 1993) and therefore it would be illogical to argue to the contrary.

Much of the evidence for the capacity of Africans to use traditional sustainability methods in the past is being discovered and documented in contemporary times but many scholars agree that this knowledge existed long before modern education. In the report, Embazzi and Namungo's Forest, Gombya and his team studied on how native Ugandans preserved forests and found that sustainability thinking was embedded in their indigenous knowledge about these forests (Gombya-Ssembajjwe, et al, 1993:5). They found that the natives knew the regenerational characteristics of the trees and their interactive nature with other beings such as bees and monkeys in the forests. Gyasi, et al, (2004) found a similar approach to gardening by native Ghanaian farmers who displayed agrodiversity sustaining practices in their work.

The traditional African has a holistic worldview and approach to existence, which respects every form of life and this view is extended it to all beings (see: Mbiti, 1989). Even before the advent of the contemporary doctrine of sustainable development, the traditional African knew how to live sustainably with nature and in so doing preserve it for future generations thus fulfilling the Earth Summit's earlier definition of sustainable development. In the article, "Sacred forests in modern Ganda society" (1994) Gombya-Ssembajjwe captures the sustainability implications behind the practice of granting sacred status to certain forests in Buganda. The Baganda have a norm of holding some forests in high esteem because they belong to the ancestral spirits or the Kabaka and this represents 'institutionalization' of sustainability that has existed for long among the Africans. Gombya observes that, "Traditional knowledge systems are sophisticated and in some cases more effective in natural resource preservation" (p.2). There are forms that this 'inherent' sustainability thinking manifests itself in Africa; for example in Buganda the clans are organized along clans majority of whom (almost 90\%) use totems of animals, birds, plants, etc. A member of a given clan is not supposed to eat or mistreat the animal or creature that represents their clan ${ }^{8}$. All the ills found within the totemic clan system notwithstanding, this culture contributed more in protecting and

\footnotetext{
${ }^{8}$ Some of the early colonial writers were intrigued by the existence of such a sophisticated 'totemic' clan system in a highly organized and civilized Kingdom like Buganda (see: Frazer, 1995:472).
} 
preserving the many species that the clan represented from extinction (at a time of less resources), than the conservation policies of the modern state of Uganda.

However, what we should be more interested in is the 'logic' behind traditional African conception of sustainability that is decipherable from those cases. Even though some modern thinkers refer to it as 'animism', the practice of rendering forests and animals sacred, had its sustainability value and the logic behind it and has proved effective in sustaining different life forms from traditional times. As a simple etymological trace would suggest, the word 'anima' means 'soul' or 'life', which means that the logic behind this approach is the acknowledgement and respect for every form of 'life'. Unlike the Western continental philosophy view or disengagement from the environment around it in order to exploit it, the traditional African knows that he lives within and side-by-side with many other beings. In traditional African ontology it is a kind of 'cosmic arrogance' for man to disrespect other forms of beings and when calamity happens it is explained in terms of punishment for such an attitude from the cosmic beings. This is in contrast with the hitherto prevailing logic within European anthropological attitudes. The Ugandan philosopher, Gervase Tusabe $(2005,2012)$ has done extensive studies on the contrast between the mostly Western influenced view of man as "apartfrom-nature" and man as "part-of-nature" which show how the former threatens man's life support system (see: Tusabe, 2003, 2012). More discussion of this logic is done under the chapter on 'Ubuntu and sustainability'.

The study therefore noticed that one of the major obstacles to the realization of sustainable development in SSA is the existence of two divergent logics of sustainability in the SD discourse. The first logic of sustainability that the study identified is the "market inspired sustainability' (MIS) represented by the Triple Bottom Lines (TBL) School of sustainability (Elkington, 2013), which insists on recasting SD within the capitalist market logic yet it faces a higher risk of producing 'cosmetic' efforts towards the realization of SD. The other logic of sustainability is the 'traditional African sustainability' (TAS) inspired by the traditional African ontology, which is still prevalent in contemporary sub-Saharan Africa. The study therefore established a gap in the available sustainability theorization which calls for either finding a more suitable sustainability logic (on which to base sustainable development policies and practices) or reconciling the two if SD is to be realized in SSA. To make it easier to notice, the nature and impact of this divergence is captured in the illustration below: 
Fig.2.1: Divergence between 'market' and 'traditional African' sustainability logic:

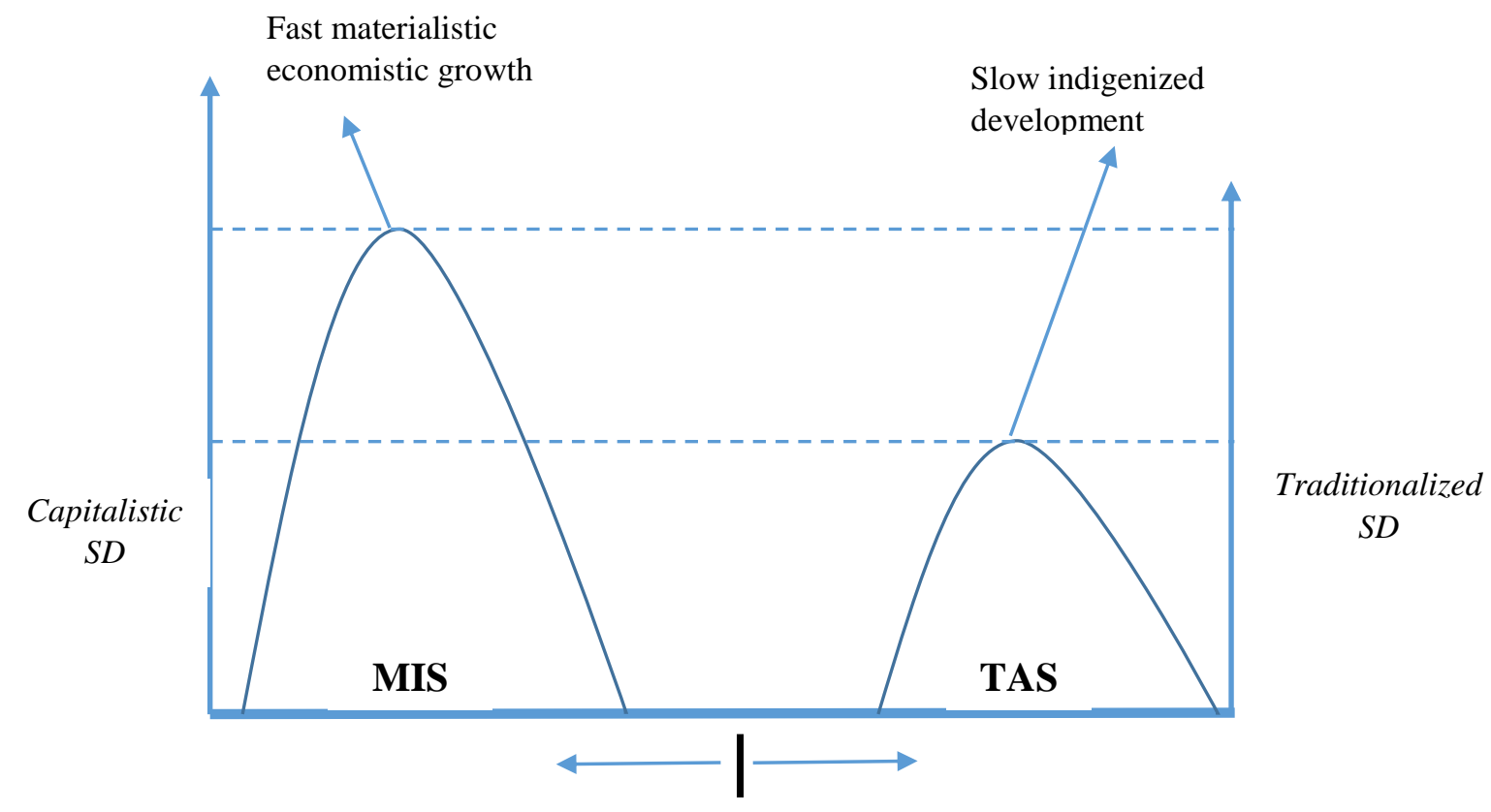

Gap of divergence

The above rendering illustrates the study's literature review finding of the existence of a conceptualization 'gap of divergence' between the 'Market inspired sustainability' (MIS) logic and the 'Traditional African sustainability' (TAS) logic. The former leads to measurement of governance and development using a 'capitalistic-market' yardstick of sustainable development. The result of this 'MIS' would be the perpetuation of a materialistic and economistic view of growth that pervades many of the societies in the world that have applied it. On the other hand the latter leads to measuring of development in traditionalized terms and is found in many societies that cherish indigenous and traditional economic values. The impact of this 'TAS' is a slow indigenized mode of development that is witnessed in most of subSaharan Africa. This is one of the major gaps that this study sought to fill by generating a more suitable conceptual framework of sustainability that could be applied in sub-Saharan Africa towards the realization of sustainable development.

\subsubsection{Review of Kaitlyn Orr's version of 'Ethical Sustainability':}

The concern over sustainability and its relationship with ethics has brought about the concept of 'ethical sustainability'. Kaitlyn Orr wrote a short paper titled, "Ethical Sustainability” (2010) in which she bases her understanding of ethical sustainability on the rejection of the distinction between 'natural' and 'unnatural'. In her paper, using a feminist ethics perspective, she argues that man is both part of nature and a 'producer of nature'. The true meaning of homo sapien should 
not be 'conqueror of nature' but he is 'part of nature'; therefore man shifts from the position of power over nature but to a position of necessary respect for non-humans. Humans are not only nature but they produce nature (Kaitlyn, 2010:2). To her man and nature are not two opposite terms confronting each other; but they are part and parcel of each other. To Kaitlyn the discussion between 'natural' and 'unnatural' is irrelevant in environmental ethics; she postulates that in order to understand 'ethical sustainability', we should correlate between the environment and humanity. She states that, "...everything we create and everything we do is also natural. There is in fact, nothing that is artificial, nothing that is unnatural because nothing lies outside of the chaosmos, the undifferentiated nature" (p.5).

In her characterization of 'sustainability' she argues that "sustainability has nothing to do with nature, but is the ethic of environmental ethics" (p.13). In my view, this however, postulates that sustainability rotates around the environment; a strong contention and assumption of this study is that sustainability goes beyond only environmentally friendly policies or actions. As discussed in detail in the section of 'comprehensive ethical sustainability', the study's main argument is that without ethics as the foundation of sustainability, all efforts towards environmental or any type of sustainability would fail. For example, a simple act or corruption could easily destroy all efforts towards environmental restoration or sustainability.

In her paper, under the section on 'comprehensive understanding of nature', Kaitlyn argues that, "Humans are a part, but not a central part of a greater network of flows and breaks of machines and differentiated substances" (p.4). This understanding of 'humans' is more applicable to a holistic of the cosmos; but a closer look at the earth as a single planet would reveal that humans have a greater role to play in affecting its environmental health and its sustainability as such. Humans, as Gervase Tusabe (2003) argued, by virtue of their position in nature's ontological hierarchy carry a higher responsibility over the sustainability of the environment. Kaitlyn goes on to say that, "If we are natural beings, then what we produce must also be natural..."(p.6). Granted, humans are 'part of nature' and also 'produce nature'; but we need to be careful because a focus on not dichotomizing between the 'natural' and 'unnatural' may lead to failure to apportion ethical responsibility. We need to be careful because without giving human agency the due attention that it deserves, there is possibility of making ethics also apply to inanimate beings such as those that Kaitlyn argues to be included in our conceptualization of ethics. If we insist on blurring the difference between 'natural' and 'unnatural' as far as ethical sustainability in the humanenvironment relationship is concerned, then we could as well conclude that even inanimate beings 
could be held ethically accountable. That would be most difficult to ascertain if we are to apportion responsibility in the quest to realize sustainability.

This implies that the actual 'comprehensive ethical sustainability' that is applicable to earth, as it were, would mean that we focus on the ethical responsibility of humans as far as it is possible. It is true that much, if not all, that man produces is from nature and part of nature; but in nature the natural occurrences appear in naturally optimal combinations of flows and forces that ensure balance and lasting stability of the natural. The natural combinations of flows, chemicals, forces, etc., are arranged or combined such that the natural systems remain in balance, i.e. achieving and maintaining sustainability. But man's often zealous and less-informed interventions in nature in terms of manufacturing and constructions and re-arrangement of nature occurrences, becomes 'unnatural' when man's 'artificial combinations' of nature's elements, flows, chemicals, forces, etc., disrupts the balance and lasting stability of nature's systems. In this sense therefore human's intervention in natural elements could lead to unsustainability even though humans and their creations are part of nature. This means that a really 'comprehensive ethical sustainability' has to necessarily take into consideration the human's agency and resultant unsustainability impact on the environment and nature as such. This study therefore proposes to generate a more suitable theoretical framework for achieving sustainability termed as 'comprehensive ethical sustainability'

\subsection{Ethics and Justice in sustainable development:}

The review explores two main avenues from which to investigate about room for possible convergences between the 'WCS' and the 'TAS' versions that could serve a means of crafting a more suitable framework of sustainability to assist in realizing sustainable development in subSaharan Africa or elsewhere. From an applied ethics point of view, the two convergence points that are identifiable as 'ethics' and 'social justice' because both variations in 'sustainability logic' that we have uncovered above display concern about the two issues.

In the earlier discussion, we pointed out that Elkington, who represents the 'TBL' adaptation of sustainable development into Western capitalist business, argues that "values and ethics" are "one of the components of the winning formula" for future business (Elkington, 1997:167). This is some of the evidence that ethics is very pertinent in the sustainable development discourse. When it comes to Bonevac, whose article we also considered earlier, he interrogates the definition provided by the Brundtland Commission and observes within it an interesting criteria for determining the 'sustainableness' of any concepts used or discussions in SD discourse. In my view 
the criteria that he unravels essentially covers issues of justice and ethics. He calls it the Brundtland-sustainability criteria and it has a "three-pronged test": i) capacity to be plausible at individual level, ii) capacity to be plausible at communal level, and iii) capacity to inspire satisfactory policies (Bonevac, 2010:88). In all, Bonevac uses both ethical consequentialist and ethical intuitive analysis to conclude that any conceptualization of SD whether from an environmentalist or other social scientific points of view, should take serious consideration of the implications of that conventionalization. Thus ethics takes a central role in SD discourse.

\subsubsection{On meaning of ethics and its place in sustainable development:}

The earliest systematic meaning of ethics can be traced from the work of Aristotle, Nicomachean Ethics, in which he set out to study the "ethe" (morals) of society (Eth. Nic. Sec. 8). The phrase "ta ethika" was used by him in the definition of his work to denote the "science of morals" or scientific discourse on morals. This means that ethics studies morality and because of this, it has come to be known as "moral philosophy". One of the prominent definitions of ethics today is the one identified in Frankena's book, Ethics (1973), in which he defines it as, "a branch of philosophy [dealing in] philosophical thinking about morality, moral problems and moral judgments" (Frankena, 1973:4). Fieser has defined ethics as “...systematizing, defending, and recommending concepts of right and wrong behaviour" (Fieser, 2003) lays out the foundational agenda of moral philosophy. This is what makes ethics a 'science' which systematically discourses on society's morality. Although to the nonethicists, 'morality' may appear interchangeable with 'ethics', there is actually a marked difference between the two 9 .

It suffices to mention that in simple terms, 'morality' could be imagined as the generally accepted standards of behavior (or conventional behavioral expectations) within a given society at a given point in time (Frankena, op cit. p.8). On the other hand 'ethics' is the science of examination of the viability of those standards. Each society or community has certain behavioral and moral standards that are wholly accepted by members of that community; nonetheless it does not automatically follow that they are 'ethically viable' (p.10-11). Therefore one of the products (or the purpose) of ethical analysis is to develop a viable and logical ethical

\footnotetext{
${ }^{9}$ A detailed differentiation between 'Ethics' and 'Morality' is not possible to go into for this study (see: Frankena, 1973 for a better discussion of the difference).
} 
theory and principles, which could be applied in deciding which directions of conduct or positions are 'right' or 'wrong', good and proper or otherwise (p.12). As an academic field of study it investigates the subject-matter and methodology used in this field; while as a product it endeavors to generate theoretical and practical solutions to ethical challenges - these may include ethical theories or ethical principles. Such principles (of ethics) are deemed necessary because unlike moral stipulations, ethical conduct demands that a principle approach is used because widens the options or possible directions of actions especially in complex ethical issues. Ethical principles do not dictate a single 'moral' course of action, but provide a means of evaluating and deciding among competing options. That is why many ethicists place emphasis on a given judgment or action or policy 'being ethical' because ethical viability or foundation of such action is of great importance to the overall ethical health of society.

Given the advances in human and social conditions in contemporary times many moral challenges are complicated. The increasing complexity of moral issues that emanate from technological, global and cultural changes calls for application of ethical principles that would guide and justify a chosen course of action (Collste, 2007:25-27). All over the world these rapid advances and changes are impacting on the ethics of different communities and sub-Saharan Africa is not exempted. Reports from this region indicate that there is growing concern over unethical conduct in various sectors of society such as governance and public service.

In a wide comparative study on Africa titled, Public Service Ethics in Africa (2001), researchers from the United Nations came to the conclusion that generally there is, "an erosion of professionalism and ethics" across most of the continent (United Nations, 2001:v). In that survey, the East African Community was represented by two countries, Kenya and Uganda; but even in other surveys where the region is fully represented by all the countries, the situation is not so good. All over the East African Community there is a growing concern over the increasing levels of unethical conduct in public service and its impact on development efforts. Corruption is one of those unethical conducts that negatively affect the realization of sustainable development in the EAC. The organization, Transparency International (TI) carries out annual surveys of the corruption indicators for over 170 countries worldwide. A consideration of the corruption indicators of the countries in the EAC reveals that there is a big challenge of unethical conduct especially in the public service. TI defines corruption as the abuse of entrusted power for private gain. The annual survey titled, Corruption Indicators 
Index (CII) measures the 'perceived levels of corruption' in the public sector, while the Global Corruption Barometer (GCB) tracks worldwide 'public opinion on corruption'.

Even though these surveys do not give data on the actual corruption figures in the areas of research, they nevertheless reveal what the citizens think is going on in their countries and some variables like the question on whether the interviewee has paid a bribe, are serious indicators of the level of corruption. So it is reasonable to use the data from these surveys to analyze the ethics dynamics in a given country and to gain useful insights into the issues of unethical conduct and its impact on achieving sustainable development. Below is a side-byside juxtaposition of excerpted data taken from both the Corruption Perceptions Index - 2013 (CPI) and from the Human Development Index - 2014 (HDI) for the East African Community. The indicators used below were purposively selected to show a correlation between unethical behavior and impact on human development.

Tab. 2.0: Correlation between CPI and HDI for EAC:

\begin{tabular}{|c|c|c|c|c|}
\hline \multirow[t]{2}{*}{ Country } & \multicolumn{2}{|c|}{$\begin{array}{l}\text { Corruption Perception } \\
\text { Index rank } \\
\text { (2013) }\end{array}$} & \multicolumn{2}{|c|}{$\begin{array}{l}\text { Human Development Index rank } \\
\qquad(2014)\end{array}$} \\
\hline & $\begin{array}{l}\text { World Rank in } \\
\text { perceived public } \\
\text { sector corruption }\end{array}$ & $\begin{array}{l}\text { Control of } \\
\text { Corruption } \\
\text { (Score) }\end{array}$ & $\begin{array}{c}\text { World HDI } \\
\text { Rank }\end{array}$ & $\begin{array}{l}\text { Life expectancy } \\
\text { at birth (2013) }\end{array}$ \\
\hline Burundi & 157 & -1.08 & 180 & 54.1 \\
\hline Kenya & 136 & -0.91 & 147 & 61.7 \\
\hline Tanzania & 111 & -0.49 & 159 & 61.5 \\
\hline Uganda & 140 & -0.87 & 164 & 59.2 \\
\hline Rwanda & 49 & 0.48 & 151 & 64.1 \\
\hline \multicolumn{5}{|c|}{$\begin{array}{l}\text { Note: a) Corruption perception ranking is out of } 177 \text { countries; }(0 \%=\text { highly corrupt and } 100 \%=\text { very clean). HDI ranking is out } \\
\text { of } 187 \text { countries. b) 'Control of corruption' refers to perception of use of public power for selfish gain. }(-2.5=\text { worst government } \\
\text { power abuse }+2.5=\text { best government). c) By the time of finishing the study the CPI for } 2013 \text { was the latest report available }\end{array}$} \\
\hline
\end{tabular}

The above indicators were selected from the CPI-2013 and the HDI-2014 but some insight can be gleaned from the correlation between the two. The public's 'perception' of corruption indicates something that is concretely wrong in their countries because the higher the perception of corruption in a given country, the lower the country human development rank. Apart from Rwanda, all the other countries are perceived to have a high level of public servants control and use of government for selfish benefit. All in all the figures indicate that there is a 
strong correlation between the levels of unethical conduct among the public service and the achievement of development or the sustainability of the same, for that matter.

More insights can also be found in the details of Transparency International's Global Corruption Barometer-2013. The online version ${ }^{10}$ of the report presents the figures for the specific questions that were asked during the survey and when one examines some of those questions, there are issues that emerge that are pertinent to the subject of sustainability. Below are selected questions that were used and their corresponding percentages:

Tab.2.1: Global Corruption Barometer-2013 for the EAC region:

\begin{tabular}{|l|c|c|c|c|}
\hline Country & $\begin{array}{c}\text { Paid bribe to } \\
\text { judiciary in last 12 } \\
\text { months to receive } \\
\text { public service }\end{array}$ & $\begin{array}{c}\text { Those who } \\
\text { thought the } \\
\text { legislature / } \\
\text { parliament is } \\
\text { corrupt }\end{array}$ & $\begin{array}{c}\text { Those who } \\
\text { thought that } \\
\text { business was } \\
\text { corrupt }\end{array}$ & $\begin{array}{c}\text { Those who strongly } \\
\text { agreed that } \\
\text { ordinary people can } \\
\text { fight corruption }\end{array}$ \\
\hline Burundi & -- & $15 \%$ & $40 \%$ & $17 \%$ \\
\hline Kenya & $58 \%$ & $68 \%$ & $29 \%$ & $37 \%$ \\
\hline Tanzania & $52 \%$ & $53 \%$ & $48 \%$ & $24 \%$ \\
\hline Uganda & $58 \%$ & $57 \%$ & $37 \%$ & $18 \%$ \\
\hline Rwanda & $11 \%$ & $1 \%$ & $10 \%$ & $56 \%$ \\
\hline
\end{tabular}

It is also obvious in this set of data that the countries of the EAC have a serious problem of corruption. As pointed out above, the perception of the citizens of a given country indicates something concrete in that community. This table indicates that apart from Burundi and Rwanda, the citizens of the rest of the member countries of the EAC think that their public sector is deeply infested with corruption. The unfortunate observation is that the people in those countries have little hope of fighting and overcoming the vice as indicated by the low figures concerning ordinary peoples' ability to fight the corruption.

\subsubsection{Correlation between public ethics and sustainable development:}

The following are the major conclusions that could be adduced from the data above:

10 The details can be viewed online at: http://www.transparency.org/gcb2013 
a) Note that the study selected two questions on the perception of corruption in the public (i.e. judiciary and legislature) and another question was on perception in business. The figures reveal that if there is corruption in a country, it affects both the public and private sectors. If this observation is projected in terms of sustainable development, it would mean that no matter the 'sustainability logic' within which one analyses, the ethical problem of corruption affects the realization of sustainable development. For instance, if we took the category, 'business' to mean the private sector, then we could apply Elkington's 'TBL' adaptation of sustainable development to it because he designed it for the corporate world. It means that unethical conduct negatively affects both the Western and traditional African logic of SD.

b) The implication of acknowledging the above observation is the fact that ethics equally affects either understandings of sustainable development (SD). Therefore ethics is a common denominator in both conceptual and practical levels of SD. The study discusses more of the implication of this observation in the chapter of 'comprehensive ethical sustainability' to prove that ethics is of foundational value in the conceptualization of 'sustainable development'.

c) The table showing the correlation between CPI and HDI also shows that the vice of corruption (or unethical conduct) of public servants impacts greatly on the lives of the people in a given country. There are great indication that corruption in the public sector affects life expectancy negatively. This means that corruption (or any other unethical conduct) in the public sector is an indicator of the existence of social injustice for certain sections of the citizenry. The question of justice and its relationship with the realization of sustainable development is discussed in greater details in the chapter on 'the justice principle in comprehensive ethical sustainability'. Even government officials know this fact as Uganda's State Minister for Economic Planning is reported to have said that, "Poor handling of governance issues can lead to instability" (Kafeero \& Nabirye, 2014).

d) It is obvious but worthy noting that the region of the EAC has a very big problem of poor ethics levels in the public sector and in government. The figures show that $80 \%$ of the region has a negative score for corruption. It means that the problem is quite overwhelming for both the citizens and their governments. These countries face similar 
trends of unethical conduct in the public service sector and government and they know that it has great impact on the realization of sustainable development. For example in the report on corruption levels in Uganda, the Inspector of Government states that,

Corruption continues to be a major concern to the people of Uganda and various stakeholders because it undermines good governance, development initiatives, and high quality service delivery. (GoU, 2011:20)

This observation that was made by a Ugandan government official is a common view among the people and the scholars of the region. Owing to the fact that globalization is increasing, problems that are originate from one part of the region easily affect other parts. Therefore it is necessary to analyze the problem of unethical conduct at a regional level and find out if the region has the necessary institutional structures and processes to handle the problem in a cooperative manner.

The three core countries of the East African Community namely, Kenya, Tanzania and Uganda are increasingly expanding their regional community in various aspects, especially strengthening of the East African historical and current linkages and institutions, (the most recent ones include: a regional parliament, the East African Customs Union Protocol, Good governance protocol, etc). Given their historical relatedness and country-specific experiences, their geographical closeness, and their strong cultural, economic and political linkages, a "cross-sectional" investigation of their ethical experiences would be of great benefit to thinkers and practitioners in the public service systems and structures in the region.

\subsubsection{Social Justice and sustainability in the EAC:}

Having isolated and examined the variables of the problem of sustainable development in the EAC, the review also considered angles from which to handle the problem. One of the issues that emerge is that there is a question of social justice or injustices that are committed or suffered by the victims of the unethical behavior that negatively affects the realization of sustainable development. Sustainability cannot be achieved when there is injustice or perception of injustice. The study handles the pertinent issue of the impact of justice or injustice on the realization of sustainability in the chapter on the "justice principle in comprehensive ethical sustainability'; but here I consider some literature that discusses social justice in the EAC. 
One of the challenges that is encountered in literature and report is the conflation of the two concepts of 'justice' and 'social justice'. There has been a long discourse on the meaning of justice since times of classical philosophers like Plato, and Aristotle. Plato used the Socratic dialogues in The Republic to discuss the meaning of justice in terms of a 'universal principle' which humans ought to use in judging what is right and what is wrong as they pursue the goal of happiness (The Republic, Bk 8-10). But even though to a greater extent Plato presented Socrates discussing 'justice' as a universal and transcendent notion, the fact that he and his interlocutors had to dialogue on it using a fictional just city known as the 'Kallipolis', is indicative of the fact that justice has to be placed in a context (see: Roochnik, 2008:69f). Aristotle's discussion of 'justice' places it in the realm of virtue and human character; to be just is to live a balanced life that seeks the 'mean' in character. The just life, which is understood as the pursuit of happiness, is discussed by Aristotle as 'excellence of character' (Nicomachean Ethics, Bk 12, 19). But in many instances, Aristotle applies the 'mean' in a dual manner, "sometimes to qualities of character, sometimes to particular responses. We cannot be sure that Aristotle himself is always apprised of his shifts..." (Broadie, 1991:96).

The contextualization of Socratic discussion of 'justice' within the 'Kallipolis' on one hand, and Aristotle's use of the 'mean' to bring in to the personal virtue level, on the other hand, is implicit of the realization that there are two levels of expressing or realizing justice. The first level is the institutional and the second is the personal. And since in Aristotelian terms, justice is both 'distributive' and 'rectificatory', there have to be both systems and willingness (or the character) to ensure that just is realized. For purposes of our discussion in this study we can postulate that the understanding of justice as an 'uncontextualized' concept; and this informs the pursuance of justice in terms of legal mechanisms and other such institutional arrangements. But on the other hand the "contextualized" ${ }^{11}$ view of justice implies that we have to take into consideration the social setting within which justice is perceived and this explains the emergence of the concept of 'social justice'. Therefore a conceptualization of justice that only takes it in the legal institutional sense would easily pass for being narrow in scope and even 'reductionist' in that sense. This is viable reasoning because 'legal justice' does not exist

\footnotetext{
${ }^{11}$ Note that by the use of the word 'contextualized' we are not insinuating 'situationalism' as such. In my view, when considered in ethical terms 'situationalism' would more or less stand for 'ethical relativism' yet we would want to avoid such a misreading of this sentence.
} 
in a vacuum and therefore the whole societal setup is critical to the realization of justice thus the preeminence of the concept 'social justice'.

But the next question would be: what is 'social justice'? In defining 'social justice' we must keep in mind the broadness of the concept established from classical philosophy debates on justice as the one above. We should also take into consideration Robinson Matthew's hint that focusing on only the key notions in social justice such as 'equality', 'equal opportunity' and 'personal responsibility' could diminish the prospect of realizing a clear definition of social justice (Robinson, 2013). Therefore we should note that there is a difference between 'social justice' as such and the notions that constitutes it. Basically, the most established definitions of social justice are generated from certain theoretical perspective; the dominant theories being egalitarianism and libertarianism. The most discussed definition of social justice is that of John Rawls, 'justice as fairness' (1985) using which he generated principles to "define the appropriate distribution of the benefits and burdens of social cooperation" (Rawls, 1971:4). On the other hand Robert Nozick understood justice as 'deserved entitlement' (Nozick, 1974), which respects peoples' rights to self-ownership and property. In his theory Nozick rejects "ahistorical" conceptions of justice which do not consider 'desert' (pedigree) of social goods.

The study discusses more on the different view between Rawls and Nozick in the chapter on 'justice and sustainability'. But since the study is in applied ethics, one possible way of reconciling the two views is by way of an ethical theoretical perspective. The perspective that could be used is Thomas M. Scanlon's version of virtuous 'contractualism' contained in What We Owe to Each Other (1998) in which he lays out another path for reaching agreement in public ethics. First, contractualism in ethics is the broad ethical theory which holds that standards of right and wrong are a result of or based on an agreement (Ashford \& Mulgan, 2010). Scanlon positions his view of moral contractualism by using 'good reason' as a basis of the moral agreement rather than 'rationality' as most traditional Kantians do.

He states that:

If we all have good reason to want acts of a certain kind not to be performed, then it is likely that any principles allowing such acts could 
be reasonably rejected, hence that they will be wrong (Scanlon, 1998:153).

The above statement captures the foundation of Scanlon's argument for establishing reasonably justifiable "basic" grounds (p.5) for public ethics, which he promised to set out from the beginning of his book. He thinks that the above approach helps "to explain more clearly how the idea that ac act is wrong flows from the idea that there is an objection of a certain kind to people's being allowed to perform such actions" (p.153). That would be ground enough because in his view reason for intention is equated with reason for action. He has continued to provide further grounds for this version of contractualism by developing it into "normative cognitivism' i.e. "the view that there are irreducibly normative truths about reasons for action" $\left(\right.$ Scanlon, 2014) ${ }^{12}$. Note should be taken that in the new book, Being Realistic About Reasons (2014), he uses the word 'reasons' but not 'reason' to connote the importance of contract.

From Scanlon's account of the foundation of public morality, we could trace grounds for an alternative view that converges both the 'Rawlsian' and 'Nozickian' views of social justice; and by so-doing we make room for the traditional African conception of the same. Nozick's insistence on a libertarian composition of SJ implies his assumption of individual rationality and justification for entitlements. But if Nozick's self-claimed 'historical' conception of SJ is to be taken seriously, then it must allow for the interrogation of the 'desert' from whence the claim for individualized entitlements comes from. And an interrogation of that pedigree would most probably reveal that the social goods were not acquired in isolation of other members of the society; there are surely 'reasons' that society agreed on for such action to have been allowed from which those social goods came. That therefore proves that Scanlon could provide a reconciliatory leaf to the Nozickian view of SJ.

It is noticeable that his approach can be of value to communities like east Africa because: i) they are essentially communitarian societies (Chachine, 2008:39-82); and ii) the appeal to 'reasons' rather than 'rationality' (Scanlon, 1998:191) exonerates them from the erroneous view that some thinkers had in the past that Africans lacked capacity for 'rationality' (Ikuenobe, 2006:36; Eze, 1993, 2008). It is also necessary to point out is that the definitions of social

\footnotetext{
12 Statement taken from the promotional page of the book on the publishers' website: <http://ukcatalogue.oup.com/product/9780199678488.do>
} 
justice that emerge are both dissimilar and similar in certain aspects to the one espoused in the traditional African justice system. In traditional African conception, social justice refers to the 'sustenance of society'; in such communities there is emphasis on maintaining sustainability by distributing the benefits and burdens of social cohesion. For any institution or action to be judged as socially just it has to pass the test of sustenance of society. To illustrate this view of social justice we use two notions in east Africa: i) 'mato oput' and ii) 'gacaca' system. 'Mato oput' is an Acholi linguistic ${ }^{13}$ phrase meaning "drink bitter fruit of 'oput"” (Yav, 2006, Tom, 2006); this involved previously warring parties taking a bitter herbal drink followed by spiritual and reconciliatory rituals in front of supervising elders and selected audience promising never to fight again. This meant that social justice was achievable through and therefore definable by acts and processes that sustain the community no matter the events of the past (Mbabazi, 2010:101-13). This implies that even though 'desert' (pedigree) brings above the terrible situation at hand, it does not prevent justice from being achieved moving forward into the future. This contradicts one feature of the Nozickian view of social justice where desert is taken as a key determinant (see: Iris, 2011:28-29).

The other example to illustrate traditional African conception of social justice is the gacaca court system in Rwanda. The Rwandese (Kinyarwanda) word 'gacaca' literally means "on the grass", it is a phrase that has entered modern lexicon in reference to an indigenous Kinyarwanda communal court system whereby members of the community gather on a grassy hill to listen and pass judgment over juridical cases in the community (Clark, 2010; Africa Rights, 2003:1; Bakuluki, 2011:58). The key tenet in 'gacaca' conception of justice is 'inyangamugayo' which means 'healing the community' (Rusagara, 2008), which incorporates truth-telling and respect of the dignity and self-worth of victims as they directly speak for themselves during the communal trials. The same understanding of justice characterizes this system as the Acholi conception. Although most modernist reports about these systems questions their competence in handling the nature of modern justice, there is need for a philosophical reconciliation between the divergent ways of defining justice if African societies are to be sustainable.

\footnotetext{
13 The Acholi are a Nilotic community of people who prior to colonial times occupied and controlled a region referred known as Acholiland (see: Odoi-Tanga, 2010). It comprises of parts of northern Uganda and southern parts of South-Sudan and majority of them still occupy that region despite belonging to different modern states. (Also see: Mwakikagile, 2009:52-55)
} 
But why is SJ very important in our study? In Why Social Justice Matters (2005) Brian Barry has put up a convincing thesis why we should take social justice seriously. Using an egalitarian perspective Barry argues that contemporary society denies some of its members justice because the dominance of a meritocratic ethos. To him, the contemporary adaptation of a meritocratic society, contrary to what it promises, by insisting on 'personal responsibility', ends up denying many members of society the equality of opportunity that they ought to access (Barry, 2005:132-150). To a great extent, his understanding of social justice is egalitarian because he places greater responsibility on the society to ensure that everyone attains justice. As a way of reconciling the differences between the egalitarian and libertarian view of the concept and yet still retain the importance of 'social justice' David Miller (1999) developed what can be called a 'consensual' view of social justice. In Principles of Social Justice, (1999) David Miller presents principles of social justice which he claims to be the, "underlying principles that people use when they judge some aspect of their society to just or unjust" (Miller, 1999:ix). To him these principles are "beliefs at a deeper level" and are discoverable when we "look at what the people themselves think" (ibid).

In the paper, "Social Justice: Reframing the 'social' in critical discourse in Africa", Taylor Viviene has argued that the question of 'social justice' is central to contemporary development discourse in Africa (p.17-20) because of the many frustrations that the post-independence generation has encountered in both their leaders and the lurking forces of neo-colonialism. African communities have to negotiate justice on two planes: i) the realities of both colonial and post-independence government weakness in service provision and human rights; and ii) the differences between the traditional and modern understanding of justice. The problems that emanated from these two conditions are many including mistreatment by state agencies, high levels of unethical behavior in public office, continuation of indigenous evil practices such as childe sacrifice, and many others. But given the enormous nature of the problem of injustices in the region, the debate on social justice in Africa must put into consideration the meta-justice conditions within which we exist.

\subsection{Regionalization and justice in cosmopolitan governance:}

The study considered it necessary to analyze the governance conditions within which the identified sustainability challenges in the region are to be found. The East African region is the area of study and it provides the 'meta-ethical', 'meta-justice' and 'meta-development' 
environment that shapes both the conceptual and policy implications of the identified problems on sustainable development.

In classical times, the Greek philosophers understood ethics and governance to belong together; that is the dialogues of Plato and Aristotle and several other philosophers were dealing with public ethics issues together with politics. In contemporary times this view of governance has made a comeback. James Brasset and Dan Bulley (2007), some of the key thinkers in contemporary political ethics, brought back this relation in their article, "Ethics and world politics: Cosmopolitan and beyond?". In that paper they discuss how the questions of 'ethics' are framed in world politics and the place of those framings in a cosmopolitan world. Their observation is that given the reality of globalization, most issues of international policy are better analyzed using a cosmopolitan view because it is a better perspective to use in "highlighting our vulnerability to social discrimination, poverty and violence in global perspective" (Brasset \& Bulley, 2007:3). According to them we need to acknowledge the "always-already political nature of ethics" (p.2) makes the analysis of globalization politics and policy richer given the cosmopolitan nature of today's state. In their analysis they identify varieties in cosmopolitanism and how they affect the approach to different global ethical concerns. Different approaches would be preferred to global issues (like military intervention, natural disasters and global social relations) by the different views such as "communitarian cosmopolitanism' or 'post-structural cosmopolitanism'. The implication of such analysis is that the type of social and political ideology that the global or regional governors choose to apply in government has direct impact on the ethics of that region.

Cosmopolitans are of course aware of the common 'nationalist' objection that is usually used to critique the cosmopolitan analysis of global ethical problems. Prakash Chandra (2009) has identified that position as 'integral nationalism' i.e. the exclusive pursuit of national politics and national integrity (Prakash, 2009:61). Integral nationalists object to a cosmopolitan ethical analysis of their actions claiming that they belong to national territories with peculiar ethos. Some even use the Rawlsian view of justice to argue for a nationalist view of global justice: for example, Blake Michael (2001) argued that since i) only the nation-state has coercive powers while the international system does not, and ii) violation of autonomy can only take place in physical terms, then a cosmopolitan view and analysis of justice in not viable. The issue of using Rawls to argue for a nationally bounded view of justice is discussed more in the chapter on 'justice and comprehensive ethical sustainability', but what can be stated here is 
that in international law the doctrine of 'respect of territorial integrity' is used a lot to mask unethical behavior by politicians and their agencies.

\subsubsection{Brock Gillian and justification for a global account of justice:}

And apart from advancing a theory of global justice, this is one of the concerns that Gillian Brock addresses in her book, Global Justice: A Cosmopolitan Account (2009), in which she addresses the cosmopolitan basis of justice. Brock agrees with a Rawlsian view of justice but argues that it should not be 'bound' to national territories; in order to make justice global, it must transcend national boundaries. In her account, she applies the Rawlsian discussion of justice to advance a cosmopolitan theory of global justice. As briefly pointed earlier, Rawls had advanced a convincing conception of 'justice as fairness' in his earlier work A Theory of Justice (1971). In that first book he had advanced principles that would guide establishment of just institutions and its realization in society. He did this by making certain hypothetical assumptions based on the notion of 'original position', but he seems to have changed the nature of that 'original position' in the later book, Law of Peoples (2001). For that reason most reviews of Law of Peoples (LP) focus on discussing the 'continuation' or 'discontinuation' of the Rawls' ideas from A Theory of Justice (TJ) to the LP.

Brock Gillian also discussed the tenets of Rawls' view of justice in the LP and here I consider three of them. The tenets that I consider include: i) the implication of Rawls' reformulation of the 'original position' in LP on his conception of justice, ii) the viability of his assumption of 'boundedness' in his categorization of the Peoples, and iii) the extent to which the assumption of liberalism (or decency) with continuous wealth or prosperity. The discussion of these differences in conception of justice (of both Rawls and Brock) has great implications for the analysis of social justice in regional governments such as the East African Community because there is always a debate in international relations between pursuing and analyzing social justice within national boundaries of the member states or use regional institutions such as the East African Court of Justice.

\subsubsection{Rawls' reformulation of the 'original position':}

In TJ Rawls generated the idea of 'original position', a hypothetical unbiased point of view from which participants in a social contract (society) approach the challenge of setting up just institutions (Rawls, 1971:15). He refers to this hypothetical idea as "the most philosophically favored ... initial choice situation for the purposes of a theory of justice" (p.18). The "original 
position' is conceived with a feature of 'a veil of ignorance', a precondition whereby the parties involved are assumed not to have knowledge of any historical, personal and social status such that they can deliberate and come up with principles of justice that are as fair as possible. Some scholars refer to this as the 'one-time original position' (Stoian, 2012:139-47) to mean that the parties are allowed direct involvement in the deliberations which implies that in the TJ Rawls argued for an egalitarian view of justice. But in LP, which is written for the international community, Rawls reformulates his 'original position', which he calls the "second original position" (Rawls, 2002:39), whereby this time he allows for "representatives of well-ordered peoples simply reflect on the advantages of ... principles of equality among peoples" (p.41). This has come to be known as the 'two-step original position' (Stoian, ibid). In the second 'original position' citizens are not granted direct deliberations on the choice of the principles to guide societal institutions but are represented by delegates.

In the TJ's 'one-step' model of the original position Rawls uses a direct liberal-egalitarian perspective that envisions individual persons that are free and equal to directly participate in choosing the principles of justice. But in LP he insinuates that the 'one-step' model is limited within national boundaries. So at the global level (Society of Peoples) the citizens are to participate through representatives ('two-step'). Brocks notes that critics have pointed out weaknesses in this position, for example Pogge (1989:245) argues that Rawls erroneously assumes that the "representatives of peoples" come from just "domestic institutions" (Brock, 2009:27). There is possibility of 'representatives' who may not really be 'representing' their constituents and therefore choosing principles or norms that promote their selfish-interest. The 'two-step original position' would deny individual members direct representation in the global discourse yet such participation is crucial in Rawls conception of 'justice as fairness'. Therefore to both Pogge and Brock, 'justice as fairness' may have been sacrificed in LP. Rawls seems to be aware of this challenge when he states that, "the government is effectively under the peoples' political and electoral control" and that "the regime is not an autonomous agency pursuing its own ambitions" (p.24). But experience (particularly in cases of African states) shows that the representative regimes usually end up betraying the justice of their domestic electorates.

\subsubsection{Rawls' idea of 'boundedness':}

Pogge's main argument in Realizing Rawls (1989) is that the two principles of 'equal opportunity' and 'difference principle' are good and their application should be extended to 
the global justice quest (find discussion of these principles in the chapter on 'justice and comprehensive ethical sustainability'). But in the LP Rawls assumed that his theory of justice was subject and limited to the existence of bounded political communities as such, which can be assumed to have self-sufficient and self-sustaining political systems (LP, p.38f). This is what frustrated 'global justice' enthusiasts who had looked up to Rawls to be applied in the quest. Rawls is critiqued for misunderstanding the 'practical realities' of the international system (Soniewicka, 2008:45) in the TJ, which is blamed for leading him to assume 'bounded communities' in the LP. To other thinkers, this 'boundedness' is more in terms of wealth than anything. Brock echoes the same observation and critique; she ultimately declares it the unconvincing assumption of "boundedness" (Brock, 2009:26).

Rawls assumed that direct-egalitarian justice discourse would only be applicable in bounded communities (national borders) but not at the global level i.e. 'Community of Peoples'. This assumption is a mistaken view in the sense that restricting direct-egalitarianism within national borders betrays the foundation of the principles of Rawls' earlier view of 'justice as fairness'. In the article, "Open and closed impartiality" (2002), Amartya Sen also adds his pen to the critique and observes that such an assumption fosters a problematic distinction between "open" and "closed" impartiality (Sen, 2002:445). It is problematic it implies that certain a selectable category of states could have justice (impartiality) for its citizens within its boundaries yet reject the same standard being applied to other at a global level. If, in terms of justice, institutions for egalitarian justice can be established within national borders, then it is also possible at a global or regional level because they are all communities of peoples.

Such an assumption would probably have been excusable in the earlier years of Rawls for reasons such as less information about the global interconnection but by the time of writing LP (i.e. 2001) there was surely enough information about the international order for him to know that many of the so-called 'well-ordered' (LP, p.108) states are actually the ones unfairly benefiting from the unjust international order. Brocks notes this when she states that, "it is insulting to characterize the relations between states of the world as cooperative because in reality the relationship is rather one of dominations and coercion" (Brocks, ibid). It is ironical that Rawls whose earlier work (TJ) had greatly turned contemporary political theory towards the cause of justice, with good principles of justice, would not follow through to apply the same principles to international order (LP). Apparently, Rawls would prefer justice at home and lack of justice in the international order. 


\subsubsection{Equating 'liberalism' with continuous 'wealth creation':}

Brocks observes that according to Rawls discussion, a 'liberal' or 'decent' political culture would automatically lead to incremental levels of wealth creation or prosperity (Rawls, 2002:108; Brocks, 2009:23). According to Rawls it is the political culture within the 'burdened' or poor states that is responsible for their poverty (ibid); implicitly, it is a liberal political culture that produces wealth or 'well-orderedness'. This thinking seems to have been the basis for the 'duty of assistance' that the 'well-ordered' states have to carry to help the others.

On that basis he argued for need to or the "duty of assistance" i.e. the "right of intervention" (p.81), as an exclusive injunction on the principle of "non-intervention" (p.37). That is the time that the 'boundedness' of other nations should be ignored according to Rawls' view of international law. But this argument assumes that the 'liberal' or 'well-ordered' and wealth peoples will always have capacity (wealth and means) to 'intervene' in the political order of burdened peoples. In concrete terms, it assumes that liberalism means continuous capacity to make wealth such that there are spare resources to intervene in other nations. But there are situations in international relations that render that assumption erroneous: i) we have observed liberal peoples (such as the USA) get economically strained because of international intervention (such as the 2003 Iraq invasion); ii) it is possibility for non-liberal peoples (such as China) to become wealthy and use that wealth to exert international influence. So the challenge is what if governments, that are unjust, use the erroneous view of equating 'wealthcreation' to 'well-orderedness' to oppress their people? At least this problem is observable in the East African community where governments justify oppressive policies by pointing to better GDP, GNP statistics.

\subsection{Relating Rawls-Brock debate to the East African Community:}

It is necessary to consider the applicability of the decisions taken about the issues raised in the Rawls-Brock debate to the framing of the East African Community and its social justice implications. The following are some observations that have social justice implications:

a) The first issue that is applicable is that of the 'original position'. Apparently the EAC decided to settle for the 'two step original position' in the sense that Rawls conceived in the Law of Peoples. Article 9 of the Treaty for the Establishment of the East African Community (1999) establishes the 'East African Legislative Assembly’ (EALA). Then 
Article 48 details the choosing of the Membership of the Assembly. The EALA is made up of nine Members elected by each Partner State; ex-officio members consisting of the Minister responsible for the East African Community Affairs from each Partner State; the Secretary General and the Counsel to the Community. Currently, the Assembly has 45 elected Members and seven (7) ex-officio Members - all totaling a membership of 52 (EAC Treaty, 2002: Art.9, chp.9). This implies that the EALA uses the 'two step' or modified version of Rawls' 'original position' where there is no direct egalitarian participation in deciding the nature of society on the side of the citizens.

These legal provisions clearly indicate that the EALA does not foster a direct egalitarian justice. The Treaty states that members of the EALA, "shall represent as much as it is feasible, the various political parties represented in the National Assembly, shades of opinion, gender and other special interest groups" in partner states (Art. 50). At first glance it may appear like an egalitarian justice is provided for in this 'two step' arrangement of representation, but on close scrutiny, one finds that Art. 14 could effectively give powers of legislation to the Council of the EAC. The Council is given powers to "initiate and submit Bills to the Assembly" (Art. 14(b)) but it is also given powers to regulate the budget of the Community (Art. 14(e)) and this means that it controls the pulse of the EALA.

Korwa Adar (2011) has basically characterized the EAC project as one being pushed by "the East African ruling elite" (Korwa, 2011:7, 10). In Korwa's view this elitist undercurrent has been there from the first experiment with integration that collapsed in 1977 and it still manifests itself in the legal provisions establishing the EALA. That is why some scholars argue that "direct elections would be the preferred method" for the EALA (Wanyande, 2005:68).

b) The other aspect to consider is the concept of 'boundedness'. The first issue to raise is that if by 'bounded' Rawls meant a cultural rather than a territorial type of it, then in the case of the EAC the former does not suffice because the region has more similarities than differences in terms of culture. There is no single member country of the EAC that could reasonably claim cultural boundedness which is significantly distinct from the others. The only slight difference that is worth mentioning is the Anglophone and Francophone usually cited as the difference between Kenya-Tanzania-Uganda on one 
side and Burundi-Rwanda on the other (Mwakikagile, 2014:569). But a deeper examination of that distinction will easily reveal that it is shallow; the colonial masters had found these people sharing many cultural and historical ties since time immemorial and they tried to drive a wedge through them for the colonial master's economic and political benefit. But since Rawls allows for the possibility of 'reasonable pluralism' and 'diversity' among reasonable peoples with different cultures (LP, p.11), then we can surmise that cultural boundedness is not what he meant and it does not apply to the EAC.

The territorial conception of boundedness is therefore the one which could have analytical implications for the EAC. If the Community was to take boundedness to its logical conclusion then it would entail exclusivity of the internal politics of each country. The question is whether all the member countries of the EAC would be classified as 'burdened' states if we use Rawls' classification; probably they are all 'burdened' but in comparative terms, Kenya, which has a richer economy and a higher GDP and most liberal, would act as the 'well-ordered' among the pack. But ironically we find Uganda and Burundi with a lesser GDP intervening in pacifying the region more than the rest (see: Jeng, 2012:261f).

But when we consider this 'intervention' in the wider global context, Uganda and Burundi were only able to go and be peacekeepers in Somalia because other more influential countries like the USA paid the soldiers bills. So Rawls was not entirely right in thinking that only the 'well-ordered' (and ipso logico wealthy) countries could carry the duty of assisting others as the EAC experience demonstrates.

\subsection{Regionalization and the ethics of public governance:}

Governance (or public administration), is a sub-discipline of the political and administrative sciences. It is both an academic discipline that grapples with classical questions of human society and political philosophy (Sheeran, 1993) and also a field of public praxis that deals with the interpretation and implementation of legislative and executive directives and policy. This study investigated ethical aspects of governance as praxis which lays emphasis on the structure and operation of public offices and systems, bureaucracies and organizations, including budgeting, personnel, and formal and informal internal controls. PA has developed into a multidisciplinary field of inquiry and practice with no single subject-matter. 
Apart from being a multi-disciplinary field, public administration also takes place across various levels of governance such as local, national and regional levels. In this particular study we focus on regional governance of the EAC and being a complex level of administration, the governance approaches used and ethical issues that arise at that level are different. Ethics is increasingly becoming part of the discourse of cross-national regional government administration. This is the trend not only in developed but also in the developing countries. It is the trend to no longer ignore ethics in the political and democratic discourse because many administrators and researchers in PA are increasingly appreciating the ethical dimension in public administration and political systems. For example, the California Local Government Ethics Ordinance (Simmons, et al, 1998) states that,

\begin{abstract}
Maintaining public trust in the integrity of democratic institutions is essential to the success of representative democracy. In that fundamental sense, ethics and democracy are intertwined. Political ethics are the basis by which citizens judge official actions, attach responsibility and exercise accountability. An ethical governmental process is a precondition for making good public policy (Simmons, et al, 1998:3)
\end{abstract}

That means that sustaining any political arrangement in the long term is no longer an amoral issue because it demands accountability to the constituents. Kishore Raga and Derek Taylor (2005) have argued that, "All government departments have to be efficient because they have to ensure value for taxpayers' money. Efficiency encompasses the qualitative and value-laden expectations of the society" (p.1). This means that public administration, by virtue of its nature, is value-laden and value-implicit; and this implies that ethical values and principles come into play when accounting for administrative decisions and actions. Value-laden means that decisions and actions taken carry ethical connotations and the defensibility of the same and evaluation means appealing to the ethical dimension of administration. That's why they also argue elsewhere that, "Training in ethics is essential to ensure that officials act confidently, knowing they have organizational support, rendering efficient, effective, ethical, and accountable public service" (Kishore \& Taylor, 2005b:22).

The same concern applies to the east African region; almost all the major governance challenges and the policies related to them raise ethical questions that cannot be ignored if the 
governance of the region is to be sustainable. For example in East Africa and the Horn: Confronting Challenges to Good Governance (2005) Bekoe and other authors analyze a number of pertinent government challenges in the region ranging from conflict, arms proliferation, identity politics, ethnicity, among others. One article by Zachary Lomo dissects the problem of Internally Displaced Persons (IDPs) in the region and according to him, dealing with the IDPs challenge entails balancing between humane treatment of fellow east Africans who are running away from fighting and the possibility of compromising the security of a given nation that welcomes them (Lomo, 2005:37-54). In Lomo's view, the member states on the regional bloc need to develop an integrated approach in order to coordinate their handling of the challenge of IDPs. But there are implicit ethical challenges that he does not give enough attention. For example on $25^{\text {th }}$ July 2013 President Jakaya Kikwete issued an executive order giving around 35,000 persons from Burundi, Kenya, Rwanda and Uganda up to 11th August to leave Tanzanian soil or risk forceful eviction. The Tanzanian media labeled them 'irregular immigrants', 'criminals', 'illegal immigrants' who want to destabilize their country. This exercise caused a humanitarian crisis especially at the border regions of countries like Uganda and Rwanda where most of the evictees fled. In most cases these people do not have enough to live on and they continue to suffer in squalid conditions having lost their livelihoods. Reports indicate that families that have lived in Tanzania for decades have been torn apart because the order declared the children born to Tanzanian fathers were bona fide citizens while their mothers are not. Some analysts blame this episode for Tanzania's isolation by the so-called 'Coalition of the Willing' $(\mathrm{CoW})^{14}$ i.e. Kenya, Uganda and Rwanda as far as fast-tracking the East African integration is concerned. This is one illustration of why the region needs leaders who are versed with the dynamics of administering a regional bloc or grouping of nations. It should however, be noted that the leaders of the nations grouped as the CoW reject the terminology because it was merely a press concoction and could cause isolation of some member countries in the bloc; they prefer to be termed as focusing on the northern corridor (or the northern artery of the region).

\footnotetext{
${ }^{14}$ The term 'Coalition of the Willing' entered in the region's media reports after an apparent rift seems to have develop between the states that make up the EAC with Kenya-Uganda-Rwanda on one side and TanzaniaBurundi on the other. The study analyses the implication of this development more in the chapter on 'political development in the EAC'. They prefer to be termed as focusing on the northern corridor (or the northern artery of the region).
} 


\subsubsection{Metagovernance and regional states:}

As mentioned earlier in the introduction, regional grouping of states require a different approach to governance and, there is need for competence in their administration; the art and science of doing that is known as metagovernance and some thinkers have defined it as 'governance of governance'. One of the key thinkers on the concept of metagovernance is the scholar Bob Jessop. He has been influential in the shaping the concept of metagovernance albeit he does so more from the perspective of the European Union (EU). In his book, State Power: A Strategic-relational Approach (2008) he writes that, “...the emergence of metagovernance in the European Union [is] part of the more general change in the forms of statehood. Metagovernance is a response to governance failure" (Jessop, 2008:218). He advances that there are three basic modes of metagovernance, namely, 'meta-exchange', 'meta-organization' and 'meta-hierarchy'. The first deals with re-designing markets; the second is the re-designing of organisations and the third is organising the conditions of self-organization. Apparently, as regionalisation advances across the globe, particularly in Europe, governments get overwhelmed or fail to deliver; the solution lies in metagovernance. It is about the engineering of political and social environment to ensure that government works. In his view, there are three ideal styles or combinations of metagovernance, and these include the i) hierarchical, ii) network, and market styles (Jessop, 2011:106-23). Jessop that,

\section{If the market, hierarchies, and peer governance are three modes of managing human affairs, then each has a meta-level where they are balanced and calibrated to deal with failures. The calibration of the three in an overall framework is the subject matter of meta-governance. (Jessop, 2011)}

So in Jessop's view, the 'metagovernor' needs to be versed with administration of public or private settings that exhibit any of the three types or their variations. Hierarchical means the old-fashioned way of governance that laid emphasis on top-bottom structures and respect of their positions in any given society. Network metagovernance means the administration of public or private entities through consciously established networks; it is more of a peer-to-peer approach that does not consider one level of authority to be superior to the other. On the other hand, market metagovernance places emphasis on the role of the market taking the lead in shaping or framing of the community. Suffice also to mention that there are also some scholars who think that a combination of all is a better option for future administrators other than concentrating on one of them (see: Mueleman, 2008). 
A hierarchical power arrangement is where authority is arranged in such a way that the higher the power grid, the more sacred the one in charge is portrayed or viewed to be. These arrangements could be upwards (vertical) or side-wards (horizontal); they could also be formal or informal and direct or indirect. From the etymological roots of the Greek hierarkhia, which meant the 'rule of the high priest', this type of power arrangement considers the office holder in sacred terms; sometime mildly and sometimes extremely. This sacred perspective was carried into both private and public administration and it has ethical implications. Donald Vredenburgh and Yael Brender (1998) carried out an analysis of the ethical nature of hierarchical power and the implications of its abuse. They developed a 'process' model (p.1340) of analyzing the impact of abuse of hierarchical power which contains two parameters i.e. disrespect of persons and interference with job performance. A cursory observation of power dynamics in the EAC shows that this could be the most prominent expression of power relations in the region. And it has caused a lot of ethical challenges in the political and administrative processes which the study considers a bit in the subsequent chapters.

The network type means an interlocking system of power relations or an interconnected group of power holders. In metagovernance it is mainly expressed in terms of public-public and public-private partnerships on different projects (Sørensen \& Torfing, 2009). The 'publicpublic' type refers to national government or state authorities collaborating on a given project or policy. On the other hand the 'public-private' type of network metagovernance means collaboration between a state organ and a private corporation in the execution of a given project. Sørensen \& Torfing argue that this type of metagovernance is very useful and could be made to foster democratic and effective administration (p.240). They mention four main purposes that network metagovernance can serve: i) regulating standards across the region, ii) conflict resolution that result from national policy differences, iii) regional planning purposes, and iv) mobilizing all the stakeholders in the region (p.234).

In the East African Community there seems to be a move towards this type of power arrangement. Many organs have been put in place and other projects have been initiated in the region. For example the Standard Gauge Railway line (2013) from Mombasa to Kigali, the Single Tourist Visa (2013), the Transnational Oil Pipeline (2014) from Hoima to Lamu and the coordinated Citizens Identity Card registration. The other organs include: East African Development Bank (EADB), the Civil Aviation Safety and Security Oversight Agency 
(CASSOA), the Lake Victoria Basin Commission (LVBC), the Inter-University Council for East Africa (IUCEA), Lake Victoria Fisheries Organisation (LVFO), and recently the East Africa Standby Force (EASF), among others.

But the first observation to make about the direction that 'network metagovernance' has taken in the EAC, is that it seems to be more the 'public-public' type. Most projects that are being undertaken are government collaborations and very few or low level project involve the private sector at the regional level. And most of the funds being used in these projects are provided through government or public means. But the other thing to note is that in some cases this 'network metagovernance' has not been handled well and some projects or policies have either been delayed or misdirected. For example the policy of citizens using citizen IDs to travel around the region and was slated to start by January $1^{\text {st }} 2014$, but reports indicate that the some member countries were reluctant to implement the policy with the usual division of BurundiTanzania going slow in comparison with Kenya-Uganda-Rwanda. Secondly it is also reported that not many citizens are informed or involved in these ventures and thus they are not enthusiastic about them. As a result by $19^{\text {th }}$ February 2014 statistics from the Rwanda's Directorate of Immigration and Emigration indicated that only 83,010 Rwandese, 29,907 Ugandans and 9,575 Kenyans had used their IDs to move in or out of the country (Mbanda \& Kabeera, 2014).

\subsubsection{The EAC Treaty and its principles of regional governance:}

In order to effectively govern the revived EAC, a new Treaty had to be devised in so as to resolve some of the legal loopholes in the earlier regionalization project that collapsed in 1977. This Treaty for the re-establishment of the East African Community was signed on $30^{\text {th }}$ November 1999 and entered into force on $7^{\text {th }}$ July 2000, following its ratification by the three original Partner States, Kenya, Uganda and Tanzania. The Republic of Burundi and the Republic of Rwanda acceded to this EAC Treaty on $18^{\text {th }}$ June 2007 and became full members of the Community with effect from $1^{\text {st }}$ July 2007.

The framers of the 1999 Treaty inserted certain major principles that are aimed at guiding the governance of the regional bloc. These principles are contained in various provisions in the Treaty; in considering the governance of this group of states, these principles are of importance and if the EAC is to be sustainable in the long run, the efficacy of these principles require 
evaluation. Many regional governance analysts agree that some principles are necessary in order to find some level of conformity in the governance and to guide regional leadership; but they need to be aligned with good governance and in tandem with the aspirations of the citizens (Best, 2008; Olinski, et al, 2014). The principles contained in the 1999 EAC Treaty are hereby reviewed for their implementability and adaptability in the east African experience. However, since a number of principles are conflated in the Treaty in this section the study selected some prominent and usually contentious principles for review purposes in relation to the governance and development sustainability of the EAC.

\subsubsection{EAC principle 1: People Centeredness:}

The 1999 EAC Treaty is laced with the language of people-centeredness all through the document; more of this principle is found in Article 5. But in other section we can also find specific reference to this principle; for example Art. 5:3(d) specifically states that: "the strengthening and consolidation of the long standing political, economic, social, cultural and traditional ties and associations between the peoples of the Partner States so as to promote a people-centered mutual development of these ties and associations" (EAC Treaty, 1999). This focus on the peoples of the region is applaudable and quiet necessary given that one of the causes for the collapse of the EAC-1 was a disconnection from the general citizenry of the region. Consequently, Articles s 120, 121 and 122 give special attention to the women of the east African states as the driving force behind the development of the region. The focus on the people raises the issues of human rights and consultation of the people concerned to the foreground of the development and governance practices in the region, at least in writing. In regards to this 'people-centeredness' the current East African Legislative Assembly (EALA) is debating a new Bill that is aimed at giving the people legal cover as they form cooperatives and engage in different activities for development. The bill is termed, the EAC Co-operative Societies Bill, 2013. The bill is being pushed on the premise that it will enhance trade and development among the people by encouraging grassroots formation of cooperative groups. The EAC Secretariat has also undertaken programmes that seek to involve the peoples in the integration process; for example the organization of activities such as the EAC military sports, the cultural events, among others.

\subsubsection{EAC principle 2: Balanced Sustainability:}

Article 5:3(a) of the Treaty expressly states that the regional bloc shall seek, "the attainment of sustainable growth and development of the Partner States by the promotion of a more balanced 
and harmonious development of the Partner States". This is what the study referred to as the 'balanced sustainability' principles in the governance and development of the EAC. In one sense, in order to attach concrete meaning inside the spirit of using the terms 'balanced' and 'sustainable', it must be noted that framers sought to overcome: i) the imbalanced development whereby some partner states benefit unevenly from the cooperation; and ii) the pitfalls of modern development that has been deemed unsustainable due to its traditional focus on mere economic growth and material consumerism at the expense of the climate, nature and future generations.

One of the established causes of the collapse of the earlier EAC was imbalanced growth that the member states were realizing; some saw it as 'unbalanced' and more beneficial for some more than others. Tension grew when some countries tried protectionism in order to 'correct' these imbalances in trade. For the case of the relationship between Kenya and Uganda at the time, Idi Amin and Jomo Kenyatta devised one policy after another against each other (such as blocking Uganda-bound goods from passing through Kenya; and retaliation from Uganda by switching off electric power to the whole of western Kenya) until the EAC-1 could not stand such disagreements anymore and it collapsed.

\subsubsection{EAC principle 3: Mutual Benefit:}

Article 6(f) of the Treaty states that the cooperation will be for "mutual benefit"; and in Article $5: 1$ it is expressed that, "The objectives of the Community shall be to develop policies and programmes aimed at widening and deepening co-operation among the Partner States in political, economic, social and cultural fields, research and technology, defense, security and legal and judicial affairs, for their mutual benefit". The traditional meaning of the term 'mutual' conveys a meaning of free and respectful reciprocity that is shared in common among the concerned parties. In legal terms, this would imply that there should be some form of contractual relationship. Either way, the parties involved are presumed to have mutual admiration for each other and to share common interests.

\subsubsection{EAC principle 4: Variable Geometry:}

Article 1(e) of the Treaty states that the Community will apply the principle of variable geometry which allows for progression in cooperation among groups within the Community for wider integration schemes in various fields and at different speeds. The Treaty explains that 
"variable geometry" would allow for 'flexibility' and progression in co-operation between or among a given sub-group of members within the integration. This implies that some members of the Community can choose to cooperate on a given issue or project and move ahead at a given speed that may be faster whilst waiting for other members to catch up or join the project. This is the most reasonable argument raised by political commentators on the regional bloc's inclusion of the 'variable geometry' principle in the Treaty was to overcome the intractable impasse that earlier EAC-1 suffered when 'consensus' could not be attained. When political differences emerged among the ruling parties within the member states, the possibility of consensus became difficult thus providing one explanation for the collapse.

This principle has been invoked or cited by analysts within the new EAC-2 framework, (see: Ajumbo, 2013) particularly in reference to the 2013-2014 series of consultative meetings that took place among the Heads of States of the three member countries of Kenya, Uganda and Rwanda; with little or no participation by the other two (Burundi and Tanzania). The three countries met in various capitals of the region to discuss issues of common interest such as common market, infrastructural development, among others. Given those concerns, the challenge that 'variable geometry' poses as far as the quest for the sustainability of the EAC goes, is quite enormous. The invocation of variable geometry, brings out concerns over good governance and public ethics, among other issues; it brings into play a number of contrasts in governance styles and development approaches among the member countries.

\subsubsection{EAC principle 5: Consensus:}

The concerns about the challenges that emanate from the application of the principle of variable geometry inadvertently raise the question of compatibility between that principle and that of 'consensus'. The Treaty holds that "the decisions of the Summit shall be by consensus" (Art. 3); and by provisioning for that principle at the highest level of decision making, a serious challenge emerges. This is because one of most discussed cause of the collapse of the EAC-1 project was irreconcilable disagreements among the leaders of the member countries of the time. (More on this cause is discussed in the chapter on EAC integration and the challenge of sustainability). Because of the leaders' personal differences, it became difficult to attain consensus on anything or policy direction for the bloc. It was therefore reasonable of the framers of the new Treaty for EAC-2 to devise a legal tool to navigate around such a nasty situation in case it emerged in the new project; in order to achieve that, they inserted the ‘variable geometry’ principle. 
A closer examination, however, of the insertion of both the principles of 'variable geometry' and 'consensus' in the new Treaty apparently reveals some incompatibility challenges. The Treaty adjures the Summit to decide using the consensus principle; this is quite ironical given that from the history of the collapse we learn that consensus was quite difficult to attain. The Summit is constituted by the Heads of State of the member countries; if they are to make decisions by means of consensus as provided for under Art. 3, then it would not only make decision making so slow but also consensus an uphill task. At that same time the Treaty provides for 'variable geometry' which is in effect allowing for sub-groups or cliques of member states to be formed to push for certain issues of common interest. The two principles seem incompatible and likely to cause more rifts or confusion in decision making within the East African Community. Since decision making by the leaders is quite important for the sustainability of the regional bloc, these principles have great bearing on the bloc's future.

\subsection{Conclusion:}

The above review is a survey of selected and indicative literature aimed at identifying the problem that the study focused on. This section has reviewed selected relevant literature and identified the major research gap as the less than necessary attention given to the ethical reconceptualisation of sustainability. It also highlighted issues of global governance and justice as critical to the attainment of sustainable governance and development of the East African Community. Specifically the review found a conceptualization 'gap of divergence' between the 'Market inspired sustainability' (MIS) logic and the 'Traditional African sustainability' (TAS) logic. The review therefore heightened the need for generating a more viable meaning of sustainability such that its applicability to the EAC is both at the theoretical and practical levels. 


\section{CHAPTER III}

\section{EAC INTEGRATION AND THE CHALLENGE OF SUSTAINABILITY}

\subsection{Introduction}

This chapter discusses the issue of EAC integration and the challenge of sustainability. It delves into drawing lessons from the past experience of the collapse of the first EAC project. It examines the emergence of the integration idea from the colonial era into modern times to understand the deeper currents that shaped and are still shaping the integration agenda. Sections of the chapter discusses the revival of the EAC and the possible future(s) of the regional bloc; then it discusses the difference between the colonialist's and natives' vision of the regionalization project in order to understand the forces that may threaten the sustainability of the bloc. The last section briefly considers that capabilities of the native leaders to govern the regional bloc.

\subsection{Integration and formation of regional states:}

In discussing the issue of regional integration we have to note that there have existed big states in the past; and one choose to use a historical perspective by starting from the large complex empires builders of the past such as the ancient Egyptians, Assyrians, Babylonians, Chinese, Persians, Arabs and Romans among others. It would have been interesting to examine how the lessons learnt by humans from those experiments would be applicable to building bigger states in contemporary times. But given the scope of time available for the study such analysis was not feasible; nonetheless, there are recurrent themes and challenges of a social, economic, governance and even spiritual nature that are still relevant to today's regional integration projects. In this study some of the recurrent questions and challenges pertaining to the framing 
and sustaining big multi-ethnic states inspired the analysis of the East African Community regionalization project.

The conventional meaning ascribed to 'regional integration' is that it is a process by which two or more nation-states voluntarily agree to cooperate and merge some or most of their administrative structures in order to achieve social and economic goals. The key thing that differentiates contemporary 'regional integration' from the ancient of colonial empire building is the voluntary agreement by the parties involved unlike the latter which was attained by conquest or military might. In modern regional integration there are three conventional stages that are assumed for the cooperating nation states have to undergo, namely, i) economic integration, ii) single market, and iii) political federation (McCormick, 1999). It is reported that the first expression of modern regional integration on a voluntary agreement basis was between Prussia and Hesse-Darmstadt (now in present-day Germany) in 1828 (Mattli, 1999:1). As the theme of Mattli Walter's quoted work underscores, in analyzing regional integration, one of the key things to do is to explicate the 'logic of integration' (p.3) that drives the process. So despite the complexity of regional integration, there is an underlying logic that explains why and how the integration takes place and its nature. A similar approach was applied in this section on analyzing the integration of the East African Community and correlating it with the question if its sustainability.

\subsection{The EAC project: from colonial protectorate-ism to indigenous regionalism?}

The current political conglomerate of nations referred to as the East African Community (EAC) is made up of five countries, namely, Burundi, Kenya, Rwanda, Tanzania and Uganda and the region is located between: $5^{0} 30^{\prime \prime} \mathrm{N}, 12^{0} \mathrm{~S}$ and $28^{0} 4^{\prime \prime} \mathrm{E}, 41^{0} 50^{\prime \prime} \mathrm{E}$. The peoples and nations in this region have been interacting for millennia through trade, marriage, culture, among other ways (Wright, 2005); but the modern political cooperation was started by colonial masters towards the late 1890s with the construction of the 'Uganda Railway' (Nzioki \& Tostensen, 2005:1) which was completed in 1901. This makes the EAC the earliest regional integration project on the African continent. The stated goal of the EAC is 'to promote sustainable development and foster a prosperous, internationally competitive, secure, stable and politically united region'.

From reading Korwa Adar G. (2005, 2011), a scholar on African regionalization, we decipher two modes of the EAC integration project: i) the colonialist-driven EAC, and ii) the nativedriven EAC; the former was pushed by the colonialist mainly for purposes of economic 
exploitation, whilst the latter was pushed by the native pan-Africanist post-colonial leaders, namely Jomo Kenyatta (Kenya), Nyerere K. Julius (Tanzania) and Obote A. Milton (Uganda) for purposes of exerting African independence. The complexities emanating from those modes of EAC regionalization birthed, in analytical terms, two projects i.e. EAC-1 and EAC-2; which have so far undergone five phases of the cooperation. Phase-1 (1903-1947) was initiated by the colonialist but with nascent institutional mechanisms; Phase-2 (1948-1961) saw a better organized institutional framework with the establishment of the East African Central Legislation Assembly; Phase-3 (1961-1967) was another restructuring which failed to decentralize the concentration of economic and administration services in Kenya; the postindependence Phase-4 (1967-1977) saw native African leadership and participation but it was doomed to collapse due to political, structural and personality challenges thus marking the end of the EAC-1 project. The 1993 Agreement for the Establishment of a Permanent Tripartite Commission (between Kenya, Tanzania and Uganda) revived the cooperation and thus igniting EAC-2 and Phase-5 (1998-date) of the project. Below is brief table indicating the phases through which the EAC project has undergone and the general ideological orientation that shaped given phases or periods of the regional integration:

Tab. 3.1: Phases of the EAC project and ideological orientations:

\begin{tabular}{|c|c|c|c|}
\hline Project & Phase & Period & Ideological orientation \\
\hline \multicolumn{2}{|c|}{$\begin{array}{l}\text { Moot stage (by colonial } \\
\text { masters) }\end{array}$} & 1895 & $\begin{array}{l}\text { Colonial protectorate-ism } \\
\text { (manipulative agreements and } \\
\text { military force) }\end{array}$ \\
\hline \multirow{4}{*}{ EAC-1 } & Phase-1 & 1903-1947 & $\begin{array}{l}\text { Colonialism - nascent colonial } \\
\text { institutional mechanisms }\end{array}$ \\
\hline & Phase-2 & $1948-1961$ & $\begin{array}{l}\text { Colonialism - East African Central } \\
\text { Legislation Assembly }\end{array}$ \\
\hline & Phase-3 & $1961-1967$ & $\begin{array}{l}\text { Colonialism - concentration of } \\
\text { economic and administration } \\
\text { services in Kenya }\end{array}$ \\
\hline & Phase-4 & 1967-1977 & $\begin{array}{l}\text { Independence struggle - Military } \\
\text { fascism affects the region (esp. } \\
\text { Uganda) }\end{array}$ \\
\hline \multicolumn{2}{|c|}{$\begin{array}{l}\text { Disintegration (Collapsed } \\
\text { stage) }\end{array}$} & 1977-1991 & $\begin{array}{l}\text { Varying political ideologies (effect } \\
\text { of Cold War era) }\end{array}$ \\
\hline \multirow[b]{2}{*}{ EAC-2 } & Phase-5 & 1991-1998 & Re-establishing EAC cooperation \\
\hline & Phase-6 & $1998-2005$ & $\begin{array}{l}\text { African cooperation - Agreement } \\
\text { for the Establishment of a }\end{array}$ \\
\hline
\end{tabular}




\begin{tabular}{|l|l|l|l|}
\hline & & $\begin{array}{l}\text { Permanent Tripartite Commission } \\
\text { (between Kenya, Tanzania and } \\
\text { Uganda) }\end{array}$ \\
\cline { 2 - 4 } & Phase-7 & 2005-date & $\begin{array}{l}\text { African regionalism - Fast-tracking } \\
\text { the EAC to political federation }\end{array}$ \\
\hline
\end{tabular}

The idea of the integration of the EAC in modern times and terms was mooted by the dominant colonial masters, the British, in 1895. This was during the early years of the colonization of the peoples of this region and it was characterized by what I have termed as 'colonial protectorateism', which basically involved coercing or forcing indigenous kings and chiefs into manipulative agreements; and in some cases the outright use of military force. As the colonialists established their rule, they set up nascent colonial institutions such as military garrisons, and outposts to curve out spheres of control in various areas of the countries in the region. These were mainly used as colonial display of power but played a key role in coordinating the colonial economy. Due to rising critique of colonialism in the 1940s, the British set up the East African Central Legislation Assembly (EACLA) in order to show a semblance of representative leadership but the office bearers of the earliest EACLA were almost 98\% non-indigenous; the member countries of this bloc were Kenya, Tanzania and Uganda. As the indigenes increased their demand for independence and the cost of the colonial project increased, by the 1960s the British started to concentrate their administrative services in Kenya due to its coastal access and this was to later to become a major historical cause of development disparities among the people of the region which the regional integration has yet to overcome up to now. The Cold War animated the struggle for independence and, as in most parts of Africa, the many newly independent administrations resorted to military rule rejecting any call for democratic rule by former colonial masters who lacked the moral authority to do so; having been even worse in their treatment of the indigenous people during colonial rule. Unfortunately, in East Africa, each member country opted for its own political path and this contributed a lot to the disintegration of the bloc. From the 1990s, however, there was revival of the EAC integration project which is currently making measured progress albeit with various challenges to its sustainability.

\subsection{Justification of the East African Community regional integration project:}

In examining the sustainability question as regards regionalization projects, it is necessary to consider the reasons why such a project should be undertaken. In this section the study considers a selected number of justifications that are usually advanced in the case of the East 
African Community. It should be noted however that since this integration project started while the east African countries are still under colonial rule, it is important to distinguish between the motivations that colonial masters had in mooting the integration idea and those of the indigenes for carrying forward the same project. In this section the study considers mainly the justifications that pertain to the indigenous people; those of the colonial masters are considered under the section on 'modes of EAC integration'.

\subsubsection{Economic sense:}

In a blog article, "The future of East African integration" (2013), Dr. Sezibera Richard, the current Secretary General of the East African Community has continuously stressed that the highest priority of the integration project is 'trade and investment' in the region. Of the twelve priority areas that he lists as the issues for the regional bloc to focus on, almost 9 of them are about economics (Sezibera, 2013). Perhaps the biggest proponent of east African integration and the most pan-African among the political leaders in the region at present, President Museveni of Uganda (Barigaba, 2012), has on numerous occasions used the economic reason for regional integration of east Africa countries (Museveni, 2013).. However he argues that mere economic integration needs to be topped up with political integration or federation in order to deal with issues that a private-sector driven integration cannot invest in such as security; and he has continuously urged the whole of Africa to take a similar path:

The greatest disadvantage Africa faced at Independence, ever since $1957 .$. was political balkanization. The foresight by the Lagos Action Plan, which pointed out the need to be organised into blocs for trade in different zones of Africa in order to tackle this balkanization was correct. Integration should have two dimensions - economic and, where possible, political integration. In East Africa, we are aiming at both - political and economic integration. The people of East Africa have for decades, been yearning for an East African Federation that will deal with both political and economic integration. This is the ultimate goal of the EAC. The bloc's people travel farther because they are either similar or compatible, and aiming at political integration, leading to the Federation of East Africa (Barigaba, 2012).

His ideas are shared among many east Africans that their economies are too small to have any meaningful competitive advantage in the global economic system. Therefore the drive to merge 
the economies of east African countries would make not only a bigger market but also provide opportunities to carry out big joint infrastructural projects than would normally be cumbersome for individual countries to undertake.

\subsubsection{Existential sense:}

Some reporters and analysts have argued that some of the real and perceived differences among the member countries plus the slower than necessary integration pace of the East African Community are an expression of failure to share a common existential goal. After following proceedings of the November 2013 EAC Peace and Security conference, reporter Christopher Kayumba observed that, "there seems to be no common existential threat to all the five states; yet, as history has taught us, such unions are made more viable by the fear of a common enemy" (Kayumba, 2013). Kayumba's musing that the existential threat that may glue the regional bloc together may be a security one, has perhaps been vindicated by the recent increase in terrorist attacks (in form of Al-Shabab ${ }^{15}$ ) and rebellions plus civil war in places like Burundi, SouthSudan and the Democratic Republic of Congo.

Chidi Odinkalu (2013) has discussed that, "In Africa today, violence presents a monumental and potentially crippling challenge to the continent's future. Violence threatens the lives and livelihoods of millions of ordinary people and their families. It threatens the future of legitimate and effective government, and the very existence of many African countries." (Chidi, 2013). He echoes what is obvious and has been a concern for African analysts for decades; but one would imagine that existential posed by violence should evoke positive energy to come together and solve it; instead the threat has persisted. One way to approach this threat is to build strong public security institutions through regional integration; but on the other hand, it contributes to the challenge of unsustainability. In the East African Community, flashpoint violent episodes such as: the 1994 Rwanda genocide, the 2007 Kenyan election-triggered, the 2009 Buganda riots in Uganda, the 2013 South-Sudan civil war meltdown, unravel underlying fissures that threaten the bloc's sustainability.

\footnotetext{
${ }^{15}$ The word 'Al-Shabab' literally means 'the youth'; this group has been engaged in radical and violent Islamic campaigns in the east African nation of Somalia which has been a failed state for over two decades since the 1990s. Most reports indicate this is an indigenous Somalian terrorist group with ideological and possibly practical affiliation with the infamous global terrorist group, Al Qaeda.
} 
In reality, these violent episodes expose deeper challenges to the region; and the African scholar, Mahmood Mamdani (2011) has identified one of them as a confused conception of 'citizenship'. Almost in the same vein as Museveni's usual criticism of the colonial balkanization of African communities, Mamdani observes that one of the legacies of colonialism was confusing the African's conception of 'citizenship', which has served as a root for many violent conflicts in the region. In a June 2011 keynote address at an East African Legislative Assembly Symposium, Mamdani implores east African scholars and leaders to go beyond 'a genocidal concept of tribal homeland' (Mamdani, 2011). He argues that one of the challenges to achieving a political federation in the East African Community is the existence of the 'two post-colonial traditions of citizenship: territorial and ethnic' (ibid). He urges the EAC to go beyond a citizenship that promotes allegiance to the many tribes in the region; and to foster a citizenship that identifies with territory in order to achieve political federation. Since the EAC is considering admitting other states in the region, especially South-Sudan and Somalia, into the regional bloc, eruption of violence based on ethnic lines in these countries would pose a real existential threat to the regional bloc and place a question mark on its sustainability. Some scholars have raised concerns over the admission of such socially unstable countries into the bloc (Zambakari, 2013).

As mentioned earlier, this existential argument for the pursuit of the integration of the east African states has even been made to be all the more important given the resurgence of radical forces like Islamic radicalism in form of groups like Al Shabab, Al Qaeda, among others. In the book, Seeds of Conflict (2004), Frans Jozef Servaas and Bernardin Mfumbusa observed that as early as the 1980 s leaders in the east African region were already under immense pressure to introduce radical Islamic Sharia laws (Servaas \& Mfumbusa, 2004:64-65). It should be noted however, that Islam per say is not the actual existential threat to east African nations because it has been part of the region's culture for hundreds of years after the encounter with the Arabs; but the radical version of Islam is the real threat. East Africans had generated a formula for living peacefully with Islam but its radicalization has increasingly become an existential threat. The recent radical Islamic inspired terrorist attacks in the region attest to that conclusion. Similarly, instances of radical militarized Christianity in form of groups like the Lord's Resistance Army (LRA) that have terrorized among other countries including Uganda, South-Sudan, DR Congo, among others, pose an existential threat to the region. These challenges cut across national borders and they require concerted efforts from all the member countries of the EAC. 


\subsubsection{Relational sense:}

The peoples of the east African region are more closely related than many western oriented scholars acknowledge. It is therefore logical to conclude that the modern states that make up the EAC are themselves 'mini-regionalization' projects. There are also a number of cases where the arbitrary manner in which the colonialists drew the borders of the colonized states divided up hitherto single communities and this problem is still a cause of many political and civil conflicts in the region (Fisher, 2012). For example the Luhya (Samia) exist in both Kenya and Uganda; the Masaai exist in both Tanzania and Kenya; and the Luo exist in all the three countries. Then there are those groups that share so much cultural overlaps that they are easily identifiable as belonging to the same ethnic groups; this is not only in terms of cultural practices but also in linguistic terms. For example the Wanga kingdom in Kenya are almost identical to the Baganda in Uganda; the Kisii and Meru are said to have migrated from Uganda's Mt Elgon side; the Baganda and Basoga in Uganda are almost identical in everything. There are therefore more natural reasons for the peoples of the EAC to form a community and federate. It would make sense to describe the EAC regionalization as a natural regionalization which means that due to the close affinity shared by the different groups of people in this region, coming together to form a regional state would be more natural than otherwise.

A closer look at the nature of the post-colonial states in the east African region (and almost the whole of Africa), shows that these modern African states are in actual fact amalgamation of various traditional historical kingdoms and chiefdoms that had been politically autonomous prior to colonization. Therefore the member countries of the EAC, i.e. the modern states that make up the group are mini-regionalizations in themselves. In pre-colonial times, the area currently known as Kenya was shared by the Kikuyu, Luhya (Samia), Luo, Kalenjin, Kamba, Kisii, Meru, Wanga, Masaai, among others. The area known as Tanzania was shared by the Chagga, Gogo, Masaai, Hehe, Makonde, Sukuma, among others. The area known as Uganda was shared by traditional kingdoms such as Buganda, Bunyoro-Kitara, Toro, Busoga, Ankole, and many other chiefdoms. Some of these traditional states still exert considerable influence on the governance of the modern African states; and in Uganda, in particular, they are constitutionally recognized. 


\subsection{Reviving and enlargement of the EAC:}

With the revival of regional integration in East Africa in the early 1990s, there was also an increase in the number of member states from the original three (Kenya, Tanzania and Uganda) to include Burundi and Rwanda. Political changes in these two countries ensured that the rulers at the time needed to anchor their states to a bigger regional structure that could insure their people. The 1994 Rwandan genocide has been subject of one book after another; one research after another and analysis after analysis; but one of the key things that resulted from that tragic event was a strong realization by most Africans in the region that the other parts of the globe either did not care that much about them or were too busy with their own problems to come to their rescue; so they had to either pull themselves up or look up to the heavens for help (see: Ilibagiza, 2014; Ndahiro \& Rutazibwa, 2008; Kuperman, 2004; Cohen, 2007).

In my view I considered this as one of the most important reason behind the inclusion of Burundi and Rwanda into the EAC. Apart from destroying any illusion that the Burundians and Rwandese pundits had of an international force intervening to rescue those countries, the other role that the genocide performed was to substantially weaken, if not break, the relationships between the indigenous Africans in those countries and their former colonial rulers. The scandalous and legendary colonial rule of the Congo-Kinshasa (now Democratic Republic of Congo) by the Belgians left an indelible moral dent on the soul of Belgium as a colonial power. But by the time of the genocide Belgium could not muster any moral authority to intervene in its former colony thus leaving other opportunists such as France who, unfortunately, sent in few de-spirited United Nations mandated soldiers with limited capacity to intervene in the course of the genocide (Kuperman, 2004). The resultant death of over 800,000 Rwandese was to leave a permanent mark on the soul of Rwanda and cause the emergence of a 'do-it-yourself' mentality in the indigenous Rwandese that characterizes the country today. In 2007 during the $5^{\text {th }}$ Extra Ordinary Summit, Burundi and Rwanda were formally inducted into the EAC with remarks from Presidents Kagame (Rwanda) and Nkurunziza (Burundi) referring to the occasion as a big 'milestone' and of great 'historic' significance for their people. The Chair of the EAC Summit at the time, President Museveni is reported to have said that, "the community was the only answer to the colonial irrationalities that divided Africa with artificial borders ... East Africa was the most well-placed to lead Africa out of the straight jacket of political balkanisation. A balkanised African continent will not guarantee the future of the black race as well as other African peoples" (Musoke, et al, 2007). 


\subsubsection{The 'Economic Magnetic Pulls' thesis on EAC integration:}

In 2013 a series of reports appeared in The East African newspaper authored by re-known regional journalists and analysts Onyango-Obbo Charles and Mungai Christine. In these articles they examined the intricacies and ups and downs of the East African Community; and also presented their considered views on the future of the regional bloc. Though they did not christen their theory thus, this study has chosen to refer to their future projection of the EAC as the Three Economic Magnetic Pulls thesis. This phrase is used to refer to the 2013 futurological thesis advanced by Onyango-Obbo and Mungai which held that given certain political but mainly economic conditions in the region, there were three possible directions of expansion of the EAC, namely, 1) westwards towards the naturally inexhaustively endowed DR-Congo; 2) eastwards towards the Indian Ocean with the rise of China and India as global economic powerhouses; and 3) northwards towards the emerging Ethiopian economic might.

Since this is the only in-depth futurological analysis of the East African Community that the study could come across, it was deemed necessary to dedicate some space to examining the possibilities and ramifications this thesis on the sustainability of the regional bloc. This is because in essence, a study on sustainability like this one is ipso facto concerning the future. So a futuristic thesis on the region live Onyango-Obbo and Mungai's Three Economic Magnetic Pulls for the EAC warrants examination. In their view, on a scale of 1 to 10, the chances of the EAC expanding westwards towards the DR Congo were 4/10 in fifteen years; whilst that of expanding northwards towards Ethiopia was 6/10 in ten years. In their estimations, if the bloc expanded thus, it would have a combined population of 600 million by 2050 and might be the strongest economic bloc on the continent (Mungai \& Onyango-Obbo, 2013a).

\subsubsection{Economic or Military forces?}

In June 2011 the youngest African state of South-Sudan applied to be admitted into the East African Community; this was followed by Somalia which submitted its application in February 2012. Per chance a consideration of these and other phenomena around the region evoked a number of elaborate reports by Charles Onyango-Obbo, in which he examined the economic, political and military forces and factors that were shaping the revived EAC in the $21^{\text {st }}$ century. In those reports that were published in The East African from June 2-9, 2012, Onyango-Obbo argued that given the events taking place in the region, it was likely to change from being the 
East African Community to become the 'Greater Horn of East Africa Economic Community' (Onyango-Obbo, 2012b; 2012c; 20102d).

In these reports Onyango-Obbo rightly observed that the direction that Kenya takes is determinant in the East African Community because it is the regions' economic powerhouse. He observes that Kenya is torn between two directions to take in its regional policy; i.e. either to remain committed to its two traditional partners, Uganda and Tanzania or to forge newer relations with Ethiopia, Somalia and South-Sudan. Obbo argues that "the most important and 'big future' economic relationship for Kenya will not be with the current EAC partners, but the Horn of Africa nations" (Onyango-Obbo, 2012a). He was of the view that the entry of the Kenya Defense Forces (KDF) into African Union's AMISOM drive to pacify Somalia “could prove decisive in the shape of the new security and political architecture in the region" (ibid.). Kenya's entry into the Somalia conflict and its billion-dollar economic projects with SouthSudan and Ethiopia ${ }^{16}$, have made the countries in the Horn critical for the region.

The centrality of Kenya's economic might to the EAC notwithstanding, recent events in the region have cast new shades on the EAC's dynamical nature and imply a need to rethink some of Onyango-Obbo's views. The December 2013 internal political breakdown in South-Sudan that quickly disintegrated into a civil war was a rude awakening to Kenya and other states in the region that it would be prudent to be cautious in dealing with a young nation in a volatile sub-region. The political players in the young country portrayed political immaturity when they failed to resolve their minor political differences amicably and resorted to military means leading to countless deaths and displacement of people; and because of that the grandiose projects that Kenya had been touting before the press suffered great set-backs. Recent studies and reports project that the South-Sudan conflict may end up costing up to $\$ 53$ billion to both the regional bloc and other stakeholders by the time it is not brought to an end (Edmund, 2015). It still remains to be seen how long it will take for those projects to be revived and accelerated given that the 2013 South-Sudan civil war is still raging with recurrent sporadic tribal-inspired fights breaking out now and then.

\footnotetext{
${ }^{16}$ In January 2012 Kenya set out to execute two important projects that were billed to change the economic and possibly political dynamics of the EAC; these are: i) the $\$ 1.2$ billion $400 \mathrm{MW}$ high voltage electricity transmission line from Ethiopia's Renaissance Dam to Kenya; and ii) the \$16 billion Lamu Southern SudanEthiopia Transport Corridor (LAPSSET).
} 
The civil war in South-Sudan also demonstrated the need for analysts not to over emphasize Kenya's economic might at the expense of military experience and leadership; and in this regard Uganda proved to be the leader in the region. It is obvious that Onyango-Obbo was aware of the fact that Ugandan troops have better military experience having reported about it earlier (Onyango-Obbo, 2012a) especially in terms of decisiveness. This was demonstrated by Uganda's quick and decisive action of sending troops to South-Sudan (Barigaba, 2013) to reverse a situation that was threatening to destroy the young state; this means that in a volatile region like East Africa, military acumen and experience is of no less importance in determining political and economic trends. Therefore Uganda, which has more military man-hours of experience in both guerilla and jungle warfare than Kenya, can also be very determinant in affairs of the EAC. Despite having a lesser military budget in comparison to Kenya and Tanzania, Uganda has consistently demonstrated her superiority in decisive military action. Historically, a similar role was played by Tanzania in the 1970s when it practically supported Ugandan exiles and sent troops to join them in toppling the British-propped Idi Amin who had played a key role in the 1977 collapse of the East African Community (see: Mamdani, 1984).

Another determinant force in the EAC are the perceived and erroneously propagated ethnic or tribal differences among its peoples. The case of South-Sudan can also be of reference in this point. Even though President Salva Kiir's government has tried to change the narrative about the outbreak of internal violence in his country such that it is not seen as a tribal conflict, even a simple examination of the conflict seems to indicate that tribalism is the problem. Kiir comes from the largest tribe in South-Sudan (the Dinka); while Riek Machar is from the second biggest tribe (the Nuer). These two tribes have traditionally fought for political and economic power even before the young nation was born; a contest that stretches back into the past. Even the late Garang, despite his enormous leadership appeal among his people and internationally, had problems containing Machar and his warrior tribesmen of the Nuer tribe. There were several times during the long struggle for independence when Machar broke away from the Sudanese Peoples Liberation Army (SPLA) with his loyal tribesmen and allied with either their common enemy, President Bashir of Sudan or with other forces. This almost derailed the birth of the nation: even though towards the time of the referendum Garang had oscillated towards remaining in the bigger Sudan, those with insider information claim that this had happened because he had feared retaliation from the alliance between Machar and Bashir. Even after the referendum and independence, there still remained a couple of tribe-based rebellions in SouthSudan. In 2010, the state of Jonglei saw the threats to rebel by former army General, George 
Athor Deng who had been defeated in the first elections (Sudan Tribune, 2010). Then there was the ragtag rebellion by rebel leader David Yau Yau from the Murle community (Sudan Tribune, 2013). These are just but a few with many other simmering tribal conflicts in the country of 64 big and small tribes. Even the political class is not spared from the tribal conflicts as witnessed by the differences between Kiir (Dinka) and Machar (Nuer) turning into bloody violence recently.

In order, therefore, for Kenya to take its deserved lead role in the region, it has to take care of both the real and perceived weakness in its military ranks. These weaknesses were brought to the fore by the 2013 Al Shabaab claimed terrorist attacks in the Kenyan capital Nairobi at the Westgate shopping complex. This attack claimed 67 lives and 174 people were injured. Apart from the disheartening and disorganized response of Kenya's security apparatus which stretched the insurgents' siege of the shopping complex and leading to fewer lives saved, the attacks revealed that there was a challenge of indecisiveness when it comes to security issues in Kenya's security circles. This problem has been seen to chronic by the various Al Shabaab attacks that continued to rock the nation; and started to turn the population against its leaders (Burridge, 2014).

\subsubsection{The 'Three Economic Magnetic Pulls' thesis:}

The main observation that we get from the above consideration of which forces are to shape the future of the EAC, is that it is too early and simplistic to take the economic forces as the sole determinant of the future of the region. In addition to the economic forces, there is need to take into consideration other forces that are pulling at the EAC and its future prospects. Therefore there is need for caution whilst considering the future expansion of the EAC on the basis of economics as such because the region has many other factors that seriously impact on its existence and sustainability. For that matter the 'Economic Magnetic Pull' thesis as advanced by Mungai Christine and Onyango-Obbo begs some scrutiny.

\subsubsection{Pull towards the east (Indian Ocean):}

Firstly, and on a serious note, the economic pull towards the east, i.e., the Indian Ocean (China, India, Russia and the other Asian economies) cannot be taken as a literal geographical expansion of the EAC. Though it is not literal geographical expansion, looking east towards the Asian economic powerhouses is a key and determinant economic factor for the future of 
the EAC; because the bloc seeks the economic power to propel it forward. The Asian trading partners such as China and India are better in comparison to countries like the USA because it is cheaper to trade with them in both logistical and political terms than with the northern economies. In fact data indicates that trade between the USA and Africa has been on the decreasing trend; whereas Africa's trade with the China is growing, by the close of 2014, USA's trade with Africa had declined to $\$ 66$ billion an unusually sharp drop from $\$ 125$ billion in 2011 (USCB, 2014; Finnigan, 2014; Yun \& Rettig, 2014).

There have been constant complaints from leaders within the EAC that the Western countries are not forthcoming when it comes to providing credit for large scale infrastructural investments which would be necessary if the region is to be competitive by lowering the cost of production. In October 2014, while launching an $\$ 8$ billion standard gauge railway President Museveni complained about the failure to access credit for big long term infrastructural projects from Africa's traditional European trade partners; meanwhile he, thanked China for stepping in to fill the gap (Lumu \& Baguma, 2014). Martyn Davies (2013) has tried to provide a theoretical explanation for the ability for China to provide credit for such huge and long term infrastructural projects in Africa. He argues that it is because China is using 'policy banks' that are politically insured; they are therefore able to invest large sums of credit without much economic risk involved (Martyn, 2013: 188-190). But this argument, which has been touted by many Eurocentric economic theorists lacks in some aspects: i) it fails to consider a historical fact that Europe has been trading with Africa for so long that the issue of risk suddenly becoming more important when it comes to advancing credit is either shallow analysis if not suspect; ii) secondly until recently Europe has traditionally had more credit reserves and been traditionally considered to be richer that China such that it is not a matter of lack of credit as such. Having considered those reasons, it becomes logical to think that the reason why Europe does not advance credit to Africa for long term infrastructural projects is more of attitudinal than not. For that matter, as long as the European financial industry retains such an attitude towards Africa, the EAC region will increasingly oscillate towards the Asian powerhouses for economic prospects and partnerships.

But for purposes of this study, the concern over sustainability of this economic arrangement could be raised concerning the EAC's pull eastwards towards the Asian economic powerhouses. Just as the European traditional trading attitude towards Africa of maintaining it simply a source of cheap raw materials could not be sustainable in the long run, there is a 
question of whether China will remain magnanimous towards the continent as she apparently is. All rational observations would simply lead one to conclude that the romantic relationship that China is having with Africa is not expected to be perpetual; at a certain point either it will not be making business sense to advance such huge amounts of credit anymore or China's economic growth may simply slow down and not be able to sustain such politically insured adventures in Africa. Besides, even if the unsustainability may not arise from China itself, there are indications that the old ugly beast of corruption and political patronage may derail these Chinese funded projects and lead to their unsustainability. For example reports of corruption in the case of the Chinese funded standard gauge railway started in the East African region even before the project commenced; Kenya had to institute a parliamentary committee to investigate corruption allegations (Collier, 2014); the same scenario has happened in Uganda and it threatens the project (Kiggundu, 2014). With corruption seemingly entrenched in the political culture of the EAC, the question of sustainability become even more relevant.

\subsubsection{Pull towards the west (DR Congo):}

The EAC expanding towards the west and encompassing the DR Congo is feasible but it is more complicated than meets a cursory analysis and for that matter, the sustainability impact of bringing the DR Congo into the regional bloc would be enormous. Mungai and OnyangoObbo implied that given the acrimonious relationship that has developed between Egypt and Ethiopia over the latter's insistence on building the 6000MW Renaissance Dam on the River Nile, the EAC countries would be hard-pressed to look westwards towards DR Congo in order to fulfill their electricity needs. At the time it was feasible to make such predictions because Egypt was under a new radical Islamic Morsi government which was sending out unveiled threats of going to war over the Nile waters; but in light of what has happened so far war seems a long shot because the radical president Morsi lost power and Ethiopia is on track to complete the Dam and export power to Kenya and South-Sudan. Besides, the DR Congo is attractive to very many powerful international players who are mainly interested in its vast underground wealth; this makes the possibility of the EAC expanding to include the DR Congo a very complicated venture. The DR Congo seems to be perpetually at war and this has entrenched many forces that would view the idea of such wealthy country joining the EAC as a threat to their interests. Nevertheless it would be culturally and geographically sensible for the DR Congo to join the regional bloc because the peoples of the country are close relatives of those in the EAC. 
The complications that DR Congo have even sucked in countries South Africa from time to time sometimes prompting President Zuma to make interesting impromptu visits to the region. For example, towards the end of 2014, South Africa's President surprised many analysts by an impromptu visit to Kampala. This sudden activity implies that there is very interesting goingson in the region that require some closer scrutiny. Everyone is aware of the vast South African economic investments in the east African region ranging from energy, real estate, information technology and mineral extraction, to mention a few. So on an economic level, it would be understandable to think that President Zuma was visiting for such reasons, at least at face value. But interestingly, he visited President Museveni who is viewed as an elder power-broker in the EAC without whom not much can be achieved in the region at the moment.

But the more realistic reason for his visit may be the feared resumption of rebel activities by the M23 and the Democratic Forces for the Liberation of Rwanda (FDLR) in the DR Congo. After a combined Tanzanian-South African-Malawian war machine routing the M23 rebel group from DRC (Mmanaledi, 2013), president Zuma has been basking in his new role as a decisive African military player. Meanwhile Kampala and Kigali are usually perceived to be sympathetic to the M23 rebels and there were fears (within Tanzania-South Africa camp) that the Nairobi-Kampala-Kigali coalition may be maneuvering to use the recently formed East African Standby Force (EASF) to flush out the FDLR from DRC which is seen as a threat to Rwanda (see: Kagire \& Nachilongo, 2015). What is more complex and interesting is the question of why the international community seems to be okay with the Tanzania-South Africa group carrying out military excursions in the eastern DRC yet they continuously condemn Kigali and Kampala for engaging in the same area yet it is their back yard. The so-called 'unbiased' international community seems to tacitly applaud military adventures by countries that are far away from the DRC yet the impact of those military campaigns affect Uganda and Rwanda most. It is just simple political logic that since these countries are land-locked, they, as a matter of necessity and survival, have to be keenly be interested and perhaps intervene where necessary in the DRC.

Given the political and economic complications that bedevil the DR Congo it is logical to argue that for the time being, bringing the country into the EAC would be carrying a huge liability. Such a decision would be potentially detrimental to the sustainability of the regional bloc given the fact that it has just been revived and relations are still fragile. Already engagement of some 
of the member countries in the DRC has caused some diplomatic tensions among the member countries; for example in 2013 when president Jakaya Kikwete of Tanzania suggested during the African Union meeting in Ethiopia that Rwanda should talk peace with the FDLR rebels, it caused a diplomatic row between Kigali and Dar es Salam (see: Nyanje, 2013). Such episodes threaten the sustainability of the EAC and therefore the bloc would be prudent to leave DRC out of the equation for the time being.

\subsubsection{Pull towards the north (Ethiopia and South-Sudan):}

The euphoric feeling that engulfed the region after the birth of the latest and youngest nation, South-Sudan was understandable given the suffering of the South-Sudanese had suffered at the hands of their northern rulers. It was an interesting case because for the first time an African nation had won independence from a fellow African ruler; a different narrative from what the 1960s classic African independence struggles had been. Since almost all the member countries of the EAC had participated in the South-Sudanese struggle for independence in many ways; so the feeling of brotherhood is strong within the region. And the idea of the world's newest independent country joining the EAC is a good one since they still need a lot of assistance to get their country to order after a protracted war of liberation. But as discussed earlier, the recent breakdown of South-Sudan into civil war was a reminder that the country still has many internal political and structural issues to sort out that a hasty joining of the EAC may simply add another angle of unsustainability. The EAC has to be careful and watch how the leaders in South-Sudan handle their political differences such that the region does not get bogged down more than necessary. As regards the Ethiopian pull, this is a more feasible option given the economic growth that the country is experiencing currently and the political stability factor that it would contribute to the region. The historical role that Ethiopia has played in the whole of Africa being host to the African Union would make it a stabilizing agent in the region in case there are diplomatic fall-outs between or among any of the traditional EAC member countries.

This pull towards Addis Ababa and Juba seems to be the most logical and politically realizable option. It would also be a great asset for the EAC to have Ethiopia as a member of the bloc because of the many advantages the country brings to the table. In this regard, Mungai and Onyango-Obbo were quite right to observe that the pull towards expanding these two countries to join the EAC is the most feasible. Ethiopia has great potential to stabilize the region in terms of security because it has one the biggest and most effective military system in Africa; so EAC 
leaders would be strategic to allow Ethiopia to join the bloc. Having set out to build one of the biggest electricity producing dams in Africa, Ethiopia is poised to be a key provider of energy for powering industrialization in the region. Besides the economic and military benefits that the EAC would gain from accepting the Ethiopians into the bloc, the region gain from the historical morale boosting role that the country has played for the continent; being the only African country that was never colonized has imbued Ethiopians with a great sense of African pride that is almost impossible to break and the EAC needs such deep pride not only for ideological but also strategic purposes.

\subsection{Modes of the EAC integration:}

As east Africans seek to build a strong and sustainable regional bloc, it is inevitable to consider the history and the embers of collapse that the project experienced. Since the concept of modern regionalization of the EAC was mooted during colonial days, there is necessarily a marked difference between the purposes for which the colonialists set out to achieve the unification of the bloc from that of the natives who took over power after the 1960s wave of independence struggles in the region. Understanding the underlying reasons why the two leaderships (i.e. colonial and native) want the regional bloc would go a long way in illuminating us on the historical and governance variables that affect the level of sustainability that the region has. This is pertinent because the vision that the colonial masters wanted the regional bloc to fulfill is markedly different and in some aspects similar to that of the native leaders. In this section therefore we examine the two 'visions' that the colonial masters and native leaders have for the EAC and relates it to the challenge of sustainability that the bloc has to grapple with. The table presented earlier in this chapter makes it noticeable that there are different 'modes' of regional integration that have characterized the EAC. The decipherable modes of the EAC integration necessitate some interrogation because they can be key in understanding the roots of the project and how it functioned in its initial stages and also to analyze its present and future sustainability.

\subsubsection{EAC Integration: The Colonialist's vision:}

Korwa (2011:1) observes that between 1895 and 1903 the British colonial masters in both Kenya and Uganda set the stage for the integration that is why he refers to that period of the EAC as Phase 1. I prefer to call this phase the colonialist-driven stream of the integration and in examining it we get the vision of the type of the integration that the colonial master had in 
mind. Therein the colonial vision of the project may lay the insights into some critical aspects of the character of the current EAC.

Mpangala (2004) has observed that the colonial powers had "interests of capitalist expansion in the colonies...Such interests included production of agricultural and mineral raw materials... and creation of markets for the industrial commodities. In order to fulfill these objectives it became necessary to dominate and control societies...politically and ideologically." (2004:4). He categorizes "regionalism" (p.5) to be among the 'divisive ideologies' that the colonialists created among the colonized people. He extensively appeals to President Kagame's views ${ }^{17}$ on the three phases of conflict in the African Great Lakes region, namely, the pre, post and neo-colonial phases. Although much of his discussion traces conflict in the colonialist-created ideology of ethnicity, he notes two key sociological theories that underlay the mindset of the colonialist as they created the regional integration, i.e. social Darwinism and biological determinism.

The philosophical roots of this approach to colonialism have been subject of investigation by many scholars. They observe that the colonialists (and in this case, the British) approached the colonial lands as not only as being occupied by inferior peoples but also only good for economic exploitation. Probably this was necessary to calm their consciences concerning the atrocities that were to be committed in order to realize their goals. And this is a deep ethical challenge that requires investigation to find out how the colonialist was able to expend such atrocities without arousing a great ethical backlash from the conventional national consciences of citizens of the countries they claimed to represent.

Bryd Hall (1971) carried out an extensive investigation into the influence of the social philosophy of social Darwinism on colonialism in Africa and beyond. His thesis was that behind the colonization project there was a strong influence of the ideology of social Darwinism. One interesting observation to make from his thesis is the manner in which this ideology transmutates into an economic ideology and a force to power the enormous political and military investments by the great powers of the day such as Great Britain. In his research Bryd cites a prominent colonial enforcer in East Africa, Lugard Fredrick, trying to turn the

\footnotetext{
${ }^{17}$ These views were contained in an inaugural lecture that President Kagame delivered at the Nigeria War College in Abuja on the $16^{\text {th }}$ September 2002. The paper was titled: "The Great Lakes conflict: Factors, Actors and challenges".
} 
social ideology into an economic one and thereby justifying the colonial actions. Lugard refers to the, "absolute necessity, for the prosperity of [England] that new avenues for commerce such as in East Equatorial Africa should be opened up..."(1971:78-79). This was a syndicated effort to turn the social Darwinism into an economic and political ideology to push the colonial project. In other words, the colonialist's projects in the colonized powers ought not only be discussed in economic or political terms but also in the fundamental terms of the philosophical streams underneath.

Unlike most critics of colonialism from a Marxist perspective who challenged ${ }^{18}$ the Kantian thought on 'other' peoples who were colonized, perhaps Lea Ypi's (2013) critique carries the day because of its political pragmatic approach to the subject. Ypi's desire for global justice is evident in the discussion she makes in the paper but what is most interesting is the observation of how colonialism transformed 'civilized' people into uncivilized as the meted out horrifying punishments to the conquered peoples around the world. But since our discussion here concerns the ideological or philosophical streams that fed into the colonial project, the key lesson we take from this is that given the fact that the colonial master "took the inhabitants of the [conquered] lands as nothing" (Ypi, 2013:173), implicitly, almost all major projects undertaken in the colonies would never have been for the good of the colonized people. Therefore as far as the East African Community project is concerned therein the philosophy lay the roots of the consequent failure of the project.

The intermittent collapse of the project inevitably raised persistent causality concerns; the interrogation of which induces variations in questions of which theoretical approach informed the regional integration in the EAC. Theoretical approach is what the immediately preceeding discussion has tried to illuminate the reader about. The 'colonialist-driven' episode of the EAC can be said, in my view, to have been a colonial-functionalist approach to regional integration; it was regional functionalism in colonial Africa at its best exemplification. The colonial administration was to ensure the implementation of minimalist structural-functionalism to the extent that it could facilitate the most parsimonious exploitation of human and natural resources to the economic benefit of the colonial master within the global capitalist order. On one hand,

\footnotetext{
${ }^{18}$ Note that some scholars (such as Howard Williams) have insinuated that traditional Marxists do this as a result of a misreading of Kant's views on conquest of new lands; that Kant was progressive in his thinking towards the 'other' as evidenced in his works: Perpetual Peace and the Metaphysics of Morals. (see: Howard, 2014).
} 
given the un-naturalness of the colonial African state, a functionalist approach to regionalization was a good approach to use for the EAC; but on the other hand, to the extent that the approach was rendered minimalist 'colonial-functionalism' which was devoid of benefits for the native, in it lay the seeds of unsustainability and eventual collapse of the cooperation.

It was obvious and well known that from the very beginning the British interest in East Africa was for economic expediency and not for any other purpose. So the machinations of state and regionalization were to facilitate that purpose. From 1887 when Sir Mackinnon formed the British East Africa Association, which finally transformed into the Imperial British East Africa Company, the expectation was to facilitate the exportation and management of minerals and other types of wealth. When the Mackinnon's business venture ran bankrupt due to extensive uprisings and a long civil war in Buganda in 1892, the government of Britain took over direct control of the colony to ensure continuous exploitation of resources. So the myth of "...benign imperialism, whose overriding purpose was not to seize land, labour and commodities but to teach the natives English, table manners and double-entry book-keeping, is a myth that has been carefully propagated by the rightwing press" (Monbiot, 2012).

\subsubsection{The Colonialist's vision and the historical-moral duty on the coastal states:}

Having made an undeniable observation that the colonial masters used a colonial-functionalist approach to the integration of the EAC, and having established that this approach was fundamentally unjust to the natives, it is necessary and logical to address the injustices that resulted from that approach. In practical and policy terms, the colonial-functionalist resulted into the concentration of colonial administrative services and capital in the coastal states of Kenya and Tanzania especially in the cities that emerged along the railways (especially Nairobi) and at the coast (such as Dar es Salam and Mombasa). This historically predisposed the coastal states, particularly Kenya to benefit more from the colonial legacy and at the time of the collapse of the EAC, the leadership took over most of the colonial-functionalist structures that were originally meant for the colonialist's exploitation of the whole region.

The fact is that the collapse of the EAC notwithstanding, the systems of extracting raw materials from the hinterland countries and using them a market for finished goods from the coastal areas continued unabated. This explains to a greater extent why Kenya's economy is 
bigger than that of the other members of the Community; it inherited a colonial system that was skewed against the hinterland countries. It was therefore easier for Kenya to successfully carry out import-substitution after the departure of the physical colonialist because Kenyan business simply replaced the colonialist and continued extracting raw materials from the interior of the EAC. Up to now, in terms of inter-EAC trade Kenya trades heavily with its fellow Community members but most of it is tilted in favor of Kenya exporting factory processed products while the others are mainly exporting raw or semi-processed goods to Kenya. This places Kenya in a position to have better balances of trade than its EAC neighbors and gives it a foundation to favorably compete in the global economy. Trade data and reports consistently show that Kenya has traditionally viewed the other countries as their backyard markets (see: The East African, 2014). Unfortunately, in order for the other EAC member countries to grow their home industries and protect them from a historically and colonially favored Kenya, they have traditionally resorted to using both tariff and non-tariff barriers. This explains the persistence of these barriers despite political commitment to remove them; they make the industrial class uncomfortable (see: The East African, 2012).

However, as the other EAC members strive to realize development through importsubstitution, Kenya has increasingly become uncomfortable and desires to maintain the status quo. This has led to a continuation of some sort of trade war within the region that is not on competitive terms but on state interventionism. For example, in 2012 the Kenya Revenue Authority (KRA) introduced a new tax dubbed the "cash bond directive" (Mugabe, 2012) which targeted sugar that was coming from Uganda that was to be sold in Kenya. Ugandan sugar manufacturers and traders viewed this as a ploy to push them out of the Kenyan market. This KRA has usually argued that these measures are put in place to maintain standards of goods entering the Kenyan market; but the trend seems to indicate something otherwise. Apart from Ugandan traders complaining about 'arbitrary' policies in the provision of port services at Mombasa, there are report of KRA officials blocking Ugandan goods using the excuse of low quality goods (see: Ladu, 2014; Wandera, 2014; Tumusiime, 2015).

This 'regional trade war' seems to be intractable because the manufacturers and business class in all the member countries are tussling it out for the same market. But one of the sensible ways to look at it is in historical terms. If we acknowledge that colonial history had a lot that it contributed to the economic muscle of Kenya today, then Kenya has a historical and moral duty to rectify these historically unjust economic imbalances. This is because due to the colonial-master's desire to exploit the interior of east Africa at the least cost possible, Kenya 
was used at the administrative and commercial base for that goal. This systemic economic injustice was continued even after the physical colonialists granted these countries their political independence. In the sincere spirit of east African brotherhood and sisterhood Kenya cannot reasonably expect the other countries to simply remain her sources of raw materials and market as the colonialists had designed it. Therefore Kenya has to acknowledge that this colonial legacy exists and has to be rectified. Various scholars of justice are increasingly calling for rectificatory justice from former colonial masters to their colonial victims (see: Collste, 2014); but it is ironical that even though Kenyan activists have successfully demanded and received compensation for colonial injustice from Britain (Karim, 2013), the country seem reluctant to rectify the colonial economic injustices that placed it in an advantageous position in the region's trade structure. In addressing this historical-moral duty we are not calling for Kenya to make monetary compensations to other EAC members such as Uganda just as Britain did to its Mau Mau victims, but we are making a moral claim that the least that Kenya would do is not to perpetuate the economic injustices that resulted from the colonialists practice through tariff and non-tariff trade barriers.

\subsubsection{EAC integration: The natives' vision:}

The colonial-functionalist approach that the colonial masters used in establishing the regional project was only to benefit them and not the natives. It was not long for the natives to realize it and present resistance to the project, in any case they had already been resisting the presence of the colonialists on their land. Therefore the regionalization project was meant for the economic benefit of the master; so only that which was really necessary to exploit the resources of the colony was established. This meant that apart from the initial atrocities committed at the time of conquest, systematic and institutionalized injustices were perpetuated throughout the colonies in order to ensure that the colonial state fulfilled its function of economically benefiting the master.

In 2012 reports surfaced in the mainstream media that thousands of documents of records of torture that was carried out in over 37 colonies by the British masters especially towards the attainment of independence by the colonized people. The Mail and Guardian (Cobain, et al, 2012) reported that although the British government tried to destroy this evidence, some still remained because they were too many and they had been locked up in the "highly secure government communication centre at Hanslope Park in Buckinghamshire near London” (ibid.). 
It is interesting that the media that revealed this information does not mention the actual 'atrocities' that the British government committed, a sign of how the British government managed to control the information flow after being challenged in courts of law by the survivors of the brutality meted out by colonialists during the Mau Mau uprisings in Kenya. It is also reported that this concealment of these documents was to protect the legacy of the colonial powers thus the name 'legacy files'. In Uganda this policy of concealment was codenamed 'Operation Legacy' whilst in Kenya (it was referred to as 'The Purge') and orders were given whereby only civil servants of 'European descent' were allowed to carry out the orders of destroying those records.

In Kenya there were atrocities such as forced evictions, forced labor on farms, rape, among other injustices. In the case of Uganda the recent act of the Bunyoro Kingdom seeking re-dress in courts of law indicates the enormity of what happened and how it still affects the psyche of the natives: the Bunyoro Kitara Reparations Association (BUKITAREPA) has dragged the Queen and the British government to court to seek for compensation for the atrocities committed during the colonial era. In Tanzania the Germans were the first to visit injustices on the native and later the British after the end of the Second World War. The researcher Elkins has stated that the "colonial logic [was]: only by physically and psychologically atomising almost the entire Kikuyu population of 1.5 million, could colonial authority be restored and the civilising mission reinstated." (Elkins, 2011). Monbiot mentions some atrocities when he reports that British citizens prefer to ignore them:

Interrogation under torture was widespread. Many of the men were anally raped, using knives, broken bottles, rifle barrels, snakes and scorpions. A favourite technique was to hold a man upside down, his head in a bucket of water, while sand was rammed into his rectum with a stick. Women were gang-raped by the guards. People were mauled by dogs and electrocuted. The British devised a special tool which they used for first crushing and then ripping off testicles. They used pliers to mutilate women's breasts. They cut off inmates' ears and fingers and gouged out their eyes. They dragged people behind Land Rovers until their bodies disintegrated. Men were rolled up in barbed wire and kicked around the compound. (Monbiot, 2012) 
In order to get the details of the nature and magnitude of the injustices that were committed in order to build the East African colonies to fulfill the masters' plan of economically sustaining the colonizers, one has to read Elkins Caroline's book: Britain's Gulag: The Brutal End of Empire in Kenya (2005).

This all means that for the majority of the natives (except for a few) the reality of colonization was a horror show. Therefore there was little possibility that the natives would cheerfully support the creation of the EAC because the colonial project was a cocktail of injustices. But interestingly we observe a phenomenon that was later to characterize the EAC: for the majority of the masses who felt and resisted the colonial atrocities, any project by the colonial masters was no good; but for the collaborating few, the colonial projects were chance to advance in social system set up by the colonialists. In reviewing Elkins' book, Brandabur (2007) observed that even though almost the entire Kikuyu population in Kenya resisted the colonialists by way of the Mau Mau rebellion, there were a few who betrayed their people or were broken by the colonialists unending brutality (Brandabur, 2007:155). It is the latter group that found the projects initiated by the colonial masters beneficial.

For that case, the vision of the native for the EAC was divided into two: the big masses of the natives wanted any project by the colonial master to fail, while a small number of elite collaborators wanted the project to succeed albeit in their favor to gain power, position and resources. So for those who were standing to gain the project was supposed to be realized while for those who had suffered at the hands of the colonialists they wanted it to fail. However, note should taken that both groups wanted the colonialists to go and both joined hands to contribute to the anti-colonialist movement in varying ways. Nevertheless, each category had a different vision for the EAC project. In reference to the Kenyan Mau Mau rebellion, Brandabur insinuates a sub-vision within the natives in East Africa for the projects of the colonialists when she mentions that:

Unfortunately, the heroic resistance of the Mau Mau insurgency was officially neglected in Kenya both under Jomo Kenyatta and his successor Daniel Arap Moi, while collaborators and white settlers continued to enjoy the best farmland and a leisurely lifestyle unrepentant and unpunished for their part in the brutal destruction of a whole community. (Brandabur, 2007:155). 
Within the natives, as mentioned earlier, there were the local people who suffered the brunt of the colonialists' injustices and this category wished and actually worked to see that the projects of the colonial masters fail. On the other hand there was the small number of elite who had either been broken by the colonial system or had collaborated with the system and this category wished that the colonial project remain for their benefit. Brandabur mentions two of Kenya's post-independence leaders, namely, Jomo Kenyatta and Arap Moi who did not seek to redress the injustices of the colonialists but instead left the legacy of the injustices intact. In actuality, most of East Africa's post-independence leaders acted to perpetuate the injustices of the colonial system because they were also benefiting from it. This resentment among the majority of the people in the region has bedeviled the East African Community project since its inception.

So when the colonial masters had started the top-bottom integration process, they focused on those aspects that could make the exploitation of the region's resources easier; for example in 1948 they set up the East African High Commission which introduced and oversaw services like the East African shilling (especially when the region was finally under the British), an integrated posts and telegraph network, an integrated income tax system and research facilities (Konrad-Adenauer, 2011:16). It is obvious that the institutions put in place were mainly for the economic benefit of the colonial master; that is why we don't find any report of an integrated healthcare system - such 'peripheral' services were left to the missionaries to provide and the colonial state did little for the health of the majority of the natives.

But it is in the post-independence era that colonial projects and institutions became useful to the elite who were benefiting from them. Therefore that would be motivation enough to perpetuate the injustices that those systems and institutions meant for the majority of natives. Mr Edwin Mtei, who is a former Secretary General for the East African Community (19741977) is reported to have made a revealing statement in the Konrad-Adenauer report, Ambition for and Reality of the East African Community in a globalized world (2011); he stated that, "the idea of an East African Political Federation became very popular among the intellectuals" (ibid., p16). This was the origin of the unsustainability of the political project that is the EAC. By the time the colonial master granted the natives independence and self-governance, the governance of this mega-state known as the East African Community was doomed to collapse 
because on one hand the majority of the people wanted every colonial project undone whilst on the other a small elite group wanted to retain the colonial system for selfish benefit.

An excerpt from the recently declassified dispatches of the colonial emissaries deployed within the colony of Uganda reveals the sentiments that existed during this period. It is reported that the American ambassador to Uganda towards independence time, Deming H. Olcott was sending dispatches back home that President Obote was determined to get Uganda out of the East African Federation against American wish. He states that, "When I told him of America's position, he said: 'Is your government trying to bribe me?' I said, 'No, we are talking about steps which we think would be helpful to all the three countries.' Obote replied, 'I am not interested in strengthening the federation..."' (Lubega, 2014). These reports give some insights into the vision of the native for the EAC project in its early years. The reported reason for Obote's lack of enthusiasm for the federation was that, “... before long there will be only one representative at the United Nations for the East African Federation; and he will not come from Uganda" (ibid).

\subsection{From a functionalist to a neo-functionalist approach to the EAC:}

By Phase- 3 of the cooperation, with the continent being whirled by anti-colonialism and the independence movement, the native leaders who inherited the colonial administration soon realized that structures had not been designed with the African in mind. For example the concentration of most industries and administrative offices in Kenya and their attendant economies of scale had been meant for the colonialist to minimize costs of administration. So even though prior to independence the new East African leaders (especially Nyerere and Obote) had been espousing the politically aggressive 'Nkrumahan' pan-Africanist functionalism (Nkrumah, 1963a, 1963b), they ironically ${ }^{19}$ preferred the advice of Philip Kjeld (a former Danish trade and finance minister) to adopt an economist neofunctionalist approach to the regionalization project. For that reason the restructuring of the EAC during Phase-3 of the cooperation did not go far enough in terms of reversal of the 'colonial-functionalist' structures of the bloc. Thus, as indicated earlier, the resultant effects of those structural injustices coupled with divergence in political ideology (Mwatha, 2009:8) soon led the collapse.

\footnotetext{
${ }^{19}$ It was ironical because Nyerere's youthful years had been greatly influenced by Nkrumah's struggle, something that he later acknowledged in his famous Accra speech, "Without unity there is no future for Africa" (6th March 1997); and in turn Nyerere had considerable influence on Obote. (It is also interesting to note that one of the current revivalists of the EAC, Yoweri Museveni, was politically mentored by those two leaders).
} 
Critical institutional analysis yields that, in many respects, the shift from colonialfunctionalism to native-neofunctionalism, simply meant a slowdown in the colonial economic agenda more than anything else. By means of structural setups like the railways and post systems, the natural resources and cheap labor continued to flow from the hinterland towards the colonial masters' homeland; i.e. all the independence and unity euphoria was, in structural terms, not able to undo the entrenched injustices that existed. It was just as Ujupan (2006) observes, "neofunctionalism puts forward the concept of spillover, reflecting gradual integration, but it fails to account for integration stagnation" (Ujupan, 2006:1).

Even though we could institutionally locate the injustices and eventual collapse of project EAC-1 within the theoretical framework of functionalism, in order to adequately analyze the contemporary undertakings and make projections for the future, we need to apply other theoretical frameworks. Given the fact that many of the nascent institutions of the EAC had been disbanded, an institutional analysis would be inadequate for understanding the revived EAC. Secondly there is a growing crop of African scholars who think that applying only an institutional approach inevitably leads one to blame colonialism yet the current development and governance challenges in Africa go beyond such analysis. Thinkers such as George Ayittey (2005) argue that using only the institutional approaches such as functionalism would end up exonerating African leaders from their responsibility for their failure in leadership. Given that the study is ethical in foundation and in order to examine this leadership responsibility it is viable to use the behavioralist framework. Such an interrogation shows that individual political agents and their perceptions were and are still critical to the sustainability of the project. Ayittey has postulated that there are two trends in political analysis in Africa currently: i) the Externalists and ii) Internalists. To him, the former includes those who blame Africa's development and governance problems on external interference; whilst the latter includes those who blame internal failures especially on poor political culture. This study agrees with that view and discusses the sustainability or unsustainability of the EAC using explanations from both within and without the region.

\subsection{Divergence in leadership and institutions: the need for metagovernance:}

Commenting on perceptions and political behavior in the EAC, Nzioki and Tostensen (2005) observe that, "perceptions take on a reality of their own, on the basis of which people continue to think and act" (p.2). It is common knowledge that the political character of the three political 
personalities of Kenyatta, Nyerere and Obote (who were key players in Phase- 4 of the EAC project) had been shaped by the independence struggle and the African unity movement of the 1960s. However, by the 1970s their political characters went adrift from the original ideals that motivated the cooperation, with Kenyatta being labeled a 'capitalist' due to his affluence and schemes to acquire massive estates ${ }^{20}$ something that made many to accuse him and his governing elite (such as Moi) of primitive accumulation. This personal accumulation of wealth heightened the "ideological differences between 'socialist' Tanzania and Uganda and 'capitalist' Kenya" (Nzioki \& Tostensen, 2005:2). Uganda's Obote is reported to have turned to tribal politics in order to reign in on growing Buganda nationalism with a serious repercussion of the 1971 Idi Amin military coup. This phenomenon also exposed Nyerere's want in diplomatic etiquette because being the senior statesman he could have acted better: due to his disagreement with Amin, he allowed himself to be dragged into a senseless war of words with the military ruler. Even in contemporary times, leadership competence for stirring the regional bloc is still a challenge, as Nzioki and Tostensen observe that even though most of the earlier crop of leaders has been replaced, there are still some at the helm who have been "recycled" and still carry the painful experiences of the past with them (p.3). Such a leadership inadequacy has tremendous impact on the overall behavior of the members-states and sustainability of the EAC.

Even though the statist angle on intergovernmentalism holds that, "it is national governments that control integration" (Ujupan, op cit) and argues for an interstate bargaining platform where states negotiate outcomes (Laursen, 2008:3), the fact of globalization and the non-naturalness of the African colonial nation-state implies that a more apt theoretical framework is necessary for a contemporary analysis. In order to factor in all the complexities involved with regionalization project, I use the framework known as metagovernance generated by the European Union scholar Bob Jessop. In his book, State Power: A Strategic-relational Approach (2008) he writes that, “...the emergence of metagovernance [is] part of the more general change in the forms of statehood. Metagovernance is a response to governance failure" (Jessop, 2008:218). To him, metagovernance means, 'engineering' the political and economic environment or conditions of governance (Jessop, 2008:7). With the incessant challenges of development and governance, especially in the global south there is a pertinent rationale to

\footnotetext{
${ }^{20}$ The 2011 Forbes magazine reported that the Kenyatta family owns land to the tune of 500,000 acres; the 2013 Ventures magazine reported that Kenyatta's widow Ngina Kenyatta was among the top three African women billionaires.
} 
investigate how regionalization projects (such as the EAC) would apply metagovernance to achieve sustainability. He advances three basic modes of metagovernance, namely, i) metaexchange, ii) meta-organization and iii) meta-hierarchy. The first deals with re-designing markets; the second is the re-designing of institutions while the third is re-designing the conditions of self-organization. He basically argues that as regionalization takes place, regional governments get overwhelmed and fail to deliver; therefore the solution lies in adopting metagovernance. It is about the engineering of political and social environment to ensure that government works.

Jessop states that, "If the market, hierarchies, and peer governance are three modes of managing human affairs, then each has a meta-level where they are balanced and calibrated to deal with failures. The calibration of the three in an overall framework is the subject matter of metagovernance" (ibid). To Jessop metagovernance is an attempt at 'rearticulating' and 'collibrating' ${ }^{21}$ the different modes of regional governance. It is finding a working formula for ensuring that a balance is made between governing amalgamated states and realizing national interests. This framework is applicable to the EAC because apart from being a huge amalgam on five countries ${ }^{22}$ (and expected to expand further to include South Sudan), the region has one the most dynamic and malleable demographic variables. By 2012 the region had a population of 135.4 million growing at an average of $2.6 \%$ with over $54 \%$ below the age of 30 years (EAC, 2012). With an average real GDP growth rate of $5.9 \%$, and a regional drive towards universal primary education and increase in school completion rates, the region is slated to have a vibrant middle class in a couple of decades. This presents one of the greatest windows of opportunity to engineer the region's institutional climate and personal attitudes for a better and sustainable Community.

A political analysis reveals disparities in the region, which call for political re-organization hence the need for metagovernance. The political culture in the core countries (Kenya, Tanzania and Uganda) indicates both resemblances and differences. A pivotal observation is that the behavior of the ruling parties veers more towards the politics "survival" rather than

\footnotetext{
${ }^{21}$ Zahid Raiz (2011) has stated the clearest explanation (in my view) of the term 'collibration'; he defines it as an approach to managing tension between opposing forces (or interests) in the social arena through government intervention.

${ }^{22}$ The EAC, as the earliest regionalization project in Africa, started with three core countries of Kenya, Tanzania and Uganda but has grown to include Burundi and Rwanda; currently South Sudan is in advanced stages of formalizing its membership in the bloc; and some analysts project the bloc to attract Somalia, and perhaps Sudan and Ethiopia in the near future (see: Obbo, 2013).
} 
"sustainability" of processes and institutions. Commitment to long-term political and social ideals and goals has been replaced with political expediency and this threatens the EAC project. At the political philosophical level, the leading political party in Uganda (the National Resistance Movement - NRM) is increasing adopting a form of 'hybrid Marxism' to ensure political longevity; this places a question of the sustainability of the institutions and processes thereof. I use the term 'hybrid Marxism' to mean a particular functional adaptation of Marxist political ideology by the NRM for purposes to keeping a semblance of being true to its guerilla founding leftist-leaning roots that gave birth to the consensus 'movement' politics. The 'movement consensus politics' had endeared the NRM to the masses after wresting power by the gun; this all changed when the NRM turned capitalist by the prompting of agencies such as the International Monetary Fund (IMF) and the World Bank through the infamous Structural Adjustment Programs (SAPs) of the 1990s. The version of 'hybrid Marxism' that the NRM has adopted is visible in its dubious dual-policy character with socialist political rhetoric from pundits whilst continuing with neo-liberalism. This explains the increase in demonstrations and strikes by the civil service and the general public that are violently crushed.

In Kenya's case, the capitalist political philosophy that Kenyatta turned to after independence built institutions that are either outdated or over-stretched by the realities of increasing calls for economic justice. As observed earlier, the institutions and systems left behind by the colonialist had been built to simply facilitate the colonial master's exploitation of the colony at the cheapest cost with as little returns to the native as possible. As the native population increased the institutions have been found wanting. Relatedly, due to fierce resistance from the natives, the British colonialists had turned to importing foreign slave labor to build their colonial system in Kenya and after independence this colonial policy produced a multicultural society. During Moi's time the Kenyan government consciously encouraged multiculturalism as a way of diffusing tribal politics but with little success to show because the structural economic realities rendered most natives poorer. This has undermined the domestic institutional framework that the colonialist left rendering the security, legal organs suffocated with endemic corruption and crime thus perpetuating systemic injustices. The fact that Moi lasted in power for such a long time amidst such levels of crime and corruption may be indicative that he may both have politically encouraged and benefited from it. Combine that with growing numbers of unemployed or underemployed youth and the situation is seen for its unsustainability. Recently, to solve those challenges, the Kenyan government promulgated a new federal constitution in order to devolve power and achieve better service delivery; but the scheme is being threatened 
by the pre-existing tribalist tendencies disguising as the politics of devolution. Suffice to note, as indicated earlier, that the institutional framework left behind by the colonialists gave Kenya economic advantage over its neighbors and there is still a lingering feeling of injustice suffered by the neighboring countries when the EAC-1 was dissolved with Kenya taking the lion-share of industries.

Tanzania underwent political transition after the death of Nyerere but by the late 1990s it was an economic mess that raised the inflation rate to $37.1 \%$ by 1994 and rendered the state coffers empty, coupled with entrenching political patronage and corruption. These were symptoms of a country that was yet to overcome the social single-party hangover that had been left behind by Nyerere. It has been a transition that has tested the socialist Chama Cha Mapiduzi (CCM) from a single-party system to a neo-liberal democracy and it is proving a challenge. The young generation is restless and wants to explore more choices than what their parents had, however there are still crops of the old guard that believe in a statist approach. This explains the slow warming towards the EAC within the current leadership in the CCM. This is coupled with the difficulties emanating from the political relationship between Tanganyika and Zanzibar. All these political and economic challenges betray symptoms of governance and development unsustainability.

\subsection{Unsustainability resulting from governance and justice issues:}

These disparities indicate that despite calls for fast-tracking the East African integration process at the level of external relations, the domestic policies and practices of the ruling parties in the three core countries are divergent and unsustainable for the regional project. A report by the committee for fast-tracking the integration that had been appointed by the Head of State during the August 2004 Nairobi Summit, recommended three fast-tracking options: i) compression of the traditional stages of integration, ii) using both overlapping and parallel processes of integration, and ii) immediate establishment of an East African federation (EAC, 2004).

Apparently the leaders have chosen the first two having realized that it takes a lot more than optimism to realize a sustainable Community of countries East Africa. The first option means that EAC member states could quickly go through the traditional stages of federation that other blocs such as the EU have worked through over the years; these include the Customs Union (realized in 2005), the Common Market (signed in 2010), Monetary Union (signed in 2013) 
and a Political Federation, which is expected soon in 2017. These stages have been captured in the table of events below as adapted from that provided by Uganda's Ministry of EAC Affairs:

Tab. 3.2: Fast-tracking the EAC:

\begin{tabular}{|c|c|}
\hline Date & Highlight \\
\hline $\begin{array}{l}\text { November 30th } \\
1993\end{array}$ & $\begin{array}{l}\text { Permanent Tripartite Commission (PTC) for East } \\
\text { Africa signed by the Heads of State of Kenya, Uganda } \\
\text { and Tanzania }\end{array}$ \\
\hline 29th April 1997 & Commissioning of the treaty in Arusha \\
\hline 22nd January 1999 & $\begin{array}{l}\text { Kenya, Uganda and Tanzania agreed to sign EAC } \\
\text { Treaty }\end{array}$ \\
\hline January 1999 & $\begin{array}{l}\text { Memorandum of Understanding (MoU) on } \\
\text { Foreign policy coordination, adoption of zero tariffs, } \\
\text { implementation of COMESA's } 80 \% \text { tariff reduction, } \\
\text { setting up of a mechanism to deal with terrorism and } \\
\text { postponement of admitting Rwanda and Burundi }\end{array}$ \\
\hline April 1999 & $\begin{array}{l}\text { This understanding led to the official launch of the } \\
\text { East African passport }\end{array}$ \\
\hline 2005 & Customs Union came into effect \\
\hline 2007 & Rwanda and Burundi joined the block \\
\hline 1st July 2010 & Common Market Protocol came into effect \\
\hline November 2013 & Signed Monetary Union Protocol in Kampala \\
\hline $2017 ?$ & Projected date of Political Federation? \\
\hline
\end{tabular}

As far as the second alternative is concerned it implies having similar or analogous programmes of integration running side by side in the whole region; and the overlapping aspect means that these programme intersect and extend into each other. It is quite commendable that the EAC Secretariat has implemented a number of activities to this effect. For example they have such activities as annual EAC Good Governance conferences, regular EAC Dialogues on Political Integration, among others. While having an in-depth interview with one of the key architects of these programmes at the Secretariat's Political Federation department, the researcher was briefed on how the Secretariat is handling the challenges being encountered towards the realization of the federation. 
From my discussion with those in charge of the implementation of these programmes the biggest fear that they harbor that of sustenance mainly due to challenge of funding. There is little indication of commitment from the individual countries' political leaders to fund the projects of the Secretariat. This is understandable because back home in the individual countries, there is little political capital in being seen to spend resources on the EAC project due to the historical reality of having been conceived by the colonial masters. This is as huge unsustainability factor for the Community's prospects. Media reports also support this fear; in 2011 it was reported that "East African Community summit in the Burundian capital Bujumbura, [had] revealed that the political leadership is more optimistic about the process than its citizens." (Naturinda, 2011).

The integration process would still face the challenge of unsustainability if lessons from the earlier experience of EAC-1 are not taken into consideration. For example the top-down elitist approach to the integration still lingers on: the integration fast-tracking report identified this challenge (EAC, 2004:12) and it recommended that a wider range of stakeholders should be included in the processes this time, which includes the private sector, professional associations, civil society and the people at large. However, the recommended three phases of strategic intervention from the preparatory through to the consolidation phase did not lay out clear strategies of involving the people. As Korwa has pointed out, there is "lack of empowerment of the East African electorate in the EAC activities either through direct elections or referenda" (Korwa, 2011:39). This is unsustainable at the very least and would be sowing the seeds of failure.

I discussed earlier the social political philosophy that motivated the colonization project and drove it to the time of independence of the colonized peoples. Scholars have identified social Darwinism as the philosophy that animated colonialism particularly in Africa and other colonies in the South (Byrd Hall, 1971). Having this approach to colonialism would make visiting injustices to the colonized people not such a big issue after all they are 'less fit to survive' in the Darwinian understanding. But being humans as they actually are the natives fought back against the unjust colonial systems and colonial projects such as the EAC suffered as a consequence. This philosophy can still be traced within the historical reverberations of the EAC and the current framers and architects of the Community would do well to found the new project on a better governance philosophy. 
In order to analyse and propose ways in which to avoid the pitfall that the EAC-1 suffered this study uses the Rawlsian view of justice as fairness to innovate ways of building a sustainable political federation in East African peoples. A detailed discussion is undertaken in later chapters but first we have to take note that although John Rawls was not focusing on sustainability of political systems as such, his views on justice could be of great relevance to the sustainability of social and political developments. In addition to the Rawlsian view of justice, the researcher thinks that using the governance theory of metagovernance as generated by Bob Jessop (2008). I think that this theory is relevant to this analysis because the EAC is a conglomerate of governments from five countries (and some are being considered to join the bloc). In simple terms metagovernance is commonly referred to as the 'governing of governments'; and if the EAC is to be sustainable there is need for leaders who are knowledgeable in the art of metagovernance.

\subsubsection{Unsustainability resulting from social injustice and in-capabilities:}

It is obvious as per my discussion so far that while investigating issues of the future of EAC's federation, colonialism cannot be ignored as a contributing factor. But wherever colonialism is mentioned, questions of justice always come up. It is therefore logically viable to relate the sustainability of the EAC with the justice challenges that there may be in the colonial practices, systems and institutional frameworks that were there by the time of mooting the idea of a federated East Africa. Likewise it is logical to connect the investigation into the sustainability of the EAC with the question of whether the colonialists prepared the native population with the capabilities to govern and manage such a large social and political project. The capabilities of the native leaders and the population are critical to ensuring a Community that can survive for long.

Therefore from a social justice point of view there are many challenges that are decipherable if the EAC is to be a sustainable political, economic and social development for the region. In this investigation I use the perspective of Rawls of 'justice as fairness' albeit aspects of the Nozickian view suffice. (I treat this issue in more detail under the chapter on: "Justice and Sustainability", in which I express why I prefer to apply the Rawlsian view to the EAC and its sustainability). But briefly, Rawls in his 1985 paper, "Justice as fairness: Political not metaphysical", argues that there is need for a 'political conception of justice' (Rawls, 
1985:224) for a modern democratic institutions ${ }^{23}$. According to him, this conception would be 'framed' to apply to the 'basic structure' of 'political, social and economic institutions' (ibid) in society.

In this particular paper Rawls argues for the perception of 'justice as fairness' not as a 'traditional moral doctrine' but as a political conception of justice. If political, social and economic institutions are to be just they ought to embed fairness in their basic structure. This postulation is based on the thinking that the purpose for political philosophy in a democratic society that is undergoing a season of 'fundamental questions' (which I strongly think the EAC is undergoing currently) is to examine underlying bases for agreement and mutually acceptable resolutions (ibid., 226). In that line of thinking therefore, and as Rawls discusses, justice is a pertinent issue to ensure that it is realized in such a political season as this that the EAC is undergoing.

Elsewhere in the study I have done a more detailed discussion of Rawlsian view of justice but at this point I want to use the elementary aspects of it in order to observe the existence or nonexistence of justice in the EAC. The region's basic structure of political, social and economic institutions as was set up by the colonialists was such that justice could not be realizable. Socially the natives were excluded from the social benefits and amenities that were available. In the book, Africa Under Colonial Domination 1880-1935 (1985) Boahen has detailedly discussed with evidence how socially unjust colonialism was in the whole of Africa. Boahen points out that even though towards the end of direct colonialism there were changes such as independence movements and constitutional changes, the underlying "social base" was infused with a colonial 'ideology' (Boahen, 1985:570). And this 'social base' was an environment of injustice that still has some impact on the former colonies albeit waning in most places. So the institutional framework that the original idea of the EAC was built on was basically an unjust system and therefore it was bound to be unsustainable.

When we look at the question of sustainability from a capabilities angle the same conclusion is made: the natives were not prepared well for the running of the institutions that were left

\footnotetext{
${ }^{23}$ Though Rawls discusses the parameter of modern democratic institutions in his paper, in this case I assume that 'democracy' as such is a preferred political good that the East African Community would make part of its institutional set-up. For that reason I would not delve into discussions of how democracy relates with the social justice and sustainability of the Community.
} 
behind by the colonialist both intentionally and unintentionally. Perhaps a comment that has appeared recently in the press from the diplomatic dispatches (to the American foreign office) made by the former British deputy governor of the Uganda colony to the American ambassador during the independence struggle would suffice to prove that the colonial master were not interested in preparing the natives to handle government:

\begin{abstract}
At one point, the British Chief Secretary, second to the Governor, called me to his office in Entebbe and said he understood that I had been quoted as being in favor of early Ugandan independence. I remember him shaking a bony finger in my face saying, 'Young man, this country is not going to be independent for at least 25years, ' and added, 'We are not going to make any concessions by bringing Ugandans into government until they fully merit it' (Lubega, 2014).
\end{abstract}

The colonial masters in Uganda consciously decided to keep the natives ignorant concerning the intracacies of adminstration and in the dark as far as regional governance was concerned. Here the deputy governor is quoted claiming that they would only do so only when the native Ugandans merited it; and that begs a question of who was to determine when the natives would 'merit' to be given some governance roles. In order to properly interrogate the sustainability of the EAC this challenge of capability needs to be addressed.

\title{
3.9.2 Unsustainability resulting from colonial governance: direct and inverse relations:
}

From the observations of Agbor, Fedderke and Viegi (2010) in their paper, "A theory of colonial governance", we can surmise that the character of any post-colonial state is to a great extent predetermined by the governance style that the colonizers applied during the period that the citizens and indigenous rulers spent under colonization. We notice that the theoretical approach that they used in their study is a retrospective comparative analysis of what became of industrial and agrarian African countries (particularly in sub-Saharan Africa) that were under colonial rule. In their analysis, they observe that the transfer of human capital from the colonial masters (especially during the periods of struggles for independence) to the elites among the natives, the colonial masters have to choose between enhancing economic productivity gains (for their selfish economic interest) on one hand and losing political power to the natives on the other (Agbor, et al, 2010:2). The choice that a given colonial power took determined what 
transpired (and in most cases still does) in the country after independence particularly in terms of economic performance and governance. The choice taken by the colonial masters while handing over power and its implementation depends on four main factors, namely, i) governance technology, ii) productivity distance between elite and masses, iii) human capital returns, and iv) production function specification. So depending of the choice made by the colonial masters, each country in sub-Saharan Africa has ended by fairing economically as far as that choice was deemed to take it.

Fortunately, this analysis is easily applicable to the East African Community because the three core members, Kenya, Tanzania and Uganda were under the rule of the British by the time of independence and the formation of the first EAC-1. When it came to choosing between enhancing economic productivity and loosing political power, the British colonial masters faced mixed fortunes in the EAC region. In the less economically advanced parts of the region (particularly Uganda and to some extent Tanzania), they apparently gave up political power with less resistance or violence. But in a country like Kenya where they had more economic vestiges, it was a difficult and bloody struggle for the natives to wrest power from the British. In Kenya between 1947 and 1961 the British violently tried to crush the famous Mau-Mau independence struggle and its warriors but failed. This proves that they were not ready to transfer human capital skills to the natives especially in the domain of governance. In retrospect, this had been the same approach applied by the Germans in Tanganyika at the turn of the century (1905-1907); they violently crushed the Maji-Maji rebellion but that violence did not destroy the native African spirit and desire for freedom and self-determination. These examples prove that the colonial masters (British and Germans) were not all that interested in the transfer of human capital from the colonial masters to the natives. As discussed earlier in some cases the colonial masters destroyed huge piles of government documentation and records in a bid to erase their brutal and inhuman colonial rule. Such actions indicate a lack to desire to transfer governance skills and tools for effective government continuation after the handing over of power by the colonial masters; this could partly explain the governance crises that soon engulfed the region after the euphoria of attaining independence.

It would be prudent to draw attention to an observation that the idea of 'human capital transfer' that Agbor and his colleagues used in their discussion would actually be interpreted to mean the transfer of capabilities from the colonizers to the natives. It implies enabling the natives to by equipping them with the skills and capacity to undertake the running of a modern political 
and economic institutional set-up for the proper sustenance of a given country. As in an earlier quotation of the former British diplomat to Uganda, it is apparent that the former colonial masters in the EAC region either deliberately refused to proactively 'transfer' this necessary 'human capital' or circumstantially found themselves failing to do so.

Given that observation and from the theoretical discussions of Agbor, et al, it is therefore logical to conclude that there emerges two main relations in the dynamic processes of power transfer from colonial masters to the native rulers. The first one is i) a direct proportionality between colonial governance style and the economic performance of post-colonial sub-Saharan African countries; and ii) an inverse relationship between transfer of capabilities from colonizers to natives and sustainability of post-independence states. In the former case, a keen observation of events in post-colonial Africa shows that the more the former colonial masters transferred human capital to the native leaders, the more stable (sustainable) those states turned out in post-colonial times. Likewise, the reverse could hold truth that the less the colonial masters transferred, they rendered the newly independent states unstable. In the latter case, the governance formula or style that the colonial masters chose to employ is directly proportional to the economic (and in some cases social) health or performance of the newly independent African state. We notice that in the case of Kenya, even though the economy was stronger than other east African economies, the colonial masters had mostly imported Asian (Indian) businessmen who were employed as middle traders for the colonial factories. This left many natives with little or no skills to meaningfully and satisfactorily engage in the economy; and this has been a legacy that has been at the bottom of instability in the country.

Fig. 3.1: Inverse and Direct relations in colonial governance:

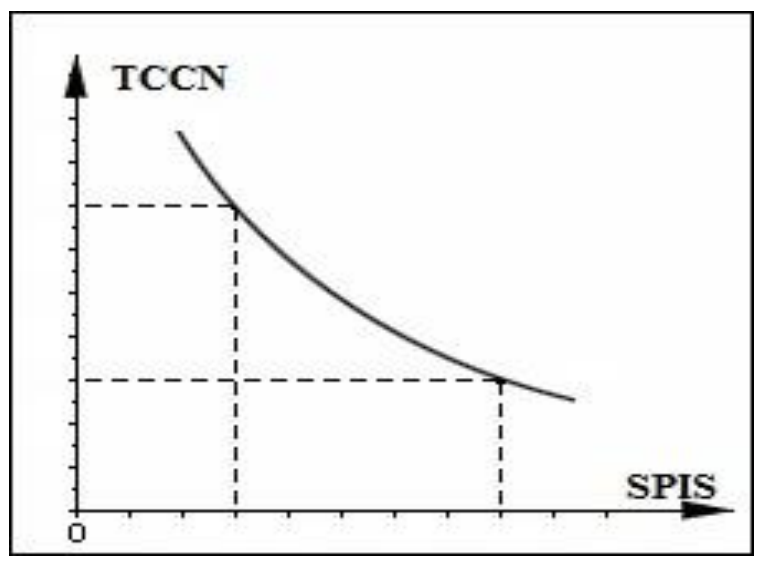

An inverse relationship between transfer of capabilities from colonizers to natives (TCCN) and sustainability of postindependence states (SPIS) 


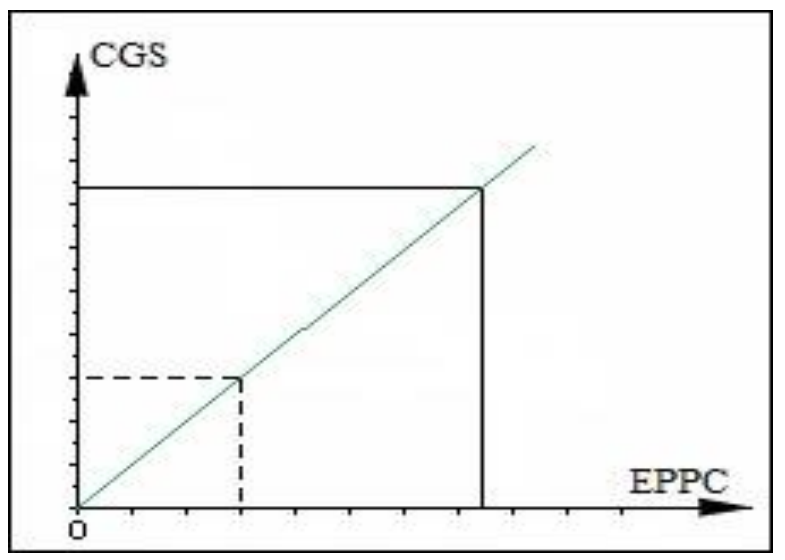

Direct proportionality between colonial governance style (CGS) and the economic performance of post-colonial (EPPC) sub-Saharan African countries

The capabilities of the natives in former colonies was greatly disadvantaged at the time of independence to many possible factors including the many years of systematic and institutionalized oppression and injustices and purposive policies that the colonizers pursued to ensure that post-independent states turned out into failed states. This was a recipe for disaster after independence jubilations particularly as evidenced by the collapse of the EAC and many other problems that ensued after independence.

\subsection{Native leaders' capacity for governing big (groups of) states:}

The above analysis and observation implies that there is need to assess the capability of the native leaders in the East African Community to govern not only the single state governments they inherited but also bigger multi-state entities such as the proposed and fast-tracked federated EAC. If it has been observed that the former colonial masters knowingly or circumstantially hindered a transfer of governance skills and capacities to the native leaders in their respective countries, then it would be all the more difficult to find such skills as required for the governance of larger or groups of states as the EAC, among the native leaders. This could be a core explanation for the quick collapse of the EAC-1 that has not previously been given enough attention. Among the immediate independence leaders of the three core EAC countries, there was little knowledge of how to run a regional government and much of their attention was occupied by national or even local governance concerns. There was little time left to focus and learn how to govern the East African Community. The only exception that is worth mentioning is the Tanzania experiment that has largely been the most successful political marriage in the region if not the whole continent: Tanganyika and Zanzibar joined in 1964 in a political marriage called Tanzania that has largely been cordial despite the stoking of cessionary forces within its borders over the years by those opposed to the political union. 
The ability to govern a larger conglomerate of states that make up the EAC has been defined by some scholars as metagovernance. As hinted on in the first chapter, the basic understanding of 'metagovernance' is that it is the governance of governance. In other words, metagovernance holds in order to be able to administer large groups of states, governance theory and practice has to shift from the traditional 'command and control' fashion of bureaucracy in smaller homogenous states to "indirect steering of actions and interactions of relatively autonomous stakeholders" (Bevir, 2009:132). The gist of metagovernance is the 'engineering' of the environment or conditions of governance (Jessop, 2008:7) and steering them towards a desired social goal. With the historical experience of the dissolution crisis that took place in the EAC there is historical evidence that the management of a regional state or 'grouping of states' as it were, is necessary in current times. There is therefore a good rationale to investigate whether the regional bloc has capacity to effectively govern itself and if so, how the EAC regionalization project is applying metagovernance to engineer sustainability.

Jessop has observed that there are three ideal styles or combinations of metagovernance, and these include the i) hierarchical, ii) network, and market styles (Jessop, 2011:106-23). Within any of these styles, the practical meaning of governance is not defined by the institutions or agents at the regional or group level but by the constituent members of the group. In another of his works, the gist of metagovernance, according to Jessop, is the 'engineering' of the environment or conditions of governance (Jessop, 2008:7). In political terms this implies that the regional or 'state-group' leaders are tasked with ensuring a conducive environment for constituent member countries to define their meaning of governance as long as these definitions adhere to the commonly shared vision of cooperation. Given the complexity of modern societies, this requires expertise not only in deciding on the appropriate style of metagovernance to adopt but also a necessarily competent knowledge of the local, national and regional conditions in which to apply it. In terms of relevance to the East African Community such a framework is applicable to: i) interrogate the competence of the leadership in governing the region towards the stated goals of the Community, and ii) to explore possible policy engineering and innovation avenues for sustainable development in the region.

It is therefore necessary to examine the ability of native leaders in terms of 'governing competence' and 'policy engineering competence' towards a sustainable Community. In the case of the EAC, its metagovernance would imply how to handle the governing of the larger body-politic referred to as the East African Community, which is an amalgam of the various 
individual state governments (i.e., Burundi, Kenya, Tanzania, Uganda, and Rwanda). The concern is whether there is capacity within the leadership pool to metagovern this larger political entity. Secondly, among the three distinguishable versions of combinations or styles of metagovernance, namely, hierarchical, network and market, there is need to find out which one or which combination is most appropriate for the bloc and whether the capacity to govern in any of those styles does exist.

\subsubsection{Tanzania: the travails of an African political marriage:}

Tanzania's leaders seem to have more experience in metagovernance, as it were due to the fact of the Tanganyika-Zanzibar political marriage that has been in effect since 1964. In terms of metagovernance, the governance style is more tilted towards network metagovernance. This conclusion could be reached based on three grounds: i) the letter of the Act; ii) the pan-African forces behind the Union; and iii) the actual governance execution by the leaders. In preamble of Act of Union of Tanganyika and Zanzibar (1964), there is mutual recognition of both the Republic of Tanganyika and the Peoples Republic of Zanzibar. For that matter it was expressly stated in the Act that the leadership was to be shared between two individuals representing both nation-states, namely, Julius Kambarage Nyerere and Abeid Karume (Art 6(2)). Since 'network metagovernance' means administration of public or private entities through consciously established mutually respectful networks, the cited portion of the 1964 Act seems to augur well with that style of metagovernance. And to a greater extent Mwalimu Nyerere's rule over Tanzania is considered to have been more or less respectful towards his Zanzibari comrades and kindred. It can at least be considered to have mutual existence because after Nyerere's reign, a Zanzibari Ali Hassan Mwinyi took over as the president of the United Tanzania; albeit his successor in Zanzibar, Idris Abdul Wakil is considered to have sowed seeds of agitation for separation by separation activists because he did not continue with the reforms that Mwinyi had started in their Island homeland.

Though this evidence proves that Tanzania could be more experienced in inter-state political metagovernance, within the very Act that brought Tanzania and Zanzibar into political marriage lay the challenges to the governance of the United Republic. Even though the president of the United Republic was given powers to appoint officials to work in the United Republic's government from both Tanganyika and Zanzibar, the Act did not specify the quota of those officials to be appointed. This could become a point of contention in case one party in 
the political marriage would feel less represented in the appointments. This has been a constant spring of wearisomeness in the Tanzanian political experiment. In any case the presumably inherent peer-to-peer approach in network metagovernance (that does not consider one level of authority to be superior to the other) came under great strain in Tanzania after the demise of Nyerere would have commanded great respect as the father of the nation and the political union has suffered increasing challenges from both parties.

Going forward therefore, Tanzania also has to skillfully navigate its way through a dynamic tension between the former dominant political philosophy of socialism and the newer neoliberal economic forces that are considered to define a contemporary state. The political party that has continued to dominate Tanzania's political landscape, Chama Cha Mapinduzi (CCM)evolved from the Tanganyika African National Union (TANU), which itself had evolved from the Tanganyika African Association (TAA). Socialism was the dominant political philosophy that animated these political struggles. The emergence of Zanzibar and Pemba's Peoples Party (ZPPP) represented a mixture of native and African-Arabic nationalism. These are the forces that were behind the Tanzanian political marriage; and they were as good as it could have been for a post-colonial Tanzania. But the pressures of a post-Cold War era forced Hassan Mwinyi in July 1986 to ascent to International Monetary Fund's (IMF) demands for introduction of conditional liberalism of the economy. In so-doing, he brought a new cultural and political force in form of neo-liberalism, a wave that has challenged the traditional political class of Tanzania. The IMF's conditions of cutting public expenditure, liberalization of trade, abolition of import taxes and currency devaluation brought changes that pitted certain sections of Tanzania's political spectrum against the leadership of the CCM. This tension is attested to by the country 2025 vision official document: in the document it is stated that, "The second national Vision was the Arusha Declaration. It articulated a philosophy of socioeconomic liberation based on socialism and self-reliance as the long-term national goal of Tanzanians" (GoT, 1999:7). In the pursuit of this vision there have emerged challenges that the leadership in Tanzania would have to confront if it is to be adequately prepared for the governance of the whole region.

\subsubsection{Uganda: governing an amalgam of traditional states:}

Following Tanzania in terms of experience in mini-metagovernance is Uganda which is actually an amalgam of a number of kingdoms (and chiefdoms) some of which were highly 
advanced in terms of statehood and government structures particularly Buganda, Bunyoro, and Toro kingdoms. By the time the British colonialists arbitrarily forced these kingdoms and other chiefdoms into the modern state of Uganda, those three kingdoms were highly advanced traditional dynasties that would qualify to be identified as self-sustaining states in the modern sense of the word; such that forging them together into modern Uganda would qualify to be referred to as mini-metagovernance. Like many scholars of pre-colonial Uganda, Christopher Wrigley (1996) has described Buganda has a highly organized and disciplined traditional whose administrative systems left lasting impression on the colonial powers; the dynamic nature of its leaders and structures (Wrigley, 2002:1-19) ensured its survival through the turbulent pre and post-colonial times. This historical position has made it determinant in Uganda's modern politics (see: Johannessen, 2005). In 1966 when the Uganda Peoples' Congress (UPC) party of Milton Obote despised this historical fact and attacked the palace of the Kabaka (king) of Buganda, this event (1966 Crisis) plunged the country into civil unrest and war for two decades. The current National Resistance Movement (NRM) did not ignore the importance of these traditional kingdoms, particularly Buganda, during its guerrilla struggle. This explains the NRM's quick success during the war (Kasfir, 2002); perhaps if it had ignored Buganda it would not have captured power or taken longer to do so. This was especially true given that Buganda is the most economically advanced (Reid, 2003) if not the richest region in Uganda with the economic muscle to sustain a guerilla movement.

Even before independence, all Ugandan leaders had in effect to be governors of an amalgam of traditional states at different stages of administrative maturity. The combined traditional states (kingdoms) of Buganda, Bunyoro, Toro, Ankole plus a number of hitherto decentralized communities and chiefdoms, make Uganda one of the best examples of the need for metagovernance skills in the east African region. The 1995 Constitution of Uganda tried to address this administrative challenge though with limited success. Chapter Eleven of the Constitution introduced decentralization, a contemporary administrative approach, but also tried to cater for traditional political sensibilities for dominant actors like Buganda; to that end Art. 178(3) provided that the districts of Buganda will have presumed to have 'automatically' cooperated, a strange but interesting twist which attests to the influence of the Kingdom. As mentioned earlier, the question of Buganda's place in Ugandan governance could not be 
ignored or relegated as the 2009 Buganda Riots ${ }^{24}$ (that left dozens dead and injured) were to prove. Administering such a state requires skills that are fit to the task; following the Riots, the ruling political party, the National Resistance Movement (NRM) set into motion both political charm and legal measures to curtail the ever growing of Buganda. For that reason, the Institution of Traditional or Cultural Leaders Act (2011) was largely a stop-gap measure to realize that effect and many Baganda and other traditional loyalists from other regions have criticized the Act arguing that was ill-motivated.

The challenges and successes registered in administering a complex state like Uganda indicate that the leadership has some experience in metagovernance, at least a mini level and in African terms. In regards to the three styles of metagovernance, and given that traditional kingdoms and states were basically administered in an authoritarian way, it can be concluded that to a great extent the style of metagovernance that has been applied in Uganda is the hierarchical type. This conclusion is all the more justifiable given the fact that at the time of its capture of power, the NRM was mainly a socialist and Marxist ideologically driven group. Such a governance philosophy is more compatible with the hierarchical style of metagovernance because it also emphasizes a top-bottom structural approach to public governance. Nonetheless it suffice to note that after the disappearance of the Cold War in the 1980s and the death of Mwalimu Nyerere who was a great mentor of the main architects of the NRM governance philosophy, the party gradually oscillated towards capitalist economics. However, even though Ugandan economics is tending more towards capitalism, the ruling political NRM has not yet overcome a hangover of socialist ideas and Marxism always turns up in its official messages and administrative practices.

This habit of sporadic continuation and discontinuation of Marxism and invocation of socialist political values and slogans makes one to conclude that the 'governance philosophy' that has informed the NRM-O regime in Uganda since the end of the Movement system is a brand of its own. This can be referred to as a kind of 'transmorphing' of Marxist ideology that is taking place in Ugandan political thinking and practice; in this case 'transmorph' as a word is used to mean a combination of two transitory processes that are taking place concurrently in the NRM,

\footnotetext{
${ }^{24}$ In 2009 after the central government blocked the Katikiro (Chief Minister of Buganda) from travelling to a youth celebration function in Kayunga District, many ultra-traditionalist Baganda interpreted that as contempt of their Kingdom and it provoked widespread riots that pitted them against the forces of the Ugandan Special Forces army (after overwhelming the police) for days. At the end many were dead and injured an occurrence which reminded Uganda and the region of the political dominance of Buganda in Uganda.
} 
i.e. transformation and metamorphosis. In order for the NRM as a political entity to realize internal cohesion, it espouses Marxist and socialist ideology and values; but at the same time it desires to deliver on its promise of developing the country and to do this it has to pander to capitalist demands by international organs like the IMF and the World Bank who provide funding for government projects and its extensive patronage network. So you find that it economically relies on the capitalist ideology but politically it espouses Marxist ideas. This is what I refer to as 'transmorphed Marxism'; meaning at the core of the party there are strong Marxist or socialist values but for economic expediency, those values are relegated in order to access global credit and attract foreign investments into the country. A case in point is the reluctance of the NRM government to publicly display commitment to clearing the central business district of Boda-boda riders (motorcycle transport providers) who are almost turning into a hazard due to the number of accidents and inconvenience they cause. In a city of 3.1 million dwellers, with only $38.5 \%$ of tarmacked roads, there is an estimated number of 240,000 boda-boda riders who account for $42.4 \%$ of motorized road and over $62 \%$ of road accidents (Kitaka, 2012). Despite these glaring figures, many NRM politicians including the president always support the boda-boda riders mainly because they are a big political mobilization machine. The phenomenon of a transmorphed Marxist political ideology in Uganda could have far-reaching implications for the East African Community because Uganda is currently playing a key role in the integration process.

\subsubsection{Kenya: the challenge of 'uhuru' and sustainability:}

In terms of metagovernance, Kenya presents as interesting case mostly because of its postindependence turn towards capitalist economics and politics. Kenya is the most capitalist member country of the EAC having decided to join the West during the Cold War era while under president Jomo Kenyatta. For that reason Kenya can be classified as a market style of metagovernance and it has the most experience among the member countries of the EAC in market responsive governance. But it also presents the best example of how this style could also harbor seeds of unsustainability for a given body-politic. As noted earlier in the cases of Tanzania and Uganda, Kenya can also be referred to as an amalgam of traditional African states that were arbitrarily brought together by the colonial masters. The dominant and most politically active groups such as the Kikuyu, Luo, Kalenjin, Luhya, among others are always pitted against each other jostling for political power and this requires advanced skills for the leaders to govern and develop Kenya sustainably. 
The two most prominent figures of the independence struggle in Kenya were Jomo Kenyatta and Jaramogi Oginga Odinga. Both of them were politically born and hewed out of the African emancipations struggle spirit of the 1940s and 50s. In the case of Jomo Kenyatta, spending some of his formative years in Britain and encountering great African nationalist figures such as Kwame Nkrumah ensured that the rhetoric he used during the independence struggle in Kenya was socialist and Marxist. Likewise, Oginga Odinga represents a similar spirit of socialist inspired African independence struggle that he encountered during his university student days at Makerere University in the 1940s. During the independence struggle both of them used socialist and leftist rhetoric to rally mass support for the cause; with Oginga Odinga forming the Luo Thrift and Trading Corporation (LTTC) in 1947; while Jomo Kenyatta joined a radical guerilla group known as Mau Mau (which evoked unprecedented terror from the British colonial masters). At time of attaining independence both joined government with Kenyatta as President and Oginga as vice president.

But after attaining power their political philosophies diverged from each other; in the book, Suffering Without Bitterness (1968) Jomo Kenyatta was apparently replying Oginga Odinga's earlier critical work, Not Yet Uhuru (1967). Oginga had used pro-poor, pro-workers and anticolonialist language to call for Kenyans not to relax thinking that they had attained freedom; he warned that complacence would lead them into economic slavery given that after being granted political independence, Jomo Kenyatta's ruling party, the Kenya African National Union (KANU) had gotten into bed with “...an increasing number of politicians in British, American and West German commerce and big business" (Oginga, 1967:298). In response, Jomo Kenyatta sought to distance himself from the militant and radical rhetoric that Oginga had exhibited in his book; even though Kenyatta had been a leading figure of the Mau Mau movement, in his book he distanced himself from the radicalism of the group; he wrote that, "Those who built up an organization of unbridled violence in Kenya were never the political associates or executive colleagues of Kenyatta" (Kenyatta, 1968:56). From that time until his death Kenyatta placed Kenya on the pathway of working with its former colonial masters who had so terribly treated and humiliated the natives of that country; this made Kenyatta and those who cooperated with him become extremely rich while leaving the majority of natives poor and bitter. This divergence has been at the root of the social fissures that Kenya has seen over the years since independence and renders governing the country a delicate balance that could easily oscillate into unsustainability if the leaders are not skilled in governance. Kenyatta's 
tilting towards a capitalist political ideology (which in effect is market metagovernance) has to a great extent been useful in quantitatively building the Kenyan economy but has unfortunately created great economic and political injustices that still bedevil the country and threaten its sustainability from time to time.

From the above analysis of the capacity of the leaders in the three core member countries of the EAC to govern multiple states joined together (metagovernance), it is deducible that there is considerable experience in handling groupings of states. But the types of states that they are experienced in governing are the traditional African kingdoms and chiefdoms that were forcefully brought together by colonialist to form the modern nation-states of the EAC. Besides, these traditional African states had been considerably weakened and some almost destroyed by the misrule of the colonialists; so in most cases by the time modern statecraft became the way of governing, the traditional African states were too disorganized to present concerted and prolonged challenges to the modern governors. Albeit in some striking cases like Buganda in Uganda, probably owing to historical and advanced social structures, there have been some insurmountable challenges in governing traditional African states.

However, contemporary governance in a globalized world where bigger nation-state groups are increasingly becoming the modus operandi, the challenges of governance could be quite different from what they have been traditional. This is mostly true in the case of almost all African post-colonial states because they inherited colonially fashioned nation-states whose structures were functionally designed to exploit the natives and benefit the colonial masters and their parent countries in Europe. This antagonism between the traditional African kingdoms and the modern colonially crafted nation-state still lies at the core of the causes of the unsustainability of most of Africa's nations today. The same challenge exists in the East African Community and it would be prudent for its leaders to take this condition into account. All the leaders in the three core member countries of the EAC, i.e. Kenya, Tanzania and Uganda have a contribution to make to the sustainable governance of the regional bloc owing to the experience in administering groups of traditional African kingdoms brought together. But the realization of the sustainability of the bloc will depend greatly on how the translate that experience into contemporary governance of larger nation-state groupings like the EAC. 


\subsection{Conclusion:}

This chapter has discussed the issue of EAC integration and the challenge of sustainability. It has examined lessons that could be learned from the past experience of the collapse of the first EAC project. It has shown that the integration idea was actually mooted by the former colonial masters and their legacy is still evident on the revived project. The research has shown that colonial masters used a 'colonial-functionalist' approach in the earlier integration and therein lay the seeds of unsustainability that contemporary leaders in the region have to take note of and resolve. The chapter discusses the need for caution and careful consideration of the possible future expansion of the EAC; there is need to consider governance issues such as social justice, economic equity, etc in order to mitigate possible causes of fissures and rifts within the region.

\section{CHAPTER IV}

\section{COMPREHENSIVE ETHICAL SUSTAINABILITY}

\subsection{Introduction}

This chapter lays out the premises upon which the scheme of "comprehensive ethical sustainability" is conceived and how it could be applied to governance and development theory and practice in East Africa Community. The study sought to advance this scheme as a contribution 
to enrich governance and development discourse. The first section introduces and explains the assumptions by which an ethical concept is conceived or generated. The second section deals with the challenge of 'moral complexity' to provide a contextual background for generating the main concept. In the first part of the second section I discuss the challenge of achieving justice in this age of globalized development arguing that the 'Capabilities approach' is the most relevant theoretical framework within ethical concerns can be comfortably raised and attended to. In the second part the moral challenges that governance faces in pushing for development and the need for 'development virtues'. The fourth section discusses 'virtue' and 'principle' demonstrating where the two approaches to moral reasoning converge in order to justify the need for comprehensive ethical sustainability.

\subsection{Definition of Comprehensive Ethical Sustainability (CES):}

The study defined CES has a scheme for understanding, founding and realization of sustainability processes and agency through the incorporation of ethics in sustainability theorization and praxis. At the theoretical level, it deals with how ethical theory can sustainably remain relevant to a related 'theoretical universe' of sustainability discourse. Practically it deals with how to sustain a viable ethical fabric in society that ensures realization of governance and development sustainability. Therefore the nature of comprehensive ethical sustainability means that the foundational aspect of sustainability that entails ensuring both the relevance of ethics to sustainability discourse and maintaining ethical character that can lead to the realization of sustainable systems and processes.

\subsubsection{Ethics as foundation of sustainability:}

Sustainability requires an ethics-base on which itought to be founded. Any conception of sustainability which is not founded on ethics, would ultimately prove untenable and therefore short-lived because ethics allows room for humaneness, justice, integrity and enhancement of the capabilities of persons involved. Ethics ought to be taken as a determinant factor in sustainability both at theoretical and practical levels. Ethics seriously intervenes in human development efforts and agendas; all other dimensions of sustainability are dependent on the 'ethical' because the ethical lies at the motivational and intentional levels of human thought and action. One unethical action that is of negative impact on sustainability can undo the sustainability of other dimensions that would have been built for years or ages. For example, just a couple of unethical actions (such as bribery) by a one or a few government officials could 
render a forest or a certain species of animal disappear in a very short time. The sustainability of such a forest or specie of animal may have taken ages to build and maintain but it can be destroyed by a single or few unethical actions. Using that example, we can logically adduce that any other dimension of sustainability such as the 'ecological', 'environmental', 'economic', 'political' are preceded by 'ethical sustainability'.

This does not mean that other dimensions of sustainability (social, economic, environmental) are of little importance; rather it means that they profoundly depend on the comprehensive ethical sustainability. If there is no ethical foundation on which to base the other aspects of sustainability, then any effort to redress the challenge would end up being wasted. Even solutions being applied to solve the challenge of climate change are being threatened by corruption because it affects the "reliability and effectiveness" of the carbon trade system (see: UNEP, 2013:2). I can therefore illustrate the foundational nature of ethics in sustainability discourse as follows:

Fig 4.1: Ethics as foundation of sustainability

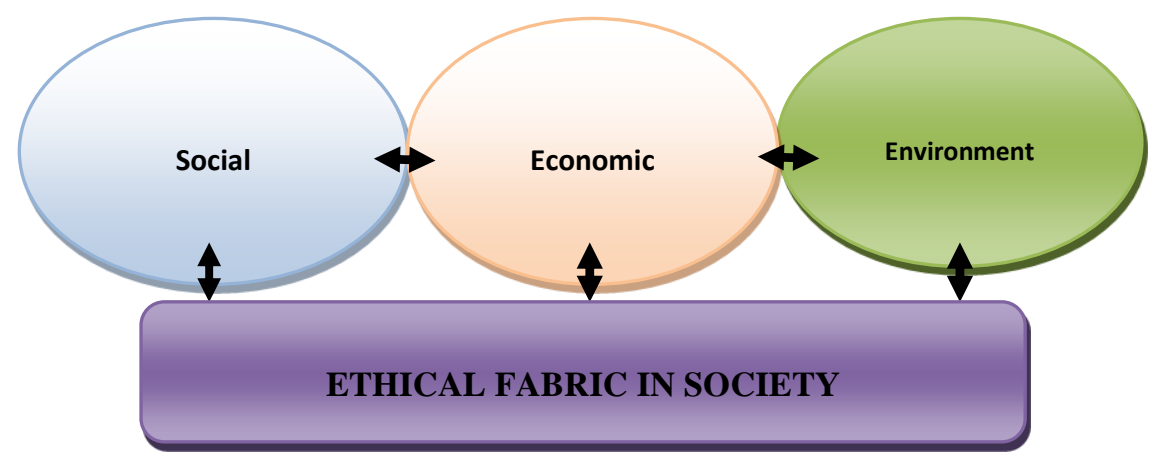

Illustration by Author

The illustration captures the reality that ethics exists both within and underneath all the spheres of sustainability. The backbone any efforts towards realizing sustainability is the ethos within 
which it is conceived and put into practice. The 2013 Report by the United Nations Environmental Programme (UNEP) that has been referred to above vindicates this argument. Sustainability undertakings and solutions do not emerge in an ethical-vacuum; rather they exist within society's moral setup which is maintained by given customs and conduct. But what lays underneath these customs are the ethical standards. Our argument is that pursuing any sustainability paradigm implies necessarily acknowledging the ethos (customs and norms) that underlies it and therefore acknowledging the ethics underneath. This makes a solid case for ethics being the support of sustainable development and therefore relegating or ignoring it can be problematic.

Ethics is important because it not only provides the foundation of all the spheres of sustainability but also inheres in all of them. The reason is because the denominator agent in all these spheres is the human being (whose thinking and action makes up human agency). Ethics becomes pivotal because it lays at the deepest level of human agency, i.e. the deepest values that motivate human thought and action. My conception of sustainability follows this line of reasoning, i.e. ethics represents the most enduring and deepest values and motivators of human agency and since sustainability depends on human agency (thought and action), we ought to focus on ethical dimension of sustainability, thus the generation of the notion of comprehensive ethical sustainability. Sustainability discourse ought to take comprehensive ethical sustainability very seriously because any attempt towards achieving sustainable development depends mainly on human agency; and yet human agency is about human conduct.

\subsubsection{Understanding the Comprehensive Ethical Sustainability (CES):}

Therefore the notion of "comprehensive ethical sustainability" is conceived and defined in both theoretical and practical terms. Theoretically, it deals with how ethical theory can sustainably remain relevant to a related 'theoretical universe' or sustainability arguments or discourse. Practically it deals with how to sustain a milieu of ethical conduct in society that ensures sustainability. Therefore in terms of definition comprehensive ethical sustainability refers to that foundational aspect of sustainability that entails ensuring both the relevance of ethics to sustainability discourse and maintaining ethical conduct that can lead to the realization of sustainable systems and processes. 
In etymological terms, the English word "sustain" came from the old French, 'sustenir', which meant, "holding up" or "making endurable"; with the same connotations it entered Latin as sustinere, meaning to "hold up something from below". Since 'to sustain' means holding up something from below, the sense in which I preposition the concept of "sustainability" is both about i) sustaining the spheres of sustainability and ii) sustaining society's ethical fabric. It entails seeking to ensure that the thinking about sustainability is ethically sustainable and also maintaining a certain level of ethical conduct in society that supports sustainable system and processes.

One strand of "comprehensive ethical sustainability" means that ethics ought to remain relevant (i.e. sustainable) to and at the same time evolve, as it were, with contemporary moral challenges. The moral challenges that are emerging today seem to be stretching from traditional ethical theory and thinking; there is thus need to keep ethical thinking up with the pace of what is going on. Some of the peculiar moral issues to grapple with in contemporary times include technological advancements, globalization, and complex social and ethnic relations, among others. Society is getting more complex thanks to changes like technology, globalization, and multi-culturalism among others. As society evolves technologically and scientifically, various aspects such as economics, governance, etc, are also evolving. Therefore ethics and ethical theory needs to keep pace with these issues. The "endurability" of ethics means the perennial questions of ethics are still important and relevant in contemporary social, technological and economic developments; and that makes ethics still relevant.

The other strand of comprehensive ethical sustainability means that we should not only be concerned about generating ethics theory but that we should also make sure that these efforts are sustainable at practical levels. Apart from ensuring that ethics remains relevant to contemporary challenges, we also need to generate practical ways in which these relevant ethical ideas are applicable to maintaining sustainable systems and processes in society. This approach is what can assist in realizing sustainable development. It means applicability to society's institutions and processes therein in order to make ethics part of their ingredients. As indicated earlier, the sustainability of these institutions and processes that human put in place depends on the ethical base (human conduct) that is underneath them. 


\subsection{Nature of the CES scheme:}

I conceive the notion as a 'scheme of principles' which means a set of selected ethical principles that are critical to sustainable systems and processes. This conception maintains both the classical Greek root-meaning of the word: 'skhema' which meant "figure" or "structure"; and the contemporary meaning of "program of action" based on "component elements". A scheme refers to systematic plan or arrangement for attaining some particular object or putting a particular idea into effect. Following the line of that meaning, the notion of comprehensive ethical sustainability is an arrangement of ethical principles aimed at achieving sustainable systems and processes in society. To that effect this notion is developed with identifying the institutional and individual levels of applicability.

As a "scheme of principles" it is composed of four key principles that are thought to ensure sustainability if applied in tandem. In generating these ethical principles I have not come up with any fundamentally or radically new principles; rather I have harvested and re-organized ideas that have been discussed by key scholars in recent years which, in my view, have great bearing on sustainability. This is because the question of sustainability is a multi-dimensional one and anyone who insists on approaching it from one angle is most likely to miss a lot of useful views. We are living in the age of multi and inter-disciplinary research and this has inspired me to re-organize ideas from a variety of views; albeit the study is in the field of applied ethics. These principles include: i) Capabilities, ii) Justice, iii) Ubuntu and iv) Integrity. In my view if these principles are applied to i) the theorization of sustainability and ii) structural arrangements and individual action they would ensure sustainability. These principles are generated with the view that they would be the best in sustaining the ethics denominators in society.

\subsection{Sustaining 'ethics denominators' and the 'ethihal':}

Any society's ethics has to necessarily have what could be termed as ethics denominators. This refers the basic tenets of the ethical fabric that uphold all the other aspects of the morals that underlie all the aspects of that society such as business, education, and marriage, among others. They may include but not limited to honesty, trust, faith, respect, honor, patience, etc. Just like the mathematical denominators in fraction calculation serve the purpose of showing how many equal parts the whole is being divided into, likewise ethical denominators are the components that make up the 'moral-whole' which I have termed the 'ethihal'. The term "ethihal" is a 
portmanteau derivation following the etymological roots of the words from which it is derived. Two words are applied: i) ethics and ii) hal. The former i.e. "ethi" (ethics) is adjustably used to mean the results that come from its established meaning of "science of morals" - here it is used to mean "the entirety of the viable codes and principles of ethics that guide society". While the latter i.e. "hal" (whole) is taken from its original old English meaning of "entire or healthy or unhurt". The derivation gives us the term, ethihal: which means the ethical whole in society consisting of all the viable codes and principles of ethics that underlie or guide human conduct. It is important to sustain the ethihal of any society without which it could spin into ethical chaos.

\subsubsection{Two complimentary modes of comprehensive ethical sustainability:}

Comprehensive ethical sustainability has two major 'modes' or fashions by which it can take place: the first one is ensuring that type of sustainability that is ethical, while the second one is sustaining the ethical itself. These two modes by which ES is conceived need to be pursued simultaneously and taken as compliments of each other.

\subsubsection{Mode 1: Ensuring sustainability that is ethical:}

The first mode of ES implies ensuring that sustainability is ethical; it is very important that our conception and pursuance of sustainability is ethical itself before it is practicalised. In discussing this mode I will consider two major aspects of sustainability, namely the theoretical and practice levels.

\section{a) Theoretical level}

In the first level of sustainability theorization, ethics has to be incorporated and taken as a key contributor to the discourse. Ethics has not been given adequate attention in the discourse because most traditional approaches to sustainability have considered the subject an amoral field that can only be solved using naturalistic methods of inquiry. We can refer to this approach as amoral naturalism. A lot of funding is given to naturalistic methods of inquiry to find solutions to sustainability challenges such as climate change. The danger in this emphasis can be illustrated by the dominant approaches to solving climate change, namely modeling and simulation.

The dominant epistemic stance that is influencing major climate change thinking and policy making (especially in critical reports such as the annual Inter-Governmental Panel on Climate 
Change-IPCC Reports) is to a greater extent amoral naturalism. These reports are based on models and simulations that are epistemically biased to the contribution of ethics to climate change concerns and the overall sustainability debate. At the level of theory building and climate change modeling, epistemic egoism can be observed and if care is not taken it can slowly turn into epistemic demagogy which can render the sustainability discourse unconcerned about ethical issues.

There is a big risk of giving little attention to ethical concerns if such an epistemic stance (amoral naturalism) is the only one relied upon in an influential report like that because increasingly such reports are becoming instrumental among development and political actors such as regional governments and NGOs. This is building a climate change knowledge community (i.e. epistemic coalition) built on the methods of modeling and simulation that are used in theorizing about the challenge. As Gough and Shackley (2001) point out, "a distinctive knowledge-based approach to climate change assessment and policy has emerged within the IPCC ... [which is] ... providing the legitimacy of inclusiveness needed for the epistemic coalition to have sufficient authority" (Gough \& Shackley, 2001:332). This epistemic coalition or community which is majorly informed by the highly technical aspect of climate change modeling and simulation is increasingly having great authority over the subject.

However, some thinkers such as Giampietro (2007) question the basis of that authority; he is getting concerned about this turn of events within the climate change debate. He has argued and demonstrated that when it comes to complex biosocial challenges such as climate change (i.e. they are immensely influenced by a mixture of both biological and social factors), the science of modeling encounters problems of inadequacies (Giampietro, et al 2007:308). I agree with his observation that complex biosocial systems (such as climate), do not behave like the lesser physical (or mechanistic) systems which only follow simpler thermodynamic laws of nature. Therefore any claim of generating an objective analytical model or simulation of such biosocial systems necessarily involves catering for both the biological laws and postulation of social meanings; and obviously such a combination carries a latent danger of epistemically tilted assumptions (p.308). The implication is that many irreducible aspects of the social-sphere such as ethical nuances and variables are likely to be ignored in the models and simulation. 
If we agree with Giampietro's observation, then it is logical to deduce that the authority that comes from theories (and policies) based on amoral-naturalistic models and simulations, is problematic. This is because the technology used in the models and simulations contains epistemology nuances that relegate irreducible but important aspects of society such as ethical variables. This is why thinkers like Isaac Held have argued that these methods present a challenge of creating truly convincing numerical simulations of our Earth's climate because there is a widening gap between simulation and understanding ${ }^{25}$ (Held, 2005:1609-14). Because of that challenge, Dale Jamieson concludes that even though climate change is likely to occur, our institutions are unlikely to respond appropriately to its effects because the inherent epistemic biases could be misleading (Dale, 1991:319-29). For example the policies that are generated using such data may ignore ethical concerns in the mitigation efforts. It is re-thinking these epistemic nuances that would enable us to re-conceptualize the theorization of sustainability.

Comprehensive ethical sustainability would contribute to solving this challenge in the theorization of sustainability by urging for the incorporation of ethics in the sustainability discourse particularly at the theory level. Theorization means conceptualizing; it means generating an explanation of a given aspect of reality using a certain 'conceptual scheme'. This conceptual scheme is mentally generated from personal mental observations and reorganization of data received from both primary and secondary sources around us. If we are to incorporate ethics into the theorization of sustainability, scholars and thinkers in that domain need to be trained to observe and mentally organize the ethical variables that exist in the realities around us. This requires changing the epistemology and pedagogy that is applied in sustainability studies; we need to incorporate ethics in the teaching of those involved.

\section{b) Practical level}

The second level of the mode of ensuring that sustainability is ethical is the practical. This implies ensuring that actions which are geared towards sustainability are ethically sustainable. At this level I am discussing the practical functioning of both individuals and institutions; if we are to ensure sustainability we need to engender ethics-oriented institutions and actions. It entails engendering ethical competence within institutions and among individuals. This

\footnotetext{
${ }^{25}$ This is indicative of the growing view that since contemporary society is built on scientific and technological assumptions, it is necessary to know the ingredients and nature of the scientific methodologies and epistemologies that underlie the scientific and technological innovations and policies they inspire.
} 
involves changing the agency of the institutions and persons in society in order to realize sustainable systems and processes. At institutional level it involves incorporating ethics in the functionings of the institute by ethically adjusting institutional parameters such as the visions and objectives of the institute among others. While at the individual level it involves ethically changing the attitudes and inner motivations of individuals in order to act in an ethically sustainable way.

To illustrate the actualizability of this practical level, I use Lawrence Kohlberg's taxonomy of moral development as an applicable scheme to achieving comprehensive ethical sustainability. In order to practically realize ES we need to acknowledge that one of the underlying causes of unsustainable societies and organizations is the pervasiveness of unethical behaviour and practices within institutions and among members of society. Therefore there is need for citizens and workers who are ethically competent in both their private and public lives and in their fields of professionalism. We can apply the generated by Kohlberg to realize this. Lawrence Kohlberg was a both a philosopher and amoral psychologist. His views on moral development were greatly inspired by the Swiss psychologist, Jean Piaget and the American pragmatist John Dewey. He represents a movement during the Enlightenment period whereby ethicists sought to scientifically study human morality; they believed that it is possible to develop a systematic understanding of human ethical (or ethical) growth just as it is possible to know biological stages of growth. Using that inspiration, he developed stages of human ethical progression to explain human development from ethical immaturity to ethical maturity. Kohlberg (1973) used cognitive psychological analytical tools to study individual ethical reasoning and development which he then applies to society at large.

The key reason why I think his theory is applicable to my current discussion is because he sought, "...to bridge the gap between naturalistic and non-naturalistic theories of moral judgement and their grounds of adequacy" (p.630). The key argument that is of importance to our discussion is Kohlberg's view that moral reasoning is the basis of ethical behaviour (Kohlberg, p.633). In his theory there are five or six stages of ethical development i.e. progression from ethical immaturity to maturity which are presented in a logical sequence parallel to biological stages of growth. Kohlberg argued that humans underwent progressive change in their ethical reasoning. These stages reflect a focus on discovering laws of social development albeit applied to individual level. He tried to establish predictable patterns in the ethical realm; thus stages of progression form ethical immaturity to ethical maturity. According 
to him, ethical progression in humans flows from "egocentric leanings" (when only simple pleasures and pains greatly determine ethical conduct) through "contractual altruism", and finally to the "principled" stage.

There are three levels: the Pre-conventional, Conventional and Post-conventional and each of these levels contains two stages of ethical reasoning. At the first level the main reasoning behind considering a given conduct comes from the threat of punishment from authority. Stage 2 within this level is characterized by one acting in one's own interest. The second level, i.e. the conventional level also has two stages: the first of which involves ethical reasoning whereby conduct is chosen based on approval from others; and while the second stage involves abiding by the law and doing one's duty. The third level, i.e. the Post-conventional level also has two stages: the first stage being governed by genuine interest in others and the last one having respect for universal principle and demands of one's conscience.

One of the key assumptions in Kohlberg's model is that once a certain level of ethical cognizance is attained it cannot be "unknown"; once it is known, it is known. This assumption is necessary because without it the whole logic of ethical progression would crumble. Kohlberg argues that one cannot jump a stage; each stage has to be attained in succession. In that case therefore, the progression is irreversible.

Tab 4.1: Kohlberg's Classification of Ethical Progress

\begin{tabular}{|l|c|l|}
\hline \multirow{2}{*}{ LEVEL } & STAGE & ORIENTATION \\
\hline Post-conventional & 6 & Universal ethical-principle \\
\cline { 2 - 3 } & 5 & Social Contract; legalistic \\
\hline \multirow{2}{*}{ Conventional } & 4 & "Law and Order" \\
\cline { 2 - 3 } & 3 & Interpersonal concordance \\
\hline \multirow{2}{*}{ Pre-conventional } & 2 & Instrumental relativist \\
\cline { 2 - 3 } & 1 & Punishment \& Obedience \\
\cline { 2 - 3 } & 0 & Egocentric judgment \\
\hline
\end{tabular}

Direction of progress

Ethical Maturity

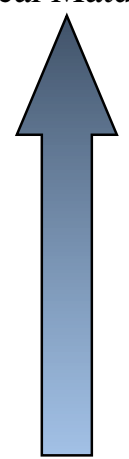

Ethical Immaturity

At the Pre-conventional level child is responsive to cultural rules and labels of good and bad.

During the Conventional level the individual perceives the maintenance of the expectations of 
his family, group, or nation as valuable in its own right. And at the final level of PostConventional the individual makes a clear effort to define ethical values and principles that have validity and application. Below is another table that captures the moral reasoning that is going on in an individual as they progress upwards.

Table 4.2: Ethical reasoning in Kohlberg's classification of ethical progress

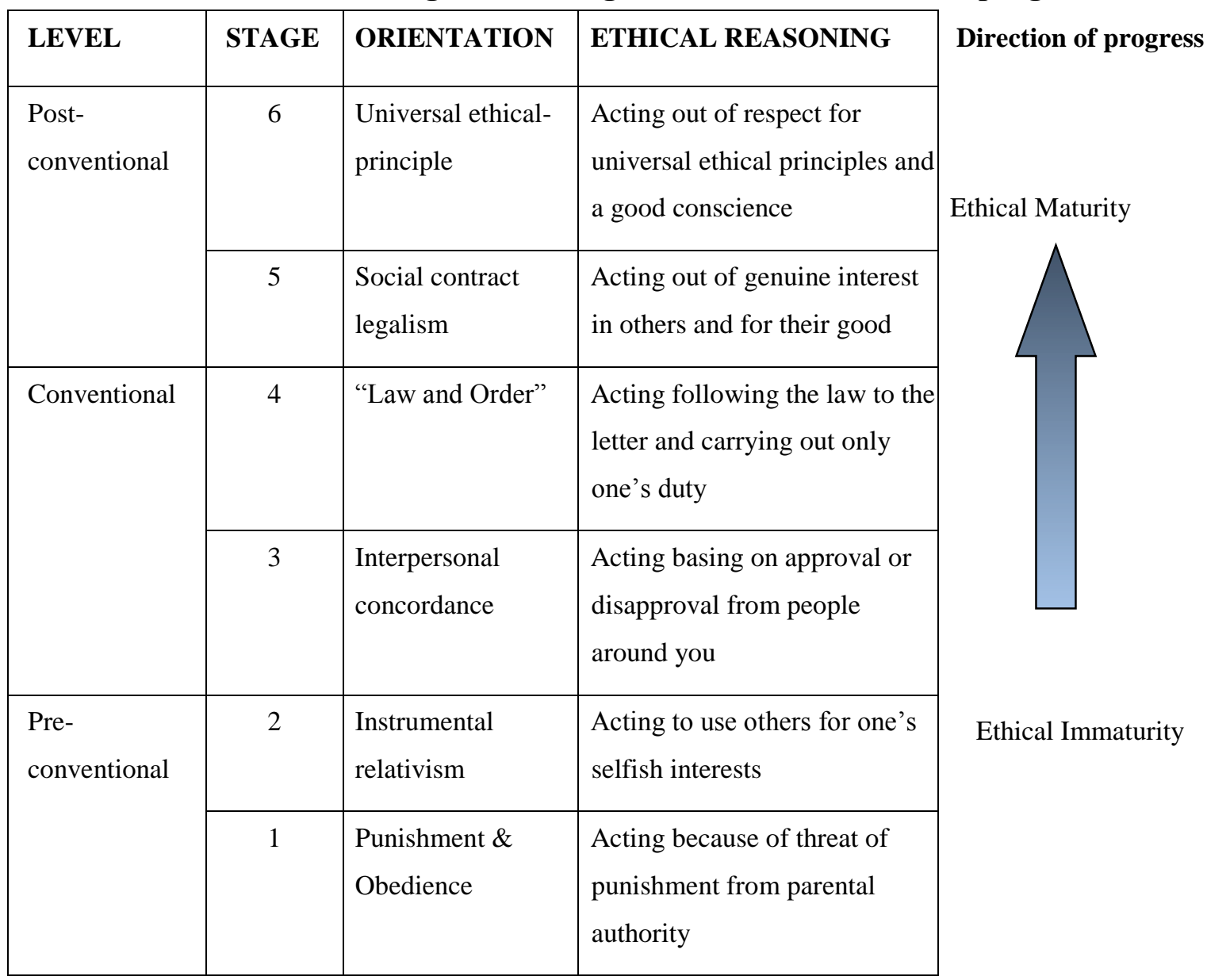




\begin{tabular}{|l|l|l|l|}
\hline & 0 & $\begin{array}{l}\text { Egocentric } \\
\text { judgment }\end{array}$ & $\begin{array}{l}\text { Acting as a simple child (no } \\
\text { concept of rules \& obligations) }\end{array}$ \\
\hline
\end{tabular}

I think applying Kohlberg to our discussion is useful because it provides a viable ground for achieving sustainability at the practical level of ethics in society. It is important to have a sense of possibility of ethical improvement within society. That sense is necessary such that we avoid a static view of possession of moral virtue; this static view refers to the thinking that individuals either have it or not in terms of ethics. We can call it the 'black or white' view of possession of moral virtue. In my view, when it comes to possession of ethical values and conduct it is not about either 'having it' or 'not having it'; I think holding such a view is incompatible with sustainability. Sustainability requires room for ethical improvement; a society that is ethically sustainable needs to hold the view that it is possible for persons and institutions to make ethical progress. We have to hold the view that it is possible to improve ethically.

Using Kohlberg we can generate practical ways of re-organizing institutions and training individuals in ethical improvement. It can be used, first of all, to evaluate the level at which an institution or an individual is in terms of ethical growth. When we recognize and encourage members of society to have the view that it is possible to make ethical progress from one stage to another, then we are practically changing the psychological attitude towards change. ES assumes that it is possible to improve ethical standards from poor to positive and therefore ethics ought to be incorporated into the practices of the society.

These stages of ethical progression could be included into the culture of corporations and social set ups. I think that some of the ways through which this comprehensive ethical sustainability can be incorporated practically is by: i) establishing bureaus of standardized ethics both at institutional and national levels; ii) encouraging people to live ethically by offering rewards for such ethical improvement; iii) teaching parents and guardians on how to train the young ones to strive to continuously improve ethically; iv) promoting a long-term media project showcasing the life-rewards of living ethically. These and many others could be used in a practical way to ensure comprehensive ethical sustainability. 


\subsubsection{Mode 2: Sustaining the ethical fabric of society itself:}

The second mode of ES is ensuring that the ethical itself; earlier in the discussion I had indicated that ES aims at sustaining the ethics denominators of the society. Ethics denominators are the basic tenets on which the ethical fabric of any society is built. The sustaining of the ethical takes place at two levels, namely the primary and the secondary levels of ethical sustenance. Sustenance means managing, conserving and preserving resources for purposes of maintaining life-cycle of a natural or social set-up.

I am persuaded that the sustainability of any human endeavor must incorporate ethics because the concept of sustainability is not complete whether in private or public enterprise without the inclusion of comprehensive ethical sustainability. Comprehensive ethical sustainability means that the activities need to be ethically recurrent but not a once for all ethical action or project. When a business, a profession or a government policy leads to an ethical dead end (negatively impacting on morality) it will soon fall out of favor with the general public and this will lead to long-term loss of business or trust among the clients. Ethics is also necessary for those who may end up working as private businesspersons, legal practitioners, and many other professions. Ethical problematics and dilemmas underlie all sectors and sub-sectors of public and private business including governance, service provision, private and public investment. Therefore ethics analysis, research and training are critical.

Ensuring the sustainability of the ethical fabric of the society is important even though there are those who may think that it is not necessary. For example, many discipline-specific experts argue that studying ethics is a waste of time distracting professionals from their core professions. But they forget that all professions, such as business people do their activities within a human society and there is nothing like an ethical-neutral activity as long as it is done by human beings. The same applies to technology experts who think that technologists should not care about ethics; they are wrong because technology is not done or applied in a vacuum - it takes place within human societies and therefore brings about ethical implications. Professionals need to be concerned with both i) whether those activities are ethical or not; and ii) the ethical impact of their activities.

One of the things that those who disregard ethics forget is that all their activities are carried out with ethical assumptions which they may not openly acknowledge or even be aware of. For example a technology professor assumes that his or her students will automatically act ethically and not steal the laboratory equipment during a practical session. Imagine some students acted 
unethically and stole the equipment. Even those who are researching on the human genome, biotechnology, chemical weapons, and other technological innovations that are normally taken to be amoral, hold an unacknowledged assumption that the people working in those projects have some acceptable level of ethical behavior.

This is a question of ethical upbringing; imagine if those students were not raised with some ethics. That is why it is important to maintain the ethical fabric of society. Those business people who usually rubbish ethics also forget that their work in deeply based on the assumptions that people are ethical enough to pay for their goods and services that they offer rather than stealing them. They also have to assume that their workers will not deceive about their work and the quality of the labor they provide! These are issues of ethical attitudes that need to be examined and instilled in the graduates of whatever discipline.

\section{a) Levels of ethical sustenance}

It is important to sustain the ethical fabric in any given society; without efforts to do so there can emerge a lull or stagnation in the ethical state of that society which can prove to be quite challenging. That is why it is necessary to ensure that the ethical fabric is sustained. Using the term 'sustenance' in this ethics discussion is intended to capture the essential importance of sustaining ethics as it is used in biological terms which connotes vital nourishment for life; likewise the ethical fabric is essential for the sustenance of society.

In the first instance, the term sustenance is used here to connote the upholding and supporting of what exists; but in the second sense, the ecological meaning of preserving and conserving also applies; in the third sense, the biological meaning of nourishment is still applicable. Any ethical system requires efforts to sustain it; and given the complexity of contemporary ethical challenges, there is need to support the ethical fabric for purposes of i) upholding the ethical integrity of the given society; and ii) making the ethical discourse to be in tandem with the changing ethical terrain. It is important to us as ethicists to ensure that a society's ethical fabric remains in existence because without such a fabric that society may relapse into moral chaos. In the same vein, it is of great necessity that the existing ethical fabric has the relevant tools of analysis, conceptual frameworks, among others, that enable it to remain relevant to the constant 
changes that are taking place in society. For instance, as society becomes more and more advanced technologically and scientifically, there are many challenging ethical questions that are coming with such changes; therefore ethicists have to generate relevant tools of analysis and concepts that can competently analyse these challenges.

In this vein, I have conceptualized the sustenance of society's ethical fabric takes place at two levels: the primary and secondary levels. There is a fundamental level that is foundational to the ethical fabric of society, I call that the primary level; then there the outer structure of the ethical fabric and I have referred to that as the secondary level.

\section{i) Primary ethical sustenance}

The primary level of ethical sustenance refers to the foundational or the fundamental aspect of the ethical fabric. The primary level means a stage of early significance; it is a determinant level of everything. This means that if we do not get it right at this level it would be difficult to correct the mistakes in the future.

\section{ii) Secondary ethical sustenance}

The secondary level of ethical sustenance refers to the additional aspects of the society's ethical fabric that are built on top of the foundational aspects. The secondary level means

\subsection{On using the 'principle-approach' in attaining sustainability:}

It is important however, to first consider the common criticism against the principle-approach: is this approach able to transform individuals and societies into ethical ones? Charles Lamore represents the dominant virtue-ethicisits' criticism against the principle-approach. In his position on moral complexity Larmore argues that virtuous living is not merely adherence to principle but applying virtue in complex political and social situations (Lamore, 1987). He strives to go beyond deontological and consequentialist theories of morality by expressing scepticism about the existence of, "...any neat principle for resolving [moral] conflicts..." (p.148). He dichotomises between 'virtue-ethics' and 'principle-ethics' and criticises the principle-approach to moral issues because much of that approach is Kantian and yet Kant's principle of universalizability could also be used to universalize immoral actions (p.27).

Interestingly Larmore invokes Aristotelianism to argue that being moral is not simply adherence to principles but about applying virtue. He argues that, "Virtue is a matter of 
character, a firm disposition to act virtuously" (p.12). But it does not necessarily follow that a principle-approach to moral questions is exclusive to being virtuous. The reason for his desire to 'separate' virtue from principle is the fear that the principle-approach could be applied in a cold and mechanist manner without a deeper commitment to balanced humane character. This is for example illustrated by his postulation that, "Deontological duties are misunderstood if construed as duties to ourselves to preserve our moral purity...Thus [becoming], neither an ethics of conviction nor an ethics of responsibility..." (p.148). Nonetheless, in my view, this statement indicates the erroneous thinking among many critics of the principle-approach; they argue that it lacks humane conviction in its application to resolving moral problems. But the question is that why should we think that humaneness and principlism are mutually exclusive? The two are not necessarily exclusive as thinkers like Larmore would want us to think. I think a brief review of the ancient Greek rendering of the concepts of 'virtue' and 'principle' is necessary in order to shed light.

Stories from ancient Greek societies were full of tragedy (both of the gods and the people) to the extent that it was developed into an art form. This is how these societies reconciled themselves with hard facts of loss, suffering, war, death, among others (see: Nussbaum, 2001). The tragedy authors had discerned that one of the causes of their failings in the face of war was the internal moral character of the people in a given polis or state. For example the story of Oedipus represents a combination of 'fate of gods' and 'human moral character' in deciding the destiny of the city of Thebes (Edumnds, 1981). But for purposes of this discussion my focus is on human moral character because many of these Greek thinkers were concerned that the internal moral character of their societies was failing them in times of great external threats.

Apart from the gods, human character had an equally important role in shaping the Greek polis. In stories of antiquity such as Homer (in Odyssey, Bk 1), the arête (i.e. virtue) that is bestowed upon human heroes by the gods is translated into courage or strength to face difficult situations. The human heroes or personalities in the stories need moral dexterity or excellence of character (virtue) in order to fulfil their destinies. This infers that the background from which the meaning of 'virtue' takes its form connotes meanings such as being 'brave' and 'effective' in character. The focus on capacities such as brevity and effectiveness in human character is what is most important. This indicates that from ancient Greek times the personal level of moral character was as important as the social level. This background connotes an implication of 'effectiveness' 
of character. Personal moral aptitudes such as brevity, strength, wit and others are to be applied together in order to fulfil one's destiny.

But a problem in this conception is identifiable in Homer's stories, as Macintyre wrote that, "In the Homeric poems cunning is such a quality because cunning may have its achievements where courage is lacking" (Macintyre, 1985:123). In other words, the Homeric characters (both gods and humans) could apply deceptiveness where necessary to realize their desires and goals (see: Iliad, 1.46). This implies that undesirable traits such as cunningness may be taken as an acceptable virtue in Greek tragedies. The allowance for traits such as cunningness and deception (as part of arête or virtue) in Greek classical literature is traceable from the belief in fateful destiny. In many Greek stories there is a bizarre mixture of fate and human responsibility. This mixture confuses the meaning of virtue; 'virtue-ism' when it is divorced from principles, could easily translate into unseemly conduct such as replacing courage with pretense, or reasoning with deceit, etc.

To escape this problem virtue ought to be conceived not merely as the inner sentimental drive in human character whose actions stabilize friendship and society as Macintyre postulates i.e. sentiments that keep the "social order" intact (Macintyre, 1985:123). If the end is just to keep social order, then the conclusion that Macintyre reached may be inescapable; that "fate is a social reality" (p.124). Macintyre writes that, "The man who does what he ought moves steadily towards his fate and his death" (ibid). This statement captures the problem in such a conception of virtue; the phrase, "what he ought" implies having a higher ideal to which one subscribes but the insinuation that thinkers such as Macintyre conjure up is that the end justifies the means i.e. if achieving one's or society's goals necessitates replacing courage with deceit, then it can be take to be morally acceptable.

That conception of virtue makes the virtue-approach to social order to appear as an undependable to uphold ethics. When he argues that "...character and incident cannot be characterized independently of each other" (p.125), he implies the subjectivization of virtue; something that seems to be antithetical to his earlier observation that virtue is for stabilizing social order. If there is possibility to replace courage with deceit (and it is celebrated), then the ability of virtue to stabilize social order becomes questionable. The challenge first is that character may be more stable because it inhibits in the individual (even though human 
individuality is also capable of fluctuations); second, incident comes in variations that could not possibly be pre-known and this makes moral issues complex.

\subsection{Reconciling the 'virtue' and 'principle' approaches in applied ethics:}

Granted, virtue in most logical formations implies the 'subjective' for it lies within - it is moral habituation that is ultimately cultivated by the individual into their person. It thus becomes a 'disposition' as Larmore indicates (op cit, p.12); but when this disposition or inner habituation comes out in form of outward action, then it also become a concern of the collective. Therefore we should not leave virtue at the subjective (and sentimental) level because if we hold that view as virtue-ethicists then we leave the collective at the mercy of the subjective. Virtue should therefore take into consideration that fact that incidents in human societies vary from time to time - that is why in many cases, personal character and the incidents (which provoke that character) may actually be characterised as different from each other.

If one acknowldges the distinction between 'personal character' and 'incident' (which keep changing), then it becomes possible to reconcile the 'virtue' and 'principle' approaches. This takes us back to the distinction we made between Macintyre's 'what he ought' to do and 'what ought' to be done. Virtue is in most cases conceived as concerning an individual's inner character to live virtuously; but this may allow for moral expediency in the sense of Homer's allowance for cunningness and deceptiveness to be part of virtue. The challenge of moral expediency arises from the observation that if an individual acts as a result of ' what he ought' to do, this localizes the moral act and it lets it depend solely on the individual's discretion and subjectivity. In this way, sometimes deception or cunningness may be justifiable. The individual's wrong character may be justified contingent on the peculiarity of the incident that he is facing. Since the incidents are varying, the individual may continuously justify wrong character to be part of his 'virtuous life'. It gives room for justification of vices which may pass for good moral character. If one agrees that this is possible then the 'virtue-approach' alone is not sufficient because it solely depends on the individual's 'disposition', which is ethically risky.

On the other hand, 'what ought' to be done differs from the former in the sense that it allows for the 'objective' (the 'collective') i.e. that which goes beyond the incident. It is true that in the 'short run' individual human concern is about the incident but in the 'long run' it shifts to the objective. In a certain sense, 'what ought to' transcends the particular 'incident' because 
after a series of incidents it is not possible to ignore the 'cumulative effect' of the summation of those incidents. Since incidents keep coming, if an individual's disposition lead to justifying vices such as deception and cunningness, it could have a long-term effect. It is the consideration of the cumulative impact of how we have acted in the previous series of incidents that brings out the importance of legacy that accrues from the repeated action or thought. In repetition of action there is an enduring (or cross-cutting attitude or approach) acknowledgement of which necessarily leads us to think about what trend or principle(s) guided those actions across space and time.

If social order is to be maintained in society, it is necessary not to solely rely on the "virtueapproach'; but in addition to individual character we also need to apply principles that cut across specific spaces and times. Ethics is about actually ensuring stability of both private and social order and one of the dimensions of this order is thinking about the 'long run'. This kind of thinking is always taking place in our minds and words - we are concerned about how we live now but more importantly about how our offspring will live tomorrow - how their social order will be; whether it will be tenable or not. Therefore we necessarily need to think of and generate principles to guide action in society.

This approach is usually referred to as the 'principle-approach' to ethics challenges or principlism. In setting forth the principle-approach in bioethics, the Georgetown team which included Beauchamp and Childress argued that the set of principles that they had proposed could be traced from both the Kantian (deontological) moral philosophy and the outcomebased (utilitarian) ethics of Jeremy Bentham and J. S. Mill (Beauchamp \& Childress, 1994:125-6). The term principlism comes from the word 'principle' derived from the old French word, 'principe' which means origin; in ancient Greek terms it meant 'axioms' or 'basic assumptions'. These are basic assumptions that are applicable to various ethical situations across time and space. Beauchamp and Childress, who were the first to extensively propound and defend the principle-approach, write that the label "principlism" was coined in the late 1980s by Clouser K. Danner and Bernard Gert to refer to all accounts of ethics comprised of a plurality of potentially conflicting prima facie principles (p.388).

Principles are on the whole taken to be, "general statements from which particular decisions are to be drawn by a process of deduction" (Van Hooft, 1999:21-29). In ethics principlism is 
an approach to solving moral and ethical dilemmas through a deductive reasoning that applies basic guidelines to various situations or fields. Principlism as an approach to solving ethical dilemmas, has gained prominence in ethical circles because it is thought to be: neutral, pluralistic and all-embracing (Miyasaka, 2002), because, “...the orderliness and relative clarity of Principlism... [has] a special appeal for practical-minded clinicians who adopted it widely" (Pellegrino, 1993:82).

\subsection{Sustainability in the CES scheme:}

The study defines Comprehensive Ethical Sustainability (CES) as the understanding of sustainability processes and agency to be founded on and realized through the incorporation of ethics in sustainability theorization and praxis. Theoretically, it deals with how ethical theory can sustainably remain relevant to a related 'theoretical universe' of sustainability discourse. Practically it deals with how to sustain a viable ethical fabric in society that ensures realization of governance and development sustainability. Therefore the nature of Ethical Sustainability means that foundational aspect of sustainability that entails ensuring both the relevance of ethics to sustainability discourse and maintaining ethical character that can lead to the realization of sustainable systems and processes.

The study postulates that sustainability requires an ethics-base on which it ought to be founded because both its means and ends have ethical implications (Sen, 1999; Gasper, 2004); and we can approach its analysis from that angle. Any conception of sustainability which is not founded on ethics would ultimately prove untenable and therefore short-lived because ethics allows room for humaneness, justice, integrity and enhancement of the capabilities of persons involved. Ethics ought to be taken as a determinant factor in sustainability both at theoretical and practical levels because it both motivates and intervenes in human development efforts and agendas. That is why this study considers all other dimensions of sustainability to be dependent on the 'ethical' because it lies at the motivational and intentional levels of human thought and action (Kohlberg, 1984; Blasi, 1984).

One unethical action that is of negative impact on sustainability can undo the sustainability of other dimensions that would have been built for years or ages. For example, just a couple of unethical actions (such as bribery) by one or few government officials could render a forest or a certain species of animal disappear in a very short time. The sustainability of such a forest or 
specie of animal may have taken ages to build and maintain but it can be destroyed by a single or few unethical actions. Using that example, we can logically adduce that any other dimension of sustainability such as the 'ecological', 'environmental', 'economic', 'political' are preceded by 'ethical sustainability'.

\subsubsection{Nature of the principles of Comprehensive Ethical Sustainability (CES):}

As indicated earlier, the study understood CES to be suitable for realization of sustainability because it allows room for ubuntu, justice, integrity and enhancement of the capabilities of persons involved. These variables were also recast as the basic principles and pillars of the CES scheme. These principles were chosen on the strength of both for their, i) 'axiomatic' value, and ii) 'utility' capacity; and within contemporary development discourse, these grounds of their value is justifiable both a priori-ally and a posteriori-ally. In terms of the former, the principles are ethically axiomizable such that they are used to capture values of profound importance to the sustainability of human society. In terms of the latter, these principles are considered to be easily applicable in building social processes and institutions in the region under question.

For purposes of avoiding the intractable debate between deductive and inductive reasoning the 'axiomization' that is applied in selecting these principle is hereby referred to as 'ethical axiomization' in contrast to modal logical axiomization. The term 'ethical axiomization' is used to mean the use of given words or expressions to compress ethical value that is considered to be intuitively and consequentially perceivable. But this 'axiomization' should not be equated with 'reductionism' as such because the explicative and applicative power of ethical principles ensures that there is little likelihood of losing the virtue import of these ethical axiomizations or principles (see: Zucker, 1984). This ethical axiomization is taken to be of necessity in order to extrapolate their ethical value across disciplines such as from applied ethics to development and governance. For example the principle of ubuntu is chosen because it axiomatizes the, i) deeper African philosophical values, and ii) essentializes the time tested ethical values of indigenous African societies. So unpacking such a principle would bring out the rich ethical values embedded therein. Below is a representation of the hierarchy of the selected principles: 


\section{Fig 4.2: Ethical Sustainability fabric:}

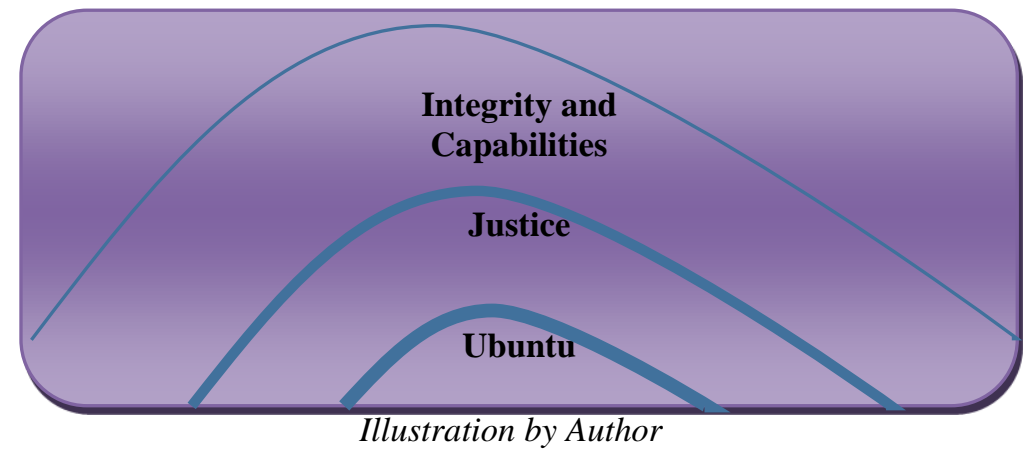

The above figure is a representation of an ethical fabric that would ensure the realization of sustainability in sub-Saharan Africa. The four principles that make up the Ethical Sustainability scheme are: 'Ubuntu', 'Justice', 'Capabilities' and 'Integrity'. The Ubuntu principle acts as the inner-core of the scheme; while the Justice principle functions as the outer-core; and the Integrity and Capabilities principles function as the mantle and the crust of the scheme respectively.

The axiomization of these principles took into consideration three characteristics, namely, being i) compound, ii) compatible and iii) complimentary. In terms of compoundness these principles were selected because they have capacity to mix more than one and inseparable aspects of the African experience and therefore capture the complexity of the region at hand such as the colonial experience by which the natives of the region suffered and benefited at the same time. In terms of compatibility, they were considered to their perceivable malleability with sometimes intractable ethical theoretical perspectives such as intuitionism and consequentialism; in addition due to their compatibility with African political and development realities. In terms of complimentarity, these principles were selected on the basis of the ease of being applied in tandem towards the goal of sustainability. Due to time limitation, in the following section of the paper I give brief remarks on the three of the principles and then focus on the Ubuntu principle. 


\subsubsection{The Justice principle:}

Justice is conceived both as a principle and condition of ethical sustainability; the application of justice in this case is in terms of social justice an understanding that goes beyond mere legalist understanding of the same. The argument is that if political and social processes are to become sustainable in the long run, they ought to incorporate social justice. The study uses the Rawlsian theory of 'justice as fairness' as a commencing point to: i) explore possible points of convergence between distributive and entitlement views of justice; and ii) argue for the indispensability of social justice in the pursuit of governance and development sustainability in the EAC. The main tenet of this principle is that any political, ecological or environmental efforts geared towards sustainability that involve unjust processes and produce injustices towards sections of a given society cannot be sustainable in the long run. This is because any unjust system breeds both i) victim disaffection and ii) villain encumbrance which conditions render that system unsustainable.

Rawls theory of justice especially as expounded in his Theory of Justice and particulalry the notion of the 'veil of ignorance' is relevant this discussion as indicated in the earlier articulation of the conception of rationality. But as I argued earlier, a Rawlsian view of achieving sustainability is redeemable only by re-conceptualising rationality. The veil of ignorance assumes a certain level on rationality among the people in Rawl's ideal society. It is on that assumption that he developed the first principles that would guide the institutions in that society. He argued that the principles that would emanate from a position of veil-of-ignorance would be, “...rational and free persons concerned to further their own interests would accept in an initial position of equality as defining the fundamentals of the terms of their association" (Rawls, 1999:11). Using that basis he generated the principles that would guide the realization of justice.

He postulates that self-interested rational persons behind the veil of ignorance would choose two general principles of justice to structure society. These two principles include: i) the principle of equal liberty (p53); and ii) the difference principle (p47). By the first principle he argued that each member has an equal right to the available liberties in society; whilst by the second principle he argued that social and economic institutions should be set-up such that (a) they benefit the least advantaged persons, and (b) their offices should be open to all members of society. 
After facing criticism over the possibility that his theory of justice would not be adequate for catering for future generations (intergenerational justice), in a later version Rawls modified his theory by adding the third principle. This is known as the "just saving principle" (p266); this was meant to place a kind of moratorium on the uncontrolled expenditure that may accrue from following the "difference principle". By trying to realize the purpose of the second principle, the justice of future generations may be negatively affected; therefore even as society build institutions that would ensure that the least advantaged receive justice, it should save for the coming generations. But he also warns against excessive saving that may over-burden the present generation; "an excessive rate of saving must on balance mitigate the burden of those bearing this hardship" (p.267).

I agree with Rawls to the extent that he developed good principles of justice that would enable us realize justice for the disadvantaged and the future generations; but his assumption of the nature rationality is problematic. I think that good as Rawls' principles are, it would be very difficult to use them to realize sustainability as long as the concept of rationality on which his veil of ignorance is founded is the self-interested as inherited from the Adam Smith conception and that of Darwin's survival-of-the-fittest. As pointed out earlier we need to move away from "self-interested rationality" to "conscientious rationality". It is very difficult to realize sustainability within a setup of self-interested persons. Rawls ends in the same boat as Adam Smith who thought that self-interest would be used for the good; Adam Smith has influenced many decades of economic thought and it is true that using that logic humans have realized massive economic gains. However, the self-interest rationality has brought us thus far with numerous problems of injustice and environmental imbalances thus rendering the current mode of development unsustainable. We cannot re-organize our society to realize justice as Rawls postulates while leaning on the same conception of rationality.

My criticism of the Rawlsian assumption of rationality should not be construed as the radical postmodern criticism of rationality that emerged during the post-war period. I still believe in the human capability of reason but it has to be re-imagined in different fashion. We need a new conception of rationality that is conscientious in order to realize sustainability. For sustainable justice to exist members of a given society ought to have a rationality that has a conscience; it is members who are genuinely compassionate about the legitimate needs of both the disadvantaged and the future generations. This would enable us to avoid the pitfalls of the past development milieu which has been characterized with unsustainability and injustices. 
Therefore the justice principle in the scheme of comprehensive ethical sustainability means establishing structures and processes that avoid mistreating or denying opportunities to any section of society; the establishment of these structures and processes should be built on persons who possess a conscientious rationality that enables them avoid selfish utilitarian exploitation of nature and fellow humans. This is important for comprehensive ethical sustainability because without ensuring justice for all, those who suffer injustices at a given time would most likely look at all the systems put in place by the oppressor group as unjust and would seek to destroy them. This would fail the goal of sustainability because in each generation those who think that they are mistreated would set out to destroy the work of the previous one.

\subsubsection{The Integrity principle:}

The study generated a working definition of integrity as the ethical wholesomeness of being and personhood. The definition seeks to capture the two major aspects on integrity: i) the totality and wholeness of a given being, and ii) steadfastly holding onto ethical principles that guide a person's or a group's conduct. The issue of ethics has been considered to be central to both aspects of integrity because in each case, the enterprise of realizing integrity requires certain standards or qualifiers that are of some ethical nature. In order for a person to be the right agent of sustainability within the social, political and legal institutions in a given community, that person ought to have ethical character. For that matter integrity in terms of personhood is achievable at two levels, namely, i) personal, virtue, and ii) professional level.

In the first instance of personal virtue, the individual or group of individuals can be said to be a person of integrity if their behavior is right and ethically principled. It concerns ensuring that individual agency is virtuous and ethically positive to the individual herself and the society at large. This is according to the virtue definition of integrity, which concerns the quality of human character. This character has to be wholesome in the sense that the inner and outer aspect of a person's behavior are in tandem, such that the individual is not a hypocrite whose outer expressions do not rhyme with the inner self. As this takes place at individual level, its cumulative effect is that a community can be said to be one of integrity. From Stephen Carter's (1996) conception of integrity, this would mean playing by the rules rather than having the mentality of winning in life at any cost. That is why in his view it involves the three steps, i.e. i) discerning what is wrong and right, ii) acting on what has been discerned, and iii) open 
expression of the actions taken. If we relate this to the Aristotelian discussion of virtue, the first would stand for 'intellectual virtue' while the other for 'moral virtue'. If the EAC project is to be sustainable, the people within this Community have to be of integrity otherwise social cohesion and group virtue is compromised. From the leaders in the Community to the local person deliberations (such as political discourse) the behavior (such as businesses) has to be such that can be relied upon to be for the good and sustainability of the Community.

The second level of 'integrity of personhood' has been identified here as the professional, and this entails elements of personal virtue but goes beyond that to include conduct at work or whatever professional an individual has chosen. An individual of integrity should be carrying out their work with ethical principles that are used to guide such things as decision making, resolution of conflict, among others. So the region of EAC needs person of integrity in business, civil service and in various institutions that are necessary for the Community to exist. For example the schools need to be in hands of people of integrity who produce human resources that are genuinely trained and capable of meaningfully contributing to the development of the region. The business enterprises and civil service needs people who are of high integrity standards in order to build the Community.

\subsubsection{The Ubuntu principle:}

The principle of 'ubuntu' is a key pillar of comprehensive ethical sustainability because it focuses on the sense of community and humanness. Ubuntu has come to be known as the 'philosophy of sharing'. Perhaps the most common use of the term is by the Linux open software system; but the philosophy behind this concept is as old as the African people and their cultures. This makes 'ubuntu' one of the oldest and most applicable moral system and ethical theoretical perspective that is still relevant to guiding our contemporary highly individualistic societies. I consider as a necessary ingredient towards the realization of sustainability because the self-interest logic of economics has failed and led us to an unsustainable system.

The meaning of the African philosophical notion of 'ubuntu' from which I have generated the principle is of profound relevancy to a selfish and unsustainable society. Ubuntu comes from the prefix ' $n t u$ ', which is found in languages across Africa, connotes the African communitarian approach to life. This implies that, in so far as one belongs to the community, one cannot define one's goals and ends without reference to the community, an important 
aspect of being ethical. Linguistically the term 'ubuntu' comprises the pre-prefix " $u$ ", the prefix "bu" and, the noun "ntu". In a linguistic context, "ntu" is a root-word; therefore "ntu" is the irreducible element of the significant word Bantu in its various forms. The latter word means "person", which can be translated as personhood or humanness (see: Kasozi, 2011:25). The term "ubuntu" as commonly found in many languages of Africans and words with a similar meaning are found throughout sub-Saharan Africa. For example: "bumuntu" (Kihayi in Tanzania), "bomoto" (Bobangi in Congo), "gimuntu" (Kwese in Angola), "umundu” (Kikuyu in Kenya), “omuntu”, “obuntu” (Baganda in Uganda), "umunthu" (Malawi), "vumuntu" (shiTsonga and shiTswa in Mozambique).

Ubuntu is an African philosophy of humanity and community (Skelton, 2002); it is a philosophy of becoming human (Swanson 2008), which encourages a holistic and inclusive view of all humans as those who share the same space and resources. It is also a worldview holding that we have to embrace a sense of our interconnectedness as a global community if we are to survive (Murithi, 2009). This African social philosophy is a way of being, which can be applied to developing a code of ethics that is deeply embedded in African culture. The underlying values of this extraordinary philosophy seek to honour the dignity of each person and are concerned with the development and maintenance of mutually affirming and enhancing relationships. Ubuntu is the inherent capacity in African culture to express compassion, reciprocity, dignity, harmony and humanity in the interests of building and maintaining community with justice and mutual caring (Nussbaum, 2003). In this study I have decided to render ubuntu as a principle in the notion of comprehensive ethical sustainability because it enables us realize and appreciate our interconnectedness as humans; and such an attitude would promote the sustainability of our social and political systems, processes and institutions.

It is argued that ubuntu exhibits humanism on a local, national and global scale. According to Archbishop Desmond Tutu, Ubuntu is a belief that "a person is a person through other persons, that my humanity is caught up, bound up, inextricably, with yours. When I dehumanize you, I inexorably dehumanize myself" (Tutu, 2008). Thus, we realize that is a powerful tool to strengthen a community, to communicate through community support, dignity, and identity achieved through mutualism, empathy, generosity, and community commitment (Tutu, 1999). The realization that those around us as human as we are would assist in realizing sustainability of society. 


\subsubsection{The capabilities principle:}

The other principle of ethical sustainability is the Capabilities principle, which is proposed here as a principle and condition in achieving ethical sustainability. In generating this principle, I am arguing that enhancing and recognizing the capabilities of the citizens of the EAC will assist in enhancing both the: i) intrinsic and ii) extrinsic ethical empowerment of both the individuals and organizations thus contributing to the governance and development sustainability of the region. This principle of capabilities is generated mainly using Amartya Sen and Martha Nussbaum's ideas on freedom and development. In a contractualist setup such as the EAC which is based on democratic principles, it is necessary to have individuals and organs that are empowered and therefore capable of meaningfully partaking of the benefits of the cooperation.

In Development as Freedom (1999) Amartya Sen sets out to re-configure the conceptualization and evaluation of development in terms of the concept of 'capabilities'. To him the capabilities approach is, “... an alternative approach to evaluation [of development] that focuses directly on freedom, seen in the form of individual capabilities to do things that a person has reason to value" (p.56). Capabilities are "substantive freedoms...to choose a life one has reason to value" (p.74). These substantive freedoms make one able to 'do' and 'be' what they 'find reason' to value. By generating this view of development theory and practice, Sen re-focused development discourse to the human person. The freedom to "do" and "be" what one values means that the individual's "doing" and "being" is boosted by since she is given a chance of 'choice capacity' using her own value terms. Sen and Nussbaum refer to this as the concept of "functionings". According to Sen and Nussbaum the concept has Aristotelian roots and it "reflects the various things a person may value doing or being" (p.75).

However much as we try to establish 'which institutional structures are better in delivering justice' or 'which theory of justice is better', at the end it is individuals as agents whose ability to effectively participate in the framing of just processes and institutions that are of most importance. This requires the empowerment of the persons in order to realize effective participation in the justice institutional framework and meaningful partaking of the justice benefits. 
Empowerment ought to be approached from both the extrinsic and intrinsic angles. The two levels of empowerment are not mutually exclusive but necessarily complimentary. In order to empower the least advantaged in society who have suffered injustice for long, we have to do it both extrinsically and intrinsically. Intrinsic empowerment involves enabling the powerless to realize, appreciate and apply their inner abilities to get them out of powerlessness. Such forms of empowerment may include inner transformation, better self-consciousness, and motivation, among others. On the other hand, extrinsic empowerment is about being enabled by means of tools and the environment within which one exists so as to decide one's destiny. It may take forms such as giving the poor loans, defending them in courts of law, among others.

\subsection{Conclusion}

In the foregoing section the study has laid out the tenets of the Comprehensive Ethical Sustainability (CES). It delves into this scheme as a contribution to enrich governance and development discourse in the East African Community: it has explained the assumptions by which such an ethical schemata could be conceived or generated, providing a contextual background for its generation and introduces the principles (and pillars) that make up the scheme. 


\section{CHAPTER V}

\section{JUSTICE AND SUSTAINABILITY}

\subsection{Introduction:}

Justice is conceived as a principle and condition of comprehensive ethical sustainability. This section is generated on the presupposition that if political and social processes are to become sustainable in the long run, they ought to incorporate justice. The main tenet of this chapter is that any development (political, ecological or environmental) efforts towards sustainability that involve or mete out injustice to members of society cannot be sustainable in the long run. In this chapter I i) discuss the meaning of justice that is I adopt and why, ii) how that understanding of justice is applicable in the comprehensive ethical sustainability scheme. This chapter makes the concerted argument that any unjust system breeds both i) victim disaffection and ii) villain encumbrance which conditions render that system unsustainable.

I argued earlier in the study to the effect that the principle-approach to attaining comprehensive ethical sustainability is viable because if social order is to be maintained in society, we cannot solely rely on the 'virtue-approach'; In addition to individual character we also need principles that cut across specific spaces and times. This is precisely because logically individuals are outlived by institutions; therefore the principle approach is both applicable to individual conduct and is also the more institutionalizable. To that effect I have decided to construe justice as a principle in the scheme of comprehensive ethical sustainability in order to capture it as a necessary condition for such as agenda. Of course justice is more than a mere principle but in order to realize the goal of this project we need to cast it as a pillar or pre-condition of a sustainable political and social system. This means that justice is a foundational condition of realizing a sustainable society. 


\subsection{On meaning of justice:}

The continuous desire that wells up from the human mind and soul coupled with the energy exerted by humans towards attaining a proper definition of justice testifies to an enduring and eternal longing to exist in a rightful and balanced universe. Therefore with that in mind, I define justice as: an eternal ideal within man's soul and mind whereby each being in existence is availed with a deserved fair share of what that being's existence requires. The human unrelenting obsession with justice implies a desire to right a wrong in our existential universe; a universe that is has certain deeply profound internal problem of failure to avail each member therein with a deserved fair share. When we consider history and the moment within which we are, we get an inexplicable sense that something is not right and we long to correct it. So necessarily the notion of justice implies correcting that inexplicable yet real wrong within our existence.

I use the phrase deserved fair share in my definition deliberately because I want to capture both the i) entitled and ii) earned aspects of justice. In the former aspect, we consent to the obviousness of the reality that beings that exist are entitled to certain fair conditions of existence; that is why, for example, even though birds do not work we see them feeding off trees and fruits that they never planted yet we never refer to that as an injustice. We simply let them because we are innately aware that they are entitled to nourishment. In my view the same sense is applicable when we give our change money to a blind or lame person begging by the street-corner; we innately take it to be just because by virtue of their existence they deserve fair conditions of existence. This aspect implies justice as such by virtue of a being's existence.

As far as the latter aspect is concerned, we also have an innate sense that justice also entails one acquiring and owning what they have labored for. For example, we take it to be fair for someone to exert their ownership claim over a property that they have worked for; thus forcefully taking it away from them would be taken as an injustice. It is in the vein of this aspect of justice that we accept a situation whereby one hardworking farmer can possess more properties than a less hardworking one; albeit we consider it unjust when one gets to possess such properties through unfair means that are detrimental to others. This aspect therefore implies justice in a procedural sense i.e. the means or process one uses to attain one's existential status or possession is an important concern of justice. 


\subsection{Justice as a principle of Comprehensive ethical sustainability:}

If we acknowledge and adopt the above definition of justice, then the notion becomes easily utilizable in a principle approach to the realization of sustainability. The definition of justice as an eternal ideal that we perpetually seek to define and attain fits well with the pursuit of sustainability because the pursuit of the latter is seeking to ensure that the conditions that uphold our existential integrity are perpetual. As discussed earlier, the principle-approach to the realization of comprehensive ethical sustainability is good because it allows for both i) generalizability and ii) difference in practical contingencies. Therefore, in my view, it is possible to render the above conception of justice as a "principle" because it augurs well with the continuous applicability of principles across spatial and temporal differences. For that reason in my generation of principles that are relevant to the realization of comprehensive ethical sustainability justice ranks as the first to consider.

I consider justice as a necessary condition for the sustainability of any political and social system, let alone for the comprehensive ethical sustainability of the same. For example if we consider the case of unfair treatment of a certain racial percentage of a given population, such a case would yield two key observations that affect sustainability: i) victim disaffection i.e. the section of the population that is unfairly treated would seek to undo the systems put in place by the oppressors, and ii) villain encumbrance i.e. it would be expensive and burdensome for the oppressors to maintain the mistreatment for long thus rendering the system unsustainable. We shall delve into the co-relation between justice and comprehensive ethical sustainability later but we need to briefly consider the variations in conceptions of justice in order to reconcile our view of justice with sustainability.

\subsection{Variations in conception of justice:}

If we are to successfully render justice as a principle of ES, it is necessary to address ourselves to the varying conceptions of justice that have emerged over the years of discussing the meaning of the term. In contemporary David Johnston's (2011) A Brief History of Justice, presents a wider and longitudinal discussion of the variance in the conceptions and renderings of the term; from classical times to present. It is necessary to comment from the first glance of the book that it is reviewing the conception of justice in Western European tradition; as we see later, a western conception of justice is increasingly becoming inadequate in a global order. 
David reviews the history of the conception of justice from the classical thinkers, namely Plato and Aristotle, through to the contemporary times of John Rawls. David's discussion and review of the history of the conception of justice is informed by the idea of "reciprocity" (p.2, 29); according to him this idea has been at the center of expressing and rendering the concept of justice over a long period of time. To him Plato construed justice in "hierarchical" terms (p.38) whereby the lesser submits to the higher; just as the appetitive part of the soul had to submit to the rational part, likewise in the wider political and social set-up justice would be when those of lesser rational capacities submitted to rule of those with higher "reasoning powers" (p.63). And for Aristotle the notion justice connotes the same sense as "rightness" or excellent "qualities of character" (p.64) towards one's neighbor. In Aristotelian terms justice was teleological towards the realization of the 'telos' of the state (polis). He observes that the ancient Greek rendering of justice were superseded by more universal ones because of their deep entrenchment in the polis and failure to transcend ancient relational structures such as slave-master, women-men, etc.

But later the understanding of justice shifted towards "equality" interpretations (p.25, 35, 66); this shift was majorly animated by the Christian movement that swept the known political and economic world of the time which the Romans could not succeed to halt. Unfortunately by the time of the Revolution, religious Christianity had allied with those that were perceived by sections of the public as deniers of justice to the common man; so the post-Revolution era saw a secularization of the definition of justice. By the close of the enlightenment season, the mantra of "from each according to his ability and to each according to his need" (p.182) had taken root. Later, thinkers such as Hobbes construed justice in arithmetical utilitarian terms trying to strike a balance in the sharing the good and bad of society. In my view Karl Marx's rendering of this mantra as form of the socialist ideology was a pivotal in the history of justice discourse because it turned it into an issue of economic justice. Despite the future failures of the practicalisation of political Marxism, this turn in conceptualizing justice concretized the impact of defining justice in material and historical terms. The ruling elite of the modern world realized that the conception of justice was a real issue that could affect real bread-and-butter issues; it was no longer confined to philosophers and ivory tower theorists. I think it was this awareness that lurked in the mind of Rawls as he thought through the meaning of justice. Even though he disagrees with the utilitarian view, he endeavors to generate a practical and applicable meaning of justice. 


\subsection{The Rawlsian view of justice as fairness:}

Probably that is what has made Rawls' views in A Theory of Justice (1971) dominant in contemporary deliberations on justice. In that work he tried to reconcile or transcend the divide between 'utilitarian' and 'intuitive' visions of justice and this leads him to the argument that justice is fairness. He basically argues that on the one hand, it is limiting to conceptualize justice only on the basis of the 'utility' principle because many aspects of justice go beyond democratic-utility and its dichotomy between pain and pleasure. On the other hand, intuitionism could suffer from particularism whereby its rendering of justice may simply be “...based on particular intuitions about particular issues" (Kymlicka, 2002:53); in that sense, intuitive justice could be interpreted to simply be "anecdotal" (ibid). For that reason, according to Kymlicka, Rawls sought to provide principles that would "give structure" to intuitive justice theory. In my view this approach to conceptualizing justice is viable and more realizable and I agree with Kymlicka's statement about the Rawlsian principles of justice that they "form the 'special conception' of justice, and they seek to provide the systematic guidance that intuitionism could not give us" (p.56).

For his principles to be applicable without bias, Rawls generates a social contractrualist notion of the "veil of ignorance" (VOI) as a foundation of the principles; the notion assumes a certain level on rationality among the people in Rawl's ideal society. He developing the VOI he argues that it,

... represents equality between human beings as moral persons, as creatures having a conception of their good and capable of a sense of justice. The basis of equality is taken to be similarity in these two respects. Systems of ends are not ranked in value; and each man is presumed to have the requisite ability to understand and to act upon whatever principles are adopted (Rawls, 1971:19)

In other words, the VOI affords all humans to come as equals who understand each other as they apply these principles to institutional building in the ideal society. It is on that assumption that he developed the principles that would guide the institutions in that society. He argues that the principles that would emanate from a position of veil-of-ignorance would be, “...rational and free persons concerned to further their own interests would accept in an initial position of 
equality as defining the fundamentals of the terms of their association" (Rawls, 1999:11). He postulates that self-interested rational persons behind the VOI would choose two general principles of justice to structure society.

These two principles include: i) the principle of equal liberty (p53); and ii) the difference principle (p47). By the first principle he argued that each member has an equal right to the available liberties in society; whilst by the second principle he meant that social and economic institutions should be set-up such that (a) they benefit the least advantaged persons, and (b) their offices should be open to all members of society. Rawls advances two main reasons for the superiority of his principles of justice: the first is that they are 'a better spelling-out of the ideals of fairness' than other intuitionist approaches to justice; and the second is that since they come from an hypo-thetical social contract, they give rational humans in the 'original position' the best conditions "for the governing of social cooperation" (Kymlicka,2002:57).

But these principles have also attracted some criticism; for instance the difference principle has come under criticism from utilitarians arguing that it is not a successful replacement of the utility principle as Rawls claims but rather it is just another scheme of distribution (Dresner, 2008:130). After facing criticism over the possibility that his theory of justice could not be inadequate, in a later version Rawls slightly modified his theory by adding what has come to be termed as a third principle i.e. the "just saving principle" (p266); it was meant to place a kind of moratorium on the uncontrolled expenditure that may accrue from implementing the "difference principle". By trying to realize the purpose of the second principle, the justice of future generations may be negatively affected; therefore even as society build institutions that would ensure that the least advantaged receive justice, it should save for the coming generations. But he also warns against excessive saving that may over-burden the present generation; "an excessive rate of saving must on balance mitigate the burden of those bearing this hardship" (p.267).

Dresner (2008) thinks that the application of a Rawlsian theory of justice to sustainability thinking would be good. He joins Rawls to criticize the utilitarian approach (that is dominant among most development thinkers) for not having a conception of "intergenerational equity" (p.129). According to his rendering, classical utilitarianism was influential on early modern economists and development thinkers; yet it focused mainly on maximizing utility; and its utility calculus could barely generate a calculation of how to defer utility for the future 
generations. To him, that is where the problem of failure to realize sustainability in modern development thinking emanates from.

In Dresner's view, classical utilitarianism and its impact of failure to realize sustainable development would only be redeemed later when John Rawls entered the picture. Rawls reinvigorated utilitarianism through his introduction of the concept of 'veil of ignorance' (Dresner, 2008:130). In his interpretation, the 'veil of ignorance' is a hypothetical situation of a certain social arrangement or organization whereby free and rational humans agree on an original position of equality (ibid). In this state it is assumed that these rational humans are not aware of any differences in class, natural abilities, economic level, or generation to which they belong. This attitude would allow room for these rational humans to think across generations and therefore afford sustainable development a chance.

Dresner acknowledges that there may be some weakness in applying Rawl's ideas to argue for inter-generational thinking on sustainable development. But he is more apologetic for a 'Rawlsian' view of intergenerational sustainable development because there are critics who use a Kantian imperative approach to argue against his view. He answers them by arguing that Kantian imperatives such as 'do to others what you would want them to do to you' are only of practical sense if the 'others' are in position to "retaliate" (p.132); may be the better word would 'reciprocate'. Since the future generations are not in such a position, then the Kantian imperative approach would be lacking in that sense. So to him the Rawlsian 'veil of ignorance' would function better in promoting sustainable development across generations i.e. ensure the sustainability of what is available for the future generations.

\subsection{Expanding the Rawlsian articulation of rationality and fairness:}

Rawls provides contemporary justice discourse with the first articulation of the application of intuitive principles of justice to both present and future generations of society. But in order to apply Rawls into the scheme of comprehensive ethical sustainability I propose to expand both his conception and articulation of the notions of rationality and fairness. To achieve that, I use this section to: i) problematize and characterize his assumption about rationality as inseparable from the economistic and Darwinian ('survival-of-the-fittest') conception of the same that has entrenched injustice in the contemporary order; and ii) provide an expanded articulation of the meaning of fairness that attempts to resolve a key aspect of institutional injustice today, namely the entitlement debate. 


\subsubsection{Social justice and the Rawlsian assumption about rationality:}

As pointed earlier, a Rawlsian view of achieving sustainability is redeemable only by a willingness to re-conceptualize rationality. I think that, good as Rawls' principles are, it would be very difficult to use them to realize comprehensive ethical sustainability as Rawlsians if we insist on a self-interest conception of human rationality the basis on which his VOI is founded. The problem is that such a view of rational has heavy overtones of Adam Smith's idea of rationality and the Darwin's survival-of-the-fittest logic. Granted, Rawls did not concern himself with the question of rationality; he simply assumed and took it as a given. But in my view this is where his theory suffers a great challenge when it comes to being applied in a liberal capitalist system founded on the market philosophy of the 'economism' and their followers.

Rawls never considered an interrogation of the impact of the nature or type of rationality possessed by the agents in his ideal vision of justice; he assumed that being rational automatically means being able to seek out and apply his principles towards a justice society. But in a economic milieu dominated by the 'rule of the market' which is based on self-interest, it is difficult to realize that ideal. Likewise the dominance of a political ethos grounded in the Darwinian logic of 'survival-of-the-fittest' or survival at all cost, the value of equal care as espoused by Rawls seems like a pipe-dream.

Note should be taken not to think that I am negating Rawls' argument for and principles of justice; I share his concern and believe in his genuine desire to see justice. But my point of departure here is the underlying assumption of rationality in his ideal of 'veil-of-ignorance'. A critical interrogation and examination of his assumed nature of "rationality" possessed by the agents in society is deemed necessary because I want his vision to be realizable in the current global order dominated by a self-interest view of rationality. In a contractual setting whereby agents are assumed to possess ability to "understand and act upon the principles that are adopted" (p.19), the nature of the rationality these agents are assumed to have becomes critical. When he states that "...rational and free persons concerned to further their own interests..." (1999:11) come together with a veil of ignorance he means that they are not going to act selfishly. But we can test this assumption to see whether it can be a solid foundation for a just society. 
Today there are various international or regional regimes that many nation-states adhere to; all these international institutions that would borrow a leaf from the Rawlsian views on justice such as the IMF, World Bank, WTO, etc. These organisations use a form of Rawlsian position to claim that they are 'rational' in their policies and actions. Even profit-motivated multinational corporations claim to be "rational" in their pursuit of profit in international business. But how far have they dispensed justice in the global system? In many cases, the public institutions are twisted to serve the self-interest of a minority of states, which selfishness is disguised as 'national interest' in diplomatic language. A case in point is the infamous manipulation of the United Nations by the USA government in order to go to war in Iraq after the $9 / 11$ attacks. The same happens in private business circles; multi-national corporations that are highly driven by the profit logic claim to be 'rationally' pursuing profit meanwhile destroying the environment or cheating the poor.

Two cases can be applied to illustrate this challenge that needs to be addressed: the first one is that of the International Criminal Court (ICC) which has recently come under heavy criticism by African states for bias. In the ideal Rawlsian terms we would assume that at the establishment of the Rome Statute, which established the ICC, state-agents came together as equals behind a 'veil-of-ignorance' (VOI); by 2013 it was 122 countries that had ratified the Rome Statute. In the case of the ICC the self-interest can be depicted in two ways. The first one concerns the accusations by African leaders that the Court is being used by rich countries to taunt the poor countries. This accusation could hold some water because out of thirteen cases before the Court, eight are from Africa yet there are places like the Middle East and Balkans that have had major crimes against humanity committed. The question the African leaders are asking is that could it be that this Court has been hijacked by the mighty countries? The second aspects concerns the fact that there is a possibility of the African leaders themselves using it to advance selfish ends; for example in Uganda's case it is the government that sent the case of the rebel leader Joseph Kony to the Court (in that case the court was on useful), but now it the reported that Uganda is the one urging African countries to quit the Court (Butagira, 2013). In all these instances, rational reasons are cited to achieve self-interested motives, For example it has been constantly mentioned that since the USA-UK invasion of Iraq, there could be a case to answer at The Hague by President Bush and Prime Minister Tony Blair over the many deaths that are taking place in Iraq. But nothing like that is expected to happen (Gwynne, 2013). 
The other case is that of the extraction industry company Glencore and its behavior which was highlighted by the documentary, Stealing Africa, which has headquarters based in a superwealthy town in Switzerland called Rüschlikon. The documentary shows scenes of members of that small town voting en masse to retain money given to the town according to Swiss law of redistribution of tax money from the wealth residents in their midst. A few members of the community had petitioned that the money is sent back to the poor Africans in Zambia where Glencore is mining and damaging the environment but the "rational" thing for the town voters to do was to reject the idea and retain the money. The documentary indicates that Glencore uses the dubious Swiss law that allows the same corporation to open 'phantom firms' in order to do insider trading; i.e. the phantom companies connive to establish very cheap buying prices for raw materials from poor countries and after selling at cheap prices and paying very little tax, the corporation sells to another phantom company that bring to the same parent corporation at very high prices thus making super-normal profits. This is an example of how these multinational corporations create or manipulate the market based on the 'self-interested rationality' of Adam Smith and his followers; and with such behavior Rawls vision cannot be realized.

\subsubsection{Social justice and conscientious rationality:}

My characterization of the Rawlsian assumption of rationality should not be construed as the radical postmodern criticism of rationality. I still believe in the human capability of reason but it has to be re-conceptualized in a different fashion. But in such a situation we cannot achieve justice despite Rawls good principles on justice. All Rawls' principles are applicable to the realization of justice on the assumption that the agents are rational. But as discussed above, that assumption carries the baggage of the view of rationality that was inherited from the economistic age of thinkers like Adam Smith who took the meaning of 'rational' to be 'selfinterest'. 'Rational' does not necessarily mean 'self-interested'.

We need a new conceptualization of rationality that is encourages genuine values of care and equal opportunity for others if we are to realize sustainability. For sustainable justice to exist members of a given society ought to have a rationality that has a conscience; it is about developing in the agents in society a capacity for genuine compassion about the legitimate needs of both the disadvantaged and the future generations. This would enable us to avoid the pitfalls of the past development milieu which has been characterized with unsustainability and injustices. 
Therefore the justice principle in the scheme of comprehensive ethical sustainability means establishing structures and processes that avoid mistreating or denying opportunities to any section of society; the establishment of these structures and processes should be built on persons who possess a conscientious rationality that enables them avoid selfish utilitarian exploitation of nature and fellow humans. This is important for comprehensive ethical sustainability because without ensuring justice for all, those who suffer injustices at a given time would most likely look at all the systems put in place by the oppressor group as unjust and would seek to destroy them. This would fail the goal of sustainability because in each generation those who think that they are mistreated would set out to destroy the work of the previous one.

I therefore propose a move away from 'self-interested rationality' to 'conscientious rationality'. It is very difficult to realize sustainability within a set-up of self-interested persons. Rawls ends in the same boat as Adam Smith who thought that self-interest would be used for the good; Adam Smith has influenced many decades of economic thought and it is true that using that logic humans have realized massive economic gains. However, the self-interest rationality has brought us thus far with numerous problems of injustice and environmental imbalances thus rendering the current mode of development unsustainable. We cannot re-organize our society to realize justice as Rawls postulates while leaning on the same conception of rationality.

\subsubsection{Re-articulating Rawls' conception of fairness:}

One of the questions that Rawls tries to tackle and is still relevant to the justice discourse today is that of entitlement. The question is: are all members of society entitled to the same claim to the primary goods in society despite the differences in natural talents and abilities? Where do entitlement come into the vision of justice and how do we resolve that challenge? Rawls was aware of the question that would arise with his proposed principles of justice, i.e. the limit of claim to entitlement due to difference in natural talents and abilities. Rawls refers to the distribution of natural talents and abilities as 'arbitrary' and therefore not a sound moral ground to use in determining how primary goods in society are shared. His proposed solution to this is to suggest that, "we regard the distribution of natural talents as a common asset and to share in this distribution whatever it turns out to be" (p.101); i.e. we adopt the "common assets thesis"(Cummiskey, 1987:15) if we are to resolve the challenge of entitlements. 
This solution has been challenged by thinkers like Nozick who argues that even though the possession of natural talents and abilities is arbitrary, it is not "illegitimate" (Nozick, 1974:225). Natural talents and abilities are not illegitimately possessed and therefore the individual is entitled to the benefits that accrue from those talents; and she reserves the right not to be forced to share those benefits. By this argument, the Nozickian vision of justice is where the state only provides the minimum conditions for individuals to exercise their natural abilities and talents and lets them enjoy the benefits or goods therefore; if any of the benefits are to be distributed, it should be done from the consent and free-will of the individuals who have possess the benefits or goods.

The divergence between these two opposing views has increased over the years and it threatens the realization of justice in society. We can use the case of the debate over healthcare insurance in USA to highlight this divergence. There is deep distrust from each end of the debate: on one there are those who hold the Nozickian view of a very minimal state (especially as represented by the radical Tea Party section of the Republican Party); they argue that any attempt by the Federal government to push for legislation that would provide healthcare insurance for the uninsured poor is an unnatural and unrightful re-distribution of wealth which contradicts their vision of justice. In some extreme cases they refer to such initiatives by government as "totalitarianism" (Limbaugh, 2012). On the other hand there are those who support a Rawlsian vision of justice whereby the government uses tax or other state instruments such as incentives to encourage insurance companies to take on the uninsured poor thus provide some level of equality in access to healthcare services. This is in line with Rawls' principle of equal opportunities.

It is obvious that there is need for resolving this divergence because it does not allow for sustainability of social and political institutions in society; for example in the case of the USA if those against the current government's vision of justice get elected into office, they will most likely undo the institutional framework that has been left behind and that is not good for ensuring sustainability of political and social institutions. But how do we resolve this divergence in the two renderings of what justice means? I think it is possible, from a Rawlsian perspective, to reconcile these positions by providing a re-articulation of the meaning of the Rawlsian ideal of justice as fairness. In particular it could be achieved by providing a more inclusive meaning of fairness in society. 


\subsubsection{Reconciling contractarian and libertarian visions of justice:}

Reconciling the contractarian and libertarian visions of justice is achievable by reconsidering the definition (and meaning) of justice the two visions articulate. For that matter the study attempted to generate a working definition of justice that is utilizable for that purpose. Hereby justice is defined as an eternal ideal within man's soul and mind whereby each being in existence is availed with a deserved fair share of what that being's existence requires. The phrase deserved fair share addresses the disparities between the Rawlsian and Nozickain visions of justice by allowing for the aspects of contention, namely i) entitled and ii) earned aspects of justice.

My discussion focuses more on the contentious issue of entitlement but it suffices to mention a key point about earned aspect of social justice. We tend to innately have a sense that justice entails one acquiring and owning what they have labored for. It is intuitively fair for someone to claim ownership of a property that they have worked for such that if it is stolen that is considered an injustice. Therefore a talented and genuinely hardworking individual can earn the right to possess more properties or benefits in society than a lazy even though talented person. But is also intuitively obvious that it is an unfair situation when a talented but lazy person claims possession of more benefits and goods in society than a hardworking one. If such a situation comes about, everyone will intuitively question the process through which the lazy person came to claim ownership of such vast amounts of property or benefits. This observation implies that justice is as much procedural as it is distributive i.e. the means or process one uses to attain one's existential status or possession is an important concern of justice.

It is not enough for the individual to appeal to the arbitrariness of talent to claim more benefits and goods in society than others; the person must earn it. But if the existing process in society rewards those who are lazy or busybodies more than the hardworking then there is fundamental injustice in the procedural set-up of that society. So to achieve justice, society has a duty of fairness to examine the procedures that are used by those who claim entitlement to more benefits in society than others yet they are lazy. If the procedures reward the lazy then, for the sake of justice, there is need to change them. This is because there is a possibility of using manipulative procedures to siphon off what others have worked hard for and then claim that it is one's entitlement. The entitlement claim does not arise out of simply having been lucky to have certain talents or having inherited some advantage, but it also means working hard with those talents to generate benefits to which one can claim entitlement. 
In my view, entitlement should not be narrowly confined to benefits accruing from one's natural abilities and talents because if we constrain it thus, we may deny justice to those whose talents or abilities may not have been discovered or understood yet and are taken as abnormality. At the same time such a narrow confinement may also lead to denial of justice to those whose talents or abilities may have contributed to the goods in society in the past but are currently not useable or beneficial. To illustrate this observation we can use the example of a young child whose natural abilities are not yet known; the logical conclusion of a Nozickian view of justice would mean arguing that the child is not entitled to the goods or benefits that others have generated using their individual talents. The same conclusion would be applicable in a case of persons with special natural talents that may not yet be understood by society; for example a person may be having a certain natural ability yet in the view of mainstream society, it is taken as a sickness or an abnormality. Because society does not understand the nature and usefulness of such a talent it may not provide the right environment for the individual to use her talent for beneficiary. A Nozickian society (where justice means that individuals with currently catered-for and beneficial talents are free to enjoy the benefits of their in isolation) may argue that such a person is not entitled to any benefits from society. The conclusion would be that the person is either worthless or a parasite living off the talent of others. But imagine that in the near future society finds out that the person's abnormality is actually a talent and she is provided with the right tools to beneficiary utilize that talent, then how would a Nozickian society justify the injustices committed against her during the time of ignorance? I think it is not reasonable to deny a person justice simply because her talent is not yet discovered or is seen to be worthless.

The other issue to consider is that changes in the economic or social or political environment make different talents to flourish at different times and the question is whether justice should fluctuate as the environment goes through such changes. Given the dominance of the market logic within which we live in contemporary times, we can demonstrate this challenge within the Nozickian view of justice. If we agree that natural talents are dependent on the economic environment within which the talents are expressed, then it becomes obvious that some talents will be expressed better in a given environment than others and those who possess it could use the entitlement to deny others the benefits from those talents. For example in a market-logic driven society, a person with the ability to be aggressive in business or predict stock exchange finds such an environment (market-driven society) conducive for flourishing and reaping 
enormous benefits from her talents. On the other hand, those whose talents would flourish in a different economic setting would have little to show for their talents, and thus a Nozickian would argue that it is the arbitrariness of nature to blame for not giving them the right talents. To such an argument I would object because in my view it is not the arbitrariness of nature that is responsible for the enormous benefits of some in comparison to others but it is the artificial construction of the social environment by man that brings about that difference. Lets imagine that the inverse of the same happens such that the economic or political environment changes in favour of those with hitherto disadvantaged talents, then it would be unjust to deny those who find themselves in similar situation (as those who are presently benefiting found themselves in previously) a fair share of the benefits.

The same conclusion would suffice if we use time as the factor to consider the entitlement argument. Those who are strong enough a certain time to use their talents and generate enormous benefits from them, in the Nozickian vision, would argue for their entitlement to those benefits and could refuse to share them with others whose time has not yet come. A current generation of workers may be generating enormous benefits from their talents unlike the young or the older who find themselves no longer able to work as creatively and energetically as the current generation. In my view it would be unreasonable to deny the young or the older generation a share of the benefits of their talents because a time will come when they also are unable to generate the same benefits from their talents as they are doing now.

In my view a Rawlsian re-articulation of the meaning of fairness would resolve these Nozickian challenges to justice. As indicated earlier that re-articulation of fairness provides for the inclusion of both entitlements and earnings. We all consent to the obviousness of the reality that beings that exist are entitled to certain fair conditions of existence; that is why, for example, even though birds do not work we see them feeding off trees and fruits that they never planted yet we never refer to that as unfair or an injustice. We simply let them because we are innately aware that they need nourishment by virtue of existence. In my view the same sense is applicable when we give some loose change to a blind or lame person begging by the streetcorner; we innately take it to be a natural requirement for nourishment and warm clothing for such a person. By virtue of the fact that they are living beings they deserve fair conditions of existence. 
So a Rawlsian vision of justice needs to argue that individuals deserve fair conditions of existence by virtue of living beings. Not possessing talents that generate enormous or higher benefits is not enough ground to deny sharing the benefits that others have generated. Paradoxically one finds that the same thinkers who use the entitlement argument to reject against a Rawlsian distribution of society's primary goods may be keeping animals or birds as pets in their homes. It is interesting to note that a Nozickian who is a pet-dog owner knows that the animal lacks natural talents to generate for itself benefits such as heating during winter and he gives it that benefit (which came from his own talents). He also supports the animal police whose job is to ensure that humans look after their pets properly (which in essence is a form of distribution of the benefits from others' talents). It is obvious that in his mind despite the animal lacking natural talents to generate a heating system for itself, it deserves warmth by the virtue of being a living being. From a Rawlsian perspective, the same attitude could be extended to those humans who may currently not be able to adequately provide for themselves everything necessary for a fair existence. A conscientiously rational person with a normal conscience that cares about those other beings around her would not reject a policy that seeks to provide for other beings fair conditions of existence.

\subsection{Converging visions of justice:}

In this section I attempt to bridge the divergence between the Rawlsian and Nozickian views the entitlement aspect of justice by i) generating a re-considered understanding of justice; and ii) re-articulating Rawls' view of fairness. In order to reach that goal I generate a definition of justice which I think captures and resolves the contentious distribution issues of i) existential fairness and ii) earned fairness. I start by briefly generating and explaining the meaning of a re-considered definition of justice. Then I briefly explain the main arguments of both Rawls and Nozick concerning the issue of entitlement within their visions of justice. And then I present my considered arguments on how the divergence between those two position would be bridged using the regenerated definition of justice. In my view, the divergence between the Rawlsian and Nozickian views of entitlement stems from a lacking understanding of the meaning of justice and application of the same in discussing the issue of entitlement.

\subsubsection{Reconsidering the meaning of justice:}

The continuous desire that wells up from the human mind coupled with the energy exerted towards attaining a proper definition of justice testifies to an enduring and eternal longing to exist in a fair and balanced universe. As humans we intuitively find ourselves passing 
judgments on what we consider to be just or unjust. Our unrelenting obsession with the question of justice implies a desire to right something that is wrong in our existential universe; a universe that in many cases seems to have a deep and profound problem of failure to avail each member therein with a deserved fair share of what is available for our existence. When we consider human history plus contemporary times, we get an inexplicable sense that something is not right and it ought to be corrected. So necessarily the notion of justice implies correcting that inexplicable yet real wrong within our existence. It is with that observation in mind that I have generated the following re-considered definition of justice.

I define justice as an eternal ideal within man's soul whereby each being in existence is availed with a deserved fair share of what that being's existence requires. I use the phrase deserved fair share in my definition deliberately because I want to capture and perhaps resolve the often contentious and confused issues in the justice debate, namely i) existential fairness and ii) earned fairness. As far as the former (existential) is concerned, I aim at capturing the obviousness of the fact that beings that exist require certain conditions of existence by virtue of their existence. That is why, for example, even though birds do not work we see them feeding off trees and fruits that they never planted yet we never refer to that arrangement as an injustice. We simply let them be because we are intuitively aware that they are require nourishment. In my view the same sense is applicable when we give our change money to a blind or lame person sitted begging by the street-corner even though they never worked for it; we intuitively take it to be just because by virtue of their existence they require fair conditions of existence. This aspect implies that we can allow for a sense justice as such by virtue of a being's existence.

As far as the latter (earned) is concerned, I aim at capturing the intuitive sense that justice also entails one acquiring and owning what they have labored for through ethical means. For example, we take it to be fair for someone to exert their ownership claim over a property that they have worked for using their natural talents; thus forcefully taking it away from them would constitute an injustice. It is with this sense that we accept a situation whereby one hardworking farmer can possess more properties or goods in society than a less hardworking one; albeit this earned aspect of justice is subject to the condition that one acquires such properties through ethical means that are not of a negative nature or detrimental to the existence of others. Therefore it is not enough to claim entitlement to more properties or goods only on the grounds of hard-work and natural talent; the means or process by which one acquires those properties or goods are critically important if society is to realize justice. This understanding of justice is 
what I use in this text to try to bridge the divergence between the Rawlsian and Nozickian views on entitlement.

\subsubsection{Entitlement meaning:}

The etymological roots of the entitlement are from the phrase "to en-title" which meant to give someone a title-deed or ownership over some property or estate. In the middle ages, an entitlement meant a legal claim to an estate or the right of possession. The meaning of the term has varied over time depending on who is using it; but if we take the Middle Ages meaning we realize that the term has connotations of rights. By the end of the World War II the use of the term had slightly changed from the old when it came to reference to the benefits of the veterans; for example in the 1967 Code of Federal Regulations of the USA, there was reference to "basic entitlements" (p.46) of the veterans families. In my view this essentially meant compensation for loss of life or limb during the war; but the interesting thing to note is that the term entitlement was no longer being used with a legal document as the background but as a moral requirement from the federal state.

In the 1970s, thinkers like Nozick almost reverted back to the middle ages legalized meaning of the term when he discussed his entitlement theory (which I briefly consider below). But almost at the same time the political discourse in the US was using terms like "entitlement program" to refer to the benefits payment program of the federal government. This meaning had taken the cue from the New Deal, or the 1930s post-depression social programs that meant direct federal state assistance of the people and businesses to ensure economic recovery. In this sense the term entitlement came to mean the right the public has to state assistance in times of need. Political disagreement with that approach to economic recovery has existed ever since; by the last 2012 US presidential elections presidential candidate Mitt Romney gave the leaked so-called "47 percent speech" in which he distinguished between an "entitlement society" and "opportunity society". Thus the current meaning of the term differs from the middle-ages meaning - for the Republicans "entitlement society" refers to a section of the population that simply wants to be given benefits from the state, while the "opportunity society" are those who prefer a minimal state which allows private businesses to compete in a market regulated atmosphere where individuals are rewarded for their talents and hard work. 


\subsubsection{0n the libertarian view of entitlement:}

Among the libertarians Nozick is credited for making entitlement the centre of contemporary political discourse. In his book Anarchy, State and Utopia (1974) he used the basic tenets of libertarianism, i.e., minimum state, self-ownership, free-market and private property to generate principles of his entitlement theory. These principle include i) the principle of justice in acquisition, ii) the principle of justice in transfer; and iii) the principle of rectification of injustice. Using the background of John Locke's theory he argues that,

A person who acquires a holding in accordance with the principle of justice in acquisition is entitled to that holding. A person who acquires a holding in accordance with the principle of justice in transfer, from someone else entitled to that holding, is entitled to that holding (Nozick, 1974:151)

By this postulation Nozick laid down the main principles by which individuals can claim entitlement to property or goods in a just society. But he was aware that there could be cases of unjust acquisition which prompted him to devise a third principle i.e. "the rectification of injustice in holding” (p.152).

It is obvious that the Nozickian meaning of entitlement is the same as the one implied by US presidential candidate Mitt Romney. In a Nozickian sense, people have a right of claimance to properties and goods that they have acquired through those principles because the ownership of self implies ownership of what that self produces. When the state intervenes to re-distribute these goods or wealth through taxation except for purposes of the rectification principle, then it is committing an injustice.

\subsubsection{Entitlement in Rawls' vision of justice:}

Rawls does not necessarily use the term entitlement that much but we can observe that his principles of justice imply a type of entitlement that the Republicans disagree with, which involves a non-natural distributive approach to justice. Using the principle-approach Rawls conceives a vision of justice where rational persons behind the veil of ignorance would choose the best principles of justice to structure society. He proposed two key principles, namely i) the principle of equal liberty (p53); and ii) the difference principle (p47). By the first principle he 
argued that each member has an equal right to the available liberties in society; whilst by the second principle he argued that institutions should be set-up such that (a) they benefit the least advantaged persons, and (b) their offices should be open to all members of society.

Some thinkers on Rawls' theory add a so-called 'third principle', which they have christened the "just saving principle" (Meyer, 2010). According to them this was meant to moderate the possibility of unsustainable expenditure that may accrue from implementing the "difference principle". By trying to realize second principle, the justice of future generations may be negatively affected; therefore even as society builds institutions that would ensure that the least advantaged receive fairness, it should save for the coming generations. Nonetheless, he also warns against excessive saving that may over-burden the present generation; "an excessive rate of saving must on balance mitigate the burden of those bearing this hardship" (p267). In order for the rational persons to choose and apply those principles effectively, they have to approach the building of the institutions with a "veil of ignorance". Rawls advances two main reasons for the superiority of his principles of justice: the first is that they are 'a better spelling-out of the ideals of fairness' than other intuitionist approaches to justice; and the second is that since they come from an hypo-thetical social contract, they give rational humans in the 'original position' the best conditions "for the governing of social cooperation" (Kymlicka, 2002:57).

Nozick disgrees with the above Rawlsian scheme of distributive justice and Kymlicka summarises the Nozickian disagreement with Rawls in two main arguments: i) Rawlsian redistribution (or other coercive government interventions in market exchanges) is incompatible with recognizing people as self-owners; ii) recognizing people as self-owners is crucial to treating people as equals (p.110). However, he also notes that "there are important continuities between Nozick and Rawls" (p.108); and it is appealing to those continuities that the divergence between the two views can be overcome. For example both of them invoke the Kantian principle of treating people as 'ends in themselves' to justify their arguments: namely self-ownership for Nozick and Rawls' argument for equal opportunity. I think that by applying the earlier stated definition of justice the divergence between these two views on entitlements could be bridged.

\subsubsection{Achieving fairness amidst arbitrary talents and abilities:}

One of the questions that Rawls raised that is relevant to the justice discourse of entitlement. The question is: are all members of society entitled to the same claim to benefits in society (as his difference principle postulates) despite the differences in natural talents and abilities? 
Phrasing that question thus is pertinent because the aspect of difference in natural talents and hard-work is the basis on which Nozick based his critique of Rawls as unjust; individuals who self-own better talents than others and use them to gain benefits should not be forced through state policies like taxation to re-distribute their benefits. Rawls was aware of the question that would arise with his proposed principles of justice, i.e. the limit of claim to entitlement due to difference in natural talents and abilities. For that reason he refers to the distribution of natural talents and abilities as 'arbitrary' and therefore not a sound moral ground to use in determining how benefits in society are shared. His proposed solution to this is to suggest that we, "we regard the distribution of natural talents as a common asset and to share in this distribution whatever it turns out to be" (p.101); i.e. we should adopt the Common Assets thesis (Cummiskey, 1987:15) if we are to resolve the challenge of entitlements.

This solution has been challenged by thinkers like Nozick who argues that even though the possession of natural talents and abilities is arbitrary, it is not "illegitimate" (Nozick, 1974:225). Natural talents and abilities are not illegitimately possessed and therefore the individual is entitled to the benefits that accrue from those talents; and she reserves the right not to be forced to share those benefits. By this argument, the Nozickian vision of justice postulates that the state only provides the minimum conditions for individuals to exercise their natural abilities and talents and lets them enjoy the benefits thereof; according to them that is natural justice even though some may view it as imbalanced. If any of the benefits are to be distributed, it should be done from the consent and free-will of the individuals who possess the benefits but not by the coercive means of the state. So the question is: is it possible to achieve justice given a situation where individuals are arbitrarily (by nature) given different talents? Is fairness possible in a situation of arbitrary talents and abilities?

The divergence between these two opposing views has increased over the years and it threatens the realization of justice in society. We can use the case of the debate over healthcare insurance in USA to highlight this divergence. There is deep distrust from each end of the debate: on one side, there are those who hold the Nozickian view of a very minimal state (especially as represented by the radical Tea Party section of the Republican Party); they argue that any attempt by the Federal government to push for legislation that would provide healthcare insurance for the uninsured poor is unnatural and unjust re-distribution of wealth which contradicts the libertarian vision of justice. In some extreme cases they refer to such initiatives by government as "totalitarianism" (Limbaugh, 2012). In other words, the poor are poor 
because they were not lucky for nature to endow them with the right talents and abilities or because they are not using their talents well. On the other hand there are those who support a Rawlsian vision of justice whereby the government uses tax or other state instruments such as incentives to encourage insurance companies to take on the uninsured poor thus providing some level of equal opportunity in access to healthcare services. In other words, their argument is that the arbitrariness of nature should not be grounds enough to leave many members of society to suffer.

This divergence requires resolution because it does not allow for sustainability of social and political institutions in soceity; for example in the case of the USA in the case that those who disagree the current government's vision of justice get elected into office, they will most likely undo the institutional framework that has been left behind and vice versa; and that is not good for ensuring sustainability of political and social institutions. In order to resolve this divergence we can provide a re-articulation of the meaning of the Rawlsian ideal of justice as fairness, which is more inclusive and allowing for: i) those who suffer due to the arbitrariness of nature (arbitrary fairness) and ii) those who prefer to retain their claim to the benefits they earn from using their talents and abilities (earned fairness).

I attempt to resolve this using the definition of justice that I generated and is stated at the top of this paper. Let me re-state the definition: an eternal ideal within man's soul whereby each bieng in existence is availed with a deserved fair share of what that being's existence requires. The phrase deserved fair share addresses the disparities between the Rawlsian and Nozickain visions of justice by allowing for the aspects of contention, namely i) arbitrariness of natural talents and abilities and ii) earned benefits from those talents. My discussion focuses on the contentious issue of entitlement but it suffices to mention a key point about earned aspect of social justice.

\subsubsection{On earned benefits from arbitrariness:}

We tend to innately have a sense that justice entails one acquiring and owning what they have laboured for. It is intuitively fair for someone to claim ownership of a property that they have worked for such that if it is stolen that is considered an injustice. Therefore a talented and genuinely hardworking individual can earn the right to possess more properties or benefits in society than a lazy person. But it is also intuitively obvious that it is an unfair situation when a talented but lazy person claims possession of more benefits and goods in society than a 
hardworking one. If such a situation comes about, everyone will intuitively question the process through which the lazy person came to claim ownership of such vast amounts of property or benefits. There seems to be no disagreement over this matter in both Rawls' and Nozick's view of justice; infact Nozick even discussed the principle of rectification of injustice in order to cater for that. This observation implies that justice is as much about the means as it is about the distribution of benefits in society i.e. the means or process one uses to attain one's existential status or possession is an important concern of justice.

It suffices to note however, that it is not enough for the indivivual to appeal to the arbitrariness of talent to claim more benefits and goods in society than others; the person must earn it and do so through ethical and genuine means or processes. But if the existing process in society rewards those who are lazy or busybodies more than the hardworking then there is fundamental injustice in the procedural set-up of that society. So to achieve justice, society has a duty of fairness to examine the procedures that are used by those who claim entitlement to more benefits in society than others yet they are lazy. If the procedures reward the lazy then, for the sake of justice, there is need to change them. This is because there is a possibility of using manipulative procedures to siphon off what others have worked hard for and then claim that is it one's entitlement. Entitlement claim arises from not only talents, but is also working hard with those talents to generate benefits that one can claim.

\subsubsection{On entitlement from arbitrariness of natural talents and abilities:}

To discuss this issue I use three factors, namely, i) abnormality, ii) environment and iii) time. In my view, entitlement should not be narrowly confined to benefits accruing from one's natural talents because if we constrain it thus, we may deny justice to those persons whose talents may not have been understood yet; and in the meantime they therefore taken to be disfavoured by nature's arbitrariness or as abnormal. At the same time that may also lead to deny of justice to those whose talents may have contributed to the goods in society in the past but whose talents are currently not useable or of negligible benefits. To illustrate this observation we can use the example of a young child whose natural abilities are not yet to be known; the logical conclusion of a Nozickian view of entitlement would mean that the child is not entitled to benefits that others have generated using their individual talents. The same conclusion would be applicable in a case of persons with special natural talents that may not yet be understood by society; for example a person may be having a certain natural ability yet 
in the view of mainstream society, it is taken as a sickness or an abnormality. Because people do not understand the nature and usefulness of such a latent talent society may not provide the right environment for the individual to use her talent beneficiary. A Nozickian society (where justice means that individuals with currently catered-for and beneficial talents retain the right to individually hold the benefits) may conclude that such a person is not entitled to any benefits from society. The conclusion would imply that the person is either worthless or a parasite. But imagine that in the near future society finds out that the person's abnormality is actually a useful talent and she is provided with the right tools to beneficiary utilize that talent, then how would a Nozickian view of entitlement justify the denials against her during the time of society's ignorance? I think it is not fair to deny a person justice simply because her talent is not yet discovered or is seen to be worthless in the meantime.

\subsection{Justice and undoing victim disaffection and villain encumbrance:}

It is my considered view that the pursuance and establishment of fair and just institutions and processes would go a long way in undoing the disaffection that the victims of injustice feel and the encumbrance that the perpetuators of injustice carry. The existence of injustices (both perceived and real) in most cases results into the dual malaises of victim-disaffection and villain-encumbrance. And the conditions are inherently detrimental to sustainability of society.

\subsubsection{Victim disaffection and the unsustainability of unjust systems:}

The concept of victim disaffection is used to mean a situation where those who are facing injustices in society have reached a point of hating the individuals and institutions that dispense both perceived and real injustices. The section of the community that feels that it is unfairly treated would seek to undo the systems that promote the injustice. This explains the perpetual conflicts and numerous power struggles in most human social contracts that are characterized with injustice. The reason why successive regimes set out to remove the institutions of the previous ones (and in some cases even the physical elimination of people who represent the previous regimes) is because of disaffection or hatred of the previous system.

As alluded to in section 4.1, the case of Amin (whose political character played a key role in the dismantling of the EAC-1) reveals the impact of victim disaffection on the leadership of a given body-politic. Since leaders emerge from among their people-group, a logical converse 
relationship could be inferred between victim disaffection and the injustices that the people undergo, to the effect that the higher the injustices suffered, the higher the victim disaffection. In other words, the higher the magnitude of injustice suffered by the victim-group, the higher will be the level of disaffection that the leaders who emerge from that group will have. In practical terms, this level of disaffection would be vented out in terms of rhetoric, actions, and even policies that seek to destroy the institutions that are perceived to be the source of the injustice. That relationship between injustice and victim disaffection explains why the former president of Uganda, Amin chose a political rhetoric and policies that eventually led to the collapse of the EAC-1.

The concept of victim disaffection is used to mean a situation where those who are facing injustices in society have reached a point of hating the individuals and institutions that dispense both perceived and real injustices. That section of the community would naturally feel that it is unfairly treated and would seek to undo the systems that promote or represent the injustices. Such a situation would give rise to a converse relationship between victim disaffection and injustice; in other words, the more victims of injustice feel oppressed and on the receiving end of injustices in society, the more they will be invested in trying to undo or destroy the institutions or systems that they perceive to be oppressing them.

Since human existence is majorly perceivable in terms of space and time, the converse relationship between victim disaffection and injustice is hereby formulated within spatial and temporal terms. In my view the most viable way to concretize such ethically value-laden but important and yet subjective variables is to use length and magnitude. The logical converse relationship between injustice and victim disaffection is dependent on the length and magnitude of antecedent. We could generate a simple logical model for this converse causal relationship as follows:

Fig. 5.1: Logical rendering of victim-disaffection

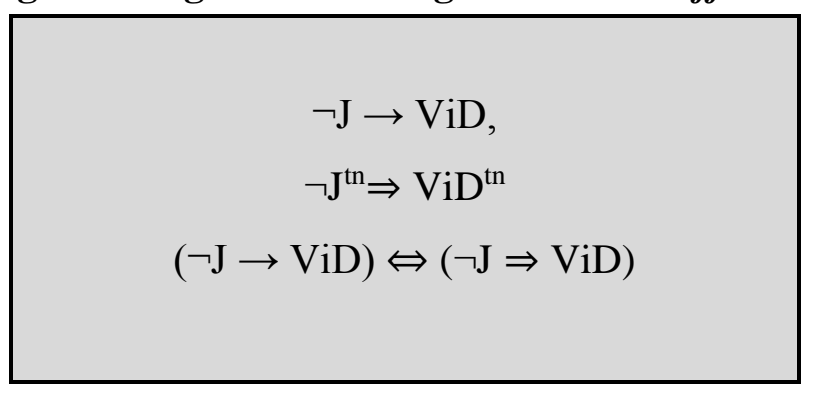


The above logical expression captures the argument that if there is injustice $(\neg \mathrm{J})$ then there will be victim disaffection (ViD); dependent on the length of time (t) and magnitude (n) to which that injustice is suffered $\left(\neg \mathrm{J}^{\mathrm{tn}}\right)$, a corresponding level of victim disaffection $\left(\mathrm{ViD}^{\mathrm{tn}}\right)$ would result. This relational model is conceived with the assumption of equivalence of both material and logical implication ${ }^{26}$.

\subsubsection{Villain encumbrance and the unsustainability of unjust systems:}

The concept of villain encumbrance is used to mean the burden that those who perpetuate injustice carry i.e. the expensiveness and burdensomeness of the unjust treatment of others. Those who are highly benefiting from the injustices that emanate from the status-quo seek to retain the systems and processes in place; unfortunately in most cases they do so at an increasingly unsustainable price. The price of establishing and maintaining unjust systems and processes would implicitly affect the sustainability of such human social contracts like the EAC regionalization project in a negative way.

Therefore a logically converse relationship could be inferred between villain encumbrance and the perpetuation of injustices i.e. the higher the perpetuation of injustice by the villain, the higher the encumbrance borne. That segment of society which perpetuates and dispenses injustice increasingly carries a heavier burden, which becomes more costly with time in order to maintain the unjust institutions and processes. And in spatial terms, the villain faces a challenge of decreasing existential space because the victims look for any opportunity either to eliminate the persons or the institutions that represent the injustices. This is exemplified by the propensity of oppressive or unjust leaders (or sections of the community) to hide behind increasing layers of security to shield themselves from the threat of retaliation from the victims; this is usually rationalized as 'being security-conscious' but in actual sense, it means losing more and more existential space for the villain. We could also generate a similar simple logical model for this converse relationship between the perpetuation of injustice and villain encumbrance as follows:

Fig 5.2: Logical rendering of villain-encumbrance

\footnotetext{
${ }^{26}$ This assumption is made because it is intuitively logical to infer that since humans universally dislike being subjected to unfair living conditions, any subjection to injustice would provoke negation from those who are suffering. Likewise, certain unjust material conditions would provoke equivalent levels of material negation.
} 


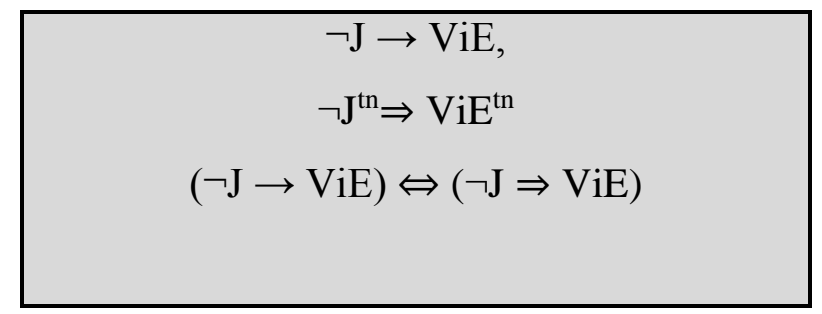

The above logical expression captures the argument that if there is perpetuation of injustice $(\neg \mathrm{J})$ then there will be villain encumbrance $(\mathrm{ViE})$ resulting from the burden of maintaining the status-quo. Dependent on the length of time (t) and magnitude (n) to which that injustice is perpetuated $\left(\neg \mathrm{J}^{\mathrm{tn}}\right)$, a corresponding magnitude of villain encumbrance $\left(\mathrm{ViE}^{\mathrm{tn}}\right)$ would result. In the same way (as in the case of victim disaffection), this relational model is conceived with the assumption of equivalency of both material and logical.

In both cases the conclusion is that such a situation would render the existing processes and systems unsustainable. In my view, the reason for the unsustainability (of the social contract) that results from this disaffection in one case and encumbrance in another, is due to the fact that the victims and the villains are existing living in different material and perceptive realities. The rationalization of each category's existence is divergent, both of which are misnomer existential justifications. Within these different and divergent rationalities each side justifies its position and actions with what is considered to be valid reasons. On the side of the villain, it is this misuse of rational validity that leads to perpetuation of injustices. The villain justifies maintaining her existential condition in terms of entitlement to claim more social goods and benefits; meanwhile the victim justifies the need to change her existential conditions appealing to the lack of fairness in sharing both the costs and benefits of the social contract. To overcome this state of affairs and to ensure sustainability fairness in sharing costs and benefits needs to be realized. When that is achieved there would be a high likelihood of having sustainable processes and systems in society. Sustainability means enduring through different time changes and a just society that caters for those who find themselves in the position of disadvantaged and advantaged at the different times of a given society. This would eliminate the tendency to violently change systems through violence or coups (whether soft or hard ones) and the desire to eliminate those persons who represent the previous unjust systems and processes. 


\subsection{Conclusion:}

This section of the study discusses the need for justice as a key pillar and principle of achieving sustainability in a social contract situation as the EAC regionalization project. It has considered the different meanings that are ascribed to justice and argues that the difference in these meanings can be bridged and therefore they should not distract us from using justice, as such, as a principle of sustainability. In order to attain that, the chapter has therefore labored to reconcile the contractarian and libertarian visions of justice by generating a reconsidered definition of justice. Basing on that reconsidered meaning of justice and a unified application of justice to sustainability; the chapter also discussed how justice is useful in undoing the dualconditions of victim-disaffection and villain-encumbrance which could render any society with injustices unsustainable.

\section{CHAPTER VI}

\section{CAPABILITIES AND SUSTAINABILITY}

\subsection{Introduction:}

This chapter explains the relation between capabilities and sustainability from the perspective of the Capabilities Approach (CA). The ideas of the two major thinkers behind the CA i.e., Amartya Sen and Martha Nussbaum are used to develop capabilities as a principle of the comprehensive ethical sustainability scheme. In order to re-cast capabilities as a principle, any misgivings about the principle approach that could arise from Sen's new book, The Idea of 
Justice (2009) had to be dealt with and discussed. The chapter then discusses the importance of capabilities in realizing sustainability developing the position that capabilities are actually about empowerment of persons and institutions in the pursuit of sustainable governance and development.

\subsection{The 'capabilities' principle in ES scheme:}

The other principle of comprehensive ethical sustainability is "capabilities" which is proposed here as a principle and condition in achieving comprehensive ethical sustainability. In developing this principle, I am arguing that in order for citizens of a given contractualist regional group of nations (such as the East African Community) to meaningfully participate and partake in both the advantages and privileges that come from the cooperation, it would be ideal for those citizens to have the capabilities to do so. The rendering of 'capabilities' as a principle in the Comprehensive ethical sustainability scheme is influenced by Amartya Sen and Martha Nussbaum's paradigm of the capabilities approach. For that reason 'capabilities' as such, is considered a pillar towards the achievement of sustainable governance and development in the EAC. A section of this chapter delves into the meaning and implication of Sen and Nussbaum's concepts of 'functioning' and 'being' as far as they are applicable in the ES scheme. Another section recognizes and discusses the importance of enhancing capabilities by focusing on: i) intrinsic and ii) extrinsic ethical empowerment of the individuals and organizations in society.

The ethical importance of the Capabilities Approach (CA) lies in its emphasis on individuals and communities pursuing and evaluating development in terms of achieving the type of lives that they have reason to value. In Sen's view, the 'value of personal freedom' (Sen, 1999:233) ought to be taken as inherent in the conception and pursuit of development; and in the CA the traditional economic idea of 'use value of opportunity' (p.76) and the political values of 'liberty and freedom of expression and action' (p.152) converge to re-focus our pursuit of development on the human person rather than anything else. The implication of such a perspective is that in order for individuals and communities to pursue such development, attention has to be given to empowering the people involved; and this takes place at both the inner (intrinsic) and the outer (extrinsic) levels. This chapter explains how this contributes to sustainability.

In order for the EAC citizens to be able to i) participate meaningfully in the governance processes in the region, and ii) meaningfully engage in the development both as individuals and communities, they ought to have the capabilities to do so. Amartya Sen, in his book, 
Development as Freedom (1999) and Martha Nussbaum in, Women and Human Development: The Capabilities Approach (2000) have developed the Capabilities Approach (CA) as a framework that seeks to make the human person the purpose of development. To them real development enables people's capabilities of flourish and it enables the realization of real freedoms. The Capabilities Approach re-focuses development theory and practice on the 'functionings' and 'capabilities' of the subjects in measuring the development of a given community.

To Sen, freedom is "intrinsically important as the preeminent objective of development" (Sen, 1999:37). Sen uses the notion of 'functionings' to denote the 'being' and 'doing' of humans, i.e. the 'freedoms' in which terms development should be measured (Nussbaum, 2000:70-96). The 'capabilities' are the doings and opportunities that the functionings affords the people, i.e. substantial freedoms (Sen, 1999:14-15). The conceptualization that Sen and Nussbaum provided had great impact on the generation of the Human Development Index (Sakiko, 2003:303) which is being used by the UNDP to measure actual development in the whole world. The study considered this approach to conceptualizing development to be pertinently relevant to the realization of sustainable governance and development of the East African Community in two major ways: i) the right conceptualization of development would enhance the capacity of the government to work towards the realization of SD; and ii) it would also enhance the capabilities of the citizens of the region too in enjoying their freedoms and thus supporting and maintaining the structure.

Nonetheless it suffice to note that in using the Capabilities Approach as a principle of Comprehensive ethical sustainability scheme, the study was aware of some of the major criticisms that have been leveled against it. Despite such critiques such as William Bernard's (1987) 'vagueness' query and Jaggar Alison's (2006) philosophical critique of the CA being 'illiberal' and 'neo-colonialist', this approach still has relevance for contemporary development discourse. First the CA was able to overcome the 'operationalization' critique that had been raised by Sugden R. (1993:1953) from which it was vindicated by its applicability in generating the Human Development Index (HDI). The HDI proved that the CA is a suitable and applicable to contemporary development challenges. William Bernard (1987) had earlier argued that Amartya Sen had not provided a coherent taxonomy of the capabilities that his theory was about (William, 1987:96); but, to a good extent, the contribution of Nussbaum to 
the CA made up for this apparent disparity in the theory. The most appealing aspect of CA framework however, is the focus on human freedom.

\subsection{Meaning of capabilities:}

In Development as Freedom (1999) Amartya Sen sets out to re-configure the conceptualization and evaluation of development in terms of the concept of 'capabilities'. In his rendering of the notion of capabilities, perhaps the clearest meaning comes out when he states that his theory was, "... an alternative approach to evaluation [of development] that focuses directly on freedom, seen in the form of individual capabilities to do things that a person has reason to value" (p.56). So to him capabilities are "substantive freedoms...to choose a life one has reason to value" (p.74). Capabilities are substantive freedoms that make one able to do and be what they find reason to value. By generating this angle of evaluating development theory and practice, Sen has to a great extent re-focused the discourse in the field of development to be human-centered other than otherwise.

In her book, Women and Human Development: The Capabilities Approach (2000), Martha Nussbaum brought a much needed angle to the capabilities approach which is the relation between justice and capabilities. One of the tenets of her thesis is that women suffer development injustices because of an inherently unjust conception of development. Most approaches to development fail to focus on the capabilities of women; and it is this inherent challenge that made earlier development paradigms conceptually 'defective' (Nussbaum, 2000:59-63). From an Aristotelian philosophical perspective, Nussbaum argues that the concerns of justice are universal for all humans and for both sexes (men and women). Using various practical examples from India she argues that the development injustices in society had narrowed the freedom space for poor women externally and internally; thus proving that freedom should not be viewed in only externalist terms. She distinguishes these two types as internal and external capabilities (p.81-84). In practical terms she generated a number of human functional capabilities on which development would focus. They include the following: life, bodily health and integrity, being able to imagine, think and reason, being able to emote and have attachments, practical reason, affiliation, recreation, and control over one's political and material environment. To her, ideal development policies should give humans, (women in particular) the freedom to 'do' and 'be' what they value; allowing them live fulfilling lives. Even though Nussbaum does not claim her list of capabilities to be final and fixed, nevertheless, she argues that they are a reflection of a need to focus development on the human person other 
than anything else (Nussbaum, 2003:33-59). The following is a breakdown of each capability listed by Nussbaum and their corresponding meanings:

Tab 6.1: Nussbaum's list and capabilities and their meanings:

\begin{tabular}{|l|l|}
\hline \multicolumn{1}{|c|}{ Capability } & \multicolumn{1}{|c|}{ Meaning } \\
\hline Life & $\begin{array}{l}\text { Being able to exist in worthy conditions with no premature death } \\
\text { threat to one's existence }\end{array}$ \\
\hline Bodily Health & $\begin{array}{l}\text { Being able to have good general and reproductive health; and } \\
\text { adequate nourishment and shelter }\end{array}$ \\
\hline Bodily Integrity & $\begin{array}{l}\text { Being able to freely move and have security against all kind of } \\
\text { assault; and opportunities for sexual satisfaction and reproduction }\end{array}$ \\
\hline $\begin{array}{l}\text { Senses, Imagination, and } \\
\text { Thought }\end{array}$ & $\begin{array}{l}\text { Being able to cultivate and use human senses to imagine, think } \\
\text { and reason through education and training; and guaranteed } \\
\text { freedoms (e.g. religious, political, literary, musical, etc) }\end{array}$ \\
\hline Emotions & $\begin{array}{l}\text { Being able to develop emotional connections and attachments to } \\
\text { people and things that one values }\end{array}$ \\
\hline Practical Reason & $\begin{array}{l}\text { Being able to engage in meaningful reflection and developing } \\
\text { one's conception of good; to protect freedom of conscience }\end{array}$ \\
\hline Affiliation & $\begin{array}{l}\text { Being able to live with others in various respectful and non- } \\
\text { humiliating social interactions }\end{array}$ \\
\hline Other Species & $\begin{array}{l}\text { Being able to live with and care for other species (animals and } \\
\text { plants, nature) }\end{array}$ \\
\hline Play & Capacity to enjoy and express recreational aspect of being \\
\hline Environment & $\begin{array}{l}\text { Being able to effectively participate in political and governance } \\
\text { decisions; and to own material properties }\end{array}$ \\
\hline
\end{tabular}

Source: Nussbaum M. (2000), Women and Development

The freedom to "do" and "be" what one values means the individual's "doing" and "being" is boosted by focusing on giving them a chance of choice capacity on their own value terms; Sen and Nussbaum refer to this as the concept of "functionings". According to Sen and Nussbaum the concept has Aristotelian roots and it "reflects the various things a person may value doing or being" (p.75). Long before the CA became popular David Crocker traced these philosophical roots and observed that the $\mathrm{CA}$ "is a philosophical and conceptual framework within which to discuss some urgent problems that arise in the course of 'development' especially economic development" (Crocker, 1992:585). To him the 'moral appropriateness' of this conception of development was mainly systematized by Nussbaum through her works on Aristotle. In a sense, this conception reflects Nussbaum making Aristotle writ large - the problems that Aristotle thought would only concern the ancient Greek citizens of a city-state are now concerns for all of humanity at a global level (see: p.587). Nussbaum calls this an 'Aristotelian moral inquiry' which would lead to an 'Aristotelian social democracy' (see: Nussbaum, 1988, 1990). 
Aristotle's synonymization of justice with virtue (because to him the just man is the one who is virtuous) and his projection of that meaning of justice onto the larger stage of the question of equity in society, must have motivated Nussbaum to see the same concern at the global level. Nussbaum's interpretation of Aristotle' concern with what it means to realize justice both at individual and communal levels makes her observe two meanings from the narrative: i) that society's deliberation on a 'communal agreement' or meaning of justice is a form of "communal self-definition and self-clarification" (Crocker, 1992:589); and ii) that the dialogue involved is a form of "self-validation" (ibid, p.590). Therefore, in Crocker's words Nussbaum postulates this "internalist evaluative inquiry" as "the ethical space of human functionings and capabilities" (ibid). In other words functionings and capabilities are a culmination of a farreaching ethical inquiry into the meaning of justice at a global level in an age of development theory and practice that had brought about injustice to many. When the global community engages in 'self-clarification' and 'self-validation' during deliberations on the meaning of justice in development discourse, the individuals within are merely expressing the internal desire for true freedom to do or be what they take to be value to them - i.e. they are expressing the need for functionings and capabilities.

From the origin of the conception of the CA, we can obviously note that it is concerned with issue of justice: i) for individual persons in local communities, and ii) for individual countries in the global community. Sen's relating of the concept of functionings to social and political justice comes to the fore in his statement that, “...being relatively poor in a rich community can prevent a person from achieving some elementary functionings (such as taking part in the life of the community...)" (Sen, 1999:71). The logical implication of this postulation of the CA is that it is unsustainable to pursue development that denies a person their functionings and capabilities.

\subsection{Capabilities and Sustainability:}

In the chapter, 'Comprehensive ethical sustainability', we observed that human agency is central to any efforts, tools and policies that may be devised for the realization of sustainability; and we also noted that ethics is determinant in human conduct and social development. Since ethics both inheres and provides a foundation for all the spheres of sustainability, the human person (whose thinking and action makes up human agency) becomes pivotal in the realization of sustainability. Therefore if we agree that ethics lies at the deepest level of human agency, 
i.e. the values that motivate human thought and action, then the enhancing of the capabilities of the human person becomes a key pillar in sustainability discourse.

Sustainability systems and goals may not be maintainable if human capabilities are either lukewarm or lacking ability to think and act in a manner that promotes sustainability. In the CA framework, human freedom is central because it is "intrinsically important as the preeminent objective of development" (Sen, 1999:37). It is freedom for humans to realize their 'functionings' based on what they value 'to be' (being) and 'to do' (doing) i.e. substantial freedoms (p.14-15). To focus our thought and act energies on something implies that we value that thing; therefore if the functionings of humans are to be directed towards the realization of sustainability, then it must be one of the key values that the freedom 'to be' and 'to do' expresses. The two, (sustainability and capabilities) go in tandem because for sustainability to be realized, human agency (capabilities) have to be directed towards that goal; but at the same time the environment for meaningful capabilities would not exist for long if sustainability is not taken as one of the values to promote. And in ethical terms, focusing on capabilities therefore could have both intuitive and consequentialist value for the sustainability discourse in the East African Community. This is because there is inherent ethical value in making human capabilities the center of development discourse; this ethical value needs to be explicated and made prominent in order to direct capabilities towards the realization of sustainability.

\subsubsection{Sustainability and the intuitive value of capabilities:}

The CA focuses on capabilities that hold inherent ethical value by virtue of placing the human person at the center for development discourse. The deontological undertones in the conception of capabilities approach make the approach to be of intuitive ethical value which is very difficult to disregard. Even though in her account, Nussbaum argues for transcending above the traditional dichotomy between consequentialist and deontological ethical theories, she nevertheless highlights the intuitive value of capabilities (Nussbaum, 2011:93-5). In using practical examples to contextualize the CA Nussbaum is careful to point out that her account of capabilities does not mean turning to 'situational ethics' (p.176).

The intuitive value of the CA lies in the freedom imperative that it places emphasis on; this emphasis is noteworthy because human agency is based on free-will. Considered in tandem with other principles of Comprehensive ethical sustainability (particularly the justice principle), having a free-willed human agent is important for sustainability because any system 
that gives less than necessary attention to human freedom cannot be sustainable. As discussed under the justice principle, human beings are naturally uncomfortable with any system that denies their freedoms; without making freedom imperative therefore the chances of collapse of such a system are high. Therefore focusing on human freedom is very important for sustainability.

The other aspect of the intuitive value of capabilities, which is also related to freedom, is the promotion of human dignity. Even though Nussbaum preferred to use the term 'basic human capabilities' in place of 'basic human rights' (Nussbaum, 2001:97), the bottom line the capabilities approach is respect of human dignity in development discourse. As Nussbaum rightly observes, the difference that she identifies between the two is more linguistic than anything else (p.99); but at the same time it mirrors a departure from using a language that favors a particular cultural tradition towards a more universal appeal. Nonetheless, in relation to sustainability, the importance is not diminished whether we refer to this value as 'basic human capabilities' or otherwise. It would be intuitively obvious that making human dignity a central part of development discourse is ethically important and it would contribute greatly to ensuring sustainability. For any system to be sustainable it is imperative to promote human dignity and the focus on 'basic human capabilities' is useful to that end.

\subsubsection{Capabilities and the spheres of sustainable development:}

Earlier in the study's chapter on 'Comprehensive ethical sustainability' we established that ethics is of foundational importance in the realization of sustainability. Having identified and advanced the four principles of Comprehensive ethical sustainability, this section, therefore explains how the specific principle of 'capabilities' would provide a foundation for the conventional spheres of sustainable development. The Johannesburg Declaration identified three, “...pillars of sustainable development i.e. economic development, social development and environmental protection [to take place] at the local, national, regional and global levels" (United Nations, 2002:1). Socially it highlighted the increasing disparities between the rich and poor countries of the world which poses a threat to stability and security. Environmentally it noted the degradation that nature is being subjected to as a threat to the sustainability of future generations; and economically it highlighted the challenges that globalization has brought to development causing some regions to remain below unacceptable poverty lines. This tripartite categorization has influenced most of the conceptions of 'sustainable development' that have 
emerged in the past decade. The concern in this section is to demonstrate how a focus on capabilities would assist in overcoming these challenges and realization of sustainability.

The environmental aspect of sustainability is one example of how capabilities approach can be utilized to realize comprehensive ethical sustainability. In order to realize meaningful and long term environmental sustainability, people have to be empowered with capabilities that make them able to value the environment and protect it; this ought to be done in such as way that their being and functioning is both proactive to environment. In the same measure it is not enough for citizens to live and express their being and functioning as they value, but it is all the more important that the being and functioning that they choose is environmentally sustainable. In this way therefore it is viable to argue that the capabilities approach is profoundly and intricately inseparable from environmental sustainability. It is therefore useful to apply the CA in analyzing and evaluating the environmental sustainability efforts and polices that are being designed and implemented in the East African Community.

This observation is more especially important given the fact that the EAC region shares some major natural features, which, if not cared for in a sustainable manner who spell great environmental, social and political problems; these include Lake Nalubaale (Victoria), it's a rain catchment basin, the crucial weather determinant mountains (such as Kilimanjaro, Kenya, Rwenzori) and the River Nile, among others. Unfortunately, the East African Community citizens that live near these shared natural resources lack the capabilities to sustainably look after and utilize these resources; and in many cases this is leading environmental degradation. The EAC Treaty recognizes that development activities (such as industrialization, agroprocessing, etc.) may have negative impacts on the environment, (Article 111:1); this is reflected in Development Objective 1.15, which aims at sustainable environmental management and economic utilization of natural resources. Environmental degradation does not only lead to depletion of non-renewable natural resources but it also pollutes the natural environment thereby negatively affecting the people's right to a clean and healthy environment. Without paying attention to this, it becomes all the more difficult to realize sustainable development.

One of the major policy expressions of the EAC's desire to attain environmental sustainability is the World Bank funded project: The Lake Victoria Environmental Management Policy (LVEMP). It has two phases: Phase I (1997-2002) and Phase II (from 2009-2017) and is pool- 
funded by a number of stakeholders including the World Bank, Swedish Development Agency (Sida), Global Environmental Facility (GEF), Governments of EAC and the local communities. This project was conceived as a 'trans-boundary project' designed to achieve two environmental objectives. The first one is to improve collaborative management of transboundary natural resources of Lake Victoria Basin and, the second is to reduce environmental stress and pollution of the lake's catchment areas as a means of improving the livelihoods of communities who live in its the Basin (Mwangi, 2014). The LVEMP is currently in its second phase which includes all the five member countries of the EAC (Burundi, Kenya, Tanzania, Uganda and Rwanda). At the policy level, the project was able to yield a comprehensive document on how to manage the lake basin in a sustainable; it is titled Strategic Action Plan for Lake Victoria Basin (Lake Victoria Commission, 2007). At the practical level the example that could be cited is the Lake Victoria Fisheries Organization (LVFO) and its stated raison d'être is to harmonize, develop and adopt conservation and management measures for the sustainable utilization of living resources of Lake Victoria to optimize socio-economic benefits from the basin for the three Partner States. It is therefore possible to use the capabilities to improve on these policies that are aimed at conservation and sustainable utilization of the natural resources in the region.

\section{4 'Arrangement-focus' and 'realization-focus' in Sen's The Idea of Justice:}

In the foregoing section, I have discussed how the capabilities approach could be useful in the realization of sustainability but this discussion would be incomplete without considering Sen's view on the 'principle-approach' to justice and sustainability. But it suffices to note that in his 2009 work, The Idea of Justice, Amartya Sen apparently discourages a principle (or structural) approach to the realization of justice; thus the need to reconcile my use of the CA as a principle with his view on how justice ought to be realized. This observation is made due to the argument he develops in favor of focusing on 'realization' rather than 'arrangements' in the pursuit of justice. My rendering of capabilities as a principle is an expression of the desire to capture those enduring and objective aspects of the human aspiration that have been brought to the fore by the Capabilities Approach. I therefore think (as argued under the chapter, 'Comprehensive ethical sustainability') that establishing such a principle as 'capabilities' that seek to preserve those enduring and fundamental lessons from the human experience is necessary because of temporal and spatial variations. 


\subsubsection{Reconciling 'Arrangement' and 'realization' focused approaches:}

Amartya Sen, in his book, The Idea of Justice (2009) identifies and distinguishes between two approaches to the realization of justice, namely, i) arrangement-focused (i.e. transcendental institutionalism), and ii) realization-focused comparison (p.7). He characterizes or defines transcendental institutionalism as an approach that "concentrates primarily on getting the institutions right and it is not directly focused on the actual societies that would ultimately emerge" (p.6). According to him, this approach focuses on "transcendental identification of the ideal institutions' while 'presuming compliance by all with ideal behavior'. This approach is concerned with answering the question: 'what would be perfectly just institutions?' He places thinkers such as Immanuel Kant and John Rawls to this category; in other words such thinkers concentrated on generating principles that would guide perfect institutions of justice; but apparently such an approach would not be of great applicable use in a world full of "manifest injustice”. In brief terms Sen criticizes what we call the principle approach to justice. On the other hand, the realization-focused comparison approach, which Sen prefers, concentrates on "actual behaviors of people and their social interactions" and it is "often interested primarily in the removal of manifest injustice from the world" that is seen (ibid). According to him this approach focuses on answering the question: "how would justice be advanced?". In that vein, he construes the project of his book as "an attempt to investigate realization based comparisons that focus on the advancement or retreat of justice" (p.8) in which he seeks to ii) take the 'comparative' rather than the 'transcendental' route; and ii) focus on actual realizations in the societies involved, rather than only on institutions and rules.

Since I am rendering his idea of 'capabilities approach' as a principle in the comprehensive ethical sustainability scheme, it is prudent that I first address the concerns that he raises concerning the principle-approach in order to avoid the accusation of misappropriating his concept. Sen problematizes transcendental institutionalism (which is actually an euphemism for the principle-approach) citing two issues, namely, i) the little or no feasibility of finding an agreed transcendental solution to the question of the nature of the 'just society'; and ii) the redundancy of the search for a transcendental solution. To be fair to Sen we have to note that he also acknowledges that there can be some positive contribution from the principle-approach such as being able to present "deeply illuminating analyses of moral or political imperatives regarding socially appropriate behavior" (p.6). To that extent I wouldn't disagree with him about the possible positive contribution to the justice debate from the principle-approach; therefore my response to him will concentrate (not on the possible positive contribution of the 
principle-approach as one would naturally expect) on the profound weakness that underlies the realization-focused comparisons approach.

Firstly, the realization-focused comparisons approach contains elements of false presupposition; the term 'realization-focused' is slightly misleading and problematic because it contains a falsely pre-supposition that this approach is the only one that is concerned with 'realizing' justice. It is as if the other approaches are non-desirous of realizing justice or are simply wasting time; no wonder he accuses the transcendental institutionalism (principleapproach) of 'redundancy'. The correct and non-condescending view would be to acknowledge that those who use the principle-approach are as much desirous of 'realizing justice' as the other camp does. Using a differing approach does not make their desire any less strong. Secondly, the realization-focused comparisons faces a big challenge of validity; by the virtue of using the term 'comparisons' Sen inadvertently concedes that he is also searching for enduring and objective ways to ensuring justice; the same function that the principle-approach serves. In my view this is so because the temporal and spatial realities of human society and existence compel any comparative enterprise to seriously address the concern of the validity. If we agree that time and space render human realities transient and fleeting, then using the 'comparisons' approach to achieve lasting impact would require first of all resolving the ancient question of 'stepping in a river twice'; because no sooner does one step in it than the water moves on. The question that exposes the weakness in Sen's approach of choice is: What can be done for justice in face of the fact of shifting realities? This has to be seriously considered because for the 'realization-focused comparisons' approach to claim validity it has to consider temporal and spatial contingencies. Otherwise the analysis of one minute ago or a week ago would not be taken serious because when we make such analysis we are inadvertently looking for enduring (or the objective) in the transient.

The question of justice is by nature enduring across time and space and in my view it would be inimical to the justice enterprise to claim that one can simply approach it from a "now-andhere' perspective. In fact the validity point raised above is vindicated by Sen's own opening paragraph in the book when he points out an enduring question from a Charles Dickens classic that was written many years ago. Even though Dickens was writing about an issue that was taking place at that time, he captured some enduing issue that remains relevant even to Sen in the 21 st century. In essence that is what the principle-approach seeks to achieve: generate principles that are applicable across time and space and in my view that is neither redundancy 
nor does temporary disagreement render it unfeasible. For that reason we ought to agree that both approached should be used concurrently even though, as pointed out above, both aim at finding enduring solutions to injustice.

Sen did not apply such a sharp dichotomy between approaches to the realization of justice as I have considered above in his earlier work, Development as Freedom (1999). For purposes of my project, I refer to that phase as the 'unradicalized capabilities' to contrast it with the radical dichotomy that he advances in The Idea of Justice (2009); I would like to tap into that original appeal and power that it exerted on development and political justice discourse. In my view, the appeal of Sen's capabilities approach in different parts of the world stems from the fact that it captures and conveys some time-transcending and space-transcending truths and aspirations of many people, particularly that of freedom. It is for that reason that I render the capabilities approach as a principle in the scheme of comprehensive ethical sustainability; and that is coupled with its applicability to various arguments for justice and fairness in development and political discourse. For example, a UNDP Research or background paper for the 2009 Human Development Report, "Immigration, ethics and the capabilities approach", applied the CA to analyse issues of migration and ethics. The author Risse (2009) uses the CA to interrogate and successfully argue for justice and ethical treatment of those who find themselves politically and economically excluded. That is an indication of the potential of cross-disciplinary and multi-subject application of the CA hence my argument that it can be construed as a principle. The most frequent usage of the CA is in the area of development and political justice because it has a rich potential of contribution to resolving the challenge of justice in development discourse and related domains. It is therefore arguable that the CA can be presented not only as a theory of development, but also as a theory of justice. Indeed Risse characterizes the CA's concept of functionings to be a form of empowerment for the hitherto powerless in society (p.15), because it can be successfully applied in the context of immigration, a field whose complexities go beyond 'resourcist' or needs-based approaches (ibid, p.17).

From my reading of Risse, the CA captures essences and underlying meanings and ramifications of development and political policies; and to her issues of immigration and ethics are issues of essence. For example the question of the quality of life as a refugee or an immigrant cannot be easily settled by needs-based approaches because mitigating it is not about simply providing needs or primary goods. It is only the CA that provides for empowering the refugee or immigrant through the argument of freedom to do and be what the person values 
(thus indicating a principle that could be applied to general and specific cases of justice). Risse's application of the capabilities approach beyond traditional development concerns such as famine and hunger, to issues of immigration and ethics proves that the approach presents a viable principle within the framework of the comprehensive ethical sustainability scheme.

\subsection{Capabilities, justice and sustainability:}

The capabilities approach has established itself as a major theory not only in political and economic philosophy but also in the globalization and global justice debate. As observed earlier, Sen's focus on 'capabilities and functionings' changed the focus of economics to address issues of justice. Its critique of the dominance of an economistic approach to development championed the justice cause such that it inspired the UN to create the Human Development Index (HDI) as a new way of evaluating development. Later the same approach played a key role in the generation of the Millennium Development Goals as the first tool to encourage human-focused development in international development discourse. This has been a big change from merely focusing on 'development as just economic growth' to 'development as quality of human life'.

As Clark (2005) observed, there are many other theories that have something to contribute to the discourse of development but, “...only the CA [capabilities approach] can address all relevant concerns" (Clark, 2005:2). His discussion of the growth of the CA is to the effect that even though earlier approaches like the Basic Needs Approach (BNA) had raised legitimate concerns especially about the needs of the poor, they had originally expressed them in an adhoc manner. But the CA manages to bring all these concerns into a "coherent philosophical framework" (ibid, p.3) thus giving the cause of justice a powerful tool to interrogate contemporary development and political arrangements. According to Sen, even the Welfare/Utility Approach (WA) has fundamental conceptual flaws because its focus on pleasure and desire fulfillment which ignores the fact that people do not always choose according to their personal interests (Sen, 1985:18-20). Clark observes that, "one of the chief strengths of Sen's framework is that it is flexible and exhibits a considerable degree of internal pluralism, which allows researchers to develop and apply it in many different ways" (op cit, p.5). It is the philosophical framework for justice that I seek to capture in my rendering of 'capabilities' as a principle of comprehensive ethical sustainability. 
However, Thomas Pogge, a key thinker on global justice, thinks that the CA is lacking in some way and therefore is not justifiably a superior framework than the "resourcist" theories. Since the capabilities concept and its approach is vital to the CES scheme of principles, it is therefore necessary for me to reply the questions that Pogge raises concerning the viability of the CA. Using what he calls a 'constructive' intent, in the article, "Can the capability approach be justified?" (2003) Pogge problematizes the CA on two issues, namely, i) that the CA phrases the question on social justice wrongly and implicitly answers the wrong question; ii) that by then the CA had not produced "a public criterion of social justice" that could viably compete with the resourcist views. Nevertheless, I think the same conclusion that I make in the earlier section (on 'rendering capabilities as a principle of ES'), as I responded to Sen's critique of transcendental institutionalism, would suffice in response to Pogge's critique of the CA: this is because in my view Pogge made those observations about the CA on the basis of the diversionary and unnecessary dichotomization between what Sen later terms as 'arrangementfocused' and 'realization-focused' approaches to justicein The Idea of Justice.

Even though Pogge agrees with the egalitarian view of justice in the CA, he postulates that believers in the superiority of the CA are answering the wrong question, namely, "which approach is superior"; instead they should focus on the question: "which approach can deliver the most plausible public criterion of social justice" (p.1). According to him, Sen's assertion that we are egalitarians suffers from the failure to differentiate between two ways of conceiving it; i.e. egalitarianism as i) an institutional scheme and ii) a criterion of social justice. In his view, Sen's writing on the re-examination of inequality ${ }^{27}$ (which laid the ground for the CA) fits the view of egalitarianism as 'criterion of social justice' (p.3).

It suffices to note that Pogge faults Sen's use of the same brush of egalitarianism to color all those who endorse "the equality and equal claims of individual human beings" (p.2) as egalitarians despite the fact that some "restrict their theory to the case of a national society. They exclude foreigners from the scope of the criterion of social justice they propose for the institutional order of a society and they also hold that their preferred criterion does not apply to the global institutional order" (p.6). Problematic as this is, it stems from Sen's conception of egalitarianism as 'a criterion of social justice'. Apparently, Pogge's argument implies that

\footnotetext{
${ }^{27}$ Sen developed the ideas which laid the foundation for the capabilities approach in his book, Inequality Reexamined (1992). In the book he examines the different conceptions of 'inequality' before advancing the CA.
} 
accepting Sen's conception of egalitarian justice would allow entities (e.g. countries) that do not care about institutional provisions for justice to join the table of the company of Rawls' 'Society of Peoples'. In other words the meaning of justice would be reduced to the level of simply ensuring that the individual's capabilities are enhanced while concern about the institutional framework for justice is sacrificed. The observation that Pogge makes about Sen's conception of the CA, as an endorsement of egalitarianism as a 'criterion of social justice', is possible to be made of Sen's work. It is also possible that such a characterization of egalitarianism would imply that we become relaxed about the institutional framework needed for justice (simply because we care about the individual capabilities).

\subsubsection{Empowering egalitarianism for sustainability:}

Nonetheless, for the purposes of my current project, it is necessary to find a reconciliatory tone between Pogge and Sen and I do this using three reasons: i) the need for universal egalitarianism, ii) necessity of empowerment to partake of justice, and iii) individuation necessarily leads to institutionalization.

\subsubsection{The need for universal egalitarianism:}

In my view, those who restrict their egalitarianism within their national borders cannot be labeled true egalitarians. Sen observed that there are certain communities which prefer to practice impartiality (or for that matter egalitarianism) within their borders, which he termed 'closed impartiality' (see: Sen, 2002:445). I prefer to call that 'closed egalitarianism'; an example of which was exhibited in Rawls' Law of Peoples (1993) in which he failed to follow up with applying his second principle in A Theory of Justice (1971) to international relations. Such a weakness would probably have been excusable in the earlier years of Rawls for reasons such as less information about the nature of our global interconnection but by the time of writing LP there was surely enough information to show him the injustices in the international order.

When Rawls argued for the "duty of assistance" and the "right of intervention" (Rawls, 2002:81), a justification of ignoring the principle of "non-intervention" (p.37), he was inadvertently acknowledging the interconnection among nations in the international arena. It is this obvious fact that I use to argue for the need for 'universal egalitarianism'. It is simply unfathomable that Rawls whose earlier work (TJ) had greatly turned contemporary political theory towards the cause of justice, with good principles of justice, would not follow through 
to apply the same principles to international order (LP). Apparently, Rawls would prefer justice at home and lack of justice in the international order. Such a missed opportunity to propagate further the cause of justice on a global scale disappoints any person who thought that his idea of justice in the TJ were good. Naturally the LP would have been the social contract writ large at the international level; but alas, in Rawls' mind, that a just social contract would only be applicable within national borders. Soniewicka (2008) has pointed out that Rawls dedicated only one paragraph in the $\mathrm{TJ}$ to the issue of international relation (p.45).

Today we have more reasons not to ignore the global nature of justice. Pogge's Realizing Rawls (1989) criticized Rawls for failing to push for distributive justice at the global level in the LP. Pogge observed that what made Rawls to renege on his commitment to distributive justice in the LP was his unexplainable decision to use a 'two-step model of the original position' (see: Stoian, 2012:139-47) justifying this decision with the argument there is no basic structure for justice at the international level. In his initial (TJ) conception of the hypothetical 'original position' Rawls postulated a starting point of free and equal persons who agree (without coercion) to choose certain principles of justice that are applicable to the realization of social and political justice. In that TJ conception of the original position, there was only a 'one time' presupposition, namely the assumption that all members of the society are coming together as free and equal members i.e. each individual person is a free and equal member for whom the principles would work impartially. However, in the LP conception of the 'original position' Rawls decided not to accept that all individual persons of the international community are free and equal and for that reason he decided not to apply the distributive justice effecting principle of his earlier work, i.e. the difference principle, which would ensure the establishment of institutions for re-distribution of global benefits or wealth from the more highly advantaged to the least advantaged. The difference between the 'one-step' and 'two-step' models of the original position is that in the former case, individual persons are free and equal to directly participate in the choosing of the principles of justice, whilst in the latter case, not all global citizens are free and equal to participate but their representatives (thus the term 'two-step').

Pogge criticizes Rawls' adoption of a 'two-step original position' arguing that what Rawls had initially generated as the 'one-time original position' (Stoian, 2012) is better because it would be regrettable if only representatives of a certain state to choose principles of justice inconsiderate of the international community and then find out that all along they are part of that system; i.e. it would be rather isolationist to generate and adopt principles of justice and 
establish national structures without taking into consideration the international community on which that state may be depending (p.244). Buchanan (2000) also disagreed with Rawls by arguing that due to the weaning importance of the old boundaries of the 'Westphalian state', and since individual persons mobility across those old borders has increased, if we follow Rawls idea of the 'two-step original position' which only allows for representatives of nationstates, then such persons would be denied justice. It would be politically unjust to deny individual members of the global community direct representation in the international discourse on how their institutions are established. In the same vein there are many communities in the global community today that are not represented by nation-states.

However, there are still some thinkers who are not convinced by the global cosmopolitanism view being propounded by the likes of Pogge and Buchanan. For example, Blake Michael (2001) used the positions that since: i) only the nation-state has coercive powers while the international system does not, and ii) violation of autonomy can only take place in physical terms; and he concluded in defense of Rawls that global distributive justice was not possible. Valentin Stoian (2012) also reiterates the anti-cosmopolitan view in defense of Rawls direction in the LP by arguing that since the global system has no coercive basic structure it would be demanding too much to call for a TJ kind of distributive justice at a global level (p.143). To Stoian, what exists is simply "a system of global interactions" and therefore, "asking to subject the global system to Rawls' principles of justice for domestic societies is too much" (ibid).

But I would like to respond to the above anti-cosmopolitan view of the non-existence of a global basic structure by arguing that at least there is a strong and undeniable foundation in which a global basic structure could be built. Am arguing that in any case such a situation (of an existing foundation for a global basic structure) suits the Rawls' TJ agenda which was a kind of 'contractarian-constructivsim, 28 , whereby structures of justice is presumed absent and members of the society come together to establish them using the best principles of justice. But in order to see and acknowledge this existing foundation for a global basic structure, we have to use different parameters of observation.

\footnotetext{
${ }^{28}$ I use this term to imply the Rawls used the social-contract framework to generate principles for building institutions of justice i.e. it is a constructionist approach following the parameters of social-contract theory.
} 


\subsubsection{Natural and constructed foundations of a global basic structure:}

I would like to re-echo Buchanan's view that we are no longer in a Westaphalian world; it is only those who are stuck in 'Westaphalian romanticism' ${ }^{29}$ that ignore the glaring facts before them. Thanks to increased technology and research we now know that there is foundational global system that goes beyond traditional national boundaries and it does not simply 'affect' us indirectly but directly coerces our individual autonomy into certain directions. We can divide this foundational system into two categories which I explain in the following segment, namely, i) the natural foundation for a global basic structure; and ii) the constructed foundation for a global basic structure. If we acknowledge these two aspects of the 'foundation for a global basic structure', then even our conception of 'coercion' would necessarily change in a great way. Suffice to note that these two facts would logically have led to the conclusion that all of us share the same challenges or goods in the global system however, the contrary is true and hence the greater need for a global system for distributive justice.

The natural foundation for a global basic structure has been illuminated by the advanced science and technological studies that are shaping our knowledge of what goes on around us today. Our advanced knowledge of the climatic science shows a connected system in the natural-sphere of the globe that we cannot ignore. A systems approach to understanding the global climatic conditions and changes reveals that there is an intricate and profound weather and climatic machine which affects each and every human being. For example in a groundbreaking documentary, Earth from Space (2013) produced by NOVA (a NASA satellite program), a revolutionalized approach to satellite observation and spacecraft reveals a very closely inter-twined climatic system which affects our lives in far deeper ways than we could have imagined or understood a few decades ago. The impact of a single weather or climatic phenomenon in one end of the globe is felt across the other ends of the earth. The natural global weather system is both more basic and coercive than we could have imagined before. The science of climate change is increasingly proving to us that our activities are far inter-twined than we ever thought they could. If we acknowledge this fact, it becomes logical to conclude that nothing can get more coercive or affect our autonomy than the natural system that supports our lives. We should go beyond the traditional view of coercion in terms of nation states; nature

\footnotetext{
${ }^{29}$ Westaphalian romanticism is used to refer to the nostalgic desire to stick to the old modern state that emerged after the treaty of Westaphalia that established the nature of the state as we know it today. In some cases (such as Europe) where it emerged indigenously, it may have been of great benefit; but in others (such as Africa) where it was externally imposed through colonialism, it has been of little benefit to the peoples who were separated by the artificial boundaries
} 
is far more coercive. Nonetheless, this global climatic inter-connectedness is unfairly affecting some members of the global community negatively while others benefit more, a situation which calls for egalitarian re-distribution.

The second aspect of the foundation for a global basic structure is the constructed network that exists in the global system; this includes institutions like the economic systems, information highways, transportation network, among others. I refer to these as the 'constructed aspect' because they have been established through human agency. Thinkers like Stoian would argue against this using the view that such systems are not coercive as the nation-state; however, such an understanding of coercion is faulty. These systems indirectly drive our lives into directions that would otherwise not have been our choosing. It is no longer feasible to feign that one is not impacted by the human constructed aspects of the global networks: for example news from one part of the globe is increasingly affecting our worldviews; the economic system is responsible for the food we find in our local store; we easily move around through the transport network that has been constructed. This constructed network would provide a foundation for a TJ Rawlsian to apply the principles of justice to the institutions that are being established. However, a similar observation, as in the case of the natural foundation above, could nonetheless be made concerning the constructed aspect, i.e. that the network are titled unjustly to certain members of the global community thus necessitating an egalitarian re-distribution of the benefits thereof.

All in all, the argument that there is no global basic structure no longer hold much water because the foundation for such a structure to be established is increasingly visible and if we really want to apply Rawls to the project of establishing institutions of global justice, we can use that foundation to do so. Likewise the argument that the global basic structure is not coercive enough is faulty because the nature of the coercion from the foundations of the global basic structure is far more potent than that of the traditional nation-state. Unfortunately, the foundations that pre-exist the global basic structure are utilized in an unjust and an unsustainable manner to some members of the global community. For example when it comes to climate, some members of the global community take the biggest chunk of the benefits while the least advantaged bear the brunt of any catastrophes that may result. When it comes to the constructed aspect such as the global economic network, the same applies: as the recent economic depression demonstrated, some members of the global community reap huge benefits from the system while others scrape around for crumbs. 
On the basis of the above discussion, this study would wish for the establishment of a 'global basic structure' that promotes fairness for all; which entails individual direct representation in the discourse. In the terms of the EAC it could be referred to as a Regional Basic Structure (RBS) that seeks to overcome the weaknesses and limitations of the current EALA institututional arrangement that has proved ineffective in terms of sustainability. A universal egalitarian and 'one-step original position' would seem to be more true to the definition of justice as fairness because when we use the 'two-step original position' the chances of misrepresentation and unnecessary 'middleman-ship' ${ }^{30}$ are heightened and they may turn to be a disservice to justice. We have observed this phenomenon again and again among the political elite whereby they betray those for whom they were sent to represent at any given level of representative leadership. In the same vein, by now we know too well that the existing global institutions based on representation rarely serve the interests of the peoples for the representative claim to go. Despite incessant talks that are stage-managed to portray genuine deliberations and representation, the truth is that many of the agreement and contracts that come out are unjust and leave the poor or the least advantaged worse off than before.

\subsubsection{Necessity of empowerment in partaking of justice:}

The second reason that both Sen and Pogge would find agreeable is the necessity of empowerment in order for one to partake of justice. However much we argue for "which institutional structures are better in delivering justice' or 'which theory of justice is better', at the end of the day we would prefer individuals or agents who are able to effectively participate in justice discourse and in benefiting thereof. Pogge inadvertently insinuates that participation of a key aspect of the justice discourse when he tackles the issue of 'compensation' and 'compensatory burdens' in the capabilities theorization of justice. He states that, "...each participant's resource entitlement under a just institutional order are to be determined in part by the overall quality of his or her natural endowments..." (Pogge, 2002:59). That statement proves that Pogge acknowledges the need for participation in whatever institutional order that may be in place for the realization of justice. For members of a society to take the institutional frameworks put in place as their own, they need to have participated in their establishment but

\footnotetext{
${ }^{30}$ This middleman-ship arises as a consequence of the 'two-step original position' (in Rawls' LP) which allows for representation of free and equal nation-states rather than free and equal individuals. It is rather unnecessary because it encumbers the realization of institutions for justice and could even foster vices such as corruption.
} 
at the same time have the capacity to effectively participate in the justice discourse that surrounds them.

\subsection{Capabilities and empowerment for sustainability:}

In my view, the members of a given society would not be able to effectively participate in the justice institutional frameworks that are in place and neither would they be able to meaningfully partake of the justice benefits that accrue from the set-up without the requisite capacities. This calls for empowerment of the persons in order to realize effective participation in the justice institutional framework and meaningful partaking of the justice benefits. It is at this juncture that I would prefer Pogge and Sen to be reconcilable: the former agrees that direct participation is crucial in the realization if justice for all while the latter's capabilities concern would make the participants empowered and therefore more effective in the justice discourse.

Empowerment theories emphasize the need to take the previously powerless and giving them a platform upon which to stand and decide their destiny. This involves increasing the political, economic and social power tools for the hitherto least advantaged in order to enable them exercise their self-determination and self-actualization. The capabilities approach is in my view, best suited to ensure the effective empowerment of the least advantaged for purposes of justice. In a background paper to the Human Development Report (1997), titled "Empowerment as an Approach to Poverty", Gita Sen argued that when it comes to empowerment it has to be approached from both the extrinsic and intrinsic levels. According to him the two levels of empowerment are not mutually exclusive. In his view in order to empower the poor or least advantaged, it must be done both extrinsically and intrinsically. Intrinsic empowerment involves enabling the powerless to realize, appreciate and apply their inner abilities to get them out of powerlessness. Such forms of empowerment may include inner transformation, better self-consciousness, and motivation, among others. On the other hand, extrinsic empowerment is about being enabled by means of tools and the environment within which one exists so as to decide one's destiny. It may take forms such as giving the poor loans, defending them in courts of law, among others.

\subsubsection{Intrinsic empowerment and sustainable justice:}

The intrinsic aspect of empowerment is concerned with enabling a person appreciate and increase their inner abilities. This aspect is realizable through the capabilities approach to justice because a big portion of the focus on capabilities actually implies a focus on inner values 
and abilities. When Sen refers to doings and beings he is to greater extent referring to the inner abilities of persons or peoples to be empowered to find and utilize their inner capabilities in determining their economic and political destiny. For justice to be sustainable persons and peoples need to be able to effectively participate in the both the establishing and running of the institutional framework that exists in society. They can only do this if they are fully empowered to make meaningful contribution. This would go a long way in avoiding the challenge of victim disaffection that I identified earlier as a key cause of unsustainability.

\subsubsection{Extrinsic empowerment and sustainable justice:}

On the other hand, the extrinsic aspect of empowerment is concerned with ensuring an enabling environment and tools for exercise of one's inner capabilities. Even if persons and peoples are internally empowered, without the right tools and an enabling environment, they cannot realize their potential nor determine their destiny in a way that can be viable. Therefore in order to realize justice that is sustainable an empowering environment ought to be established such that persons or peoples are availed space to meaningfully participate and partake of the benefits from that justice discourse. This means that the circumstance (environment) within which one exercises one's capabilities and functionings is as important as the capabilities themselves. Sen assents to this interpretation when he argues that it is the "protective power of democracy" (Sen, 2009:349) that provides the right environment in which to exercise one's freedom; because it provides room for "participatory politics" and "public agitation", "democratic freedom can certainly be used to enhance social justice and better and fairer politics" (p.351). Therefore true freedom (capabilities and functionings) is not sustainable without a conducive political environment.

Apart from the political environment, another aspect of extrinsic empowerment that we could consider is the economic environment. For sustainability purposes it is critical that a regional bloc like EAC is economically empowered to realize its growth potential and be able to fund its own budgetary needs instead of depending on donors, a habit that is not sustainable in the long run. This sentiment over the economic sustainability of the EAC has been echoed by some researchers thus: ...the regional venture might become so popular with the donor community that its secretariat becomes overpopulate with expatriate advisors and seconded staff. In the short and medium term the result could easily be loss of control over its own agenda. In the long run such donor dependency would clearly not be sustainable ... the proportion of the budget that is donor-funded is worrisome. (Nzioki \& Tostensen, op. cit, p.27) 
It is interesting to note that the developed countries find it easier to take the role of donors in the EAC regional project other that investing (effectively trading) in the economies of the region. In 2010 it was reported by the African Development Bank (ADB) that "among the five African regions, Eastern Africa was the lowest recipient of foreign direct investment (FDI) in 2008 and 2009" (AfDB, 2010:5). In terms of sustainability it is more reasonable to focus on investment in order to build the economic and human capabilities instead of pouring in large amounts of donations which encourage dependency. I therefore agree with African economist Dambisa Moyo (2009) ${ }^{31}$ who argues that aid, as altruistic as it may be, does not augur well with the goal of enhancing capabilities and empowering African countries. It is engaging in peer-to-peer trade with the African countries that would teach them 'to fish for themselves' rather than 'giving them fish'. But this requires the developed countries to remove the economically crippling formal and informal barriers that block African products from entering their markets.

Likewise and relatedly it is necessary to ensure that economic empowerment of member states of the EAC takes place in order to be able to eventually take over the budgetary needs of the regionalization project. It calls establishing an extrinsic environment that enables the members, especially those that are economically weaker to attain viable levels of economic growth to sustain both the national and regional economies. This is mainly applicable to the question of establishing a monetary union that was recommended by the Fast-Tracking Committee; there were serious challenges even at the stage of a customs union whereby some members states (especially the coastal states of Kenya and Tanzania) were accused of establishing non-tariff barriers to goods bound for the hinterland nations. Nonetheless, there is need for putting in place institutional provision that balance and share out the costs and benefits of the proposed monetary union in case of crisis (Ligami, 2013) in order to avoid the recent scenarios during the Eurozone economic crisis.

Even though there is seeming disagreement between the resourcist (such as Pogge) and capabilitists (such as Sen) stemming from the former's focus on institutional conditions for

\footnotetext{
${ }^{31}$ In her book, Dead Aid (2009), Dambisa Moyo presents one of the most compelling arguments that even though aid was good in the short-run for sub-Saharan Africa, in the long-run it has proved a "disaster" because it ruins their economies by exonerating the political class of their responsibilities and denying the region a locally driven democratization process that is conducive for development. In effect it distorts the 'African social contract'.
} 
justice while the latter focuses on justice at a individual level, a closer interrogation would reveal that they each depend on the other. When we follow both the logical and practical conclusion of an individuated approach to justice, it would ultimately lead to institutionalization. In my view, what Sen refers to as 'realization-focus' approach is in principle and effect an individuated (or situated) approach; if that approach repeatedly realizes its goal of justice in particular situations, it would in time become institutionalized i.e. it becomes an 'arrangement' thus turning into the 'arrangement-focus' that Sen tries to avoid. The logical conclusion from that observation is that justice needs to be served or realized whatever approach one uses; either the 'realization-focus' or the 'arrangement-focus'.

\subsection{Conclusion:}

The foregoing section explains the relation between capabilities and sustainability from the perspective of the Capabilities Approach (CA). The ideas of the two major thinkers behind the CA i.e., Amartya Sen and Martha Nussbaum are used to develop capabilities as a principle of the comprehensive ethical sustainability scheme. It sought to remove any challenge that may arise in using the concept of capabilities as a principle of sustainability by reconciling the apparent dichotomy that Amartya Sen discusses between 'arrangement-focused' and 'realization-focused' approaches to justice. The chapter has positioned the discussion of sustainability within the egalitarian theoretical discourse on justice; and on those grounds it has established the natural and constructed foundations of global justice. The chapter has demonstrated that applying capabilities to sustainability in the EAC implies both intrinsic and extrinsic empowerment of citizens and institutions in the region. 


\section{CHAPTER VII}

\section{UBUNTU AND SUSTAINABILITY}

\subsection{Introduction}

This chapter discusses ubuntu as a key principle of the comprehensive ethical sustainability scheme. A section is dedicated to establishing the meaning of 'ubuntu' within the continuum of African metaphysics of being and human existence. The chapter also discusses how ubuntu could be applied in reconciling the various divergences that exist in selected governance issues and approaches to solving them. The study postulates that if ubuntu is applied thus, the realization of governance and development sustainability is not an impossibility.

\subsection{Making Ubuntu an ethical principle:}

The Ubuntu principle is another principle within the Comprehensive ethical sustainability scheme that seeks to contribute to the realization of government and development sustainability within the East African Community. As indicated in the chapter on 'Comprehensive ethical sustainability', one of the key features of the principles used in this scheme is being of axiomatic value to the governance and development milieu at hand. In this case, Ubuntu is chosen as one of the principles because it axiomatizes the, i) deeper African philosophical values, and ii) essentializes the time tested ethical values of African societies. But as we transform Ubuntu into a principle we need to ensure that it does not lose its ethical power because in many cases 'axiomization' is equated with 'reductionism' and there are fears among ethical scholars over the possibility of losing the virtue aspect in the principles that may have been obtained (see: Zucker, 1984).

It is therefore necessary to explain the kind of 'axiomization' that should be applied to this principle which the study has termed as 'ethical axiomization'. This explanation is necessary as far as the Ubuntu principle is concerned because of the common but errorneous thinking that African philosophy lacks a logical form ${ }^{32}$. As done in earlier chapters, this study here also

\footnotetext{
${ }^{32}$ This is not our concern of this section of the study; but for more on this issue one can see the works of Eze Chukwudi (1993), Gyekye Kwame (1997) and some sections in Lajul Wilfred (2014). They have discussed the issue of the existence and validity of traditional African logic to various degress in their works.
} 
distinguished 'ethical axiomization' traditional modal logical-axiomization in particular for purposes of avoiding to appear to be presenting either deductive or inductive inclined ethics. The principle of Ubuntu is designed to capture and represent the essence of the three most common broad approaches to resolving the development and governance challenges of Africa among notable African scholars that were identified in chapter two, namely, re-dignification, unification and re-construction. In all these three approaches the ideals of Ubuntu can still be represented. In terms of 're-dignification' the incorporation of ubuntu brings back the dignity of the native African as one who can also contribute to the ethics and governance discourse in the region; and it also gives the native room to apply a philosophy that she is well versed with (Vervliet, 2009:19-21). In terms of 'unification', ubuntu has potential of unifying varying views within Africa and finding a meeting ground for the many tribes that exist in the continent. In terms of re-construction, ubuntu also contributes to the re-making of the processes and the institutions of the region.

\subsection{Ubuntu: the African philosophy of humanness:}

Christian Gade (2011) discovered that the word 'ubuntu' first appeared in written texts in 1846 in a missionary's text about the gospel of Jesus Christ in South Africa (Gade, 2011:306). But Ubuntu as a worldview has been in existence among native Africans for long. It could be defined as a traditional African philosophy which espouses the value of humanness and the enablement of the flourishing of both humans and other beings in the environment. Perhaps the most common use of the word 'Ubuntu' is the communally developed computer software known as 'Ubuntu Linux' ${ }^{33}$. But the philosophy behind this software is as old as the peoples of Africa and their cultures. As recent genetic studies on Africans ${ }^{34}$ have indicated that the earliest people were in east Africa, perhaps ubuntu ethics could be the oldest and most enduring ethical theoretical perspective in human society.

\footnotetext{
${ }^{33}$ The development of the software known as Ubuntu Linux was initiated by Mark Shuttleworth a South African who was inspired by the Ubuntu philosophy which they translate as 'humanity to others'. The software company that provides its services holds that humans should be able to share. This is the most popular reference to the traditional African worldview of ubuntu but there is more to the philosophy than a software version.

${ }^{34}$ It is also worth noting that in genetic studies after the paper, "Mitochondrial DNA and Human Eve" by Rebecca Cann, et al (1987) in Nature, many scholars agree that humanity migrated out of Africa. If we agree that it is true, then it would be more reasonable to think that the most probable philosophy that guided that early life would be very informative
} 
The term "ubuntu" is commonly found in many languages of Africans and words that are almost the same or similar are found across the continent; which implies that values of ubuntu are of deep meaning for majority of natives throughout sub-Saharan Africa as they have been preserved in all those dialects. The following are some the variants of the usage of the word in selected African communities and languages:

Tab. 7.1: Variants of ubuntu in Africa:

\begin{tabular}{|l|l|}
\hline Variant of Ubuntu & Community/Language \\
\hline Bumuntu & Kihayi (in Tanzania) \\
\hline Gimuntu & Kwese (in Angola) \\
\hline Umundu & Kikuyu (in Kenya) \\
\hline Mundu & Bagisu (in Uganda) \\
\hline Bomoto & Bobangi (in Congo) \\
\hline Omuntu & Baganda (in Uganda) \\
\hline Umunthu & Malawi \\
\hline Umunthu & Zambia \\
\hline Vumuntu & shiTsonga (in Mozambique) \\
\hline Umundu & Rwanda \\
\hline Unhu & Shona (Zimbabwe) \\
\hline Ubuntu & Nguni (South Africa) \\
\hline
\end{tabular}

The above simple survey would make it reasonable to hold that the appearance of all these variants of the word ubuntu across much of sub-Saharan Africa cannot simply be a coincident or an accident of evolution. Rather it means that the significance and value in this word was preserved in all the dialects as different Africans migrated across the continent. The implication is that traditional Africans who used this word must have been referring to something of a deeper value to them that we need to understand.

Some views have been expressed questioning the significance and prevalence of ubuntu philosophy across African communities. For example, Wilfred Lajul has argued that, "...though the concept sounds so wonderful, most African ethnic or social groups' understanding of ubuntu ends within the boundaries of their societies. Foreigners who spoke different languages or with different origins were never accorded the same social hospitality 
practiced under ubuntu philosophy" (Lajul, 2014:109). This statement seems to hold that attitudes and conduct expressible as 'ubuntu' only exists within and towards members of a given traditional community but are not extended to other humans outside that particular community. But in my view this is an erroneous characterization of ubuntu because as it is observable in the table above the philosophy of ubuntu is expressed in various languages on the continent and since most Africans share the same genetic ancestry, implicitly these Africans took this worldview with them wherever they migrated. Since genetics researchers have discovered a common ancestry of humans from sub-Saharan Africa (see: Cann, et al, 1987), we can surmise that the ubuntu worldview emerged as they needed to stay together to survive the harsh conditions of the time. This means that ubuntu is not a simple 'skin-deep' concept that some African communities talk about but it is deeply rooted in the primal survival instinct of the human race. The particular survival instinct is that of coming together in smaller or larger groups in order to pool energies and resources together for the betterment and survival of the members of that group. Secondly, such a conclusion as Lajul makes is a result of not viewing ubuntu as an ideal that all communities should aspire to achieve in practical living; an ideal is an aspiration that may not be expressed in perfection in different communities but that does not hinder the given communities from seeking to live together in harmony. Each community has certain major ideals to which they aspire but the actual expression of that ideal may vary or be affected by contingencies as time and space changes, but the ideal remains of great inspirational value; therefore ubuntu should be viewed as an ideal to which all humans ought to aspire.

In a related way, Didier Kaphagawani and Jeanette Malherbe (2004) in their chapter titled, "Epistemology and tradition in Africa" make a mistake of thinking that in ubuntu, it is the 'ubu' that is the root word. Though much of the chapter deal with traditional African epistemological perspective, there is section dedicated to the 'metaphysics of ubuntu philosophy' in which they postulate that the key prefix in the word 'ubuntu' is 'ubu' and they refer to its meaning as a being 'marked by uncertainty' (Kaphagawani \& Malherbe, 2004:278) and that is where they made an error. To their merit however, they rightly observe that there is an "onto-triadic structure of being" in traditional African ontology which includes the: i) 'yet-to-be-born', ii) 'living' and iii) the 'living-dead'. However, the makes them postulate that "according to the ubuntu understanding of be-ing, the world of metaphysics is the world of ' $u$-nkulu-nkulu': the greatest of the great and the ineffable" (ibid). In their conclusion African metaphysics is in the unknowable realm; for that matter they erroneously conclude that ubuntu religion has no theology. 
Kaphagawani and Malherbe make a fundamental mistake in their analysis by focusing on the wrong prefix in the word 'ubuntu'. The key to unlocking the metaphysical meanings in 'ubuntu' is not 'ubu' as they claim but 'ntu'. Kasozi Ferdinand (2011) has done thorough research ${ }^{35}$ on this aspect of ubuntu philosophy and demonstrated that the root word in 'ubuntu' is 'ntu', that is why the root 'ntu' is found in many languages of the native African peoples who migrated across the continent (see table above). The variations in its rendering are 'ntu', 'ndu', 'ndo', 'nthu', among others. When we appreciate this, then it becomes easy to understand the deep metaphysical wealth that these languages were trying to preserve in keeping that root word in their reference to being. Therefore ipso logico, these natives knew what they were preserving; it would therefore be illogical to conclude as Kaphagawani and Malherbe do that ubuntu metaphysics is unknowable.

\subsection{On Ubuntu metaphysics:}

The word 'Ubuntu' has its roots in African prefix word ' $n t u$ ', which, as demonstrable by the above table, is found in many languages across Africa. Its existence in a number of languages on the continent and in vast regions beckons for further analysis to understand why that is the the case and what lessons could be picked from such a situation. Linguistically the word 'ubuntu' comprises the pre-prefix " $u$ ", the prefix "bu" and, the noun "ntu". In a linguistic context, "ntu" is a root-word (Kasozi, 2011); therefore "ntu" is the irreducible element of the significant word 'Bantu' in its various forms. The latter word means "person", which can be translated as personhood or humanness (see: Kasozi, 2011:25).

To understand the metaphysical undertones of ubuntu we can use the Baganda who are found in Uganda, East Africa, and see how they use the concept. In his study, Introduction to an African Philosophy: The Ntúology of Baganda (2011), Kasozi observes that the prefix 'ntu' is of static rootage to almost all the major words used by the Baganda. In his study of Ntúology, which he defines as the substantive philosophical study of the meaning, function and value of the root word 'ntu', (p.17), Kasozi observes that "ntu is the irreducible element of the significant word Bantu in its various forms" (p.25). The key issue that he brings to our attention is that of 'irreducibility'; to explain this important role of 'ntu' in Buganda. It is perhaps

\footnotetext{
${ }^{35}$ Note should be made of the fact that by the time of KaphagawaniDidier and MalherbeJeanette publication, the detailed research by Kasozi Ferdinand (2011) on the root word 'ntu' had not yet been published, so their conclusion would be excused on that count.
} 
noteworthy that according to the Baganda's story of origin, the first man on earth was called 'Kintu'. He is also considered the first Kabaka (King) to rule the Kingdom of Buganda (Nsimbi, 1956).

Metaphysically this is centralization of a mythical figure implies the importance attached to the concept of 'ntu'. Kintu embodies the Baganda's deepest roots of origin, they trace him to have descended from 'Ggulu' a translation of which means 'heaven'. So he came from Katonda (The Creator) and he was not only the first man but also the first Kabaka. It therefore captures the divine-human connection that the Baganda sought to establish in order to authenticate their existence and co-join it with cosmic existence. This has had great impact on the psyche of every Muganda because of the knowledge of deep roots of her existence. This mythical figure Kintu is credited for having gathered the Baganda together and made them into a kingdom. Actually the literal meaning of the word 'Muganda' is 'bundled together'; hence the high level of cultural attachment and social cohesion among the Baganda. This also provides the basis of Buganda's political and governance philosophy which is based on cultural tenets known as 'nnonno' which are said to have been mediated by Kintu.

The word 'ntu' is also applied to things that are inanimate and things that are unknown, to denote the fact that in traditional ontology there was respect for the being of other things in the universe. The Baganda use the word 'ekintu' to mean 'something'; while at the same time, 'omuntu' means 'a person' or 'abantu' means 'people'. But in cases when they do not understand something, they refer to it as 'ekintu ekitategerekeka', meaning 'something that is not understandable'. This application of the 'ntu' prefix brings out an interesting aspect in Baganda metaphysics and ontology. It means that being is found in each and everything whether we may understand the nature of that thing or not. It infers acknowledgment of the fact that something exists. This is critical twist in the use of 'ntu' because it is applied to both living and non-living things: 'abantu' means 'people' or 'human beings', while 'ebintu' means things, as such, whether visible or invisible and whether they are tangible or ideas.

This implies that 'Ntu' means existence both in human terms and the existence of other beings. So to be 'omuntu' (a person) is first of all to exist; likewise for something to be referred to as 'ekintu' it means that it exists. This informs us a lot about the existential philosophy of the Baganda; it implies acknowledgment and respect of the being of others. Kintu, as a mythical character in Baganda folklore in which he is taken as the first Muganda and first Kabaka, is 
therefore a reference to the depth of human existence. It captures ancient meanings of existence in traditional Buganda society. Perhaps this is the essence the term ' ubuntu' carries across the African continent wherever it is found. So when the Baganda refer to someone as 'omuntu mulamu', it means a 'person of noble character' (see: Hyman \& Katamba, 2006) but in a deeper sense it means a person who respects the being and existence of others. This is because it is from the deep respect for the existence of others that one behaves or conducts themselves appropriately towards them. Hence the ethical roots and usefulness of ubuntu draws from the deep meaning of existence and being that is derivable from the metaphysics thereof.

\subsection{Flourishing of human existence:}

Ubuntu is an African philosophy of humanity and community (Skelton, 2002:497); it is also defined as a philosophy of becoming human (Swanson, 2009:4), which encourages a holistic and inclusive view of all humans as those who share the same space and resources. It is a worldview holding that we have to embrace a sense of our interconnectedness as a global community if we are to survive (Murithi, 2009). The underlying values of this philosophy are purposed for respecting the dignity and contribution of each person and promoting the flourishing of human existence and relationships. The essence of the values that are embedded in the ubuntu philosophy has been expressed by Desmond Tutu as Michael Battle quotes:

\section{A self-sufficient human being is subhuman. I have gifts that you do not have, so consequently, I am unique. You have gifts that I do not have, so you are unique. God has made us so that we will need each other. We are made for a delicate network of interdependence. (Battle, 2009:35)}

Ubuntu represents the inherent capacity in African culture to express compassion, reciprocity, dignity, harmony and humanity in the interests of building and maintaining community with justice and mutual caring (Nussbaum, 2003). In this study I have decided to render ubuntu as a principle in the notion of comprehensive ethical sustainability because it enables us realize and appreciate our interconnectedness as humans; and such an attitude would promote the sustainability of our social and political systems, processes and institutions.

Ubuntu exhibits the flourishing of both humans and other beings on a local, national and global scale. According to Archbishop Desmond Tutu, Ubuntu is a belief that "a person is a person through other persons, that my humanity is caught up, bound up, inextricably, with yours. 
When I dehumanize you, I inexorably dehumanize myself' (Tutu, 2004). Thus, we realize that [ubuntu] is a powerful tool to strengthen a community, to communicate through community support, dignity, and identity achieved through mutualism, empathy, generosity, and community commitment (Tutu, 1999). It is the realization that those around us are as human as we are; and acknowledgement of that fact would assist in attainment of sustainability of society particularly in terms of human relations.

\subsection{Ubuntu and sustainability:}

The traditional ${ }^{36}$ African principle of "ubuntu" is hereby presented as a condition of ethical sustainability because it captures the sense of community and humanness. I consider it as a necessary ingredient towards the realization of sustainability because as most critics of modern economic and development thinking (Gasper, 2004), the self-interest logic of economics has failed us and lead us to an unsustainable system. Ubuntu captures the time-tested ideals ${ }^{37}$ of traditional African societies such as, interconnectedness, harmony, communitarianism, wholeness and continuity. All these ideals resonate well with the pursuit of sustainable political development particularly to the east African because they would perceive these concepts well.

The African ideal of 'interconnectedness' meant that each and every being in society is profoundly and mystically connected to the other. This meant that when one is harmed or suffers it ends up affecting the rest of the members. Evidence of this view of society is found in myriads of proverbs, sayings, folklore that they used to teach this ideal to the young. Such an idea would be applicable to the sustainability of the EAC. Traditional Africans strove to live in 'harmony' both with nature and everybody else. Up to now one still finds great admiration and deification of natural objects among Africans; the desire to appease what they took to be nature's mystical forces portrayed a pursuit of harmonious living with nature. Despite its scientific shortcomings, obviously such a view of life is necessary today given the enormous challenges of climate change and the need to preserve natural resources such as forests and

\footnotetext{
36 The appeal to 'traditional Africa' should not be construed as a nostalgic and unrealistic 'romanticization' of old African glory as some critics would argue. Rather it is reaching into the rich heritage of African philosophy in order to harvest ideas and concepts applicable to contemporary human challenges. Like any society which regularly searches its history to seek for inspiration in times of necessity, Africa is not an exception. There is a lot that contemporary Africans and the world at large can learn from its past; if this is done by modern pharmaceutical corporations who spend millions of dollars in research on traditional African medicine, then it is also logical to do the same in other domains of research.

${ }^{37}$ It should also be noted that these ideals were not always achieved but their existence represents a deep desire to actualize them. Just any other society they were ideals that provided a vision of the society which they could strive to build.
} 
lakes that form the backbone of the economies of the EAC. Tapping into this respect of nature would assist in preserving a shared and delicate resource such as Lake Victoria ${ }^{38}$. The concept of 'community' has been crucial to African social and political philosophy for time immemorial; it was captured by the famous statement by John Mbiti, "I am because we are; and since we are, therefore I am" (Mbiti, 1989:141). The notion of 'community' is resurging as the theory of 'communitarianism' in global political debate (see: Kymlicka, 2002:208-83) and it has a lot to contribute to the justice discourse. It suffices to note, however, that i) the ideal of traditional African communitarianism is different from the Marxist notion of communism, and ii) contrary to many critics of this ideal, it did not imply that the individual rights were never respected in traditional ${ }^{39}$. If such an approach was applied to the EAC, it would assist in realizing the sustainability of the Community.

\subsubsection{Converging the divergences in sustainability logic:}

The study earlier revealed that there is a divergence in the dominant perspectives or conceptions used in the realization of sustainable development. It was observed that some thinkers approach the challenge of sustainability from a 'capitalistic' or individualistic perspective while others may use a 'collectivist' perspective (see: Sec. 1.9.3). With this divergence in perspective, there is a possibility of generating sustainability policies that may be biased towards either of the views. But ubuntu can be invoked to resolve these divergences in various ways some of which include the following:

\subsubsection{Reconciling 'capitalist' and 'socialist' views of governance:}

In the EAC there have been experiments of governance in both economic and political philosophies of 'capitalism' and 'socialism'. It was observed in the chapter on 'political development in the EAC and the challenge of sustainability' that one of the causes of the failure of the first EAC project was divergence in political ideologies applied by the different governments that made up the Community in the 1970s. Julius Nyerere (Tanzania) increasingly tilted towards African socialism as he pursued his ideology of Ujaama (see: Nyerere, 1966),

\footnotetext{
${ }^{38}$ Lake Victoria is the single most important natural resource that unites all the three core EAC countries (Kenya, Tanzania and Uganda) and it's preservation and fair sharing means a lot for the sustainability of the bloc. But there are numerous reports that indicate the imminent danger that the lake is facing. This is considered so important that the EAC established the Lake Victoria Basin Commission.

${ }^{39}$ In traditional Africa there were many ways in which an individual would exercise her individual abilities and freedom to excel; that is why there was room for heroes but all this was allowed as far as it supported and sustained the community. Apart from the numerous songs and stories that celebrate heroes, that quotation from Mbiti explicates this interpretation.
} 
while Jomo Kenyatta (Kenya) tilted towards capitalism. This divergence in political ideology grew wider and wider such that towards the end of 1970s there were marked differences between the two countries that they were leading. Nyerere was able to foster a Tanzanian brotherhood (that still runs deep in the country up to now) but at the expense of rapid economic growth because the turn attracted negativity from the capitalist superpowers of the time. His policies suffered major setbacks due to the economic divide that had grown between the West (mainly the USA and the UK) on one hand and the East (mainly USSR and China). Since the socialist bloc was getting weaker, Nyerere's system was sabotaged both from within and without (see: Mwakikagale, 2006, 2009b) and one of the impacts was making the EAC unsustainable. On the other hand, Jomo Kenyatta pursued a capitalist economic and political ideology $y^{40}$ after initially opposing the British during the Mau Mau rebellions. After the independence struggle Kenyatta and some of his friends embarked on a privatization drive right from 1964 and the Kenyatta family ended up as one the biggest beneficiaries from the exercise (see: Hornsby, 2013:142, 314). For that reason by the 1970s the collapse of the EAC would inadvertently be in their favor.

In the book, Beyond Capitalism vs. Socialism in Kenya and Tanzania (1994) some authors have set out a thesis that the economic experiences in these two countries indicate that this divide between the two countries is more imaginary than real. He argues that in reality the two countries no longer have compelling differences in economic ideologies; they have gone beyond then because the facts on the ground say so. For example, infrastructure in both Kenya and Tanzania suffered the same setbacks after the founding fathers departed (p.177); both countries have been borrowing almost as the same rate (p.35-37). But what is interesting to note in the ensuing economic analysis is the statement that one of the immediate problems that these government have to deal with is the, "Africanization of the economy, education, unemployment, welfare services, and provincial policies must be handled in ways that will not jeopardize growth" (p.107). The issue of africanization implies the need to use African views to solve the problems faced by these countries.

\footnotetext{
${ }^{40}$ Note should be taken of the fact that Jomo Kenyatta started as an ardent opponent of the British colonial system which essentially represented capitalism. However, after getting into office he kept the policies going and transformed Kenya into one of the most capitalist states in Africa. Some thinkers blame it on the suffering the he met while under custody which may have 'broken' but that may be for another discussion.
} 
But am application of the principle of ubuntu to governance in the region would help in bringing such divergent views closer because since it is a fact that these two streams of political ideologies flow through the politics of the region, neither should seek to be the winner who takes all. The basic foundation on which ubuntu builds a society is that we are all humans who deserve respect and a chance as members of society. When the focus is shifted from political ideology to humankind, then what is best for the people of the region is what will be considered in policy making. Ubuntu places the focus on what is best for the African people in the region not on the pursuing a particular political ideology from either the West or East.

\subsubsection{Resolving the development antagonism exhibited in Darwin's Nightmare:}

The documentary Darwin's Nightmare (2005) by Austrian film director, Herbert Sauper encapsulates the sustainability challenges that the EAC region faces. Sauper uses the $\$ 900$ million trade in Nile Perch fish from Lake Victoria to tell the story of "a booming multinational industry of fish and weapons has created an ungodly globalised alliance on the shores of the world's biggest tropical lake: an army of local fishermen, World Bank agents, homeless children, African ministers, EU commissioners, Tanzanian prostitutes and Russian pilots" (Sauper, 2004). Others have referred to the British colonialists' experimental introduction of the Nile Perch in the lake as 'turning the lake into an ecological wasteland. But economically it is good'. Tanzania's President Kikwete's angry reaction to the documentary (Xan, 2006) blaming it for drop in fish exports to Europe, demonstrates the antagonist views of development in the region.

This debate shows one of the key sustainability issues in the east African region, because there are many resources that are shared by the member countries such as the Indian Ocean and its coral reef system, Lake Victoria, many river systems and forests among others. We can use Lake Victoria as an example: the Lake Victoria Basin covers an area of $250,000 \mathrm{~km}^{2}$ and has a population of 35-40 million people; lake in particular covers $69,000 \mathrm{~km}^{2}$ shared among Tanzania, Uganda and Kenya. It has the largest freshwater fisheries producing 700,000 to 800,000 tons of fish annually, worth US\$350-400 million at the landings and US\$250 million in export (LVBC, 2009). However, the lake and its basin are faced with heightened pollutions and degradation due to human activities such as industrialization (Okungu \& Opango, 2012; Kayombo \& Jorgensen, 2006). After observing the environmental damage that the lake was suffering, the regional bloc instituted the Lake Victoria Basin Commission (LVBC) which was tasked with preserving the environmental integrity of the lake and its surrounding basin. But 
the findings of these scholars indicate a debate between the anthropocentric and envirocentric views of development. For example Kayombo and Jorgensen indicate some the data collected in a certain study is disputed and therefore governance policy could be affected unless it is confirmed (Kayombo \& Jorgensen, 2006:436). Relatedly, other scholars have concluded that there is connection between the environmental degradation in the region as a whole and the increase in conflict and civil tension (Lang, 1995).

Using ubuntu as a worldview would to inform the policies to resolve the dichotomy and divergence between those who think the focus of development should be fulfilling the demands of the market and those for who the environment is the focus. As decipherable from the earlier discussion on ubuntu metaphysics, it is not simply 'humanistic' but rather sensitive to all beings ('ebintu'). The word 'ntu' is also used in reference to other beings rather than humans, an indication of acknowledgment of their existence and contribution to human existence. So ubuntu respects both animate and inanimate beings, thus avoiding the Anthropos-environment dichotomy. The essence of 'ubuntu' is about 'respect of being' as such and this 'being' doesn't start or stop with humans but goes beyond that. It allows for the flourishing of human existence; but it also does the same for the existence of other beings, appreciating the fact that all beings support the existence and flourishing of each other. Inside ubuntu philosophy therefore, there is room for individual flourishing and also for community flourishing; that is the reason in many traditional African societies there are tales and folklore celebrating the accomplishments of individuals such as warriors and kings who did great things. But at the same time the individual was never to forget that they exist within a certain environment and the community was part of that environment. Ubuntu represents a vast amount of knowledge and experiences that native Africans had learned over the years not to neglect either.

\subsubsection{Reconciling traditional and modern governance philosophies:}

This view or approach has to be examined further and concrete ways in which it can be applied should be explored in order to overcome some of the development problems in the region. There have been some efforts to incorporate traditional African forms of administration in the modern governance system but in my view most of them are case of incorporating the 'traditional African administration form' rather than the 'traditional African governance philosophy'. In a recent publication, Public Administration in Africa: Performance and Challenges (2013), Shikha V. and Tshombe L. have tried to present a case for the incorporation 
of traditional leadership structures within the modern African governance system. According to their discussion, there is still a condescending attitude or a great measure of distrust among the administrators of the modern state towards the traditional native systems. The table below indicates what I can glean from their analysis of the trends that the incorporation of traditional leadership have taken in selected countries:

Tab. 7.2: Incorporation of traditional leadership in EAC:

\begin{tabular}{|l|l|l|}
\hline \multicolumn{1}{|c|}{ Country } & $\begin{array}{l}\text { Role of traditional } \\
\text { leaders in modern } \\
\text { state }\end{array}$ & \multicolumn{1}{c|}{ Comment } \\
\hline Kenya & $\begin{array}{l}\text { Not given viable } \\
\text { recognition }\end{array}$ & $\begin{array}{l}\text { The Kenyan Constitution (2011) } \\
\text { is silent on traditional leaders; } \\
\text { even gags traditional conflict } \\
\text { resolution mechanisms (Chp. 10 } \\
\text { Art. 159(3)) }\end{array}$ \\
\hline Tanzania & $\begin{array}{l}\text { Not given } \\
\text { constitutional } \\
\text { recognition }\end{array}$ & $\begin{array}{l}\text { Nyerere's African ujamaa } \\
\text { legacy eroded much of ethnicity } \\
\text { identities and affinities }\end{array}$ \\
\hline Uganda & $\begin{array}{l}\text { Recognized } \\
\text { (Traditional and } \\
\text { Cultural Leaders Act) }\end{array}$ & $\begin{array}{l}\text { They are barred from elective } \\
\text { politics (Clause 13). } \\
\text { Collaborative role for mass } \\
\text { support }\end{array}$ \\
\hline
\end{tabular}

The above tabulation reveals that: i) there has been some considered effort to incorporate the traditional African forms of leadership into modern state system, ii) there is still a non-positive attitude towards these traditional institutions from modern state framers; iii) the traditional African institutions are simply used to legitimatize the modern authorities.

But from a philosophical point of view, a closer scrutiny shows that the incorporation of the traditional leaders in the modern African state is more about the 'form' rather than the 'substance'. Form is used here to mean the visible shape of structure that a certain thing takes while substance refers to the inner subject matter or properties that make up something. Most of legal provisions that recognize the native African leadership use generic structural and 
simplistic references to them such as 'House of Chiefs', 'Traditional Leaders', 'Cultural Institutions', among others. Much of the engagement with traditional institutions is more cosmetic than serious and therefore the engagement does not explore deeper enrichment of governance philosophy in modern post-colonial African states. The only identifiable exception is South Africa's Traditional Leadership and Governance Framework Act (2003) which provides for the promotion of indigenous knowledge and participation in policy development (Chp. 2, Art. 4 e, h). A deeper engagement of the modern African state with traditional systems would involve understanding the philosophical base of those traditional systems and institutions and exploring ways in which that philosophy could be applicable in modern governance situations.

Since ubuntu metaphysics appreciates both human and non-human life, it would provide a deeper foundation on which to generate more suitable policies for resolving the challenges. Ubuntu respects the humans in the EAC but also respects the importance of environmental variables such as forests, animals, climate, among others. Ubuntu is neither radically anthropocentric nor radically envirocentric; therefore it could inspire policies that can balance the human needs with environmental ones. As Carolyn Logan (2008) concluded, "African societies are often quite adept at integrating seemingly incompatible institutional structures, such as traditional institutions" (Logan, 2008:iii).

\subsection{Using ubuntu to solve contemporary African governance problems:}

As we seek to apply Ubuntu principle to resolving the challenge of sustainability, it is of necessity to address the question of whether Ubuntu is applicable to contemporary challenges. There are various criticisms raised and they overlap in the domains of governance, economics and morality. In the article "Ubuntu as moral theory and human rights in South Africa" (2011), Thaddeus Metz has pointed out three major criticism that are advanced to explain why ubuntu could not be appropriate for public morality in a modern state. The three include: i) 'vagueness': that it too vague; ii) 'collectivism': it fails to acknowledge the value of individual freedom; and iii) 'anachronism': it is only fit for traditional, small-scale culture more than a modern, industrial society (Metz, 2011:532, 534). In order to address these criticisms, I use the example of 'human rights' to prove that ubuntu philosophy is applicable. 


\subsubsection{Application to human rights:}

Many critics of ubuntu philosophy have raised the argument that it does not fulfill the rigorously individualistic demands of the modern human rights political dispensation. Metz has identified this critique as 'failure to acknowledge the value of individual freedom'. One of the key propagators of this critique is Lucy Allais, who argues that ubuntu cannot provide a singlevalue moral theory on which to base a human rights articulation ${ }^{41}$. She critiques Metz's project to allow room for individual rights in ubuntu in her paper, "In defence of an Enlightenment conception of reason: A critique of a single-value moral theory based on ubuntu" (2014); and then she goes ahead to suggest that a Kantian conception of morality would provide a better foundation for human rights theorization.

Allais was replying Metz's article, "Ubuntu as moral theory and human rights in South Africa" (2011) in which he set out to generate a philosophical interpretation of ubuntu that is not susceptible to such a critique and one that allows for individual human dignity (Metz, 2011:523-3). According to Metz his interpretation of ubuntu would make, “...typical human beings have dignity by virtue of their capacity for community, understood as the combination of identifying with others and exhibiting solidarity with them, where human rights violations are egregious degradations of this capacity" (ibid). Metz argues that a proper understanding of the moral philosophy within ubuntu requires that one regards it beyond the traditional European 'utilitarian-Kantian' dichotomy (p.536). That traditional Africans make a statement like, 'umuntu ngumuntu ngabantu' (a person is a person through other persons), they are not simply merely making an empirical claim of material survival through community (p.537) but it goes much deeper than that. When it is stated that, 'a person is a person', it implies a development of a moral person something that is a prerequisite of being able to depend on community. Therefore the injunction of society, in this understanding, delimits 'personal fulfillment' from turning into 'selfishness'; personal fulfillment or becoming 'a person who is a person' entails performing 'morally-right actions' (p.538). Becoming a 'fulfilled person' is not “equivalent to doing whatever a majority of people in society want or conform to..." (ibid); but knowing the importance of "communal relationships as an objectively-desirable kind of interaction" (ibid) in order to mutually realize 'identity' and 'solidarity'. In that case of realizing these two, the

\footnotetext{
${ }^{41}$ This argument is contained in a seminar series paper, "In defence of an Enlightenment conception of reason: A critique of a single-value moral theory based on ubuntu", which she presented at the Department of Philosophy, University of Witwatersrand, 5-9 $9^{\text {th }}$ August 2014
} 
'I' and the 'We' still exists but not in the Western philosophical tradition of opposing but complimenting each other.

Lucy Allais is not convinced by Metz's articulation of moral value in ubuntu. In the article, "In defence of an Enlightenment conception of reason: A critique of a single-value moral theory based on ubuntu" (2014) she argues that Metz's 'African moral theory' is not plausible and it does not fit the tag 'African'. But in order to understand why she argues thus, we can find her reasons in an earlier article titled, "Kantian idealism and the secondary quality analogy" (2007). In that paper she sought to go beyond the 'two-world' interpretation of Kant's transcendental idealism i.e. rendering it a phenomenalist-epistemological dichotomy (Allais, 2007:460). Her desire to achieve a unification of the various interpretations of Kant was expressed more forcefully in another paper, "Kant's one world: Interpreting transcendental idealism" (2004) in which she argued that the 'phenomenalist' interpretations of Kant are too strongly idealist while the epistemic interpretation are not idealist enough (Allais, 2004:656). That debate aside, this is the intellectual background from which she comes and disagrees with Metz arguing that Kantian conception of morality is a better grounding for human rights than ubuntu.

I disagree with Allais' critique of Metz because of the presuppositions that she holds that are latent in her discussion. That is why the above intellectual background was necessary in order to connect with the meaning that is decipherable from the first segment of the title of her seminar article, namely "In defence of an Enlightenment conception of reason". It betrays an assumption that Metz's interpretation of ubuntu is an affront to 'Enlightenment reason' which therefore needs defending. Apparently when Metz sets out to re-interpret ubuntu and argues that it provides room for individual human rights that is not 'African' in Allais' view. In her view an 'African moral theory' would not result from Metz's desire to “...construct an ethical principle that not only grows out of indigenous understandings of ubuntu, but is fairly precise, clearly account[ing] for the importance of individual liberty...” (Metz, 2007:534). I think Allais is wrong to insinuate that Metz's application of reason to develop a ubuntu understanding of individual freedom in an affront on 'Enlightenment reason' and not African. The issues that we are dealing with is the dominant presupposition that traditional African philosophical view are 'collectivistic' by default and therefore incapable of allowing room for individual freedom. In my view that is a wrong characterization of African thought and society. 
This debate over the existence of rational capacity in African thinking has been around for quite some time. It is premised on the erroneous figment that in traditional Africa individual could reason on their own and were subjugated by the collective. The debate attracted the great mind of Chukwudi Eze who studied original notes of Kant's lectures in anthropology and discovered that even though many modern Kantians wish to hold that his earlier views in anthropology ${ }^{42}$ did not influence his later works like the Critique that was not the case. Eze identified that the roots of the view that African thinking lacks 'reason' among the traditional Kantian school, were to be found in Kant's belief that nature did not give non-European people such as Africans and Red Indians the 'gift' of rationality (Eze, 1997:115). To go beyond this debate, Eze argues, in the book, On Reason (2008) that rationality is a capacity that all humans have and in times of multiculturalism we should not use rationality as a tool for cultural exclusivism or imperialism but as a tool to build a multicultural world.

The thinking that ubuntu does not allow for individual freedom (human rights) is based on the erroneous and unviable views of equating, i) ubuntu with collectivism, and ii) individual freedom with rationality. As we have discussed from the start of this chapter, the first equation comes from a wrong understanding of the metaphysics in ubuntu and can be corrected by interrogating the meaning on 'ntu' which yields that there is room for personal fulfillment. Evidence from traditional folklore also shows that traditional African praised their heroic individuals and those who did great things, a sign that there was room for independent thinking and excellence. As regards the second equation, it comes from an erroneous view of the meaning of rationality as Eze as discussed.

\subsection{Ubuntu and governance: Observations on Buganda political philosophy:}

Having discussed the probable role that ubuntu, as a traditional African philosophy, would play in contemporary African governance and development, it suffice to explore how it could actually be used in the pursuit of sustainability of governance and development in the region. In this section the study uses Buganda kingdom as a case of where greater than usual sustainability has been registered in an African governance environment, to discuss how the

\footnotetext{
${ }^{42}$ Eze discovered that Kant gave more lectures on anthropology and physical geography than in metaphysics and moral philosophy. He also found out that material from Kant's lectures in anthropology found their way in his lectures in 'ethics' and 'metaphysics' (Eze, 1997:104)
} 
EAC could apply certain traditional African governance approaches towards the achievement of sustainable governance and development. Selecting a case of an ancient African governance style to experimentor explore possible ways of application a tradition African philosophy to regional sustainability is aimed at: i) demonstrating that traditional African governance approaches could still be relevant to contemporary governance; and ii) inspiring the EAC region to gain confidence in learning best governance practices from cases that are near home and easier to understand and relate with. It should be noted however, that since the investigation in this section is exploratory, the discussion of issues such as origin of the kingdom, etc. is not as detailed as a person who is reading about Buganda for the first time would have preferred because that is not the central topic of the research. Nonetheless the observations and conclusions being made are of great relevance to overall goal of the study.

Buganda presents an atypical and inspirational case under consideration because of some of its unique characteristics. Among those unique characteristics are: i) its longevity from precolonial to contemporary times where many other African kingdoms collapsed; ii) its 'higher order' form of centralized government in comparison with other kingdoms in the region; iii) its existential fortitude having survived a ban by modern governance systems; and iv) its continued central role in Ugandan politics despite being founded on traditional African ideas (see: Johannssen, 2005). All these reasons make Buganda a unique case not only in the region but across the continent; and therefore make it a possible good source of inspiration for regional governance in contemporary times. In his review of E.S Haydon's book, Law and Justice in Buganda (1960), James S. Read pointed out that Buganda's traditional governance and judicial systems "are now recognized as being in the first rank of African courts" (Read, 1961:191). By implication therefore, a lot could be learned from the traditional approaches to organizing and governing society that they have evolved in Buganda from ancient times.

\subsubsection{On origin and nature of Buganda's governance philosophy:}

Like any case of an ancient kingdom, legend often mixes with or even overshadows facts and Buganda is not excluded among kingdoms whose stories of origin are blurred with sentimental and mystical stories of origin. Owing to the dominance of oral means of transmitting information from one generation to another at the time, about two or three versions of the origin of Buganda kingdom have been identified and recorded by scholars of Buganda history. But the central figure in the emergence of Buganda that all agree about is the mythical personality, 
Kintu who is credited with having founded the kingdom. Rather than being seen as a weakness, the existence of a number of versions of Buganda story of origin with similar central figures or actors, may be actually be indicative of the truth and factuality of the stories being told.

As discussed earlier in the chapter the name Kintu is pivotal in Buganda in various terms: cultural, mythology and philosophy. Kintu is considered the first Muganda; and the word Muganda means 'joined together' which means that the name holds a deep sense of unity among the Baganda. Kintu is also a name of a god among the Baganda and this comes from the traditional African practice of transforming their heroes into deities. Kintu also provides the root word on which the Baganda's understanding of being and ontology are anchored: as indicated earlier, ' $n t u$ ' is a root word in other important words that refer to existence such as 'omuntu' (a person), 'obuntu' (personhood/things), 'abantu' (people), 'ekintu' (a thing), etc. In philosophical or ontological terms therefore, Kintu refers to existence in a deeper sense and for that reason some scholars like Kasozi Ferdinand (2011) have analyzed it as a philosophical root word on which linguistic and cultural premises are set in Buganda society. Acknowledging this deeper and permeating meaning of Kintu is important because it enables one appreciate the central role of the mythological figure Kintu within Buganda.

Some thinkers hold that Kintu was indigenous to Buganda (Keebungero, 1993). Kintu, who is thought by some historians to have migrated from the Ethiopian islands, is credited with having come with better political and governance skills compared to the clans that he found around the area known as present day Buganda (which later stretched into some parts of present day western Kenya and north eastern Tanzania). Kintu is said to have come as conquering hero with 13 tribes that he had migrated with and reorganized the decentralized and disunited tribes that he found there. Legend has it that he gathered the clan heads at a place known as 'Nnonno' (presently in Mityana, central Uganda) and they deliberated on the form of governance that would be applied in the new kingdom; thus forming the unwritten Buganda Constitution, which is a series of unwritten 'nnonnos'43 (deep and strongly binding mystical principles of culture and governance).

\footnotetext{
${ }^{43}$ The word 'nnono' is variantly given meaning in the dictionary such as 'signficance', 'essence', 'source', 'place of origin/birth', 'tradition', and 'heritage', among others. This variation in meaning indicates the depth and permeating nature of the meaning of the word nnonno. It is used not only to captures tangible realities but most importantly intangible relities about the Buganda experience and governance; and explains the origins and foundations on which Buganda's governance philosophy and culture was built.
} 
Most analysts of traditional Buganda governance philosophy translate the Luganda word, 'nnono' as 'principle' in trying to understand the meaning of the norms and values on which Buganda social and government order is based. In his paper, "The socio-political philosophy of traditional Buganda society: Breaks and continuity into the present" (1992), Wamala Edward used the term 'principles' as he discussed continuity of Buganda's the social and political philosophy. One of the most important nnonno in Buganda's governance philosophy that we can briefly consider is the nature and extent of the power of the King. According to him the Baganda's understood and took the Kabaka (Buganda's term for 'King') as both 'semi-divine' but 'not at absolute monarch' (Wamala, 1992:57). Legend has it that this nnonno about the Kabaka was established by Buganda's founder Kintu who refused to project himself as an absolute monarch and allowed to share his power with the Bataka (clan-heads) as per their deliberated position at the beginning. So we find that in Buganda, even though the Kabakaship was hereditary within the royal family, there were various checks and balances on his power and many other power-bases such that it was very difficult for the Kabaka to turn into a selfdestructive absolute monarch.

These principles gradually turned into the customs and norms; and became 'sacred' grounds among the Baganda on which social and government order has been based for hundreds of years. One of the unique features of this approach to social and government order is the fact that despite not being written down anywhere, both the people and the leaders seem to intuitively know and value them from the lowest strata of Buganda society to the highest. Scholars like Gombya-Ssembajjwe (1994) holds that these values have not only been responsible for preservation of social order but also the sustainability of natural resources such as forests and animals since the 14th century (Gombya, 1994:2).

\subsubsection{Selected political approaches in Buganda applicable to regional governance:}

There are a number of inspirational observations that contemporary regional governors in the EAC could make from the builders of Buganda's governance systems and processes. Despite the weaknesses that existed within this system, especially as exposed at the coming of the colonialists, the fact that this traditional kingdom has continued to exist even in contemporary means that there are some lessons on governance sustainability that the framers of the EAC can pick from it. Bringing together 52 clans and keeping them together for centuries, giving them the same vision, governing on the basis of an unwritten 'constitution', and building 
consensus among various groups of people and tribes are not mean feats. From these and other accomplishments, we can make some observations that could inspire the framing of a sustainable regional bloc.

\section{Building institutional stability and longevity:}

One of the key ambitions for those who wish to build sustainable governance strucutres is to establish institutions that are stable and able to last for generations. Buganda provides a case of inspiration because its institutions have been able to evolve and become resilient for centuries and this could provide a lesson for contemporary builders of society. One of the key features of the story of Kintu and his exploits in the laying down the building blocks of the Buganda kingdom was his willingness to share power with the Bataka (clan heads). The Kabaka and his appointed executives weld 'political' power whilst the Bataka weld 'cultural' power; and they share the 'economic' power because the Kabaka could appoint the Mutongole (Kabaka's representative) to oversee the conquered lands and exact levies but the nnonno of Buganda did not allow him to touch or re-distribute land that was allocated to a clan.

This respect for each 'power-base' was instilled in both the leaders and the population; for example during the coronation of the Kabaka, without the participation of designated clanheads in certain rituals, the Kabaka's power would not be considered legitimate. But it suffice to point out, as Wamala observes, that the Kabaka was bestowed with many mystical and sacred titles and symbols in order to reinforce the perception that the king was a continuation of a royal lineage and he was the symbol of the stability of the community. So in order to preserve the community, every member of society has to preserve the Kabakaship. When the Kabaka was coronated, the Baganda used the expression, 'obuganda buladde' meaning the Buganda is now peaceful and settled; therefore when people met and greeted each other from day to day, they would use the phrase, 'eladde?', by which they were inquring whether the interluctor's life was peaceful and stable. But for a typical Muganda, life could not be peaceful and stable as long as there is no Kabaka on the throne or as long as the throne suffered political or social unrest.

There are many implicit observations that could be gleaned from that approach and applied to the regional governance but the most relevant one to this study is the building of a symbol of leadership that is resepected among the citizenry. Without a symbol of power or office that unifies and evokes deep respect from east Africans, it would be a tall order to build a sustainable 
governance environment for the region. The EAC ought to build such a system that all the members of the regional bloc could pledge their allegiance and be willing to protect and ensure its existence even in the face of enormous challenges. One of the causes of the failure of the leaders of the region to work out their differences in the earlier phase of the EAC was due to the fact that there was no universally appealing symbol of authority that could have made them member states to forget their petty or lesser difference and seek to preserve that symbol.

It is important to point out that it does not necessarily mean that in getting inspiration from Baganda governance philosophy, the EAC should simply duplicate the ideal symbols and setup of Buganda's Kabakaship. Neither does it necessarily follow that the EAC ought to build an individual cult-like figure around whom citizens rally. Rather the approach could be employed in building certain institutions that east Africans hold in great esteem and respect such that they could be useful and pivotal in playing the role of unifier for all the member states and citizens. Since it is not possible to renact the ancient traditional economic and political conditions that existed at the time of forming Buganda, the EAC could employ contemporary tools or methods of legitimacy to endear the established institutions to the citizens of the region. These can include mediums like institutions for free and fair elections, genuine and just policies that care about the local people, culturally sensitive institutions, etc.

\section{Using people-focused functionalism:}

The above paragraph brings us to another approach that the traditional Baganda used that could be adopted or adapted by the EAC i.e. employing a 'people-focused functionalist' approach to framing and building the EAC. In simple terms, a 'people-focused functionalist' approach simply means making institutions work for the benefit of the people as a whole rather than a few or a given class of people. This approach entails two major ingredients: i) ensuring that the systems and processes function effectively; and ii) making sure that the functionality includes the people and makes their lives better.

It was noted earlier in the study that the roots of the EAC were traceable from the colonial times when the region was under foreign rule; and the colonial masters used the colonialfunctionalist approach in framing the first EAC-1 project. Essentially, colonial-functionalism simply meant making institutions that were established in the colonized areas work for the benefit of the colonial masters; this meant establishing institutions like legislature, postal systems, railways, etc. in such a way that the colonial master siphoned off or exploited as much 
as possible of the resources found in the colonized areas. To that end, the colonialist worked to ensure that the systems and processes were effectively running to his benefit; but at the same time not passing on the skills of managing or administering those to the natives.

Unfortunately, many of the structures that the colonial master left behind are still behind and their legacy is still fresh in the EAC. Secondly, for those institutions or structures that the natives have taken control over, the requisite capabilities or skills to: i) effectively run them; and ii) make them work for the good of the native, are inadequate. This explains the chronic disconnect between the people and the institutions that are meant to work for their good. The natives do not think that the government institutions are working for their good and they do not think that they should try to maintain those structures. Even those new institutions that have been established are not initiated by the people themselves; they are either proposed by the socalled donor community (whose agenda is most cases determined by the former colonial masters of the region) or by policy makers or leaders who admire the systems of the former colonial masters. Such systems end up failing to work for the good of the people and are in most cases unsustainable.

A people-focused functional approach would go a long way in rectifying these challenges in the region by encouraging the EAC institutions work for the good of the people. It means that the people ought to be the ones to initiate the types of institutions and structures that they think are of their benefit; the building of the structures has to involve the people such that they own those structures and are willing to maintain them. This would go a long way in ensuring that the structures that are put in place are sustainable.

\subsection{Conclusion:}

The foregoing chapter has discussed ubuntu as a principle of the comprehensive ethical sustainability scheme. It has argued and concluded that ubuntu is useful in realizing governance and development sustainability; it represents a subliminal survival instinct for larger groups and synergies for the betterment and survival of the members of that group. It is also an ideal towards which different communities aspire; and therefore it would be an applicable philosophy for sustainability in the EAC. 


\section{CHAPTER VIII}

\section{INTEGRITY AND SUSTAINABILITY}

\subsection{Introduction:}

This chapter discusses the principle of integrity as one of the pillars of the comprehensive ethical sustainability scheme. The discussion revolves around the need for integrity both in the conduct of public office holders and the east African region as such in order to attain its governance and development sustainability. The first discusses the meaning of integrity and endeavors to reconnect it to traditional African moral understanding. The next section deals with the possibility of casting of 'integrity' as a principle and argues that just like other principles in the Comprehensive Ethical Sustainability (CES) scheme, rendering 'integrity' a principle is possible given its axiomatic value. The next section discusses the 'integrity crisis' that is being witnessed in the regional bloc's public service; relating it to its impact on professionalism and rule of law in the region. In this section the study also examines the applicability of Edward Wamala's thesis on explaining the nature of this 'integrity crisis' and considers its limitations. The final section discusses the application of the meaning of integrity to individual and institutional ethical sustainability in the EAC.

\subsection{On meaning of 'integrity':}

In order to use integrity in proposing solutions to the challenge of sustainability in the EAC we need a clear understanding of what integrity means. Since the term tends to be used variously in different domains such as virtue ethics studies, business ethics, international law, among others, it is of necessity that we devote some space to interrogating its meaning. In etymological terms, the word 'integrity' has been traced from the Latin, 'integritas', which they used to mean 'wholeness'. But other etymologists trace 'integritas' itself from the French, 'integrité', standing for 'blamelessness' or 'chastity'; that one is also derivable from the French, 'entiereté' which means 'totality'. From this background modern English generated the word 'integer' which means 'whole' as opposed to 'fraction'. As informative as that simple etymological enquiry might be, it remains only a semantical exercise and therefore it wouldn't suffice to give us a better meaning of integrity. None of the ancient philosophers is known to have used the 
word 'integrity' as such but they are known to have discussed virtues that are similar to integrity. The word 'integrity' as such does not seem to have a long history of usage in moral or ethics studies but some scholars argue that when Aristotle, used the Greek word, 'timiótita', translated as the 'mean', he used it for 'truthfulness' or 'honesty' and it is considered to carry the equivalent of integrity (see: Curzer, 2012, Chp. 10). In other veins although Heidegger's (1992) rendering of Parmenides' 'aletheia' to mean 'unconcealing' or 'truth' was controversial, it elucidated a Greek envisioning of honesty or integrity. In Aristotelian terms, the search for the 'mean' could be construed as the search for 'balance' in the moral universe.

Since the study is on Africa, it is necessary to reconnect our understanding of ethical terminology with traditional or ancient African thinking such that our ideas can resonate with the thinking of the people of the region. For that reason, when we think of integrity in the Aristotelian tradition of finding the 'mean' or 'balancing' the moral universe, as it were, we realize that this understanding resonates with ancient Egyptians' understanding of 'moral balance' in the universe. The ancient Egyptians conveyed their search for 'moral balance' in the universe with the word, 'maát' ${ }^{44}$, which meant 'cosmic moral balance'. To the ancient Egyptians, the goddess Maát represented 'truth', 'order' and 'cosmic balance' (see: Dunn, 2004), meaning that society aimed at reaching that balance in their moral conduct. The person who behaved well, had the resultant impact of effecting balance in the cosmic moral order through her character; and she would attract the favor of the goddess Maát. This was the moral aspiration of the ancient Egyptians manifested in holding prayers and practicing rituals that represented 'good' conduct as taught by the priests in the quest for 'balance' in the cosmos. It represents humankind's search for the perfect or blameless moral conduct that seems to cut across all communities of people albeit expressed differently.

Carrying this idea of the 'balancing' of the cosmic moral order, makes it possible to establish a connection between the ancient Egyptian understanding of morality and the conceptualization of morality in traditional East African communities. The words used for morality may be different phonetically but the meaning and goal is related to the one observed above in ancient

\footnotetext{
${ }^{44}$ We should keep in mind that in ancient Egypt this word was used to mean a number of ethically related ideas: i) the first is a name of a god who is in charge of the weighing people's hearts in the afterlife; ii) the second is as a single moral principle of 'cosmic moral balance'; and iii) the whole set of moral teachings that were taught to the people to guide them during this life such that the god Maát could bestow upon them a good life after death.
} 
Egypt. In Swahili' ${ }^{45}$ for example, the word used to mean 'ethics' is 'maadili', which has a strong similarity with the ancient Egyptian word 'maát'. In the same vein, the Swahili 'adili' is translatable as 'equity' in English. In contemporary Swahili the word used for 'integrity' is 'uadilifu'. This implies that the same pursuit of a 'cosmic moral balance' is still attached to the conceptualization of ethics in Africa. In Luganda the word commonly used for 'integrity' is 'obwesimbu' which means 'uprightness', 'justice', 'fairness' (Luganda-English Dict., 1972:57); in literal terms, the word stands for being 'planted on firm principles'.

As the concern over integrity in personal and institutional life grows in contemporary times, the ancient Egyptian theme of 'balance' seems to underlay the definitions and discussions that surround it. In contemporary times, the most quoted interrogation of the meaning of integrity is the 1996 the book by Stephen Carter titled, Integrity (1996); in which he used a virtue approach to define it in terms of steps as qualifiers of who a person of integrity is. According to him, Step 1: discerning what is right and what is wrong; step 2: acting on what you have discovered, even at personal cost; and step 3: saying openly that you are acting on your understanding of right from wrong (Carter, 1996:7). When Kirshak Ray (2000) reviewed Carter's Integrity, he observed that Carter was motivated by the fact that, "predictability, reliability, consistency and trust are the currency of human exchanges" (Kirshak, 2000:316). By this we can still detect the drive to achieve a social order that is balanced in integrity discourse.

Bater, et al (2012) carried out a commendable survey and analysis of the meaning and general perceptions of integrity; they concluded that, "The concept of integrity is complex and subject to disagreement. Attempts to define integrity commonly involve appeals to other specific values or virtues, such as honesty, objectivity, conscientiousness etc., to the extent that it is tempting to define it as a 'cluster concept' amounting to no more than a vague agglomeration of other principles or character traits" (Baxter, 2012:11). Aside from delving into selected personal and organizational 'virtues' and 'values' and the methods of inculcating them into a given corporation or community, their study did not explain further what they meant by a 'cluster concept'; perhaps the most insightful aspect of that study. Nonetheless it is fair to

\footnotetext{
${ }^{45}$ Note that Swahili is estimated to be the most widely spoken language in Africa; it has over 50 million users scattered across the African countries of Burundi, DR. Congo, Ethiopia, Kenya, Malawi, Madagascar, Mozambique, Somalia, Tanzania, Uganda, Rwanda and Zambia (see: Pawliková-Vilhanová, 1996:160-161). Some reports even indicate that it has gained traction in the Comoros Islands. Archeological linguists also hold that Swahili is basically a Bantu language in structure (Rollins, 1983:19)
} 
mention that they identified certain aspects that constitute integrity, namely i) wholeness of character, ii) ethical values, iii) identity, and iv) standing for something (p.17).

As Audi and Murphy (2006) have observed, most considerations of integrity are in terms of virtue, but since we are also discussing it in relation to the sustainability of a regional grouping of states in the form of the EAC, it is necessary to accommodate its employment in international relations discourse. One of the principles that ought to guide the relations of nation states in a globalized order is that of territorial integrity, a reference to which indicates that even at the state level, thinkers are concerned with just treatment of each other and the 'balance' of the global order. Mark Zacher (2001) holds that this principle is considered a 'norm' in inter-state relations and its respect and observance became more important after the nasty and unethical conduct of nation-states during World War II (Zacher, 2001:221-4). The resurgence of this principle in the aftermath of the WWII relates territorial integrity to ethical conduct of states especially in terms of military encounters that, "reveal a great deal about the development of the territorial integrity norm" (p.223). This WWII backdrop indicates that the 1970 United Nations Declaration on Principles of International Law, sought to achieve harmonious existence among nation-states; the fact of which brings in the observation of the need for 'balance' in the international system. The Declaration's preamble reminiscences that past misconduct of nation-states when it states that it seeks to 'ensure that nations live together in peace', betraying a fear of nation-state moral breakdown as it had happened in the past great wars.

Even though globalization has since superseded the nation-state level of concern over international relations, the decisive agent in international law still remains the state. That is why Patrick Riley declared that in 'modern international relations', the "legitimate political unit is the state" (Riley, 1973:104). That conclusion was traced from the classical Leviathanlike theoretical argument whereby he likened the 'nation-state' to the men in the 'state-ofnature' who would destroy each other without the intervention of the Leviathan (p.102-3). This state-centrism has however been challenged by some authors as outdated for a global age; for example the feminist thinker, Gillian Youngs (1999) has argued that the contemporary global order has to go beyond the state because it is superficial to still hold and use it as the theoretical framework for international relations (Youngs, 1999:67-83). 
Nevertheless, we need a working definition to use in our discussion and considering that integrity is applied to both personal and social virtue and international relations, we need such a definition as captures those applications. On that note the study generated a working definition of integrity as the ethical wholesomeness of being and personhood. The definition seeks to capture the two major aspects on integrity: i) keeping the totality and wholeness of a given being, and ii) holding of steadfast principles that guide one's or a group's conduct. The issue of ethics has been considered to be central to both aspects of integrity because in each case, the enterprise of realizing integrity requires certain standards or qualifiers that are of some ethical nature. For example keeping the integrity of a nation-state or a group or institution requires commitment to certain standards of conduct which cannot be immoral. Likewise at a personal level, for an individual to realize integrity, they need to hold certain principles or ideals that are also ultimately ethical in nature.

\subsection{Integrity as a principle of sustainability:}

Integrity is the fourth principle within the Comprehensive ethical sustainability scheme that seeks to contribute to the realization of government and development sustainability within the East African Community. This particular principle axiomizes the two main definitions that are attributed to the word, integrity, namely, i) the quality of honesty or being morally principled (i.e. moral personhood); and ii) the state of wholeness. The first meaning refers to adhering to certain ethical or moral principles whilst the second one refers to maintaining the essence of being of a given entity i.e. not compromising one's or a thing's quality of existence. Both variations in understanding the meaning of integrity do apply to our pursuit of governance and development sustainability in the East African Community.

In advancing this principle I use both definitions of integrity; because in my view both ultimately have a profound bearing on sustainability in society both at individual and institutional levels. Integrity was deemed necessary to make a stand-alone principle because as Cox, et al (2013) have argued, "Modern moral theories, the most representative of which are utilitarianism and Kantian moral theory, do not concern themselves directly with virtue and character. Instead, they are primarily concerned to describe morally correct action" (Cox, $2013)^{46}$. Since both definitions of 'integrity' apply to the realization of sustainability in the East

\footnotetext{
${ }^{46}$ It should be noted that those who raise this criticism, as far as utilitarianism is concerned, raise it mainly against 'act-utilitarianism' rather utilitarianism as a whole.
} 
African Community, the study recast the ethical (moral) meaning of integrity in terms of acting ethically both in personal and professional life; and the essence definition of integrity was recast in terms of wholeness of the East African Community as a region i.e. ensuring that it does not disintegrate.

In the article, "Teaching business ethics in Africa: What ethical orientation? The case of East and Central Africa" (2006), Christine Wanjiru Gichure discussed the peculiarity of the professional ethics situation in region. She disputes the conventional assessment among most business ethics analysts that the rampant ethics challenges in Africa imply that traditional "African culture has no regard or concern for ethics" (Wanjiru, 2006:39). Even though Wanjiru's paper focuses on the private sector, she nonetheless highlights a growing concern about the high levels of corruption and unethical conduct in professional life. Wanjiru observes that there is a kind of 'clash of values' that has arisen in East and Central Africa's business and development environment; and one its manifestation is the "...confusion [that] arises as to what is more serious: matters economic or matters that refer to human life and its integrity" (p.44). This sort of 'values confusion' has been construed by some thinkers as a debate between 'African relativism' and 'Western universalism' with the presumption that there may not be values in traditional Africa that could be of universal appeal. For that matter, Egbeke Aja (1997) has called for 'revisiting' traditional African values in order to meet these news demands (Egbeke, 1997:531-43).

\subsection{Integrity crisis in EAC's public service:}

Earlier in the study we cited a United Nations comparative study titled, Public Service Ethics in Africa (2001), in which researchers came to the conclusion that generally there is, "an erosion of professionalism and ethics" across most of the continent (UNDP, 2001:v). In that survey, the East African Community was represented by two countries, Kenya and Uganda and the findings were an indictment on the unethical manner of public service delivery. All over the East African Community there is a growing concern over the increasing levels of unethical conduct in public service and its impact on development efforts. Corruption is one of those unethical conducts that negatively affect the realization of sustainable development in the EAC.

As an indication of increasing concern over the ethical crisis in the public domain, Hasmukh Dawda, wrote an opinion piece in the Daily Monitor titled, "Lack of ethics killing every sector in this country" (Hasmukh, 2010). In this piece he warned that if Uganda does not take ethics 
seriously, it would fail in all major sectors as a nation. He pointed out various critical sectors in Uganda, namely business, industry, judiciary, religion, health and politics (leadership) that were being eaten away by the neglect of ethics. His conclusion was that, "To take this country forward, we must all practice ethics, transparency and accountability". In Tanzania, the National Governance and Corruption Survey (2009) found that all major public sectors were reeling with unethical conduct. According to David Minja, in Kenya the story is no different because unethical practices in organizations and at the political arena have been widely reported in the wake of many high-profile management and financial scandals (Minja 2009). But despite all these reports, public service in the region contains deplorable levels of corruption.

Unfortunately this culture of corruption is not confined to the national public service; but reports indicate that there is a massive culture of questionable and wasteful expenditure of public funds at the East African Community secretariat itself accompanied by uncanny secrecy among the public servants that work there. If this corruption trend is not addressed, it will seriously compromise the integration process and its sustainability. In January 2015 an audit report on the Secretariat presented to the EALA Accounts Committee revealed high level corruption disguised as unclear travel expenses, crocked procurement practices and over expenditure. For example it was exposed by the audit that during the 2012/2013 financial year the organs of the EAC Secretariat dubiously spent $\$ 3.4$ million on travel tickets alone; and these payments had been made to unqualified staff on the basis 'meeting authorization forms' rather than the acceptable procedure of using the 'travel authorization forms' (Karuhanga, 2015; Ubwani, 2005).

Such low levels of professional integrity have penetrated the regional bloc's administrative arm; and this could compromise the oversight role of the Secretariat. In turn this could have negative effect on the integration process and the overall sustainability of the bloc. In light of the fact that a big percentage of the budget of the Secretariat is funded by donors, this trend of sophisticated high level corruption threatens the argument for the self-reliance of the region and the building of its capacity for self-sustenance. As indicated in the chapter on capabilities, one aspect of extrinsic empowerment relates with the EAC's economic sustainability. For sustainability purposes the region will only attain economic empowerment and sustainability when it begins to fund its own budgetary needs instead of depending on donors (a habit that is 
not sustainable in the long run); but this will only be attained if the leaders exercise frugality while using the little funds available.

\subsubsection{Integrity crisis and compromise of professionalism and rule of law:}

Transparency International's annual East African Bribery Index (EABI) has consistently reported that three sections of the public service in the region have ranked highest in bribery proneness, namely the Police, Judiciary and Lands Services. These sections are of intangible value to the realization of social justice in any given country and thus have a great impact on the social and political sustainability of the EAC. Using the findings contained in the 2012 EABI, the State of East Africa report series identified the ten most bribery-prone sectors in public service in the region and tabulated them thus:

Tab 8.1: Ten most bribe-prone public service sectors in the EAC:

\begin{tabular}{|l|l|c|}
\hline \multicolumn{1}{|c|}{ Rank } & \multicolumn{1}{|c|}{ Sector } & Index (0-100) \\
\hline 1 st & Ugandan Police & 85 \\
\hline 2nd & Tanzanian Police & 82 \\
\hline 3rd & Kenyan Police & 71.7 \\
\hline 4th & Kenyan Land Services & 70 \\
\hline 5th & Burundian Judiciary & 63.3 \\
\hline 6th & Burundian Police & 63.3 \\
\hline 7 th & Tanzanian Judiciary & 45 \\
\hline 8th & Ugandan Judiciary & 44 \\
\hline 9th & Rwandan Police & 37.5 \\
\hline 10th & Burundian Land Services & 35.8 \\
\hline
\end{tabular}

It is obvious that the most compromised sectors of public service (due to bribes) are the Police and Judiciary yet they are key in public life. These figures indicate a very precarious and worrisome situation that the regional bloc faces; the fact is that there is a marked compromise on the level of professional ethics and the rule of law. And this could have a great impact on the sustainability of the regional bloc; reason being that these institutions, particularly the Police and Judiciary, are supposed to be the dispensers of social justice in society. When they 
succumb to bribery and corruption then it the most advantaged (the rich and powerful) who access these services which leads to further alienation of the disadvantaged in society (the poor and vulnerable). This mostly likely sets the stage for victim disaffection and the accompanying desire to undo or destroy the political and social systems that are perceived as the sources of the injustices that the disadvantaged are suffering.

\subsubsection{Integrity crisis; subverting law enforcement and fueling conflict:}

The 2012 USAID report on: "East African Regional Conflicts and Instability Assessment" (2012) indicated that one of the key challenges that make the east African region so prone to conflicts and instabilities is corruption and unethical behavior within its public service, especially those along the border lines. According to the report, "Local government officials working in border areas with significant smuggling and illegal mineral transit are under intense pressure, and corruption is a serious temptation to officials who are poorly supported by central government" (USAID, 2012:20). The region has attracted myriads of mineral searching cartels that are actively "...subverting and weakening the state's role in law enforcement; and all contribute directly to the region's exceptionally high levels of corruption. Some but not all actively foment instability through armed conflict or humanitarian crises" (p.28).

So apart from unethical conduct among public servants causing many natives to fail to access justice, such a high level of corruption and bribery is exploited by self-seeking international and local business cartels to undermine government service provision. This is even more especially worrisome given the reports cited earlier of rampant corruption within the police and the judiciary. Because the region is endowed with vast amounts of natural resources, resourceinspired violence and abuses are rampant; the victims of crimes such as displacement, human rights abuses, sexual and gender-based violence, etc. may not get deserved justice. The result is that many of them develop a higher propensity to resort to violence and conflict in order to seek justice against their perceived tormentors, namely, those in government. The result is vicious cycle of victimization-conflict-and-more-victimization. Such phenomena characterize the many conflicts that are scattered all over the region and they are a threat to its sustainability; hence the dire need for integrity in government and service provision if the EAC is to be sustainable. 


\subsubsection{Integrity crisis and undermining the principles of the integration:}

It does not require much convincing for one to acknowledge that without the requisite level of integrity, it would be impossible to realize the ideals of the principles that are contained in the 1999 EAC Treaty that are meant to guide the governance and development of the regional bloc. Integrity lies at the bottom of each of the principles that are meant to guide the East African Community; and below we briefly consider integrity prerogative in some of these principles. This integrity prerogative and sustainability realization analysis is brief having done a more detailed review in the main chapter on literature review.

\subsubsection{Undermining the principle of People Centeredness:}

The 1999 EAC Treaty is laced with the language of people-centeredness all through the document; more of this principle is found in Article 5. But in other section we can also find specific reference to this principle; for example Art. 5:3(d) specifically states that: "the strengthening and consolidation of the long standing political, economic, social, cultural and traditional ties and associations between the peoples of the Partner States so as to promote a people-centered mutual development of these ties and associations" (EAC Treaty, 1999). This focus on the peoples of the region is applaudable and quiet necessary given that one of the causes for the collapse of the EAC-1 was a disconnection from the general citizenry of the region. Consequently, Articles 120,121 and 122 give special attention to the women of the east African states as the driving force behind the development of the region. The focus on the people raises the issues of human rights and consultation of the people concerned to the foreground of the development and governance practices in the region, at least in writing. In regards to this 'people-centeredness' the current East African Legislative Assembly (EALA) is debating a new Bill that is aimed at giving the people legal cover as they form cooperatives and engage in different activities for development. The bill is termed, the EAC Co-operative Societies Bill, 2013. The bill is being pushed on the premise that it will enhance trade and development among the people by encouraging grassroots formation of cooperative groups. The EAC Secretariat has also undertaken programmes that seek to involve the peoples in the integration process; for example the organization of activities such as the EAC military sports, the cultural events, among others.

However, despite the good intentions of such initiatives, there are early signs of low levels of integrity affecting the realization of such hopes. For example in January 2015 when the bill was hoped to be tabled for final consideration, there were reports that the Members of 
Parliament representing Tanzania at the EALA were conspicuously delaying or dragging their feet in joining the deliberations. This occurrence that stoked fears over signs of lack of harmony among the member countries; with some sections of the media reporting that they were 'missing' (Nkwame, 2015). Given that towards the end of 2014 the EALA legislators had impeached the Speaker over political in-fighting, there are all indications that the regional legislative body would need to raise its integrity levels if the ideal of people-centered development is to be realized.

At a more practical policy level, the principle of people-centeredness has been apparently placed under pressure by the land acquisition policies and practices that have been adopted by the ruling regimes in the EAC member states. The phenomenon of land-grabbing by the ruling elite in connivance with the global economic players has increased in the region in the recent decade and seems to get worse. The Kenyan elite class seems to be the leader of this pack of land-grabbers (O’Brien, 2011; Klopp, 2000); this phenomenon is also pervasive in Uganda with National Association of Professional Environmentalists (NAPE) reporting that these grabbers are responsible for the meteoric land price rise (NAPE, 2012) and this disadvantageous for the poor. The biggest challenge in this phenomenon of land grabbing is the involvement of state officials in displacement of the poor and disadvantaged people; this raises pertinent questions about the governments' commitment to exercise the principle of 'people-centeredness'.

\subsubsection{Undermining the principle of Balanced Sustainability:}

Article 5:3(a) of the Treaty expressly states that the regional bloc shall seek, "the attainment of sustainable growth and development of the Partner States by the promotion of a more balanced and harmonious development of the Partner States". This is what the study referred to as the 'balanced sustainability' principles in the governance and development of the EAC. In one sense, in order to attach concrete meaning inside the spirit of using the terms 'balanced' and 'sustainable', it must be noted that framers sought to overcome: i) the imbalanced development whereby some partner states benefit unevenly from the cooperation; and ii) the pitfalls of modern development that has been deemed unsustainable due to its traditional focus on mere economic growth and material consumerism at the expense of the climate, nature and future generations. 
One of the established causes of the collapse of the earlier EAC was imbalanced growth that the member states were realizing; some saw it as 'unbalanced' and more beneficial for some more than others. Tension grew when some countries tried protectionism in order to 'correct' these imbalances in trade. For the case of the relationship between Kenya and Uganda at the time, Idi Amin and Jomo Kenyatta devised one policy after another against each other (such as blocking Uganda-bound goods from passing through Kenya; and retaliation from Uganda by switching off electric power to the whole of western Kenya) until the EAC-1 could not stand anymore.

As discussed earlier in the study, there still exists systemic and policy tools in place that perpetuate this imbalanced economic growth among the partner states in the region. For example, as other EAC members (especially the land locked ones) strive to realize development through import-substitution, Kenya has increasingly become uncomfortable and desires to maintain the status quo. This has led to a continuation of some sort of trade war within the region that is not on competitive terms but on state interventionism. For example, in 2012 the Kenya Revenue Authority (KRA) introduced a new tax dubbed the "cash bond directive" (Mugabe, 2012) which targeted sugar that was coming from Uganda that was to be sold in Kenya. Ugandan sugar manufactures and traders viewed this as a ploy to push them out of the Kenyan market. This KRA has usually argued that these measures are put in place to maintain standards of goods entering the Kenyan market. All these phenomena indicate that without integrity it becomes increasingly impossible to implement the principles of the EAC.

\subsubsection{Undermining the principle of Mutual Benefit:}

Article 6(f) of the Treaty states that the cooperation will be for "mutual benefit"; and in Article 5:1 it is expressed that, "The objectives of the Community shall be to develop policies and programmes aimed at widening and deepening co-operation among the Partner States in political, economic, social and cultural fields, research and technology, defense, security and legal and judicial affairs, for their mutual benefit". The traditional meaning of the term 'mutual' conveys a meaning of free and respectful reciprocity that is shared in common among the concerned parties. In legal terms, this would imply some form of contractual relationship. Either way, the parties involved are presumed to have mutual admiration for each other and to share common interests. 
Mutuality is almost unattainable without integrity; the parties involved are presumed to act in the interest of all the partners in accordance to a shared vision. But the biggest test of this mutual respect so far has been the diplomatic row that erupted between Kigali and Dar es Salam. Diplomatic tension arose between Tanzania and Rwanda in 2013 when President Jakaya Kikwete of Tanzania suggested during the African Union meeting in Ethiopia, that Rwanda should talk peace with the FDLR rebels. Rwanda's President Kagame interpreted this as a sign of disrespect and it caused a diplomatic row between Kigali and Dar es Salam (see: Nyanje, 2013). Such episodes threaten the sustainability of the EAC and therefore the bloc would be prudent to leave DRC out of the equation for the time being.

\subsection{Understanding the nature of the 'Integrity Crisis' in the EAC's public service:}

In the article, "Status to contract society: Africa's integrity crisis" (2008) the scholar Edward Wamala has presented a plausible explanation of the nature of and why there is an 'Integrity Crisis' in most of Africa's public service departments. In a diagnostic fashion, Wamala's main argument is captured in these statements:

...the integrity crisis we are witnessing today in a product of the transition from a typically tribal society guided by notions of reciprocity and honour to a typically contractual society founded on contract relationships and the market. As people have transited from traditional tribal society guided by traditional notions of status and honour and joined modern contract society, they have not only lost a sense of consensus on core moral values that have traditionally woven society together into a moral community, but they have also been overwhelmed by the new demands and obligations that they have not adequately prepared for (Wamala, 2008:196).

Wamala problematizes the 'transitional' character of the modern African as the root underneath the poor levels of integrity within society in general and public service in particular. Using Ali Mazrui's concept of 'trans-class-man' (see: Mazrui, 1968), Wamala observes that the typical contemporary African finds himself having to be a loyal 'tribesman' (i.e. being an 'honorable' member of his tribe's tradition) and all the while having to fulfill the demands of modern structures of existence (such as the state and its legal and institutional obligations). He refers to this type of African as the "tribesman in transition" (Wamala, 2008:195) the persistent existence of whom, is evidence of the failure of sub-Saharan African societies to complete the 
"moral evolution from a tribal, ethnic set-up to a modern contractual set-up" (p.203). The results of this social condition are multiple political and development challenges such as 'corruption and graft...nepotism, greed and all manner of office abuse' (p.195).

Wamala's thesis may be acknowledged to be correct because it brings out the historicalsociological dimension of the African integrity crisis, a dimension that lacks in many mainstream analyses of the ethical challenges in Africa. The African condition, just like any other human condition elsewhere cannot possibly be separated from its historical and sociological context; and in this regard the colonial legacy becomes crucial in analyzing it and proposing solutions. It is observable that many modern Africans find themselves in a kind of 'ethical quagmire' whereby they lack a firm cultural foundation on which to base their ethical decisions; they are neither expressly traditional Africans nor are they fully modern Europeans. To a great extent, this is a legacy of the colonial experience which brought about abrupt political and social changes in a continent that perhaps has deeply rooted cultural histories than any other. The reality is that the in ethical terms, the impact of the colonial state was more cosmetic than not; the application of intolerable levels of violence and state machinery to coerce the colonized into social and political change rendered genuine and long-lasting ethical change almost impossible. As a result many Africans who chose to work in the colonial state did so out of survival instinct since the colonial master had destroyed their traditional economic systems; but they deeply loathed the colonialist. The UNDP report captured the impact of this situation in the statement that, "In considering the public service structures of [Africa], cultural and historical factors cannot be neglected. The countries in the region have the legacy of colonial administrations which largely shaped their current legal frameworks, organizational structures, and administrative systems. However, the European colonial powers have bequeathed a state structure that has not been geared to being responsive or accountable to the local population. This lack of accountability and transparency has been exacerbated in those countries..."(UNDP, 2001:2).

Nonetheless the extent to which the 'status-to-contract' argument's presumed historical awareness is stretchable; it turns out to be wanting in some aspect, particularly in relation to the meaning of integrity. If we are to generate more suitable solutions to poor ethical levels in east Africa's public service, the concept to interrogate is 'integrity'. Given the above discussion, it is noticeable that 'integrity' may not be realized as long as Africans do not embrace their core attributes that make them who they are, i.e. having integrity of being and 
existence. The essence of existence is being oneself (i.e. having integrity of oneself or being true to oneself) first and foremost and afterwards acting with integrity.

It is my considered view that this is what must have made traditional African communities morally stable (note that I am not referring to perfection) when compared to the modern colonially-birthed African states. Traditional Africans had their traditional social and political structures (or 'states' in the African sense); and one of the principles that kept their moral fabric stable was that of 'kinsman' around which their societies revolved; and it should be noted that this concept was not considered bad by its owners until the colonialists declared it so in a bid to destroy the social fabric that formed the backbone of anti-colonial resistance. The colonial masters used modern state tools such as the law, army, police, and judiciary to dismantle this traditional loyalty to fellow kinsmen among the Africans and up to now many African view the state as an enemy of their traditional values. The colonialist's legal dictates twisted things; for example helping a fellow tribes-man was termed 'nepotism'; taking a gift of gratefulness to a chief was termed 'bribery'; communal policing was termed 'mob-justice'; and other traditional ways of running society were declared unlawful and heavily punishable by the state. The traditional African could not understand why this strange colonial master placed more value and invested heavily in forcing him to pay taxes to the state rather than to assist his fellow tribes-man or woman. The colonial master would bring ten or twenty soldiers with guns to flog or shoot a native who had opted to remain home rather than go to work on the cotton plantation and look after his sick mother or grandmother.

Consequently, the African's moral sensibilities undergo confusion as he is torn between the two options: working in the cotton plantation to pay taxes or resisting and staying home to take care of his garden and his family. Even though the colonialist claimed that the modern state would use taxes to take care of his family, it was just a lie because the colonialist siphoned off the money to his mother country in Europe. For that reason the psyche of the traditional African has never trusted the modern state; in any case the same system of siphoning off funds from Africa to Europe has continued despite getting independence and having native leaders in charge; they still steal public funds and hide them in offshore accounts in secretive European banks. To the traditional African who had spent centuries living with and observing nature, it was 'natural' and 'ethical' for like creatures to share and assist each other in order to survive; but to those who worked in the colonial administration that was declared 'nepotism'. But the Africans were soon to find out that the colonial masters who had taught them the values of 
modern statehood were not so truthful after all; because they observed that European colonialist used state resources to treat his fellow European favorably contrary to what he was teaching to the native African. The same hypocrisy can be found in the global system today and lies at the root of global injustices. While African states are coerced by bodies like the IMF and World Bank to cut public expenditure and decrease on social security provision for the poor, most Western countries provide welfare to their poor. While African governments are told to allow 'free trade', many Western governments provide enormous subsides to their farmers and other strategic industries. This disillusionment with modern statecraft and the unjust international global order makes many African leaders fail to react properly given that many of them are not fully grounded in traditional African value systems and neither are they fully convinced about the modern western value systems; and to a great extent this explains the ethical confusion that is exhibited in African public service. If we are to restore integrity in east Africa the foregoing analysis must be kept in mind because it assists in understanding the nature of integrity and its applicability to the sustainability of the EAC.

\subsection{Integrity in ethical and wholeness terms:}

The above discussion yields the realization that integrity is understanding and used in two main ways: i) the ethical (moral) i.e. living ethically both in personal and professional life; and ii) the essence i.e. the wholeness of an entity or a given thing. The first meaning conveys meanings of personal and professional virtue; and being principled in conduct. The second meaning conveys ensuring that something does not disintegrate.

\subsubsection{Ethical: Personal and professional integrity:}

Since both 'personal' and 'professional' integrity are actually relating to individual behavior, the study chose to refer to both as 'personhood integrity'. Personhood in this case is used to encompass both the socio-political and legal aspects of human existence. In order for a person to attain the right status before the social, political and legal institutions, that person has to have the proper character and also have the resources to attain it. For that matter integrity in terms of personhood is attainable at two levels, namely, i) personal ethical quality, and ii) professional level. This study particularly applies this discussion of integrty to the holders of public offices (such as politicians and public servants) that are determinant in decision making for the region.

In the first instance of personal virtue, the individual or group of individuals can be said to be a person of integrity if their behavior is right and principled. It concerns ensuring that individual 
agency is virtuous and ethically positive to the individual herself and the society at large. This is according to the virtue definition of integrity, which concerns the quality of human character. This character has to be wholesome in the sense that the inner and outer aspect of a person's behavior are in tandem, such that the individual is not a hypocrite whose outer expressions do not rhyme with the inner self. As this takes place at individual level, its cumulative effect is that a community can be said to be one of integrity. From Stephen Carter's (1996) conception of integrity, this would mean playing by the rules rather than having the mentality of winning in life at any cost. That is why in his view it involves the three steps, i.e. i) discerning what is wrong and right, ii) acting on what has been discerned, and iii) open expression of the actions taken. If we relate this to the Aristotelian discussion of virtue, the first would stand for 'intellectual virtue' while the other for 'moral virtue'. If the EAC project is to be sustainable, the people within this Community have to be of integrity otherwise social cohesion and group virtue is compromised. From the leaders in the Community to the local person deliberations (such as political discourse) the behavior (such as businesses) has to be such that can be relied upon to be for the good and sustainability of the Community.

But that necessarily begs a question of "who or how the right and principled conduct is determined'. To answer that question the study has to refer to the other principles in this scheme, particularly the ubuntu principle. Being a geographically African region, Ubuntu would provide a more suitable (both culturally and historically) ethical milieu within which both traditional and modern African ethical sensibilities are catered for. As discussed in the chapter on ubuntu, there is room within ubuntu philosophy for individual freewill to be exercised and individuals to make person decisions. Nonetheless, ubuntu philosophy would entail an individual to exercise freedom within the limits that society's existence can accommodate without breaking up. This is one of the ways in which this dimension of integrity would contribute to the sustainability of the EAC.

The second level of 'integrity of personhood' has been identified here as the professional, and this entails elements of personal virtue but goes beyond that to include conduct at work or whatever professional an individual has chosen. An individual of integrity should be carrying out their work with ethical principles that are used to guide such things as decision making, resolution of conflict, among others. So the region of EAC needs persons of integrity in business, civil service and in various institutions that are necessary for the Community to exist. For example the schools need to be in hands of people of integrity who produce human 
resources that are genuinely trained and capable of meaningfully contributing to the development of the region. The business enterprises and civil service needs people who are of high integrity standards in order to build the Community.

The other side of this dimension of 'integrity of personhood' is the artistic and scientific competence in whatever profession someone is involved in. For example a researcher has to be ethical in their research such that their policy recommendations are both viable and reliable in decision making. It involves being committed both to the profession but also to the ethical standards that guide that profession. This has to be taken seriously because some professionals may conflate professional-passion with professional-ethics; the two have to go hand in hand and not sacrificing one at the expense of the other. An emphasis of this would produce the right manpower that is needed for the sustainability of the regional bloc.

\subsubsection{Wholeness: integrity as essence of 'being':}

In general metaphysics, 'being' encompasses everything; both as its instances in nature and as constructs by humans. Each of these types of being have their essence that makes them what they are and identifiable from each other. If the essence of a certain being changes, then it is no longer what it was before; it effectually becomes another thing. Therefore integrity of 'being' also means: i) remaining true to the essence of that nature, and ii) that being remaining as integral (as a whole). This meaning can be applied and achieved both for humans and nonhumans and for both natural systems and human institutions.

In the instance of essence, it means the attributes or characteristics that define the being of something in its fundamental nature. The integrity of something means ensuring that the attributes that make up this fundamental nature are kept intact. Beings or systems fail or collapse and become unsustainable when their essence is compromised of lost. A human being loses the integrity of their being if those attributes that make her a human are compromised or destroyed. Likewise a political project like the East African Community must protect its integrity first by keeping those attributes that make it unique and fundamentally itself intact. It entails knowing those unique attributes that make the EAC what it is. This means that the governors and framers of the EAC have to establish what these attributes are and put in place measures to keep them from being compromised or lost. 
The other aspect of integrity of being is integral, which means a being remaining whole. It is critical that if anything is to continue to exist that it remains a 'whole' because a fractured existence means compromised integrity. In the case of the EAC, it is very important to ensure that the bloc does not disintegrate into fractions. This is all the more important given the colonial history that the region underwent and the globalized nature of the world in which we exist. One of the major reasons why the colonialist was able to conquer the region was the existence of small communities of the peoples of eastern Africa; they had been divided along small tribal lines that would fail to resist the colonialist effectively. During the colonial times the colonialists used those social weaknesses to keep the peoples of east Africa divided and hence ruled and exploited them (see: Arens, 1976:53). And in the post-colonial times and the neo-colonial times this seems to have continued. In order to ensure the sustainability of the EAC the leaders and framers of the regionalization project have to ensure that the region remains integral and also undo the fractured nature of the peoples of the region.

This is of particular importance in motivating the EAC foreign relations policy; it is inevitable that the EAC requires partnerships both among the member states and outside the region. The regional bloc has to establish ways or mechanisms of detecting and deterring the disintegration of the Community. It is possible that there could occur both intentional and unintentional actions or events that could threaten the Community's integrity, as it were; thus the need to stop such from happening. This may include watching the type of investors that are welcomed into the region and the immigration policies or trends in order to find out whether could be subversive activities. It is noteworthy however, that some threats could be domestic and that also requires serious attention from the leaders in the region to tackle it before they escalate. Threats like domestic terrorism and even imported radicalism pose a formidable threat to the integrity of the Community and they need to be addressed.

\subsection{Sustainability through integrity of agency in the EAC:}

It is noticeable that the integrity concerns that keep recurring in the above discussion of the sustainability of the EAC, are at two main levels: i) personal and ii) institutional integrity. The first case concerns with the individual players in the regionalization project, which entails identifying and understanding issues such as the goals and motivations of the key individuals, their personality differences, political goodwill, among others. The second level deals with colonial and post-colonial institutional frameworks and involves identifying weaknesses in the 
economic, political and legal set-ups. This underscores the necessity of understanding the nature of institutional and individual sustainability agency.

Since we are aiming at applying integrity to achieve agents of sustainability that are effective in the East African Community, it is imperative that we establish the meaning of 'agency' as such. This necessary such that we properly grasp the co-relation between individual and institutional agency, on one hand, and their effective functioning towards the sustainability of the EAC, on the other. The etymological roots of the word 'agent' are from the Latin 'agere' which means the force or the one 'who acts' and effects change in others. To be an effective agent, therefore implies to initiate change in other beings. If we understand agency in that manner, then it means that to be an agent is to be a change-initiator towards a given purpose. It means that 'agency' is meant for a purpose or to change things towards a certain direction or goal, i.e. they are instruments of change towards a given goal or purpose

\subsubsection{Individual agency and integrity:}

In relation to the above discussion of the meaning of integrity, this corresponds with some aspects of 'integrity of being' and 'integrity as personal virtue' because the individual exists (being) and acts (virtue). From a behaviorist analytic point of view, one of the causes of the disbanding of the EAC was the integrity inadequacies among the pivotal leaders in the member countries of the union. As discussed earlier (in chapter 3) personal differences between the leaders of the EAC in the 1970s played a key role in the collapse of the EAC-1. The leaders did not trust each other and neither did the people trust them and that greatly affected the political will necessary to sustain the project.

The former Tanzania minster for East African Community Cooperation, Hon. Buberwa Kamala, has pointed out that:

The sustainability of the East African Community and the achievement of a political federation will depend on a level of political good will. That is why there is a need for sustaining political goodwill and public support. (Buberwa, 2006:14)

By referring to the inadequacy of political goodwill, Hon Buberwa was implying that the key role of individual political agents in the regional project. Aside from the traditional business use of the term 'goodwill', political goodwill, as such, is a kind of political compassion and 
more of a subjective adjective. It therefore depends on the agency of the individual holding a given political office; and for that reason if 'political goodwill' plays a key role in the integration and sustainability of the EAC, then the agency of the individuals holding political office is of uttermost importance. Individual agency therefore plays a pivotal role in the ensuring the integrity of the EAC.

In the same speech he mentioned that there is a fear of losing power among the political elite of East Africa (p.14). The term 'elite' has etymological roots in 'elect' or 'being chosen'; therefore reference to 'political elite' amplifies the privileged or determinant positions that certain individuals hold in society; their attitudes and actions are of importance in society. Therefore the political character of the personalities of the member states could either make or break the goal of realizing a sustainable EAC. For that matter individual agency is of great importance in the EAC; its sustainability rests on the essential and functional integrity of those personalities.

\subsubsection{Essential and functional integrity in individual agency:}

In terms of essential integrity, the political character of the individual leaders ought to be stable, trustable and genuine in order to be reciprocated by, i) the people that they are leading in specific members states, and ii) other actors in other nations that form the region. As discussed above, integrity in terms of essence entails remaining true to those attributes that fundamentally make up a being. In the case of EAC, the personalities that occupy pivotal political office must be cognizant of those peculiar attributes that make east Africans who they are; they need to appreciate those attributes and avoid compromising them. The EAC can't maintain its integrity if its leaders are not aware of this aspect of integrity. The peculiar attributes may include cultural heritage, pre-colonial historical realities, and ethnic relatedness of the people of the region, among others. There is need to establish these attributes and make them part of the political discourse in the framing of the EAC.

Having essential integrity is of great advantage in a complex global order where cultural heritages of developing nations are threatened. Regional governance is a complex and delicate balance between costs and benefits that the member-states have to continuously consider. When it comes to intra-regional negotiations, knowing the fundamental attributes that make the EAC would assist in overcoming unnecessary disagreements. Likewise when it comes to 
negotiating with actors outside the region, essential integrity would also enable the leaders or negotiators on behalf of the EAC, to know issues that cannot be compromised.

A lack of this aspect of integrity was witnessed in the past as regards the disagreements among the member states of the EAC that deteriorated into personal attacks between Idi Amin and Nyerere; and also between Nyerere and Kenyatta. If they knew and appreciated what fundamentally made them east Africans, it would have been easy to forego non-essentials and forge a way forward in order to preserve what made them fundamentally east African. Unfortunately, the same lack of essential aspect of integrity may still be around among the key leaders of the region. For example there are press reports of the emergence of the so-called "coalition-of-the-willing" 47 (Mwangi, 2013) that is claimed to be a marriage of convenience among Kenya, Uganda and Rwanda while isolating Burundi and Tanzania. Analysts are postulating that it is the deliberate political actions of the three presidents i.e. Kagame (Rwanda), Kaguta (Uganda) and Kenyatta (Kenya) that are driving an apparent wedge within the EAC thus posing a possible threat to its sustainability. Even though Tanzania is reported to have refuted the idea of leaving the EAC (Anami, 2013), if such developments are not handled carefully they pose a threat to the sustainability of the regional cooperation. Similarly there is a recent spate of animosity between the current speaker of the East African Legislative Assembly - EALA and some members of the House (Kiggundu, 2014). It is also reported that the genesis of the Speaker's problems was a personal political tussle against a fellow contestant from the same country, Uganda (Sserunjogi, 2012). According to the Speaker, Hon. Margeret Zziwa, the political debacle which started as 'peer rivalry' between her and her electoral rival Hon. Dora Byamukama has spilled into a 'geo-politics' (Wanambisi, 2014) and is threatening the institution. This is another case of evidence for individual political personalities affecting the integrity of the EAC; if they are properly aware of the essential integrity of being east African, it would be easier to overcome such unnecessary political showdowns that threaten the sustainability of the Community.

On the other hand the functional integrity in individual agency means that the core attributes that make up the being of a given person (or in this case, a body-politic) are operationalized or put into action. This could be achieved through avenues like policy, legislation, investment,

\footnotetext{
${ }^{47}$ As noted earlier, the leaders of Kenya, Uganda, Rwanda and South-Sudan prefer to be termed as focusing on the northern corridor (or the northern artery of the region)
} 
etc. In these terms therefore, individual functional integrity would mean that the individual political actors ought to align their decisions and actions with the recognized attributes that make the EAC what it really is. For example in generating the 'core values' of the Community, these essential attributes of east Africans ought to be captured and reflected in any official document thereof. For that matter officially stated core values of the EAC Secretariat such as: professionalism, accountability, transparency, teamwork and unity in diversity (EAC, 2012:9) need to be operationalized in lieu of the essential attributes of being east African. Professionalism does not mean that cultural values of the peoples of the region are destroyed or undermined, rather civil servants work in tandem in respect of the cultural norms of the people.

\title{
8.7.2 Institutional agency and integrity:
}

In terms of earlier discussion on integrity this corresponds with being 'integral' and 'wholesomeness' because at a regional level like the EAC, institutions ought to be 'integrated' and also 'based on wholesome principles' that guide their conduct. From a cosmopolitan point of view (due to the large number of tribes and cultural groupings), weakness in the existing institutional framework for regional governments does not only undermine their delivery of service and goods but most importantly, their legitimacy. Buchanan and Keohane (2006) have argued that,

\begin{abstract}
It is important not only that global governance institutions be legitimate but that they are perceived to be legitimate. The perception of legitimacy matters because, in a democratic era, multilateral institutions will only thrive in they are viewed as legitimate by democratic publics ...[if not]...public support for global governance institutions may be undermined and their effectiveness in providing valuable good may be impaired (Buchanan \& Keohane, 2006:407).
\end{abstract}

This means that as globalization takes place and bigger governance structures are put in place, the question of legitimacy and effectiveness becomes pertinent. The institutions must be both legitimate and also perceived to have attained legitimacy genuinely; both the real and perceived legitimacy of the institutions affect the agency of those institutions in fulfilling the purpose for which they were established. Buchanan and Keohane infer that the legitimacy of global (i.e. regional) institutions is based on the democratic character of that institution; and in order to 
have genuine democracy that the EAC citizens would approve, there must be high standards of integrity in those institutions. These may be organs (agents) that are put in place to ensure democracy such as electoral bodies, power separation instruments, human rights protection bodies, and others. If these organs that are responsible for the democratic cycles such as elections, lack integrity or are perceived not to have it, there is most likely to be a crisis of legitimacy and that would threaten the sustainability of the body-politic. This implies that there is a direct inverse relationship between the integrity of the agents of democracy and the legitimacy of the institutions in question.

\subsection{Conclusion}

The paper has endeavored to present integrity as a key pillar if the EAC is to realize sustainable governance and development. The chapter conveys a simple but pivotal idea that without the requisite personal and institutional ethical conduct especially within the political class and the bearers of public office, it will be a greater challenge to achieve sustainability in governance and development. Much emphasis is placed on resource mobilization and increment; most politicians spend their energies on either securing loans or encouraging or attracting private capital to invest in the region. But without a corresponding level of integrity in the region, most of these resources and investments face a high risk of being abused and becoming of no benefit to the citizens of the regional and more so posing a big threat of eventual disintegration of the bloc.

\section{CHAPTER IX}

\section{CONCLUSIONS AND RECOMMENDATIONS}

\subsection{Introduction:}

This section of the study is a presentation of the main conclusions of the research and suggested recommendations towards the realization of governance and development sustainability of the 
East African Community. The first part of this section is a recap of the key conclusions from the discussions and analysis in the major chapters of the dissertation. The next portion tries to generate possible practical application of the Comprehensive Ethical Sustainability (CES) scheme in the East African region. And the last portion is dedicated to some suggestions for further research direction that any future researcher on a similar quest would consider taking up.

\subsection{The task of the study:}

This study set out to contribute to the ethical enrichment of sustainability discourse, particularly in terms of governance and development in the East African Community (EAC). This was to be done by: i) interrogating the conceptualization of sustainability from an applied ethics perspective; and ii) generating a more suitable framework towards the realization of sustainable governance and development the East African Community (EAC). In that vein, it set out to achieve three major goals: i) to establish the underlying fundamental cause(s) of the unsustainability of the East African Community from political, philosophical and ethical perspectives; ii) to elucidate the significance of incorporating ethics in the conceptualization and pursuance of sustainability in the East African Community and beyond; and iii) to generate a more suitable theoretical framework for application towards the realization of sustainability of the East African region.

The study used qualitative methodology mostly because it was thought that in terms of applied ethics, the analysis of the ethical meanings of the theoretical perspectives and concepts in question and their impact on political, development and social processes and projections would be best studied using qualitative methodology. This type of methodology was preferred more specifically because studies like this that delve into matters of values and perceptions and their effect on society are better executed using qualitative methodology. In order to transcend the sometimes intractable debate between deductive or inductive reasoning in classical epistemological discourse, the study devised the approach known as the reflective equilibrium method that has gained traction within applied ethics studies. The study was designed as an analytical-constructive research employing it on an atypical case-study of the East African Community. This was done in order to be able to carry out a deeper analysis of the EAC regionalization project and at the same time constructively contribute to the framing of sustainable governance and development processes and institutions in the region. 
To that end the study employed tools such as analytical observation, philosophical critique, theoretical sampling, conceptual clarification, thought experimentation, diagnostic analysis, prescriptive analysis, and constructive argumentation. These tools were applied analyzing secondary sources and documents relating to governance thinking and practice within the member states of the EAC. They were also used in deciphering the ethical thinking in the framing of the EAC and the incorporation of the concept of sustainable development in the region. The secondary sources included treaties, protocols books, journal articles, policy declarations, media reports, government reports, online secondary data, integration programs, etc.).

\subsection{Relating goals with main analytical conclusions:}

In relation to the three major goals of the study certain major conclusions and findings resulted from the research. In terms of establishing the underlying fundamental cause(s) of the unsustainability of the East African Community, the study was able to analytically perceive that: i) Social-Darwinism was the underlying philosophy that greatly influenced the colonial masters' governance of the current member states of the EAC. The influence of that philosophy on the colonial governance of the colonies has negatively impacted current pursuit of the ideal governance and development sustainability of EAC.

Secondly it was also revealed that the initial colonial master inspired regionalization of the east African region was approached using the Colonial-Functionalist approach. This approach to regionalization meant that colonial masters only focused on building those state institutions and processes that benefited their colonial agenda of economic and political exploitation of the colonies with little or no consideration of the natives. This has to great extent proved detrimental to the ideal of sustainable governance and development in the EAC; this is because, apart from not adequately preparing the native leaders for regional governance, it also left a legacy of skewed development in favor of the coastal nations that has remained a challenge in the integration process.

The second major goal of the study was to elucidate the significance of incorporating ethics in the conceptualization and pursuance of sustainability in the East African Community and possibly beyond. To that end the research was able to: i) explicate the implicit ethical values embedded in the EAC policy direction. This was done by analytically demonstrating that the ideal and values of sustainability are contained in the Treaties and policy documents of the 
EAC; thus augmenting the position that working towards the realization of sustainable governance and development in the region is in tandem with the framers of the EAC integration.

Secondly the research has been able to demonstrate that ethics should be of foundational importance in sustainable development discourse in the region. For that matter, the study argued that incorporating and mainstreaming ethical thinking in the integration process is not as peripheral and ignorable as has so far been the case within certain political, business and administrative quarters of the region.

The third goal of the study was to generate a more suitable theoretical framework for application towards the realization of sustainability of the East African region. It was able to generate and proposed a framework for approaching sustainability, which has been termed the Comprehensive Ethical Sustainability (CES) scheme. The CES is a 'scheme of principles' which means a set of selected ethical principles that are critical to sustainable systems and processes; these principles are the 'component elements' of a 'program of action' towards the attainment of sustainability. Therefore the comprehensive ethical sustainability scheme is an arrangement of ethical principles aimed at achieving sustainable systems and processes in society, and particularly in regionalized states such as the EAC. To that effect this notion is developed with identifying the institutional and individual levels of applicability.

As a 'scheme of principles' it is composed of four key principles that are thought to ensure sustainability if applied in tandem. In generating these ethical principles I have not come up with any fundamentally or radically new principles; rather I have harvested and re-organized ideas that have been discussed by key scholars in recent years which, in my view, have great bearing on sustainability. This is because the question of sustainability is a multi-dimensional one and anyone who insists on approaching it from one angle is most likely to miss a lot of useful views. We are living in the age of multi and inter-disciplinary research and this has inspired me to re-organize ideas from a variety of views; albeit the study is in the field of applied ethics. These principles include: i) Capabilities, ii) Justice, iii) Ubuntu and iv) Integrity. In my view if these principles are applied to i) the theorization of sustainability and ii) structural arrangements and individual action they would ensure sustainability. 


\subsection{CES: the four-principle scheme:}

The study defined CES has a scheme for understanding, founding and realization of sustainability processes and agency through the incorporation of ethics in sustainability theorization and praxis. At the theoretical level, it deals with how ethical theory can sustainably remain relevant to a related 'theoretical universe' of sustainability discourse. Practically it deals with how to sustain a viable ethical fabric in society that ensures realization of governance and development sustainability. Therefore the nature of comprehensive ethical sustainability means that foundational aspect of sustainability that entails ensuring both the relevance of ethics to sustainability discourse and maintaining ethical character that can lead to the realization of sustainable systems and processes.

The study understood CES to be suitable for realization of sustainability because it allows room for ubuntu (humaneness), justice, integrity and enhancement of the capabilities of persons involved. These variables were also recast as the basic principles and pillars of the ES scheme. These principles were chosen on the strength of both for their, i) 'axiomatic' value, and ii) 'utility' capacity; and within contemporary development discourse, these grounds of their value is justifiable both a priori-ally and a posteriori-ally. In terms of the former, the principles are ethically axiomizable such that they are used to capture values of profound importance to the sustainability of human society. In terms of the latter, these principles are considered to be easily applicable in building social processes and institutions in the region under question.

For purposes of avoiding the intractable debate between deductive and inductive reasoning the 'axiomization' that is applied in selecting these principle is hereby referred to as 'ethical axiomization' in contrast to modal logical axiomization. The term 'ethical axiomization' is used to mean the use of given words or expressions to compress ethical value that is considered to be intuitively and consequentially perceivable. But this 'axiomization' should not be equated with 'reductionism' as such because the explicative and applicative power of ethical principles ensures that there is little likelihood of losing the virtue import of these ethical axiomizations or principles (see: Zucker, 1984). This ethical axiomization is taken to be of necessity in order to extrapolate their ethical value across disciplines such as from applied ethics to development and governance. For example the principle of ubuntu is chosen because it axiomatizes the, i) deeper African philosophical values, and ii) essentializes the time tested ethical values of indigenous African societies. So unpacking such a principle would bring out the rich ethical values embedded therein. 
The axiomization of these principles took into consideration three characteristics, namely, being i) compound, ii) compatible and iii) complimentary. In terms of compoundness these principles were selected because they have room within which one can mix more than one and inseparable aspects of the African experience and thereby capture the complexity of the region such as the colonial experience through which the natives of the region suffered and benefited concurrently. In terms of compatibility, they were considered to their perceivable malleability with sometimes intractable ethical theoretical perspectives such as intuitionism and consequentialism; in addition due to their compatibility with African political and development realities. In terms of complementarity, these principles were selected on the basis of the ease of being applied in tandem towards the goal of sustainability.

\subsubsection{The Justice principle in the CES scheme:}

Justice was conceived both as a principle and condition of ethical sustainability; the application of justice was in terms of social justice an understanding that goes beyond mere legalist understanding of the same. The argument was that if political and social processes are to be sustainable in the long run, they ought to incorporate social justice. The study used the Rawlsian theory of 'justice as fairness' as a commencing point to: i) explore possible points of convergence between distributive and entitlement views of justice; and ii) argue for the indispensability of social justice in the pursuit of governance and development sustainability in the EAC. The main tenet of this principle is that any political, ecological or environmental efforts geared towards sustainability that involve unjust processes and produce injustices towards sections of a given society cannot be sustainable in the long run. This is because any unjust system breeds both i) victim disaffection and ii) villain encumbrance which conditions render that system unsustainable.

\subsubsection{The Integrity principle in the CES scheme:}

The study generated a working definition of integrity as the ethical wholesomeness of being and personhood. The definition sought to capture the two major aspects on integrity: i) the totality and wholeness of a given being, and ii) steadfastly holding onto ethical principles that guide one's or a group's conduct. The issue of ethics has been considered to be central to both aspects of integrity because in each case, the enterprise of realizing integrity requires certain standards or qualifiers that are of some ethical nature. In order for a person to be the right agent 
of sustainability within the social, political and legal institutions in a given community, that person ought to have ethical character. For that matter integrity in terms of personhood is achievable at two levels, namely, i) personal, virtue, and ii) professional level.

\subsubsection{The Capabilities principle in the CES scheme:}

The other principle of the comprehensive ethical sustainability scheme is the Capabilities principle, which was proposed as a principle and condition in achieving ethical sustainability. In generating this principle, the study aimed at enhancing and recognizing the capabilities of the citizens and institutions of the EAC in order to enhance the: i) intrinsic and ii) extrinsic ethical empowerment of both the individuals and organizations thus contributing to the governance and development sustainability of the region. This principle of capabilities was generated mainly using Amartya Sen and Martha Nussbaum's ideas in the capabilities approach in which they argue that freedom is the core value of development. In a contractualist setup such as the EAC which is based on democratic principles, it is necessary to have individuals and organs that are capable i.e. empowered and therefore capable of meaningfully partaking of the benefits of the cooperation. In becoming so, the long term sustainability of the integration could be contributed to because a population that is capable of taking advantage and benefiting from the regionalization project would not feel excluded.

\subsubsection{The Ubuntu principle in the CES scheme:}

The Ubuntu principle is another principle within the CES scheme that seeks to contribute to the realization of government and development sustainability within the East African Community. As indicated earlier, this principle axiomizes the, i) deeper African philosophical values, and ii) essentializes the time tested ethical values of traditional African societies; thus through 'ethical axiomization' Ubuntu can be rendered a principle of ES. As a principle, it captures and represents the three common approaches by African thinkers to resolving the African development challenge, namely, re-dignification, unification and re-construction. In re-dignification terms, ubuntu brings back the dignity of the native African as one who can also contribute to the governance and development of the region using a philosophy that she is well versed with. In terms of unification, ubuntu has potential of unifying varying views within East Africa because it arises from shared spiritual and moral aspirations of the people of the region. In re-constructive terms, ubuntu contributes to re-conceptualizing and re-framing of the processes and the institutions of the region. 


\subsection{Specific chapter findings and conclusions:}

Chapter two reviewed selected relevant literature and identified the major research gap as the less than necessary attention given to the ethical reconceptualisation of sustainability. It also highlighted issues of global governance and justice as critical to the attainment of sustainable governance and development of the East African Community. Specifically the review found a conceptualization 'gap of divergence' between the 'Market inspired sustainability' (MIS) logic and the 'Traditional African sustainability' (TAS) logic. The review therefore heightened the need for generating a more viable meaning of sustainability such that its applicability to the EAC is both at the theoretical and practical levels.

Chapter three discussed the EAC integration and the challenge of sustainability and carried out an examination of the lessons that could be learned from the past experience of the collapse of the first EAC project. The examination showed that the EAC integration idea was actually mooted by the former colonial masters who were majorly motivated by colonial exploitation and that legacy is still evident in the current revival of the project. It showed that the colonial masters used a 'colonial-functionalist' approach in the earlier integration and thereby laid down the seeds of unsustainability that contemporary leaders in the region are dealing with. The chapter therefore called for caution and careful consideration of the possible future expansion of the EAC; pointing out the need to consider governance issues such as social justice, economic equity, etc in order to mitigate possible causes of fissures and rifts within the region.

Chapter four laid out the tenets of the Comprehensive Ethical Sustainability (CES). It concluded that the CES scheme would contribute to an ethically enriched governance and development discourse in the East African Community. It ethically enriched the meaning of sustainability and proposed a more suitable framework for achieving sustainability in the East African Community (EAC). The CES scheme placed ethics at the foundation of sustainability thinking and theorization and application. Therefore it concluded that if the EAC is to realize sustainable governance and development, ethics has to be incorporated in its framing.

Chapters five to eight made the claims and discussed the nature of the four principles of the CES scheme, namely, justice, integrity, ubuntu and capabilities. In justice chapter the main conclusion was that any political, ecological or environmental efforts geared towards sustainability but involve unjust processes and produce injustices towards some members of a 
given society cannot be sustainable in the long run. In the integrity chapter the conclusion was that in order to attain sustainability individuals and institutions require certain standards of integrity that foster trust and legitimacy among the citizens and members of society. The capabilities chapter concluded that in a contractualist integration process such as the EAC which is based on democratic principles, it is necessary to have individuals and organs that are capable i.e. empowered and therefore capable of meaningfully partaking of the benefits of the cooperation. And the ubuntu chapter concluded that in order to overcome the detrimental legacy of colonialism and its impact of current government in the EAC, there is need to appeal to deeper African philosophical views that contain time-tested traditional ethical values that can restore the dignity of the African and foster unification among the many sub-groups in the region.

\subsection{Recommendations:}

Basing of the study's analysis and conclusions many suggestions can be derived from this research. In this section I consider and present some suggestions that would be gleaned from the study and probably contribute to a better East African Community.

\section{Mitigating the inadequate capacity for regional governance within the EAC:}

There is need to put in place mechanisms that would mitigate the inadequate capacity for regional governance within the leadership class of the EAC. Given the conclusions from the study's analysis of the philosophical attitudes and ideas that impacted colonial governance, there was little or no preparation of the native east Africans to take charge of leading a regional government. There is evidence of latent ability to governance multiple states because of the many traditional kingdoms and chiefdoms that were amalgamated together into modern nation states. However that latent ability needs to be sharpened and improved according to contemporary governance challenges and theories such as metagovernance.

\section{Restoring ethics to being a foundation stone of sustainability discourse:}

The study recommends that theorists and policy makers in the field of sustainability should make ethics a foundational stone of the discourse such that there is increased incorporation of ethical reasoning in regional governance and development. One of the major observations of the study was that all other dimensions of sustainable development such as the 'environmental', 'economic', and others are preceded and premised on the 'ethical' dimension. For example without the requisite ethical fabric in society, enormous financial and other resources may be 
expended on ensuring sustainability of the natural ecology or a forest or specie of animal; and it may have taken ages to build and maintain but all that can be destroyed by a single or few unethical actions by a few corrupt officials. This makes ethics central (and not peripheral) in sustainability efforts.

\section{Focusing on building individuals and institutions of integrity:}

For purposes of attaining sustainability in the East African Community there is a great need for individuals and institutions that have good levels of integrity. Distant and recent historical events in the region (ranging from civil unrest to outright genocide) have demonstrated the need for special attention to this issue. Given the higher propensity towards volatility in the region emanating from variations in political views, large number of tribes and cultural groupings, the young population in the region, weaknesses in the institutional integrity of existing frameworks for regional governments do not only undermine service delivery but most importantly, also raise questions on the legitimacy of the existing structural mechanisms. If such a situation is not addressed, systems such as elections, adjudications, policing, peacekeeping missions, etc. would be greatly undermined in the eyes of the citizens and that would negatively affect the bloc's sustainability. This could be done through specialized integrity training in regional institutions and strengthening of the regional judiciary mechanisms in order to tackle the integrity and ethical challenges that may emerge from time to time.

\section{Enrich regional governance and development with ubuntu:}

Ubuntu represents the inherent capacity in African culture to express compassion, reciprocity, dignity, harmony and humanity in the interests of building and maintaining community with justice and mutual caring. It exhibits the flourishing of both humans and other beings on a local, national and global scale; it can also assist in closing the gaps of divergence among various perspectives used towards the realization of unsustainability in human society. It is also applicable to contemporary social and governance values such as human rights, privacy, etc. The thinking that ubuntu does not allow for individual freedom (human rights) is based on the erroneous and unviable views of equating, i) ubuntu with collectivism, and ii) individual freedom with rationality. This equation comes from a wrong understanding of the metaphysics of ubuntu and can be corrected by interrogating the meaning of the root word 'ntu' which yields that there was and still is room for personal fulfillment in traditional Africa. 


\section{Focus on building natives' capabilities to participate in the integration:}

Capabilities hold inherent ethical value by virtue of placing the human person at the center for development discourse. The deontological undertones in the conception of capabilities approach make the approach to be of intuitive ethical value which is very difficult to disregard. As indicated earlier, in a contractualist integration process such as the EAC which is based on democratic principles, it is necessary to have individuals and organs that are capable i.e. empowered and therefore capable of meaningfully partaking of the benefits of the cooperation. Sustainability of a regional integration project like the EAC requires that citizens are capable to take part and own the systems, processes and institutions thereof.

\section{Build a Comprehensive Ethical Sustainability (CES) scheme evaluation mechanism:}

Having demonstrated the need for a more suitable framework for the realization of sustainability such as the CES, there develop an evaluative mechanism that could be used in the CES scheme. It was pointed out earlier that this is a scheme of principles that are can form a program of action. It is possible to develop a CES-criterion by which various regional processes and policy initiatives can be assessed. The proposed CES-criterion can be used to generate a monitoring and evaluation mechanism for the EAC. The EAC could take the CES monitoring and evaluation mechanims as two separate but complimentary activities of the organisation aimed at ensuring efficiency, effectiveness and measuring implementation of designed policies or projects. It could also be used as a management tool and in developing and actualising sustainability in the region.

The CES evaluative mechanism could be applicable in the phases of traditional monitoring and evaluation, i.e. planning, implementation, progress and closure. In terms of planning and implementation sustainability problems that may be encountered at organisational and execution levels could be detected and traced from either the planning level or the implementation level. That would make mitigation more timely and useful. It would also help in observation of whether the challenges being encountered in the organisation or a given project are at the planning level or implementation level. In terms of progress review the EAC would need a mechanism of periodically reviewing sustainability progress; this progress could be defined by the vision of the regional bloc.

\subsection{Suggestions for further research:}

Below are a few suggested areas for further research: 


\section{Research into modeling ethics of socially dynamic political entities:}

The study observed a need for further research into the nature of ethics in socially dynamic political entities like the East African Community. There is need for generating models of the ethical dynamics in society in order to understand the flows that influence the ethics and morality in the region relating them to governance and development. Such studies would provide findings that could be useful in developing ethical restorative policies and measures given the deterioration of ethical standards in the region.

2. Research into explaining the effect of colonial-functionalism on the EAC integration:

The study revealed that the use of a colonial-functionalist approach by the former colonial masters in the region has had enormous bearing on the integration process. However, there is need for further research to explain the actual role of this approach and how its legacy would be minimised. Its impact on governance and development in the region also needs to be understood properly and reflected in the framing of the integration.

\section{Research into the compatibility of ubuntu with values such as human rights, etc}

The study realized that there is a prevalence of the perception that the traditional African philosophy or worldview of ubuntu is incompatible with contemporary values such as human rights, privacy, and democracy, among others. This thinking seems to form the presupposition or background from which many analysts or political philosophers base their usual conclusion that African nation-states have a fundamental democracy problem. My initial observation is that this position is not logically tenable if subjected to further investigation. But in order to understand this better, there is need for further research to know whether traditional African perspectives are compatible with contemporary values. 


\section{REFERENCES:}

African Development Bank, (2010), Eastern Africa: Regional Integration Strategy Paper 2011-2015, African Development Bank

Africa Rights Organization, (2003), Gacaca Justice: A Shared Responsibility, Report by Africa Rights, Africa Rights Organization Publication

Ajumbo Gerald, (2013), "Is variable geometry leading to the fragmentation of regional integration in East Africa", http://www.afdb.org/en/blogs/integrating-africa/, accessed $12 / 12 / 2014$

Allais Lucy, (2004), “Kant's one world: Interpreting transcendental idealism”, British Journal of the History of Philosophy, Vol. 12 No. 4 (2004), pp. 655-684

Allais Lucy, (2007) "Kantian idealism and the secondary quality analogy”, Journal of History of Philosophy, Vol. 45 No. 3 (July 2007), pp. 459-484

Allais Lucy, (2014), "In defence of an Enlightenment conception of reason: A critique of a single-value moral theory based on ubuntu", seminar series paper presented at the Department of Philosophy, University of Witwatersrand, 5-7 ${ }^{\text {th }}$ August 2014

Almond Brenda, (2009), "Review of New Directions in Ethics: The Challenge of Applied Ethics", Philosophical Books, Vol. 28, Issue 4 (Feb 2009), pp. 238-239

Ambe J. Njoh, (2006), Tradition, Culture and Development in Africa: Historical Lesson for Modern Development Learning, Ashgate Publishing Ltd

Anafara V., \& Mertz N., (2006), Theoretical Frameworks in Qualitative Research, Sage Publications Ltd

Analo Trevor, (2014), "Protests: East Africa tries to tame an army of angry men", The East African, 23/12/2014, http://bit.ly/1zknoa5, accessed 25/12/2014 
Anami Luke, (2013), “Kikwete: Tanzania will not cause EAC's collapse”, The Standard, <http://www.standardmedia.co.ke/business/article/2000097452/kikwete-tanzania-will-notcause-eac-s-collapse>, accessed 18/11/2013

Arens William, (1976), A Century of Change in Eastern Africa, Walter de Gruyter

Aristotle, Nicomachean Ethics (W.D Ross, trans), The Internet Classics Archive, http://classics.mit.edu/Aristotle/nicomachaen.html, accessed 23/05/2011

Arjan de Haan, (2009), How the Aid Industry Works: An Introduction of International Development, Kumarian Press

Ashford Elizabeth \& Mulgan Tim, (2010), "Contractualism”, in Zalta Edward, ed., (2012), The Stanford Encyclopedia of Philosophy, (Fall 2012 Edition),

<http://plato.stanford.edu/archives/fall2012/entries/contractualism/>, accessed 31/01/2014

Audi Robert and Murphy E. Patrick, (2006), "The many faces of integrity", Business Ethics Quarterly, Vol. 16 No. 1 (2006), pp. 3-21

Audi Robert, (2009), “Moral virtue and reasons for action”, Philosophical Issues, Vol. 19, Issue 1, pp. 1-20

Audrey L. Richards, (2014), Multicultural States in East Africa, McGill-Queens Press

Axster Sabrina, (2009), "Book review: Dead Aid", http://www.povertytofreedom.com/development-issues/book-review-dead-aid/, accessed $5 / 6 / 2011$

Ayittey George B.N, (2005), “The 'colonialism-imperialism' paradigm is kaput”, <http://www.utexas.edu/conferences/africa/ads/815.html>, accessed 12/11/2013

Babacar Sall, (2012), “Cheikh Anta Diop: Great African scholar revisited”, The Journal of Pan African Studies, Vol 5 No 1 (March 2012), pp. 253-255 
Bach Daniel, ed., (2005), Regionalisation in Africa: Integration and Disintegration, Indiana University Press

Bach Daniel, (2008), “The European Union's 'Strategic Partnership' with the African Union” in Akokpari J, et al, eds (2008), The African Union and Its Institutions, Fanele \& CCR

Baehr R.P, Björn Wittrock, et al, (1981), Policy Analysis and Policy Innovation: Patterns, Problems and Potentials, Sage Publications

Bakuluki Paul, (2011), Negotiating Retributive and Restorative Justice in Conflict Transformation Efforts: A Case of Northern Uganda, LIT Verlag Münster

Barigaba Julius, (2012), "Museveni now well placed to be first pan-African leader", The East African, Dec 8 2012, <http://www.theeastafrican.co.ke/news/Is-Museveni-planning-to-beKing-of-Africa/-/2558/1639628/-/hadt81z/-/index.html>, accessed 8/12/2012

Barigaba Julius, (2013), "Uganda now steps in, sends troops to South-Sudan", The East African, Dec 21, 2013, <http://www.theeastafrican.co.ke/news/Uganda-now-steps-in-andsends-troops-to-South-Sudan-/-/2558/2121192/-/9xh17mz/-/index.html>, accessed $21 / 12 / 2013$

Barkan Joel, (1994), Beyond Capitalism vs. Socialism in Kenya and Tanzania, Lynne Reinner Publishers

Barry Brian, (2005), Why Social Justice Matters, Polity publishers

Basedau M. \& Mehler A., eds., (2005), Resource Politics in sub-Saharan Africa, Hamburg African Studies, Vol. 14, GIGA-Hamburg Publishers

Battle J. Michael, (2009), Reconciliation: The Ubuntu Theology of Desmond Tutu, Pilgrim Press

Baxter Jim, et al, (2012), Real Integrity: Practical Solutions for Organizations Seeking to Promote and Encourage Integrity, Chattered Accountants Trust Limited, University of Leeds 
Beauchamp T.L, \& Childress J.F, (1994), Principles of Biomedical Ethics, 4th Edition, Oxford University Press

Beauchamp T.L \& Childress J.F (2001), Principles of Biomedical Ethics, Fifth Edition, Oxford University Press

Beauchamp T.L \& Terry P. Pinkard, eds., (1983), Ethics and Public Policy: An Introduction to Ethics, Prentice-Hall, Inc., New Jersey

Bentham Jeremy, (1781), An Introduction to the Principles of Morals and Legislation, Batcho Books, <http://socserv.mcmaster.ca/econ/ugcm/3113/bentham/morals.pdf>, accessed $13 / 09 / 2013$

Best Edward, (2008). "The assessment of regional governance: Principles, indicators and potential pitfalls", UNU-CRIS Working Papers, W-2008/10

Bevir M., (2009), Key Concepts in Governance, SAGE Publications Ltd

Bhengu J. Mfuniselwa, (2010), “'Ubuntu' as an African metaphysics in Economics: Towards a cultural-economic synergy in humanizing our economic system", paper presented at the International Institute of Social Studies conference, Erasmus University, The Netherlands, 2122 June 2010

Blake Michael, (2001), "Distributive justice, state coercion and autonomy", Philosophy and Public Affairs, Vol. 30, No 3 (summer 2001), pp. 257-296

Blasi, A., (1984), "Moral identity: Its role in moral functioning", in W. M. Kurtines \& J. L. Gewirtz, eds., (1984), Morality, moral behavior, and moral development, Wiley-Interscience (pp. 128-139)

Bo Petersson, (2000), “What is this thing called 'Reflective Equilibrium'?”, in Bo Petersson, ed., (2000), Applied Ethics and Reflective Equilibrium, Centre for Applied Ethics, Linköping University 
Boateng, E.A., (1978), A Political Geography of Africa, (Reprint Ed.), Cambridge University Press

Boehm, C.H, (1982), "The evolutionary development of morality as an effect of dominance behavior and conflict interference", Journal of Social and Biological Structures, Vol 5:413422

Boehm C.H, (1983), "The evolutionary development of morality as an effect of dominance behavior and conflict interference", in Margaret Gruter and Paul Bohannan, 1983, Law, Biology and Culture: The Evolution of Law, Ross-Erikson Publishers Inc

Bonevac Daniel, (2010), “Is Sustainability sustainable?”, Academic Questions, Vol 23 Issue 1 (March 2010), pp. 84-101

Booth, D. and Cammack, D., (2013), Governance for Development in Africa: Solving Collection Action problems, Zed Books

Botha Anneli \& Mahdi Abdile, (2014), "Radicalisation and al-Shabaab recruitment in Somalia”, Institute of Security Studies, Pretoria, South Africa, paper No. 266, September 2014

Brandabur Clare A., (2007), “Britain's Gulag: The Brutal End of Empire in Kenya”, in The Journal of Pan African Studies, Vol. 1, No. 10, Nov 2007, pp. 152-155

Broadie Sarah, (1991), Ethics With Aristotle, Oxford University Press

Brock Gillian, (2009), Global Justice: A Cosmopolitan Account, Oxford University Press

Buberwa Kamala, D., (2006), "The achievements and challenges of the New East African Community cooperation”, Research memorandum 58 (June 2005), open lecture at the University of Hull, Business School, May 3, 2006, http://www2.hull.ac.uk/hubs/pdf/memorandum58.pdf, accessed 5/5/2011 
Buchanan A., \& Keohane R.O., (2006), "The legitimacy of global institutions", Ethics \& International Affairs, Vol 20 No 4, 2006 pp.405-37

Buchanan A., (2000), "Rawls' Laws of Peoples: Rules for a vanished Westaphalian world", Ethics, Vol 110, No 4 (July 2000), pp. 697-721

Burridge Tom, (2014), “Al-Shabab attacks put Kenyan government under pressure”, $B B C$, Dec 2, 2014, <http://www.bbc.com/news/world-africa-30290993>, accessed 02/12/2014

Butagira Tabu, (2013) “Uganda leads Africa's move to quit international court", The Daily Monitor, <http://www.monitor.co.ug/News/National/Uganda-leads-Africa-s-move-to-quitinternational-court/-/688334/2028352/-/lrw672z/-/index.html>, 16/10/2013

Butler Samuel, (2011), "Homer", Iliad, (trans by Samuel Butler), The Internet Classics Archive, http://classics.mit.edu/Homer/iliad.html, accessed 5/05/2011

Butler Samuel, (2011), “Odyssey”, Iliad, (trans by Samuel Butler), The Internet Classics Archive, http://classics.mit.edu/Homer/iliad.html, accessed 5/05/2011

Bungu Jerry, (2014), "Making use of traditional institutions in modern African institutions", Mmegionline, 17/07/2009, http://www.mmegi.bw/index.php?sid=6\&aid=16\&dir=2009/July/Friday17, accessed $21 / 04 / 2013$

Broodryk Johann, (2005), Ubuntu Management Philosophy: Exporting Ancient African Wisdom into the Global World, Knowres Publishers, Indiana University

Brown Eric, (2011), "Plato's ethics and politics in The Republic", in Zalta Edward, ed., (2011), Stanford Encyclopedia of Philosophy, http://plato.stanford.edu/archives/win2011/entries/plato-ethics-politics/, accessed 23/03/2012 Byrd Hall, (1971), Social Darwinism and British Imperialism 1870-1900, M.A thesis submitted to Texas Tech University, December 1971 
Cajes S. Alan, (2011), Philosophy of Sustainable Development, Compendume Publishing and Consultancy Services, Manila

Cann Rebecca, Stoneking M., \& Allan C. Wilson, (1987), "Mitochondrial DNA and Human Eve”, Nature, 325 (January 1987), pp. 31-36

Carter L. Stephen, (1996), Integrity, Basic Books, New York

Caselli G., and Egidi V., (2007), “The need for multi-disciplinary approach”, Population, Vol 62, No 1, 2007

Ciaffa Jay, (2008), "Tradition and modernity in postcolonial African philosophy", Humanitas, Vol. 21 No. 1, (2008)

Chachine E. Isaias. (2008), Community, Justice and Freedom, Uppsala Studies in Social Ethics, No. 37, University of Uppsala

Chidi Odinkalu, (2013), "Why violence in Africa presents an existential threat", Open Society Justice Initiative, Feb 13, 2013, <http://www.opensocietyfoundations.org/voices/whyviolence-africa-presents-existential-threat>, accessed 15/02/2013

Chu I. Stan, (2006), The Face of Africa: Looking Beyond the Shadows, AuthorHouse Publishers

Chuwa Leonard, (2014), African Indigenous Ethics in Global Bioethics, Springer

Clark David A., (2005), “The Capability Approach: Its Development, Critique and Recent Advances”, Global Poverty Research Group Working Paper Series, GPRG-WPS-032

Clark Phil, (2010), The Gacaca Courts, Post-Genocide Justice and Reconciliation in Rwanda: Justice Without Lawyers, Cambridge University Press

Cohen Jared, (2007), One Hundred Days of Silence: America and the Rwanda Genocide, Rowman \& Littlefield Publishers 
Cobain Ian, Owen Bowcott \& Norton-Taylor R., (2012), "Atrocities of colonial past haunt Britain again", The Mail \& Guardian, April 20 2012, <http://mg.co.za/article/2012-04-20colonial-past-haunts-britain-again>, accessed 28/10/2013

Cole Michael, (1996), Cultural Psychology: A Once and Future Discipline, The Belknap Press of Harvard University

Collier Sarah, (2014), "End of the line? Allegations of corruption knock Kenya's railway project off-track", Think Africa Press, March 27, 2014, $<$ http://www.thinkafricapress.com/kenya/allegations-mismanagement-unlikely-significantlyderail-east-african-rail-megaproject>, accessed 27/03/2014

Collins Robert \& Burns James, (2013), A History of Sub-Saharan Africa, $2^{\text {nd }}$ Edition, Cambridge University Press

Collste Göran, ed., (2007), Perspectives on Applied Ethics, Studies in Applied Ethics, Center for Applied Ethics, University of Linköping

Collste Göran, (2012), “Applied and professional ethics”, Kemanusiaan, Vol 9 Issue 1, (2012), pp. 17-33

Collste Göran, ed., (2013), Social Justice: Perspectives from Uganda, Centre for Applied Ethics, University of Linköping

Collste Göran, (2014), Global Rectificatory Justice, Palgrave Macmillan

Common M., (1995), Sustainability and Policy, Cambridge University Press

Cox D., et al, (2013), “Integrity”, in Zalta E.N., ed. (2013), The Stanford Encyclopedia of Philosophy, (Fall 2013 Edition), <http://plato.stanford.edu/archives/fall2013/entries/integrity>, accessed 13/11/2013

Crisp Roger, (2005), “Aristotle: Ethics and Politics”, Routledge Encyclopedia of Philosophy, Taylor and Francis 
Crocker, David, 1992, “Functioning and capability: The foundations of Sen's and Nussbaum's development ethic", Political Theory, Vol. 20, No. 4 1992, pp.584-612

Cummiskey D., (1987), "Desert and entitlement: A Rawlsian consequentialist account", Analysis, Vol 47 (1), Jan 1987, pp.15-19

Curzer J. Howard, (2012), Aristotle and the Virtues, Oxford University Press

Dalfovo A.T, et al, (1992), The Foundation of Social Life: Uganda Philosophical Studies I, Council for Research in Values and Philosophy, Washington DC

Dambisa Moyo, (2009), Dead Aid: Why Aid Is Not Working and How There Is A Better War For Africa, Farrar, Strauss and Giroux

Dambisa Moyo, (2010), Uncommon Knowledge, Highlights of the Hoover Institute, Fora.tv Series, The Hoover Institute Conference Channel, Stanford, CA, USA, 06/05/2009

Daston Lorraine \& Galison P., (1992), "The image of objectivity", Representations, Vol. 0 Issue 40, pp. 81-128

Daston Lorraine, ed., (2000), Biographies of Scientific Objects, The University of Chicago Press

Daston Lorraine \& Galison Peter, (2007), Objectivity, Zone Books Ltd

De Marco Joseph \& Fox Richard, eds., (1986), New Directions in Ethics: The Challenge of Applied Ethics, Routledge \& Kegan Paul

Dedman Martin, (1996), The Origin and Development of the European Union 1945-95, Routledge

Denzin N. \& Lincoln Y., eds., (1994), Handbook of Qualitative Research, Sage Publications Inc., California 
Derideaux Pieter, (2002), History of East Africa, web-book, $<$ https://sites.google.com/site/historyofeastafrica/>, accessed 23/11/2011

Diawara Manthia, (1988), "Popular Culture and oral traditions in African film", Film Quarterly, Vol 41 No 3 (spring 1988), pp. 6-14

Dick Ahlstrom, (2009), “Morality 'a result of' natural selection”, The Irish Times, Tue 02 Feb 2009, <http://www.irishtimes.com/newspaper/ireland/2009/0217/1224241279479.html>, accessed 28/05/2011

Dobronogov Anton \& Farole Thomas, (2012), “An economic integration zone for the East African Community”, Wolrd Bank Policy Research working paper series, No. WPS5967

Douglas F.P Taylor, (2011), Can Ubuntu Provide the Ethical Basis for King III?, MA dissertation, University of Witwatersrand, Johannesburg

Douglas F.P Taylor, (2014), "Defining Ubuntu for business ethics: A deontological approach", South African Journal of Philosophy, Vol. 33 Issue 3, 2014, pp. 331-345

Dunn Jimmy, (2004), "The ethics and morality of ancient Egyptians", http://www.touregypt.net/featurestories/ethics.htm, accessed 07/07/2013

EAC (1999), Treaty for the Establishment of the East African Community, EAC Secretariat, Arusha

EAC, (2007), Report of the Committee of Fast-Tracking East African Federation, EAC Secretariat, Arusha

EAC, (2005), Prospectus for the Regional East African Health Policy Initiative (REACHPolicy), EAC Secretariat, Arusha

EAC, (2012), East African Community Facts and Figures - 2012, EAC Secretariat, Arusha 
EAC, (2012), Strengthening Popular participation in the East African Community, EAC secretariat, Arusha

Easterly R. William, (2006), The White Man's Burden: Why The West's Efforts to Aid the Rest Have Done So Much Ill and So Little Good, Penguin Press

Eckersley Robyn, (1992), Environmentalism and Political Theory: Towards an Ecocentric Approach, Suny Press

Economic Commission for Africa, (2007), Relevance of Africant Traditional Institutions on Governance, Economics Commission for Africa, Addis Ababa

ECFESD, (2000), Sustainable Governance: Institutional and Procedural aspects of sustainability, Office for Official Publications of the European Communities, Brussels

Edmund Blair, (2015), "South Sudan war to cost regional states \$53 billion - report", The East African, Jan 14 2015, <http://www.theeastafrican.co.ke/news/South-Sudan-war-to-costregional-states--53b/-/2558/2589034/-/10jnijj/-/index.html>, accessed 14/01/2015

Edmunds Lowell, (1981), The Sphinx in the Oedipus Legend, Hain \& Indiana University

Egbeke Aja, (1997), "Changing moral values in Africa: An essay in ethical relativism", The Journal of Value Inquiry, Vol. 31, pp. 531-543

Eisenhardt, K.M, (1989), "Building Theories from Case Study Research", The Academy of Management Review, Vol. 14, No. 4, Oct, 1989, pp. 532-50

Elkington John, (1997), Cannibals With Forks: The Triple Bottom Line of $21^{\text {st }}$ Century Business, Capstone Publishing Ltd

Elkington John, (2013), “Enter the Triple Bottom Line”, in Henriques A. \& Richardson J. eds., (2013), The Triple Bottom Line: Does It All Add Up?, Earthscan 
Elkins Carline, (2005), Britain's Gulag: The Brutal End of Empire in Kenya, Pimlico Publishers

Elkins Carline, (2011), "My critics ignored evidence of torture in Mau Mau detention camps", The Guardian, April 14 2011, <http://theguardian.com/commentisfree/2011/apr/14/torture-mau-mau-camps-kenya>, accessed 27/10/2014

Emmet E.R, (1964), Learning to Philosophize, Penguin Books

Escobar A., (1995), Encountering Development: The Making and Unmaking of the Third World, Princeton University Press

Easterly William, (2015),Tyranny of Experts: Economists, Dictators and Forgotten Rights of the Poor, Perseus Books Group

Espinosa Angela \& Walker Jon, (2011), A Complexity Approach to Sustainability: Theory and Practice, Imperial College Press

Eze E. Chukwudi, (1993), "Rationality and the debates about African philosophy", (January 1, 1993), ETD Collection for Fordham University, Paper No: AAI9403294, <http://fordham.bepress.com/dissertations/AAI9403294>, accessed 23/10/2009

Eze E. Chukwudi,(1997), “The color of reason: The idea of 'race' in Kant's anthropology”, in Eze E.C, ed., (1997), Postcolonial African Philosophy: A Critical Reader, Blackwell Publishers Ltd

Eze E. Chukwudi, (2008), On Reason: Rationality in a World of Cultural Conflict and Racism, Duke University Press

Fanon Frantz, (1965), The Wretched of the Earth, Groove Press, New York

$+$ 
Finnigan wa Simbeye, (2014), “China seen as East Africa's leading trade ally”, Tanzania Daily News, Nov 20, 2014, <http://www.dailynews.co.tz/index.php/biz/38460-china-seen-aseast-africa-s-leadng-trade-ally>, accessed 22/11/2014

Fisher Max, (2012), "The dividing of a continent: Africa's separatist problem", $<$ http://www.theatlantic.com/international/archive/2012/09/the-dividing-of-a-continentafricas-separatist-problem/262171/>, accessed 05/11/2012

Flyvbjerg Bent, (2006), "Five misunderstandings about case study research", Qualitative Inquiry, Vol 12, No. 2, April 2006, pp.219-45

Folke Tersman, (1993), Reflective Equilibrium: An Essay in Moral Epistemology, Almquist and Wiksells International, Stockholm

Frankena William, (1973), Ethics, Princeton-Hall

Frans de Waal, (2009), "Morals without God", Huffingtonpost, Oct 10 2009, <http://www.huffingtonpost.com/frans-de-waal/morals-without-god_b_316473.html>, accessed 29/05/2011

Frans de Waal, (2009), The Age of Empathy: Nature's Lessons for a Kinder Society, $1^{\text {st }}$ Edition, Broadway Books

Fraser Cameron, (2005), “The EU Model of Integration-Relevance Elsewhere?” in Jean Monnet/Robert Schuman Paper Series, Vol.5 No. 37 Dec 2005, <http://www6.miami.edu/eucenter/Cameronfinal.pdf>, accessed 20/08/2009

Frazer James George, (1995), Marriage and Worship in Early Societies: A Treatise on Totemism and Exogamy, Mittal Publications,

Gade Christian, (2011), "The historical development of the written discourses on Ubuntu", 
South African Journal of Philosophy, Vol. 30, Issue 3, (2011), pp. 303-329

Gakwandi Arthur, ed., (1999), Uganda Pocket Facts, $2^{\text {nd }}$ Edition, Fountain Publishers

Gann L.H, \& Duignan P., eds., (1975), The Economics of Colonialism, Cambridge University Press

Gasper Des, (2004), The Ethics of Development, Edinburgh University Press

Gerring John, (2007), Case Study Research: Principles and Practices, Cambridge University Press, New York

Giampietro Mario, (2010), "Integrated assessment of agricultural sustainability: Pros and cons of reductionism”, Reports on Environmental Sciences, Institut de Ciència i Tecnologia Ambientals, $<$ http://ddd.uab.cat/pub/estudis/2010/hdl_2072_96137/RepEnvSci_201001.pdf>, accessed 28/05/2011

Gildenhuys J.S.H, (2004), The Philosophy of Public Administration: A Holistic Approach, African Sun Media

Gombya-Ssembajjwe W., et al, (1993), “Embazzi and Namungo's Forest: A Site Report”, Uganda Forestry Resources and Institutions Center, Makerere University, Forestry Department, Kampala, Uganda

Gombya-Ssembajjwe W., (1994), "Sacred forests in modern Ganda society", paper for the FAO Forestry Working Group on Common Property, Oxford Forestry Institute, Dec 15-18, 1994

Goode J. William \& Hatt P.K, (1952), Methods in Social Research, International Edition, McGraw Inc

Government of Ghana, (1992), Constitution of the Republic of Ghana-1992, Accra

Government of Kenya, (2011), Constitution of the Republic of Kenya-2011, Nairobi 
Government of South Africa, (2003), Traditional Leadership and Governance Framework Act-2003

Government of Tanzania, (1999), The Tanzania Development Vision 2025, Dar es Salam

Government of Tanzania, (2009), National Governance and Corruption Survey, Vol. 1, Dar Es Salam

Government of Uganda, (2011), Second Annual Report on Corruption Trends in Uganda: Using the Data Tracking Mechanism, Inspectorate of Government, Government of Uganda Publication

Gwynne Dyer, (2013), "Gwynne Dyer: The African Union, the International Criminal Court, and accusations of racism", <http://www.straight.com/news/502686/gwynne-dyer-africanunion-international-criminal-court-and-accusations-racism>, accessed 02/10/2013

Gyasi E.A, et al, (2004), Managing Agrodiversity the Traditional Way: Lessons from West Africa in Sustainable Use of Biodiversity and Related Natural Resources, United Nations University Press

Gyekye Kwame, (1997), Tradition and Modernity: Philosophical Reflections on the African Experience, Oxford University Press

Haas, Ernst B., (1958), The Uniting for Europe: Political, Social and Economic Forces, 1950-1957, Stanford University Press

Haas, Ernst B. and Philippe Schmitter, (1964), "Economics and differential patterns of political integration: Projections about unity for Latin America", International Organization, Vol. 18 , No. 4, pp. 705-37

HancockGraham, (1992), Lords of Poverty: The Power, Prestige and Corruption of the International Aid Business, Atlantic Monthly Press

Hans Carl von Carlowitz, (1713), Sylvicultura Oeconomica, oder Haußwirthliche Nachricht 
und Naturmäßige Anweisung zur Wilden Baum Zucht, Leipzig

Harlow J., et al, (2011), “A Review of Utopian themes in sustainable development discourse", Sustainable Development, 10, June 2011, John Wiley \& Sons Ltd

Hasmukh Dawda, (2010), "Lack of ethics killing every sector in this country", The Daily Monitor, 25 ${ }^{\text {th }}$ May 2010, Monitor Publications Ltd, Kampala

Hedl John, Glazer H., \& Chan F., (2005), "Improving the moral reasoning of allied health students", Journal of Allied Health, Vol 34, Issue 2, (Summer 2005) pp. 121-122

Heidegger Martin, (1977), "The Age of the World Picture”, in Heidegger M., (1977), The Question Concerning Technology and Other Essays, Garland Publishing Ltd, London

Heidegger Martin, (1992), Parmenides, (trans by Andre Schuwer \& Richard Rojcewcz) Indiana University Press

Herbert Mercuse, (1990), "From Consensual Order to Instrumental Control”, in, Jeffrey C.A. \& Seidman Steven, Eds. (1990), Culture and Contemporary Debates, Cambridge University Press

Hobbes Thomas, (1651), Leviathan, Andrew Crooke

Hospers John, (1985), “Justice versus 'social justice': The idea of justice in the market economy", The Freeman, Vol. 35 No 1 (January 1985), pp. 9-24

Hountondji Paulin, (1996), African Philosophy: Myth and Reality, Indiana University Press

Howard Williams, (2014), “Colonialism in Kant's political philosophy”, Diametros, 39(2014): 154-181

Hursthouse, Rosalind, (2013), "Virtue Ethics”, in Zalta Edward, ed., (2013), The Stanford Encyclopedia of Philosophy (Fall 2013 Edition), $<$ http://plato.stanford.edu/archives/fall2013/entries/ethics-virtue/>, 06/11/2013 
Hyman M. Larry \& Katamba X. Francis, (2006), “The word in Luganda”, in Erhard Voeltz, ed., (2006), Studies in African Linguistic Typology, John Benjamins Publishing, pp. 171-193

Igwe C. Stanley, (2012), How Africa Underdeveloped Africa, iUniverse Publishers

Ikejiaku Brian-Vincent, (2009), “The concept 'development' revisited towards understanding: in the context of sub-Saharan Africa", Journal of Politics and Law, Vol. 2 No. $1(2009)$

Ikuenobe Polycarp, (2006), Philosophical Perspectives on Communalism and Morality in African Traditions, Lexington Books

Ilibagiza Immaculate, (2014), Left to Tell: Discovering God Amidst the Rwandan Holocaust, Hay House Inc.

International Institute of Sustainable Development, (2012), Sustainable Development Timeline, <http://www.iisd.org/pdf/2012/sd_timeline_2012.pdf>, accessed 10/09/2013

Iris Marion Young, (2011), Justice and the Politics of Difference, Princeton University Press

Irving Dianne N., (2001), “The Bioethics

Mess",<http://www.lifeissues.net/writers/irv/irv_37bioethicsmess.html>, accessed on $27 / 06 / 2005$

Iwu M.M and Wooton J., (2002), Ethnomedicine and Drug Discovery, Elsevier

Jaffar Amin \& Akulia Margeret, (2010), Idi Amin: Hero or Villain?, Millenium Global Publishers

Jaggar Alison, (2006), "Reasoning about Well-Being: Nussbaum's Methods of Justifying the Capabilities”, The Journal of Political Philosophy, Vol. 14, No. 3, (2006), pp.301-322 
Jahoda M., et al, (1973), Models of Doom: A Critique of 'Limits of Growth', Universe Publishing

James Brusset and Dan Bulley, (2007), "Ethics and world politics: Cosmopolitan and beyond?" International Politics, Vol. 44, (2007) pp. 1-18

Jan-Peter V., Dierk B., \& René Kemp, (2006), Reflexive Governance for Sustainable Development, Edward Elgar Publishing

Jef van Gerwen, (2002), “Three methods in Applied Ethics: A critical review”, in Chadwick Ruth \& Schroeder Doris, eds., (2002), Applied Ethics: Methods and Scope, Taylor and Francis

Jeng Abou, (2012), Peacebuilding in the African Union: Law, Philosophy and Practice, Cambridge University Press

Jessop Bob, (2008), State Power: A Strategic Relation Approach, Polity

Jessop Bob, (2011), “Metagovernance”, in Bevir M., ed., (2011), Handbook of Governance, Sage Publication Inc

Johannessen Cathrine, (2005), "Kingship in Uganda: The role of Buganda Kingdom in Ugandan politics", Research Notes series on: The Legal and Institutional Context for the 2006 Elections in Uganda, Christen Michelsen Institute, Norway, Oct. 2005

Jomo Kenyatta, (1968), Suffering Without Bitterness: The Founding of the Kenyan Nation, East African Publishing House

Jorge Martinez-Vazquez, Javier Arze del Granado, Jameson Boex, (2007), Fighting Corruption in the Public Sector, Elsevier

Jurgen S, Calvin H.W, Hastings M, (2000), Sustainable Development: The Challenge of Transition, Cambridge University Press 
Kafeero Stephen \& Nabirye Lois, (2014), "Minister: Abuse of power is dangerous", The Daily Monitor, Nov 13 2014, <http://www.monitor.co.ug/News/National/Minister--Abuseof-power-is-dangerous/-/688334/2520212/-/oil32g/-/index.html>, accessed 14/11/2014

Kagire Edmund \& Hellen Nachilongo, (2015), "Rwanda pushes for military action against FDLR, Tanzania hesitant", The East African, Jan 10 2015, $<$ http://www.theeastafrican.co.ke/news/Rwanda-and-Tanzania-set-for-clash-over-FDLRmilitary-offensive-/-/2558/2584342/-/hml71hz/-/index.html>, accessed 10/01/2015

Kaitlyn Orr, (2010), "Ethical Sustainability”, Verge 6, 2009-2010, <http://www.goucher.edu/academics/verge/past-issues/verge-6/orr>, accessed 30/03/2011

Kant Immanuel, (1785), Grounding for the Metaphysics of Morals (trans by: J.W Ellington), Third Edition, 1993, Hackett Publishers

Kaphagawani Didier \& Malherbe Jeanette, (2004), "Epistemology and tradition in Africa", in Coetzee P.H \& Roux A.P.J, (2004), The African Philosophy Reader, Routledge

Karenga Maulana, (2010), "The ideal and ethics of Ubuntu: A kawaida conversation”, The Sentinel, Thursday 20 June 2010, <https://www.lasentinel.net>, accessed 12/12/2012

Karim Faith, (2013), "UK to compensate more than 5000 Kenyans over colonial-era torture", CNN, June 7, 2013, <http://edition.cnn.com/2013/06/06/world/africa/uk-colonialcompensation/index.html>, accessed 08/07/2013

Karl-Henrik Robèrt, (1991), "Educating a Nation: The Natural Step”, Making It Happen, No 28, Context Institute, Langley

Karuhanga James, (2015), “Audit unearths misuse of funds at EAC Secretariat”, The New Times, Jan 25 2015, <http://www.newtimes.co.rw/section/article/2015-01-25/185293/>, accessed 25/01/2015 
Kasaija K. Apuuli, (2006), "Fast Tracking East African Federation: Asking the Difficult questions", paper presented at public dialogue on: Fast tracking the East African federation, organized by DENIVA, Kampala, 24th Nov 2006

Kasfir Nelson, (2002), "Dilemmas of popular support in guerrilla war: The National Resistance Army in Uganda 1981-86”, paper presented at LiCEP 6, UCLA, November 2002; <http://www.yale.edu/macmillan/ocvprogram/licep/6/kasfir/kasfir.pdf>, accessed on $04 / 04 / 2011$

Kasozi F. Mutaawe, (2011), Introduction to an African Philosophy: The Ntu'ology of Baganda, Karl Alber Freiberg

Kayombo, S., \& Jorgensen, S.E, (2006), "Lake Victoria: Experience and lessons learned”, <http://www.worldlakes.org/uploads/27_Lake_Victoria_27February2006.pdf>, accessed 9/5/2013

Kayumba Christopher, (2013), “So, what's East African Community's problem?”, The East African, Nov 22 2013, <http://www.theeastafrican.co.ke/Rwanda/Opinion/So--what-s-EastAfrican-Community-s-problem-/-/1433246/2084570/-/36sppu/-/index.html>, accessed $22 / 11 / 2013$

Keebungero Chelirenso E.S, (1993), Ssekabaka Kintu ne Bassekabaka ba Buganda Abamusooka, Crane Publishers Ltd

Keenan Thomas, (1997), Fables of Responsibility: Aberrations and Predicaments in Ethics and Politics, Stanford University Press

Kelly Charlotte, (2011), "Origins of sustainability", $<$ http://www.its.leeds.ac.uk/projects/sustainability/resources/Origins\%20of\%20Sustainability .doc>, accessed 19/02/2013

Khunou S. Freddie, (2011), “Traditional Leadership: Some reflections on morphology of constitutionalism and politics of democracy in Botswana", International Journal of Humanities and Social Sciences, Vol. 1 No. 14 (October 2011), pp. 85-94 
Kiggundu Edris, (2014), "How railway deal went sour”, The Observer, Aug 06 2014, $<$ http://www.observer.ug/index.php?option=com_content\&view=article\&id=33170:howrailway-deal-went-sour>, accessed 06/08/2014

Kiggundu Edris, (2014), "Zziwa loses control of EALA, hangs onto hope”, The Observer, 21 Nov 2104, <http://bit.ly/1toMCBF>, accessed 21/11/2014

Kiiza Barnabas \& Glenn Perdeson, (2013), "Export-led growth in the face of terms of trade volatility: The case of the East African Community trade bloc", Uganda Strategy Support Program, International Food Policy and Research Institute, Research Note No. 15, Jan 2013

Kirshak Ray, (2000). "Book review: Integrity by Stephen L. Carter, Harper Perennial, New York, 1996”, Sociological Practice, Vol. 2 No. 4 (2000), pp. 315-317

Kishore Raga \& Derek Taylor, (2005), "Impact of accountability and ethics on public service delivery: A South African perspective”, Nelson Mandela Metropolitan University, available at: http://www.ibrarian.net, accessed 23/08/2012

Kishore Raga \& Derek Taylor, (2005b), "Impact of accountability and ethics on public service delivery: A South African perspective" The Public Manager, (Summer 2005), pp. 2226

Kitaka M. Andrew, (2012), "Promoting non-motorized transport: Case study of the NMT pilot corridor", presentation at a UNEP Share the Road workshop, Kampala, Oct 2012, $<$ http://www.unep.org/Transport/sharetheroad/PDF/Test_workshop/AndrewKitaka_Uganda_ NMT_Pilot.pdf>, accessed 09/01/2014

Klaus Bosselmann, Ron Engel, \& Prue Taylor, (2008), Governance for Sustainability: Issues, Challenges, Successes, IUCN Environmental Law Centre

Kleuder Christiaan, ed., (2010), State, Society and Democracy: A reader in Namibian politics, Macmillan Education Namibia Ltd 
Klopp M. Jacqueline, (2000), "Pilfering the public: The problem of land grabbing in contemporary Kenya”, African Today, Vol. 47 No. 1 (Winter 2000), pp. 7-26

Knud Vilby, (2007), Independent? Tanzania's Challenge since Uhuru: A Second Generation nation in a globalized world, E \& D Division Publishing Ltd

Kobusingye Olive, (2010), The Correct Line? Uganda Under Museveni, AuthorHouse

Koigi wa Wamwere, (2002), I Refuse to Die: My Journey for Freedom, Seven Stories Press

Kohlberg Lawrence, (1971), "Stages of moral development as basis for moral education”, in Sullivan V. Edmund, ed., (1971), Moral Education, University of Toronto Press, pp. 23-92

Konrad-Adenauer Stiftung, (2011), Ambition For and Reality of the East African Community In A Globalized World, Konrad-Adenauer Stiftung Pub, Tanzania

Korwa Adar G., (2005), "New regionalism and regional reconstruction: The case of the East African Community", Politeia, Vol 24. No 1, 2005 pp. 28-48

Korwa Adar G., (2008), "Federalism and East African Community Integration Process: The Role of the East African Legislative Assembly", paper presented at the CIGI/GARNET conference on Mapping Integration and Regionalisation in a Global World: The EU and Regional Governance Outside the EU, Bordeaux, France, 17-20 Sept 2008

Korwa Adar G., (2011), "East African Community”, in Finizio G. \& Vallinoto N., (2011), The Democratization of International Organizations, International Democracy Report 2011, International Democracy Watch. Online version at: <http://www.internationaldemocracywatch.org/attachments/458_EAC-adar.pdf>, accessed $23 / 09 / 2013$

Koul Lokesh, (2009), Methodology of Educational Research, Vikas Publishing House, New Delhi 
Kuperman J. Alan, (2004), The Limits of Humanitarian Intervention: Genocide in Rwanda, Brookings Institute Press

Kwesi E.B., (2011), "An Overview of Sustainable Development in Africa”, in Area Studies Regional Sustainable Development: Africa, edited by Kwesi E.B., in Encyclopedia of Life Support Systems (EOLSS), Developed under the Auspices of the UNESCO, Eolss Publishers, Oxford

Kymlicka Will, (2002), Contemporary Political philosophy, Oxford University Press, New York

Ladu Ismail Musa, (2014), "Ugandan traders threaten to boycott Mombasa port", The East African, Nov 28 2014, <http://bit.ly/1EnVUYb>, accessed 28/11/2014

Lajul Wilfred, (2014), African Philosophy: Critical Dimensions, Fountain Publishers

Lake Victoria Commission, (2007), Strategic Action Plan for Lake Victoria Basin, East African Community, Arusha, Tanzania

Lake Victoria Basin Commission, (2009), "Lake Victoria Water and Sanitation Project",<http://www.lvbcom.org/index.php/programmes-projects/lvwatsan>, accessed $25 / 02 / 2013$

Lamore E. Charles, (1987), Patterns of Moral Complexity, Cambridge University Press

Lang Christopher, (1995), "Environmental degradation in Kenya as a cause of political conflict, social stress and ethnic tension", <http://mercury.ethz.ch/serviceengine/Files/ISN/246/ipublicationdocument_singledocument/ 73d911af-aa2b-466e-b951-6e6d54be11ab/en/doc_248_290_en.pdf>, accessed 6/8/2012

Laursen Finn, (2008), “Theory and Practice of Regional Integration”, Jean Monnet/Robert Schuman Paper series, Vol. 8, No. 3, February 2008 
Lewis W.C, (1991), The Ethics Challenge in Public Service, Jossey-Bass Publishers, San Francisco

Liberman Mark, (2012), "Entitlement”, <http://languagelog.ldc.upenn.edu/nll/?p=4240> $22 / 10 / 2013$

Ligami Christabel, (2013), "Regional states differ over articles in draft monetary union protocol", The East African, <http://www.theeastafrican.co.ke/news/-/2558/2075698//7omgs2z/-/index.html>, accessed 17/11/2013

Lipjhart, Arend, (1971), "Comparative Politics and the Comparative Method" The American Political Science Review, Vol 65, No 3, Sept 1971, pp.682-93

Logan Carolyn, (2008), "Traditional leaders in modern Africa: Can democracy and the Chief co-exist?", Afro Barometer working paper no. 93, <http://www.afrobarometer.org/files/documents/working_papers/AfropaperNo93.pdf>, accessed 17/10/2013

Lomo Zachary, (2005), "Refugees in East Africa: Developing an integrated approach" in Bekoe A. Dorina, ed., (2005), East Africa and the Horn: Confronting Challenges to Good Governance, Lynne Rienner Publishers

Louw, Dirk J., (2010) "Power sharing and the challenge of Ubuntu ethics", in Du Toit, C.W. ed., (2010), Power Sharing and African Democracy, Research Institute for Theology and Religion, University of South Africa, Pretoria, pp.121-137

Lubega Henry, (2014), "Pioneer American ambassadors and their reports on Obote, Amin", The Daily Monitor, 26 October 2014, $<$ http://www.monitor.co.ug/Magazines/PeoplePower/Pioneer-American-ambassadors-andtheir-reports-on-Obote--Amin/-/689844/2498932/-/kmek4lz/-/index.html>, accessed $27 / 10 / 2014$ 
Lumu David\&Raymond Baguma, (2014), "Standard gauge railway construction launched", The New Vision, Oct 8, 2014, <http://www.newvision.co.ug/news/660557-standard-gaugerailway-construction-launched.html>, accessed 08/10/2014

Lyons D.I., \& Deutz P., (2010), "Regional sustainable development: Making development work in politically contingent space”, Sustainable Development, 18, pp.183-186

Macintyre Alasdair, (1985), After Virtue: A Study in Moral Theory, Gerald Duckworth \& Co Ltd

Magobe B. Ramose, (1999), African Philosophy Through Ubuntu, Mond Books, Indiana University

Mahoney, James, (2003), "Strategies of Causal Assessment in Comparative Historical Analysis" in James Mahoney \& Dietrich Rueschemeyer, eds., Comparative Historical Analysis in the Social Sciences, Cambridge University Press

Mamdani Mahmood, (1984), Imperialism and Fascism in Uganda, Africa World Press

Mamdani Mahmood, (2011), "Can East African federation go beyond the genocidal concept of tribal homelands?", The East African, July 10, 2011, $<$ http://www.theeastafrican.co.ke/news/Moving+beyond+the+genocidal+ideology+of+tribal+ homelands/-/2558/1197940/-/bow0rtz/-/index.html>, accessed 10/07/2011

Manzi Tony, Karen Lucas, Lloyd Jones T., \& Judith Allen, eds., (2010), Social Sustainability in Urban Areas: Communities, Connectivity and the Urban Fabric, Earthscan Publishers

Maruping Mothae, (2005), "Challenges for Integration in Sub Saharan Africa: Macroeconomic Convergence and Monetary Coordination", in Teunissen J.J \& Akkerman A., (2005), Africa in the World Economy: The National, Regional and International Challenges, FONDAD, The Hague

Marsden G.R, Kimble M., Nellthrop J., \& Kelly C., (2009), “Sustainability appraisal: The definition deficit”, International Journal of Sustainable Transport, Vol. 4, No 4, pp. 189-211 
Materu S. Francis, (2014), The Post-Election Violence in Kenya: Domestic and International Legal Responses, Springer Publishers

Martyn Davies, (2013), "How China is influencing Africa's development”, in Barton Benjamin \& Jing Men, eds. (2013), China and the European Union in Africa: Partners or Competitors?, Ashgate Publishing Ltd

Mattli Walter, (1999), The Logic of Regional Integration: Europe and Beyond, Cambridge University Press

Matsiko Kahunga, (2011), "East African Community integration priority is upside down", The Observer, Dec 11the 2011, http://bit.ly/10SgfUo, accessed 11/12/2011

Mazrui A. Ali, (1968), "Political superannuation and the trans-class man", International Journal of Comparative Sociology, Vol. 9, No. 2, (June 1968), pp. 81-96

Mbabazi Christine M., (2010), "The Acholi worldview: Why rituals are important for the reintegration of formerly recruited girls in northern Uganda”, in Bård Mæland, ed., (2010), Culture, Religion and Reintegration of Child Soldiers in Northern Uganda, Peter Lang

Mbanda John \& Eric Kabeera, (2014), "EAC presidents launch use of national IDs to cross borders", The New Times, $20^{\text {th }}$ February 2014

Mbiti John, (1989), African Religions and Philosophy, $2^{\text {nd }}$ Ed., Heinemann, Oxford McCormick John (1999)The European Union: Politics and Policies, Westview Press, Colorado

McDonald David, (2010), "Ubuntu bashing: The marketization of 'African values' in South Africa", Review of African Political Economy, Vol. 37 No. 124 (June 2010), pp. 139-152 
Meadows Donella, et al, (1972), The Limits of Growth, Universe Books

Melakou Tegegn, (1997), “Development and Patronage”, in, Oxfam, ed., (1997), Selected Articles on Development in Practice, Oxfam Publications

Merihew R. Adams, (2006), A Theory of Virtue, Oxford University, New York

Meyer, Lukas, (2010) "Intergenerational Justice", The Stanford Encyclopedia of Philosophy (Spring 2010 Edition), Edward N. Zalta (ed.), <http://plato.stanford.edu/archives/spr2010/entries/justice-intergenerational/> 23/08/2013

Metz Thaddeus, (2011), "Ubuntu as moral theory and human rights in South Africa", African Human Rights Law Journal, Vol. 11 (2011), pp. 532-559

Miller David, (1999), Principles of Social Justice, Havard University Press

Minja David, (2009), "Ethical practice for effective leadership: Fact or fallacy - The Kenyan experience”, KCA Journal of Business Management, Vol. 2 No. 1 (2009), pp. 1-14

Mmanaledi Mataboge, (2013), "SA revels in M23's defeat following its CAR debacle”, Mail and Guardian, Nov 08 2013, <http://mg.co.za/article/2013-11-07-sa-revels-in-m23s-defeatfollowing-its-car-debacle>, accessed 09/11/2013

Murithi T., 2009, “An African Perspective on Peace Education: Ubuntu Lessons in Reconciliation”, International Review of Education, Vol. 55 Issue 2, pp. 221-233

Musoke Cyprian, Wasike Alfred \& Musamali Geresom, (2007), "Rwanda, Burundi formally joins EAC", The New Vision, June 182007

Miyasaka Michio, (2002), “A Broader Definition of Justice in Global Bioethics", <http://www.clg.niigata-u.ac.jp/ miyasaka/narrativejustice/EPMH2002.html>, accessed 20/04/2006 
Mofeli Asante, (2014), The History of Africa: The Quest for Eternal Harmony, Routledge

Monbiot George, (2012), "Deny the British empire crimes? No, we ignore them", The

Guardian, April 13 2012, <http://www.theguardian.com/commentsfree/2012/apr/23/britishempire-crimes-ignore-atrocities>, accessed 27/10/2014

Mpangala, G.P (2004), "Origins of political conflicts and peace building in the Great Lakes region", paper at symposium organized by the Command and Staff College on:

'Ramifications of instability in the Great Lakes zones', Arusha, Tanzania, February 2004

Mueleman Louis, (2008), Public Management and the Metagovernance of Hierarchies, Networks and Markets, Physica Verlag Heidelberg

Mugabe David, (2012), "Kenya blocks Uganda goods over new tax", The New Vision, Sept 18 2012, <http://www.newvision.co.ug/news/635341-kenya-blocks-uganda-goods-over-newtax.html>, accessed 18/09/2012

Mungai Christine\& Onyango-Obbo Charles, (2013a), "The future shape of East Africa: What happens when the sleeping giant of Congo awakes", The East African, June 22, 2013,<http://www.theeastafrican.co.ke/news/The-future-shape-of-East-Africa//2558/1891228/-/h2tlb2z/-/index.html>, accessed 23/06/2013

Mungai Christine\& Onyango-Obbo Charles, (2013b), "Juba and Addis: Why the coffee smells so strong in the north", The East African, June 29, 2013,<http://www.theeastafrican.co.ke/news/East-Africa-s-future-The-pull-of-the-north-//2558/1898914/-/oij8nsz/-/index.html>, accessed 29/06/2013

Muriuki Godfrey, (1978), The Breaking Up of the East African Community, Staff Seminar Paper, Vol. 2 Iss. 2 University of Nairobi, Department of History

Murphy J.D., et al, (1972), Luganda-English Dictionary 1972, The Catholic University of America Press 
Musaazi Namiti, (2011), "Uganda walk-to-work protests kick up dust”, Aljazeera, April 28th 2011, <http://www.aljazeera.com/indepth/features/2011/04/201142831330647345.html>, accessed 09/1/2012

Museveni Yoweri Kaguta, (1971), “Fanon's theory of violence: Its verification in liberated Mozambique" in Shamuyarira Nathan, ed., (1971), Essays on the Liberation of Southern Africa, Tanzanian Publishing House, Dar-Es-Salam, pp. 1-24

Museveni Yoweri Kaguta, (2013), "State of the East African Community speech" by President Museveni at EALA's $23^{\text {rd }}$ Sitting, Third Assembly, $5^{\text {th }}$ Meeting, First Session, Kigali, Rwanda

Mutibwa Phares, (1992), Uganda Since Independence: A story of unfulfilled hopes, Africa World Press

Mwakikagile Godfrey, (2009), Tanzania Under Mwalimu Nyerere: Reflections on an African Statesman, Intercontinental Books

Mwakikagile Godfrey, (2009), Ethnicity and National Identify in Uganda: The Land and Its People, Intercontinental Books

Mwakikagile Godfrey, (2009b), My Life as an African: Autobiographical Writings, Intercontinental Books

MwakikagaleGodfrey, (2014a), Why Tanganyika United with Zanzibar to Form Tanzania, Intercontinental Books

Mwakikagile Godfrey, (2014b), Restructuring the African State and the Quest for Regional Integration: New Approaches, New Africa Press

Mwangi Isaac, (2013), "Is the 'coalition of the willing' the beginning of the end for the EAC?", The East African, <http://www.theeastafrican.co.ke/Rwanda/Opinion/Is-coalition-ofthe-willing-the-beginning-of-the-end-for-EAC/-/1433246/2066408/-/wgcfy8/-/index.html>, accessed 14/11/2013 
Mwangi Mary, (2014), "LVEMP II at a glance”, <http://lvemp.eac.int/lvemp-ii-at-a-glance/>, accessed 07/09/2014

Mwapachu Juma, (2010), "EAC: Past, present and future”, in,East African Community: 10 Years of Integration (Special Issue), First Magazine Ltd,pp. 10-13

Mwatha Karega R.G, (2009), "Benefits Experienced by Ordinary Citizens from the East African Community (EAC) Regional Integration”, paper for EAC $10^{\text {th }}$ Anniversary Symposium 13-14 Nov 2009, Arusha, Tanzania

NAPE, (2012), “A Study on land grabbing cases in Uganda”, National Association of Professional Environmentalists (NAPE), available at: $\langle$ http://reliefweb.int/sites/reliefweb.int/files/resources/Full_Report_3823.pdf $>$, accessed $09 / 05 / 2013$

Naturinda Sheila, (2011), “EA Community: Are we running fast yet still standing?”, Daily Monitor, Dec 10, 2011, <http://www.monitor.co.ug/SpecialReports/-/688342/688342//eduqir/-/index.html>, accessed 12/12/2011

Ndahiro Alfred \& Privat Rutazibwa, (2008), Hotel Rwanda Or the Tutsi Genocide as Seen by Hollywood, Hamattan Publishers

Nitin Sawhney, (2000), “Understanding ethics in development: Rational reasoning and cultural attitudes", <http://pubs.media.mit.edu/pubs/papers/DevEthics.pdf>, accessed $20 / 06 / 2012$

Njogu Kimani, (2009), Healing the Wound: Personal Narratives about the 2007 PostElection Violence in Kenya, African Books Collection

Nkrumah Kwame, (1963a), "The people of Africa are crying for unity", speech at the Organisation of African Unity (OAU) meeting, 24th May 1963, Addis Ababa 
Nkrumah Kwame, (1963b), Africa Must Unite, Heinemann, London

Nkwame Marc, (2015), “Tanzanian MPs 'missing' ahead of EALA session”, Tanzania Daily News, Jan 20 2015, <http://www.dailynews.co.tz/index.php/local-news/40591-tanzanianmps-missing-ahead-of-eala-session>, accessed 20/01/2015

Norman Daniels, (1996), Justice and Justification: Reflective Equilibrium in Theory and Practice, Cambridge University Press

Norman Daniels, (2013), "Reflective Equilibrium”, in Zalta N. Edward, (2013),The Stanford Encyclopedia of Philosophy (Winter 2013 Edition), <http://plato.stanford.edu/archives/win2013/entries/reflective-equilibrium/>, accessed $1 / 2 / 2014$

Norzick R., (1974), Anarchy, State, and Utopia, Basic Books

NOVA, (2013), Earth from Space, <http://news.discovery.com/earth/earth-from-spacedocumentary-nova-130213.htm>, 21/08/2013

Nsimbi B.M., (1956), Amannya Amaganda n'Ennono zaago, Uganda Society, Kampala

Ntibagirirwa Symphorein, (2001), “A Wrong Way: From Being to Having in the African ValueSystem”, chp. in Giddy Patrick, ed., (2001), Protest and Engagement: Philosophy After Apartheid, South African philosophical studies Vol. 2, Council for Research in Values and Philosophy

Nugent Neill, (1999), The Government and Politics of the European Union, Duke University Press

Nussbaum Barbara, (2003), "Ubuntu: Reflections of a South African on our common humanity", <http://www.barbaranussbaum.com/downloads/reflections.pdf>, accessed $1 / 2 / 2011$ 
Nussbaum M., (1988), "Nature, Function and Capability: Aristotle on Political Distribution”, Oxford Studies in Ancient Philosophy, Suppl. Vol. 145:84, 1988

Nussbaum, M., (1988), "Non-relative virtues: An Aristotelian approach", Midwest Studies in Philosophy, Vol. 13, pp.32-53

Nussbaum, M., (1988), "Nature, Function and Capability: Aristotle on Political Distribution", Oxford Studies in Ancient Philosophy, Suppl. Vol. 145:84, 1988

Nussbaum, M., (1990), “Aristotelian social democracy”, in Bruce Douglas R., et al eds. Liberalism and the Good, Routledge, London, pp.203-52

Nussbaum, M., (2000), Women and Development: The Capabilities Approach, Cambridge University Press

Nussbaum M., (2001), The Fragility of Goodness: Luck and Ethics in Greek Tragedy and Philosophy, Cambridge University Press

Nussbaum Martha, (2003), "Capabilities as fundamental entitlements: Sen and social justice”, Feminist Economics, Vol. 9, Issue 2-3, pp.33-59

Nussbaum, M., (2009), Frontiers of Justice: Disability, Nationality, Species Membership, Harvard University Press

Nussbaum, M., (2011), Creating Capabilities, Harvard University Press

Nyerere J.K., (1997), "Without unity there is no future for Africa", speech in Accra Ghana, 6th March 1997

Nyanje Peter, (2013), “Kikwete asks Museveni to tell Kagame to cool off”, The Daily Monitor, Aug 30 2013, <http://www.monitor.co.ug/News/National/Kikwete-asks-Musevenito-tell-Kagame-to-cool-off/-/688334/1972964/-/npajnm/-/index.html>, accessed 30/08/2013

Nyerere J.K., (1966), Freedom and Unity, Oxford University Press 
Nyquist Nancy Potter, (2002), How Can I be Trusted? A Virtue Theory of Trustworthiness, Rowman and Littlefield Publishers Inc., Oxford

Nzioki T.K., \& Tostensen A., (2005), Fast-tracking East African Integration: Assessing the Feasibility of a Political Federation by 2010, Chr. Michelsen Institute, Bergen

Oakley, J., (1996), "Varieties of Virtue Ethics", Ratio, Vol. 9, Issue 2, pp. 128-152 (September, 1996)

Odoi-Tanga Fredrick, (2010), Politics, Ethnicity and Conflict in Post-Independence Acholiland, Uganda 1962-2006, University of Pretoria

Oginga Odinga, (1967), Not Yet Uhuru, East African Educational Publishers

Oitamong, A.M., (2010), The Revived East African Community: Fast-Tracking the Political Federation, LAP Lambert Academic Publishing

Okechukwu U. \& Osita G.A, (2005), Sustainable Development in Africa: A Multifaceted Challenge, Africa World Press

Okungu John \& Opango Perterlis, (2012), "Pollution loads into lake Victoria from the Kenyan catchment", <http://library.lvbcom.org:8080/xmlui/handle/123456789/68>, accessed $9 / 5 / 2014$

Olav Stokke, 2009, The UN and Development: From Aid to Cooperation, Indiana University Press, Bloomington

Olav Stokke, ed. (1991), Sustainable Development: Papers from the 6th EADI General Conference, Routledge

Olinski Tyler, Sonja Pfeiffer, \& Alessandra Ricci, (2014), “Determinants of regional leadership: IBSA in perspective", UNU-CRIS Working papers series, No. W-2014/10 
Onyango-Obbo Charles, (2012a), "War and Peace in Somalia: Seven lessons Burundi and Uganda can teach Kenya's soldiers", The East African, May 5 2012, $<$ http://www.theeastafrican.co.ke/news/Seven+lessons+Burundi+and+Uganda+can+teach+K enya+soldiers/-/2558/1399910/-/wl4x4x/-/index.html>, accessed 5/5/2012

Onyango-Obbo Charles, (2012b), "Torn between the East African Community and the Horn: The tale of a 'two-axis' nation", The East African, June 2, 2012, <http://www.theeastafrican.co.ke/news/The+Greater+Horn+of+East+Africa//2558/1418928/-/qgn80i/-/index.html>, accessed 03/06/2012

Onyango-Obbo Charles, (2012c), "Cloak and dagger: How new East Africa was born out of fires", The East African, June 2, 2012,<http://www.theeastafrican.co.ke/news/How-new-EastAfrica-was-born-out-of-the-fires/-/2558/1418930/-/hgd6ue/-/index.html>, accessed $03 / 06 / 2012$

Onyango-Obbo Charles, (2012d), "How guns and bombs redrew the economic map of East Africa and the Horn", The East African, June 9, 2012,<http://www.theeastafrican.co.ke/news/How-guns-and-bombs-redrew-the-economicmap-of-East-Africa/-/2558/1423896/-/4w4u1rz/-/index.html>, accessed 10/06/2012

O’Brien Erin, (2011), Irregular and Illegal Land Acquisition by Kenya's Elite: Trends, Processes and Impacts of Kenya's Land-Grabbing Phenomenon, The International Land Coalition

Pawliková-Vilhanová Viera, (1996), "Swahili and the dilemma of Ugandan language policy”, Asian and African Studies, Vol. 5, No.2 (1996) pp. 158-170

Pearce D., Barbier E., \& Markandy A., (1990), Sustainable Development: Economics and Environment in the Third World, Edward Elgar Publishing Ltd, Aldershot

Pellegrino E.D, (1993), “The Origins and Evolution of Bioethics: Some Personal Reflections", Kennedy Institute of Ethics Journal, 9:1 (1993), pp. 73-88

Peter Rogers, et al, eds., (2012), An Introduction to Sustainable Development, Earthscan 
Pertz Jean, Naples Adam \& Robert Sternberg, (2003), "Recognizing, Defining and Representing Problems", in Janet Davidson \& Robert Sternberg, eds., (2003), The Psychology of Problem Solving, Cambridge University Press

Pittenger David, (2001), "Hypothesis testing as a moral choice", Ethics and Behavior, Vol. 11 Issue 2, pp. 151-162

Plato, The Republic, trans by Benjamin Jewett, available at The Internet Classics Archive, http://classics.mit.edu/Plato/republic.html, accessed 28/03/2012

Pogge T.W, (2002), “Can the capability approach be justified?”,Philosophical Topics, Vol. $30: 22002$

Pogge Thomas, (1989), Realizing Rawls, Cornell University Press

Pogge Thomas, (2002), “Can the capability approach be justified?” Philosophical Topics, Vol. 30:2 2002

Prakash Chandra, (2009), Theories of International Relations, Vikas Publishing House Pvt Ltd

Rarieya Marie, (2009), “Towards development in Africa: Challenges, opportunities and policy implications", IOP Conference. Series: Earth and Environment Science, Vol. 6, 582022

Rawls John, (1971), A Theory of Justice, Belknap, Harvard University Press

Rawls John, (1985), “Justice as fairness: Political not metaphysical”, Philosophy and Public Affairs, Vol. 14 Issue 2, (Summer 1985), pp. 223-251

Rawls John, (1999), The Law of Peoples, Harvard University Press, Cambridge, Mass 
Read S. James, (1961) “Law and Justice in Buganda by E.S Haydon”, Journal of African Law, Vol. 5, No. 3 (Autumn 1961), pp. 191-93

Reid Richard, (2003), Political Power in Pre-Colonial Buganda: Economy, Society and Warfare in the Nineteenth Century, Ohio University Press

Rest James, (1979), Development in Judging Moral Issues, University of Minnesota Press Richard Rorty, (1981), Philosophy and the Mirror of Nature, Princeton University Press

Richardson Dick, (2012), “The politics of sustainable development”, in Baker Susan, ed., (2012), Politics of Sustainable Development, Routledge

Riley Patrick, (1973), "The origins of federal theory in international relations ideas", Polity, Vol. 6 No. 1 (Autumn 1973), pp. 87-121

Risse Mathias, (2009), “Immigration, Ethics and the Capabilities Approach”, UNDP - HDR Research Paper 2009/34, August 2009

Robinson Matthew, (2013), “What is Social Justice?”, March 2013, <http://gjs.appstate.edu/social-justice-and-human-rights/what-social-justice>, accessed $12 / 05 / 2014$

Rodríguez S.I., Matthew S.R, Sturhahn S.C. \& Terry E.H., (2002), “Sustainability assessment and reporting for The university of Michigan's Ann arbor campus", (unpublished) paper for MSc in Natural Resources and Environment studies, University of Michigan, April 2002

Rollins Jack Drake, (1983), A History of Swahili Prose Part I: From Earliest Times to end of Nineteenth Century, Brill Archive

Roochnik David, (2008), Beautiful City: The Dialectical Character of Plato's Republic, Cornwell University Press

Roosa Stephen, (2010), Sustainable Development Handbook, The Fairmont Press Inc. 
Rusagara Frank, (2008), “Gacaca: Origin et philosophy”, Peace and Conflict Management Review, Vol. 1 Issue 1 (2008) Article 8, pp. 10-11

Sakiko Fukuda-Parr, (2003), “The Human Development paradigm: Operationalizing Sen’s ideas on capabilities", Feminist Economics, Vol. 9 (2-3), 2003, pp. 301-317

Sanders, David, (1994) "Methodological Considerations in Comparative Cross-National Research”, International Social Science Journal 46: 513-21

Sandrine, B., (2007), "Why the Capability Approach is Justified”, Applied Philosophy, Vol. 24 Issue 1, pp. 16-25

Scanlon M. Thomas, (1998), What We Owe to Each Other, Harvard University Press Scanlon M. Thomas, (2014), Being Realistic About Reasons, Oxford University Press Sen Amartya K. (1985), Commodities and Capabilities, Elsevier Science Publishers Sen Amartya K. (1999), Development as Freedom, Oxford University Press Sen Amartya, (1984), Resources, Values and Development, London: Blackwell Publishers Sen Amartya, (2002), “Open and closed impartiality”, Journal of Philosophy, Vol 99 No 9, pp. $445-46$

Sengupta A., (2008), "Political Economy of the Legal Empowerment of the Poor", paper for doctoral course on 'Human Rights and Legal Empowerment of the Poor', organized by the Centre for Development and the Environment (SUM), University of Oslo, 2-4 Oct 2008

Sertima Ivan \& Obadele W. Larry, (1986), Great African Thinkers: Cheikh Anta Diop, Transaction Books 
Servaas F. Jozef \& Bernardin Mfumbusa, (2004), Seeds of Conflict, Pauline Publications Africa

Sezibera Richard, (2013), "The future of East African integration", $<$ http://www.eac.int/sg/index.php?option=com_content\&view=article\&id=110:the-furue-ofeac\&catid=40:sgs-blog\&Itemid=>, accessed 10/11/2013

Sheeran Patrick, (1993), Ethics in Public Administration: A Philosophical Approach, Greenwood Publishing House Ltd

Shikha V., et al, eds., (2013) Public Administration in Africa: Performance and Challenges, CRC Press

Shivji Issa G., (2009), "Pan-Africanism and the Challenge of East African Community Integration", paper for EAC $10^{\text {th }}$ Anniversary Symposium 13-14 Nov 2009, Arusha, Tanzania Simmons W. Charlene, Helen Roland, \& Kelly-DeWitt J., (1998), Local Government Ethics Ordinance in California, California Research Bureau

Sims R. Ronald, (2003), Ethics and Corporate Social Responsibility: Why Giants Fall, Greenwood publishing Group

Silverman David, (2001), Interpreting Qualitative Data: Methods for Analysing, Talk, Text and Interaction, $2^{\text {nd }}$ Edition, Sage Publications Ltd

Skelton A, (2002), "Restorative Justice as a Framework for Juvenile Justice Reform: A South African Perspective", The British Journal of Criminology, Vol. 42, pp. 496-513

Soniewicka Marta, (2008), “The problem of global distributive justice in Rawls' The Law of Peoples", Diametros, No. 17, (Sept, 2008), pp.45-59

Sørensen Eva and Jacob Torfing, (2009), "Making governance networks effective and democratic though metagovernance”, Public Metagovernance, Vol. 87 Issue 2 (June 2009), pp. $234-258$ 
Sserunjogi Mukiibi Eriasa, (2012), “Zziwa: EALA’s first female speaker”, The Independent, Friday 22 June 2012, <http://www.independent.co.ug/column/insight/5965-zziwa-ealas-firstfemale-speaker>, accessed 14/05/2012

Stoian Valetin, (2012), “Global or national justice? An analysis of Pogge's and Buchanan's reply to Rawls' Law of Peoples", Public Reason, Vol. 4 No 1-2 (Jan-Dec 2012) pp. 139-47

Sudan Tribune, (2010), “Athor's threat to attack Jonglei capital amounts to rebellion”, Sudan Tribune, May 12, $2010<\mathrm{http}: / / w w w . s u d a n t r i b u n e . c o m / s p i p . p h p ?$ article35050>, accessed $07 / 03 / 2012$

Sudan Tribune, (2013), "South-Sudan in talks with David Yau Yau group to abandon rebellion”, Sudan Tribune, Oct 3, 2013

<http://www.sudantribune.com/spip.php?article48281>, accessed 04/10/2013

Sugden R., (1993), “Welfare, Resources, and Capabilities: A Review of Inequality Reexamined by Amartya Sen”, Journal of Economic Literature, Vol. 31, pp.1947-62

Swanson D.M, (2009), "Where have all the fishes gone?: Living Ubuntu as an ethics of research and pedagogical engagement”, in Caracciolo D. \& Mungai A. eds., (2009), In the spirit of Ubuntu: Stories of Teaching and Research, Sense Publishers, pp. 3-21

Swanson Richard, (2013), Theory Building in Applied Disciplines, Berrett-Koehler Publishers, San Francisco

Tabu Butagira, (2013), "Uganda leads Africa's move to quit international court", Daily Monitor, Sept 12, 2013, <http://www.monitor.co.ug/News/National/Uganda-leads-Africa-smove-to-quit-international-court/-/688334/2028352/-/lrw672z/-/index.html>, Oct 2013

The East African, (2012), "Non-tariff barriers push up cost of doing business in East Africa", The East African, Nov 20 2012, <http://www.theeastafrican.co.ke/news/Non-tariff-barrierspush-up-cost-of-doing-business/-/2558/1624992/-/12dgl6c/-/index.html>, accessed $20 / 11 / 2012$ 
The East African, (2014), “Tanzania becomes Kenya's largest east African market”, The East African, Aug 30 2014, <http://www.theeastafrican.co.ke/news/Tanzania-edges-Uganda-asKenya-s-biggest-market-/-/2558/2435624/-/3o1uv4/-/index.html>, accessed 31/08/2014

The Economist, (2011), “Africa Rising”, in The Economist, Dec 3rd 2011, <http://www.economist.com/node/21541015>, accessed 13/02/2012

Thembi Mutch, (2012), "Zanzibar and the Mainland: The shaky state of the union", Think Africa Press, 20/11/2012, <http://thinkafricapress.com/tanzania/zanzibar-tanzania-shakystate-union-uamsho>, accessed 02/06/2013

Tom Patrick, (2006), "The Acholi traditional approach to justice and the war in northern Uganda", Beyond Intractability Project, University of Colorado, <http://www.beyondintractability.org/casestudy/tom-acholi>, accessed 24/09/2013

Transparency International, (2013), Corruption Perceptions Index 2013, Transparency International Publication

Trewhella Jill, (2009), "Multidisciplinary research: An essential driver of innovation", paper presented at the Australian Financial Review Higher Education conference, Sydney 9th March 2009

Trianosky, G.V, (1997), "What is Virtue Ethics All About?” in Statman D., (1997), Virtue Ethics, Edinburgh University Press, Cambridge

Tumusiime K.Abdulaziiz, (2015), “Over 3000 Ugandan containers face auctioning at Mombasa port", The East African, Jan 142015 <http://bit.ly/1IvCDUg>, accessed $14 / 01 / 2015$

Tusabe Gervase, (2003), The Human Person and Environmental Ethics, PhD dissertation, Department of Philosophy, Makerere University, Kampala 
Tusabe Gervase, (2012), Deep Ecology in Enhancing Sustainable Development, LAP Lambert Academic Publishing

Tutu Desmond, (1997), No Future Without Forgiveness, Double Day Publishers, New York Tutu Desmond, (2004), God Has a Dream: A Vision of Hope for Our Time, Doubleday Publishers, New York

Ubwani Zephania, (2015), "Report exposes wanton expenditure at the EAC", The East African, Jan 26 2015, <http://www.theeastafrican.co.ke/news/Report-exposes-wantonexpenditure-at-EAC/-/2558/2602684/-/19cuw9z/-/index.html>, accessed 26/01/2015

Ujupan Alina-Stefania, (2006), "Reconciling theories of regional integration: A third way", <http://www.jhubc.it/ecpr-istanbul/virtualpaperroom/060.pdf>, accessed 20/08/2009

Ulrich Grober, (1999), “Der Erfinder der Nachhaltigkeit”, Die Zeit, November 25, 1999

Ulrich Grober, (2007), 'Deep roots - A conceptual history of 'sustainable development' (Nachhaltigkeit)", Discussion paper No P 2007-002, Wissenschaftszentrum (Social Science Research Centre), Berlin, <http://econstor.eu/bitstream/10419/50254/1/535039824.pdf〉, accessed 09/06/2011

Ummy Ally Mwalimu, (2004), “Globalization and East Africa: Patterns, policy and legal issues on international labor migration in Tanzania", Economic and Social Research Foundation, working paper series No 13, April 2004

UNDP, (1997), Governance for Sustainable Development, Report on international conference by United Nations, New York

United Nations, (1970), Declaration of Principles of International Laws Concerning Friendly Relations, United Nations Publications, New York

United Nations, (2001), Public Service Ethics in Africa, United Nations Publications, New York 
United Nations, (2002), Report of the World Summit on Sustainable Development, United Nations Publications, New York

UNDP, (2014), Human Development Index 2014, United Nations, New York

United Nations Economic Commission for Africa, (2012), Towards Sustainable Development in Eastern Africa: Key Policy Messages, Economic Commission for Africa, Addis Ababa

United Republic of Tanzania, (1964), Act of Union of Tanganyika and Zanzibar (1964)

United States Census Bureau, (2014), "Trade in goods with Africa", <https://www.census.gov/foreign-trade/balance/c0013.html\#2014>, accessed 24/01/2015

USAID, (2012), “East African Regional Conflicts and Instability Assessment”,

Valentin, Stoian, (2012), “Global or National Justice? An Analysis of Pogge's and Buchanan's Reply to Rawls's Law of Peoples”, Public Reason, Vol 4, 1-2, 2012, pp.139-47

Van Evera, Stephen, (1998), Guide to Methods for Students of Political Science, Cornell University Press

Van Hooft S., (1999), "Socratic Dialogue as Collegial Reasoning”, in Ethics and Justice: An Interdisciplinary Public Affairs Journal, Vol. 1, No. 1, pp. 21-29

Vervliet C., (2009), The Human Person, African Ubuntu and the Dialogue of Civilisations, Adonis \& Abbey Publishers Ltd

Vredenburgh Donald and Yael Brender, (1998), “The hierarchical abuse of power in work organizations", Journal of Business Ethics, Vol. 12 Issue 17 (1998), pp. 1337-47

Viviene Taylor, (2013), "Social Justice: Reframing the 'social' in critical discourse in Africa", in Tangen Sarah, ed., (2013), African Perspectives on Social Justice, FriedrichEbert-Stiftung 
Vartanian T.P, (2011), Secondary Data Analysis, Oxford University Press, New York

Walter Rodney, (1973), How Europe Underdeveloped Africa, Tanzanian Publishing House, Dar-Es-Salam

Wamala Edward, (1992), “The socio-political philosophy of traditional Buganda society: Breaks and continuity into the present", in Dalfovo A.T, et al, (1992), The Foundation of Social Life: Uganda Philosophical Studies I, Council for Research in Values and Philosophy, Washington DC

Wamala Edward, (1995), "Cultural elements in social reconstruction in Africa", in Wamala E., ed., (1995), Social Reconstruction in Africa: Uganda Philosophical Studies II, Council for Research in Values and Philosophy, Washington DC

Wamala Edward, (2008), "Status to contract society: Africa's integrity crisis", Journal of Global Ethics, Vol. 4 Issue 3, (Nov 2008), pp. 195-205

Wamala Edward, (2010), "Building an ethical Public Service for improved service", Philosophia Africana, Vol. 13 Issue 2 (Fall 2010), pp. 99-112

Wamala E., Lajul W., \& Kasozi F., (2013), "Emphasis on values over virtue eroding ethics and integrity in governance", Research workshop report, <http://news.mak.ac.ug/2013/06/emphasis-values-over-virtue-eroding-ethics-and-integritygovernance>, accessed 24/06/2013

Wanambisi Laban, (2014), "I am still the EALA speaker says Zziwa”, Capital News, Thur 27 Nov 2014, <http://www.capitalfm.co.ke/news/2014/11/i-am-still-the-eala-speaker-sayszziwa/>, accessed 27/11/2014

Wandera Stephen, (2014), "President Museveni: we can block Kenyan goods", Daily Monitor, Nov 27 2014, <http://bit.ly/11xcHqI>, accessed 27/11/2014 
Wanjiru Christine Gichure,(2006), "Teaching business ethics in Africa: What ethical orientation? The case of East and Central Africa", Journal of Business Ethics, Vol. 63, pp. $39-52$

Wanyende Peter, (2005), "The Role of the East African Legislative Assembly", in Rok Ajulu, ed., (2005), The Making of a Region: The Revival of the East African Community, Institute of Global Dialogue, South Afirca

Welfens J. Paul, (1999), Globalization of the Economy, Unemployment, and Innovation: Structural Change, Schumpetrian Adjustment, and New Policy Challenges, Springer

Welz Martin, (2012), Integrating Africa: Decolonization's Legacies, Sovereignty and the African Union, Routledge

Wibren can der Burg, (2000), "Reflective Equilibrium as a dynamic process", in Bo Petersson, ed., (2000), Applied Ethics and Reflective Equilibrium, Centre for Applied Ethics, Linköping University

Wilbren van der Burg \& Theo van Willigenburg, eds., (1998), Reflective Equilibrium: Essays in Honour of Robert Heeger, Kluwer Academic Publishers

Williams Bernard, (1987), “The Standard of Living: Interests and Capabilities”, in Geoffrey Hawthorn, ed., (1987), The Standard of Living, Cambridge University Press, pp.94-102

World Bank, (1992), Governance and Development, International Bank for Reconstruction and Development, Washington

World Bank, (2007), “Options for Strengthening East African Community’s Trade Integration", Report No. 40978-AFR, World Bank

World Commission on Environment and Development (1987), Our Common Future, Oxford University Press, Oxford 
Wright David, (2005), "New perspectives on early regional interaction networks in East

Africa: A view from Tsavo National park, Kenya", African Archeological Review, Vol. 22,

No 3, Sept 2005, pp. 111-40

Wrigley Christopher, (1996), Kingship and State: The Buganda Dynasty, Cambridge

University Press

Yav Joseph Katshung, (2006), "Mato oput versus the International Criminal Court (ICC) in Uganda", Pambazuka, Issue 271 (28-09-2006),

<http://pambazuka.org/en/category/comment/37403>, accessed 30/02/2012

Youngs Gillian, (1999), International Relations in a Global Age: Conceptual Challenges, Polity

Yun Sun\&Michael Rettig, (2014), “American and Chinese trade with Africa: Rhetoric vs. reality", $<$ http://thehill.com/blogs/pundits-blog/international/214270-american-and-chinesetrade-with-africa-rhetoric-vs-reality>, accessed 06/10/2014

Zacher Mark, (2001), "The territorial integrity norm: International boundaries and the use of force”, International Organization, Vol. 55 No 2 (March 2001), pp. 215-50

Zahid Raiz, (2011), The Role of Collibration in Addressing Agency Conflicts: Remuneration governance in Australia, PhD thesis, The University of South Wales, 2011

Zambakari Christopher, (2013), "South Sudan's entry into the East African Community:

Prospects and Challenges", Harvard Africa Policy Journal, 2013

Zandberg Jeroen, (2010), The Philosophy and the Origins of Democracy, Lulu.com

Zucker Arthur, (1984), "Moral monads and ethical reductionism", The Journal of Religious Ethics, Vol. 12 No 1 (spring 1984), pp. 116-122 
